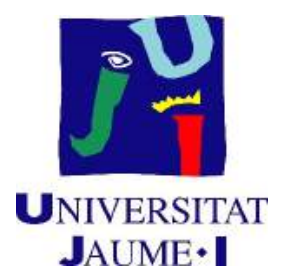

Programa de Doctorado en Tecnologías Industriales y Materiales Escuela de Doctorado de la Universitat Jaume I

\title{
SÍNTESIS DEL PIGMENTO CORAL DE HIERRO: INFLUENCIA DE LAS VARIABLES DEL PROCESO
}

\author{
Memoria de tesis presentada por \\ EULALIA ZUMAQUERO SILVERO \\ para optar al grado de Doctora por la Universitat Jaume I
}
Eulalia Zumaquero Silvero Sergio Mestre Beltrán María José Orts Tarí
Profesor Titular Profesora Titular
de Ingeniería Química de Ingeniería Química

Castelló, julio 2019 


A mi familia

A mis hijas Leire y Laia 
AGRADECIMIENTOS 

El trabajo de investigación que se presenta en esta memoria ha sido realizado en el Instituto de Tecnología Cerámica de la Universitat Jaume I de Castelló, por tanto, querría mostrar mi agradecimiento al centro por permitirme disponer de la infraestructura necesaria y permitirme realizar los ensayos experimentales en sus instalaciones.

En primer lugar, me gustaría agradecer sinceramente a mis directores de tesis, el Dr. Sergio Mestre y la Dra. Ma José Orts, el apoyo y confianza mostrada, así como la implicación que han puesto en la dirección y desarrollo de esta tesis.

Quisiera hacer extensiva mi gratitud a todos aquellos compañeros del Instituto de Tecnología Cerámica que han prestado su ayuda y colaboración para desarrollar y llevar adelante este trabajo de investigación, especialmente a Lola Palacios. A mis compañeras del Laboratorio de Caracterización FísicoEstructural por los ánimos recibidos, a mi compañera de camino Jessica Gilabert por todos sus consejos y a José Luis Amorós por el interés que ha mostrado en el desarrollo de este trabajo tanto a nivel personal como técnico.

De forma muy especial agradezco a mis compañeras y amigas Magda Lorente, Silvia Arrufat y Encarna Blasco su disponibilidad, complicidad y paciencia ayudándome a nivel científico y personal a llevar este trabajo a buen puerto.

Quiero dar las gracias a mi familia, por su compresión y confianza y por ayudarme a cumplir este reto personal.

Gracias a todos los que en algún momento os habéis preocupado por mi trabajo de investigación y por darme fuerza hasta el final.

GRACIAS. 

ÍNDICE 

1. INTRODUCCIÓN ...............................................................5

1.1 Pigmentos CERÁMICOS ..................................................... 7

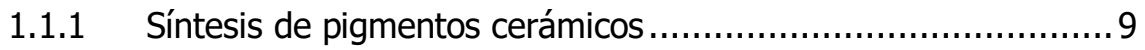

1.1.2 Pigmentos con estructura de circón ............................... 11

1.1.3 Pigmento coral de hierro-circón................................. 14

1.1.4 Mecanismos de síntesis del pigmento coral de hierro-circón ... 16

1.2 PROCESO DE MEZCLADO .......................................................22

1.2.1 Grado de mezcla o índice de mezclado............................. 25

1.2.2 Evaluación del grado de mezcla en pigmentos cerámicos ....... 27

1.3 TRANSFORMADA DE FOURIER DISCRETA (TFD) ...............................

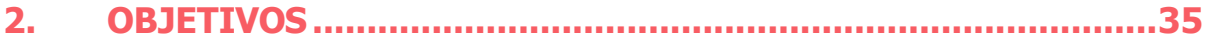

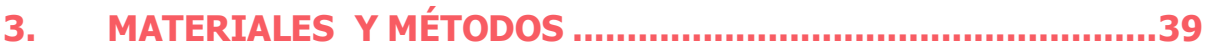

3.1 MATERIALES Y REACTIVOS..............................................41

3.2 Procedimientos de MEZCLAdo .........................................49

3.2.1 Preparación de las mezclas en molino planetario de bolas (vía húmeda/vía seca) ............................................................ 50

3.2.2 Preparación de las mezclas en un molino horizontal de bastidores o tipo Alsing ............................................................... 51

3.2.3 Preparación de las mezclas en un molino de cuchillas............ 51

3.2.4 Preparación de las mezclas en un molino de mortero............. 52

3.3 SÍNTESIS DEL PIGMENTO ...................................................53

3.4 DESARROLLO DE COLOR ....................................................54 
3.5.1 Distribución de tamaño de partícula.................................... 55

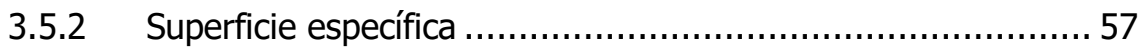

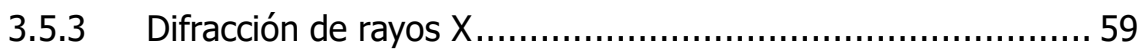

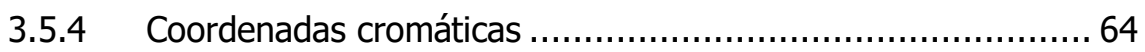

3.5.5 Microscopía electrónica de barrido (MEB) ............................ 67

3.5.6 Análisis de imagen y obtención de la Transformada de Fourier

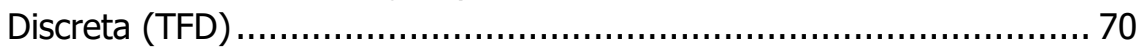

4. RESULTADOS Y DISCUSIÓN..................................................73

\subsection{COMPARACIÓN INICIAL DE LOS MÉTODOS DE MEZCLADO VÍA HÚMEDA Y}

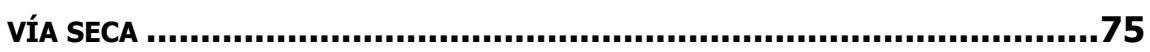

4.1.1 Caracterización mineralógica............................................. 76

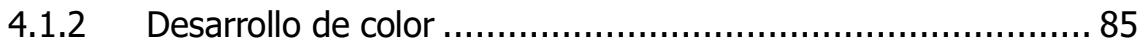

4.1.3 Caracterización microestructural....................................... 91

\subsection{Propuesta de un índice de mezclado en mezclas de materias} PRIMAS.

4.2.1 Estudio del grado de mezcla a partir de las micrografías obtenidas por el microscopio electrónico de barrido ........................................ 100

4.2.2 Obtención del espectro de potencia de la TFD ................... 104

4.2.3 Estudio del grado de mezcla a partir de los valores del espectro de potencia de la TFD................................................................. 108

4.2.4 Estudio del grado de mezcla a partir de la imagen del espectro de potencia de la TFD 109

4.3 INFLUENCIA DEL TRATAMIENTO TÉRMICO................................118

4.3.1 Efecto de la temperatura máxima...................................... 118

4.3.2 Tiempo de permanencia a temperatura máxima.................. 121

4.4 MÉTOdOS DE MEZCLADO Y CICLOS TÉRMICOS ALTERNATIVOS........124

4.4.1 Modificación del proceso de mezclado................................ 124

4.4.2 Modificación del tratamiento térmico …............................. 128

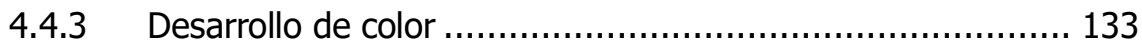

4.4.4 Caracterización microestructural.................................... 138 
4.5.1 Mezclado por etapas en el molino de cuchillas .................. 144

4.5.2 Mezclado en el molino planetario vía seca ...................... 146

4.5.3 Mezclado en molino de bastidor ................................. 147

4.5.4 Mezclado en el molino de mortero................................. 165

4.6 OPTIMIZACIÓN DEL MEZCLADO víA HÚMEDA .........................179

4.6.1 Estudio de las variables de operación en el molino planetario 179

4.6.2 Adición del cuarzo a la mezcla en una etapa posterior ......... 183

4.6.3 Utilización de agua como fluido durante el mezclado ........... 186

4.6.4 Efecto de la distribución granulométrica del mineralizador.... 193

4.6.5 Modificación de la velocidad del molino.......................... 199

4.6.6 Modificación del ciclo de cocción ..................................... 204

4.6.7 Adición del cuarzo por etapas .................................. 208

4.7 CONFIRMACIÓN DEL MECANISMO DE FORMACIÓN DEL PIGMENTO CORAL HIERRO-CIRCÓN .................................................................213

4.7.1 Tratamiento térmico en Ciclo Rápido ........................... 214

4.7.2 Tratamiento térmico en Ciclo STD ............................... 221

4.7.3 Mezcla de materias primas .................................... 226

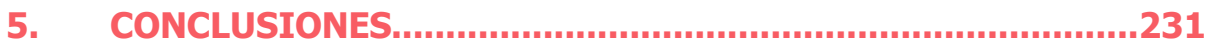

6. PUBLICACIONES Y CONGRESOS ...................................237

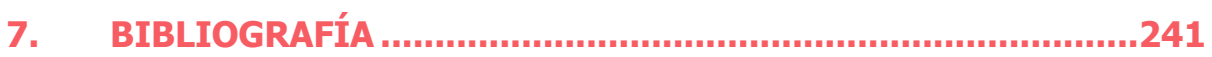



RESUMEN 

En esta memoria se exponen los resultados obtenidos en el estudio del proceso de síntesis del pigmento coral de hierro-circón, haciendo hincapié en la influencia de las variables del proceso. Para la obtención del pigmento se seleccionaron dos circonas, dos óxidos de hierro, un cuarzo, un mineralizador utilizado habitualmente en la síntesis de este pigmento como es el hexafluorosilicato sódico y un fluidificante para favorecer el mezclado entre las partículas (sílice pirogénica).

En primer lugar, con estos materiales se prepararon composiciones mediante mezclado vía seca y vía húmeda para poder evaluar el efecto del proceso de mezclado en la homogeneidad de la muestra. Las mezclas obtenidas fueron caracterizadas y fotografiadas mediante un microscopio electrónico de barrido (MEB). A partir de estos datos se definió un índice de mezcla basado en los espectros de potencia de la Transformada de Fourier Discreta de las imágenes obtenidas en el MEB. Se evaluaron diferentes parámetros siendo el número de píxeles del espectro de potencia el más adecuado para definir un índice de mezcla. Este parámetro permitía diferenciar entre diferentes circonas y óxidos de hierro utilizados en la preparación de las mezclas. Por otra parte, se correlacionaron el índice de mezcla propuesto con las propiedades finales del pigmento (poder colorante principalmente)

Paralelamente, se realizaron diseños de experimentos para evaluar la influencia de las variables del proceso de síntesis. Se estudió el método de mezclado (vía seca y vía húmeda), tipos de molinos (molinos de cuchillas, planetario, molino de bastidor y molino de mortero), tiempos de mezclado, el orden de adición de las materias primas, así como diferentes tratamientos térmicos. Cada uno de los pigmentos obtenidos fueron caracterizados mineralógicamente teniendo en cuenta tanto las fases cristalinas presentes como la posible presencia de fase vítrea, realizando también un estudio microestructural y una evaluación de su poder colorante en vidriados cerámicos.

Mediante el microscopio electrónico de barrido, se observó que aquellos pigmentos con un elevado poder colorante presentaban cristales de circón bien formados y con un tamaño del orden de las 5 micras, capaces de ocluir en su interior partículas de hematites, creando por tanto una cápsula protectora. Por el contrario, aquellos pigmentos con escaso poder colorante mostraban aglomerados de partículas embebidas en una matriz de aspecto vítreo.

Se comprobó que el pigmento coral de hierro-circón es muy sensible a los cambios en las variables relacionadas con el tratamiento térmico. De esta forma, se demostró que una velocidad de calentamiento elevada favorecía la formación de circón con una microestructura adecuada generando un pigmento con un elevado poder colorante. Adicionalmente, se corroboró que la distribución espacial de las partículas de las diferentes materias primas influía de forma importante en la obtención del pigmento. Las condiciones más favorables para la síntesis del pigmento se consiguieron partiendo de una 
mezcla en la cual el mineralizador estuviera íntimamente mezclado con la circona y la hematites, y separado espacialmente de la sílice, generando aglomerados compactos y resistentes.

Las conclusiones obtenidas en el trabajo de investigación permiten proponer dos mecanismos de síntesis diferentes: el primero de ellos a través de la formación de una fase vítrea viscosa, que no permitiría la formación de cristales de circón de tamaño suficiente para encapsular las partículas de hematites y, por tanto, conduciría a pigmentos con escaso contenido en circón y bajo poder colorante. El segundo mecanismo se basaría en un transporte en fase gaseosa y la formación de cristales de circón con suficiente tamaño para encapsular las partículas de hematites, obteniendo pigmentos con alto contenido en circón y elevado poder colorante. 
1. INTRODUCCIÓN 



\subsection{Pigmentos cerámicos}

En este capítulo se introducen los conceptos más relevantes relacionados con el trabajo de investigación sobre pigmentos cerámicos, haciendo hincapié en las propiedades del pigmento coral de hierro-circón, así como en su mecanismo de síntesis.

De forma general, un pigmento cerámico se define como una sustancia inorgánica que, mezclada en proporciones que oscilan de un 1 a un $5 \%$ en peso en una matriz vítrea, genera una coloración en la misma. Para que sea aceptable, éste debe reunir ciertos requisitos como son [1], [2]:

a. Poseer una estructura cristalina estable a temperaturas elevadas. Según la estabilidad térmica del pigmento se podría diferenciar entre aquellos pigmentos de baja temperatura y los que son estables a altas temperaturas y utilizados en cerámica fina, porcelana, gres porcelánico... como es el caso del pigmento coral de hierro-circón.

b. Ser insoluble en la matriz vítrea durante la cocción produciendo una coloración homogénea en la matriz.

c. Tener una intensidad de color o poder colorante elevado.

d. No modificar las propiedades de la matriz como pueden ser la resistencia a la abrasión, al ataque de ácidos o bases...

Por lo que concierne a los tipos de pigmentos, existen numerosas clasificaciones de pigmentos cerámicos según el color que desarrolla el pigmento (1965 Tcheichvili y Weyl) [3], o teniendo en cuenta la estructura cristalina (1968 Evans) [4]. Sin embargo, en 1980, se hizo necesaria una clasificación más completa, como consecuencia del requisito legal de establecer un registro que incluyera todas las sustancias químicas, ya fueran tóxicas o no, que eran manufacturadas, importadas o procesadas en EE.UU. Dicha clasificación fue llevada a cabo por la DCMA (Dry Colors Manufacturers' Association) [5], actualmente renombrada como CPMA (Colors Pigments Manufacturers' Association) [6]. Ésta se basa en criterios químico-estructurales, es decir, en la estructura cristalina y en los elementos que lo componen, así como el color final que desarrolla. Como resultado de este estudio, se definieron catorce familias estructurales $[6,7]$ que se detallan en la Figura 1.1. 

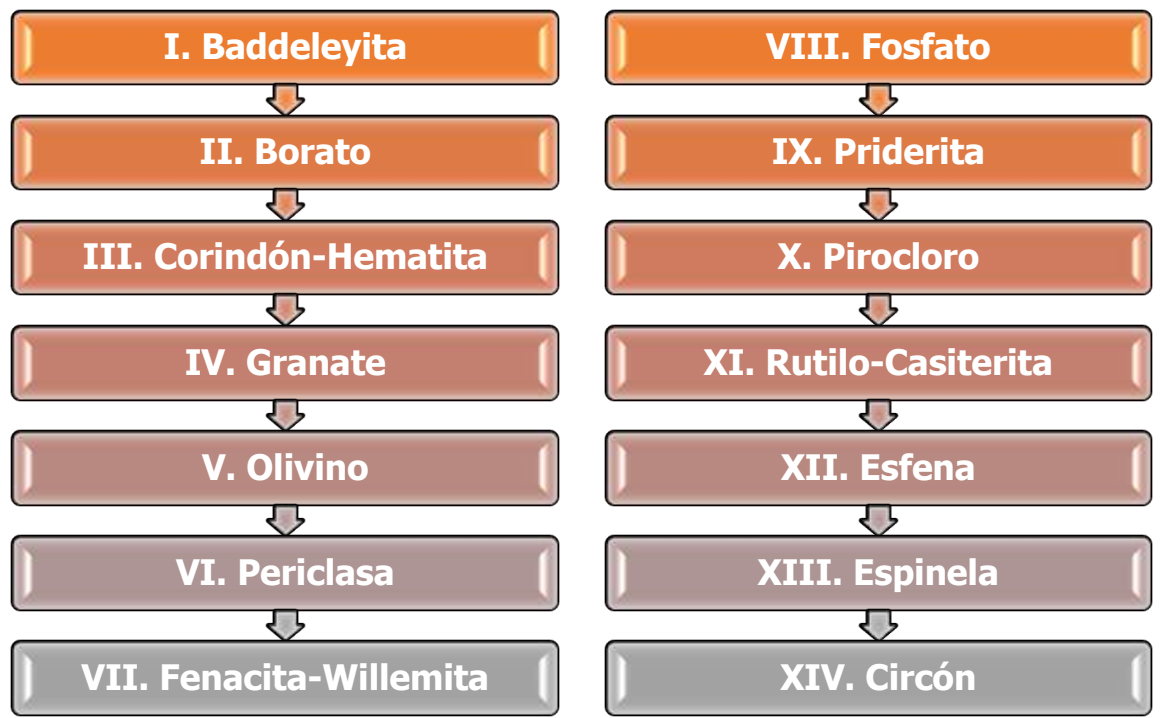

Figura 1.1 Clasificación de los pigmentos según CPMA

Además de clasificar los pigmentos por su estructura cristalina, los pigmentos cerámicos pueden organizarse en función del mecanismo de formación y coloración del pigmento [8], tal y como se detalla a continuación:

a. Pigmentos estructurales: En este tipo de pigmentos, el elemento que aporta el poder colorante está integrado en la estructura, que es estable frente al vidriado. Un ejemplo de este tipo de pigmentos es la espinela de cobaltoaluminio $\left(\mathrm{CoAl}_{2} \mathrm{O}_{4}\right)$ o pigmentos basados en la estructura granate como puede ser el verde de uvarovita $\left(\mathrm{Ca}_{3} \mathrm{Cr}_{2}\left(\mathrm{SiO}_{4}\right)_{3}\right)$.

b. Pigmentos encapsulados: Los cristales de la sustancia o elemento cromóforo (hierro, cadmio...) están encapsulados en un cristal de la red huésped. Un buen ejemplo de este tipo de pigmentos es el pigmento coral de hierro-circón o el circón-sulfoseleniuro de cadmio (rojo).

c. Pigmentos mordientes: El elemento cromóforo está incorporado superficialmente en la estructura receptora. Básicamente es una deposición de una capa coloidal de material cromóforo sobre una partícula. Un ejemplo podría ser el amarillo de vanadio-circona. Según algunos autores [9] el pentóxido de vanadio se deposita en una capa coloidal sobre la partícula de circona. Aunque hay otros autores que consideran que se trata de una disolución solida de $\mathrm{V}^{4+}$ en la red monoclínica de $\mathrm{ZrO}_{2}$ o que el color es debido a la inclusión de pentóxido de vanadio en los cristales de circona monoclínica [10].

d. Disoluciones sólidas: En los pigmentos considerados como disoluciones sólidas el elemento se incorpora a la red sustituyendo alguno de los cationes que forman parte de la red cristalina, como por ejemplo el azul de vanadio- 
circón $\left((\mathrm{Zr}, \mathrm{V}) \mathrm{SiO}_{4}\right)$, donde el vanadio tetravalente forma una disolución sólida con el ortosilicato de circonio, desarrollando la tonalidad azul y donde el mineralizador utilizado va a ser un factor importante en la tonalidad final del pigmento $[11,12]$.

No obstante, en algunos casos, la clasificación de un pigmento según su mecanismo de formación no resulta simple. Existen algunos pigmentos de tipo mordiente o disoluciones sólidas que tienen problemas de estabilidad térmica, ya que su poder colorante va a modificarse en función de diferentes variables que afectarán al proceso de síntesis [9]. Algunos de estos pigmentos con problemas de estabilidad, en realidad, son pigmentos de tipo encapsulado, y el grado de encapsulamiento va a depender en gran medida del método de síntesis, así como de los precursores utilizados. Prueba de ello es el pigmento coral de hierro-circón que en sus inicios fue considerado como un pigmento mordiente y posteriormente se ha podido concluir que se trata de un pigmento encapsulado, aunque algunos autores apuntan a que puede producirse cierta fracción de solución sólida del óxido de hierro en el circón.

\subsubsection{Síntesis de pigmentos cerámicos}

La fabricación de pigmentos y colores cerámicos se basa fundamentalmente en el método cerámico tradicional de mezcla de precursores (óxidos, carbonatos, hidróxidos...) y posterior calcinación, aunque existen otros métodos de síntesis no convencionales que han sido objeto de estudio y que proporcionan características y resultados muy similares.

En el sector cerámico, y en concreto en la fabricación de pigmentos cerámicos, se ha fomentado el desarrollo de nuevos materiales y metodologías que permitan conseguir pigmentos más puros, que proporcionen una mayor estabilidad térmica y un menor impacto sobre el medio ambiente. Siguiendo esta línea, en los últimos años se han desarrollado nuevos métodos de síntesis alternativos a las reacciones en estado sólido a alta temperatura como son el método sol-gel, pirólisis, plasma, láser, deposición química de vapor (CVD), vía hidrotermal... que aportan ventajas a nivel de calidad de los productos y de impacto medioambiental frente al método tradicional. Sin embargo, la transferencia a la escala industrial se ha visto dificultada por diferentes motivos.

En la Figura 1.2 se presenta el diagrama de flujo para el proceso de fabricación industrial de pigmentos cerámicos por el método cerámico tradicional. 


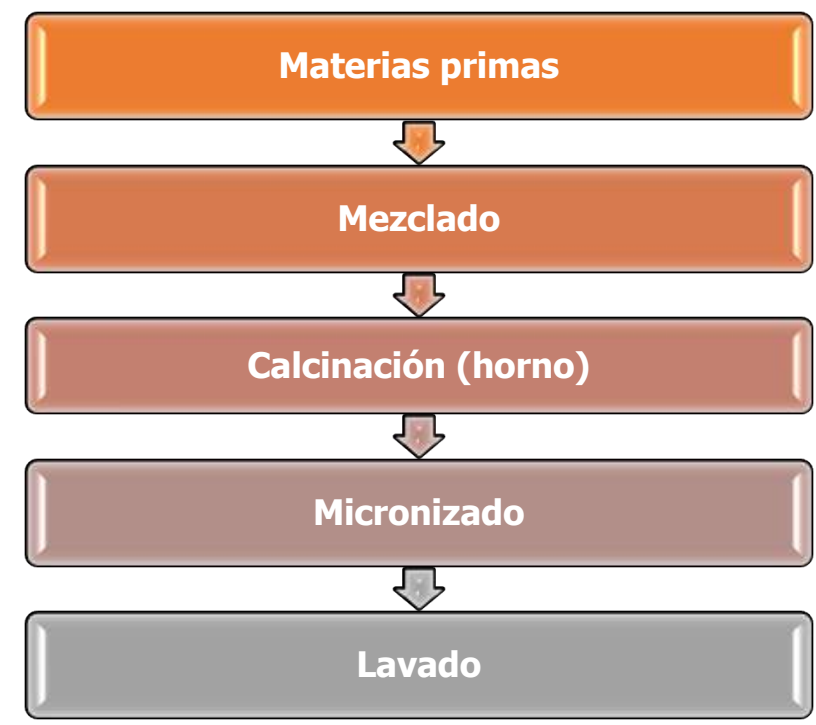

Figura 1.2 Proceso de fabricación industrial de pigmentos cerámicos

El método cerámico es el mayoritario a nivel industrial. Dicho método se basa en la interacción entre partículas sólidas, generando el producto mediante un mecanismo basado en la difusión, nucleación y crecimiento de las fases (Mecanismo de Wagner) [13]. Dependiendo del sistema concreto pueden transcurrir por mecanismos diferentes. En la mayoría de los casos se pueden considerar etapas de transferencia de materia a través de una fase líquida o gaseosa y etapas de difusión a través de una red cristalina.

Los factores más relevantes que influyen en las reacciones en estado sólido son la estabilidad de las fases cristalinas (aspectos termodinámicos), la velocidad de las diferentes etapas de la reacción (cinéticas de reacción) o los procesos de difusión. En algunos casos, tras la reacción superficial inicial, uno de los reactantes sublima y se deposita sobre la superficie del reactante menos volátil por lo que tiene que difundirse a través de la capa de producto que se va formando, siendo esta etapa la más lenta y la que controla la velocidad global del proceso [14-19].

Por tanto, uno de los principales problemas que presenta el método cerámico es de tipo cinético, ya que las reacciones en estado sólido a alta temperatura se basan en procesos lentos de difusión iónica $[20,21]$ y para que se formen gran cantidad de núcleos se necesita una elevada superficie de contacto (superficie especifica de los reactivos), similitud estructural de los reactivos (relacionado con la velocidad de nucleación) y temperatura, siendo esta última un factor limitante muy importante tal y como se ha comentado anteriormente [8]. 
Por otra parte, resulta fundamental controlar no solo la estructura del tratamiento térmico (velocidades de calentamiento y temperaturas máximas de cada etapa), sino también la atmósfera de cocción y el tipo de crisol a utilizar, ya que debe ser químicamente inerte con respecto a los precursores iniciales en el rango de temperaturas utilizado.

Entre las desventajas más importantes que se asocian al método cerámico tradicional a la hora de sintetizar pigmentos cabe destacar la utilización de temperaturas de calcinación elevadas y la heterogeneidad del producto final a nivel de composición química y de estructura cristalina. Para minimizar estos efectos se suelen utilizar diferentes tipos de fundentes y mineralizadores, que actúan incluso en concentraciones muy pequeñas, acelerando las transformaciones que tienen lugar en las reacciones en estado sólido y disminuyendo las temperaturas y tiempos de reacción, formando fases líquidas durante el transcurso de la reacción o generando especies volátiles que faciliten el transporte de materia a través de la fase gas (boratos, haluros alcalinos...). Existen principalmente dos grupos de mineralizadores [12]:

a. Mineralizadores estructurales: Un ejemplo de este tipo de mineralizadores son los utilizados en los pigmentos azules de vanadio-circón. Se trata de fluoruros que pueden sustituir a los iones óxido permitiendo de este modo una mayor incorporación de $\mathrm{V}^{4+}$ en la disolución sólida aumentando la intensidad del tono azul turquesa.

b. Mineralizadores promotores de la reactividad: Son compuestos que aumentan la reactividad de la mezcla ya sea por generación de fases líquidas, generación in-situ de fases volátiles (transporte de $\mathrm{Si}$ en forma de $\mathrm{SiF}_{4}$ en la síntesis de los pigmentos de hierro-circón), por activación de la superficie, por estabilización de un estado de oxidación específico del agente cromóforo...

Por tanto, la utilización de los mineralizadores minimiza las desventajas que supone la utilización del método cerámico tradicional.

\subsubsection{Pigmentos con estructura de circón}

La aparición de nuevos productos cerámicos que son tratados térmicamente hasta temperaturas superiores a $1200^{\circ} \mathrm{C}$, con tiempos de cocción de 40 a 60 minutos, ha promovido el desarrollo de colores y pigmentos cerámicos con estructuras estables a elevadas temperaturas y resistentes al ataque de los vidriados. Por ello, las estructuras del corindón y del circón se han convertido en la base para la síntesis de pigmentos cerámicos, ya que permiten obtener un amplio abanico de tonalidades, aportando propiedades muy apreciadas como son la elevada estabilidad térmica y química [8].

El uso cerámico del circón surgió como consecuencia de la necesidad de sustituir el óxido de estaño en su papel de opacificante en fritas y esmaltes, debido esencialmente a su elevado coste [22]. Posteriormente, tanto el circón como el óxido de circonio (baddeleyita) se han convertido en una de las 
principales materias primas para la elaboración de esmaltes y fritas, y en la producción de pigmentos cerámicos.

Los pigmentos basados en el óxido de circonio se pueden dividir en dos grupos:

- El primer grupo de pigmentos basados en la estructura de óxido de circonio es el que no contiene sílice en su composición como es el pigmento amarillo de circona-vanadio.

- El segundo grupo abarca aquellos pigmentos que contienen el óxido de circonio y sílice, de forma que tras el tratamiento térmico se genera circón. En este grupo se pueden encontrar el azul-turquesa de vanadio-circón $\left(\mathrm{V}-\mathrm{ZrSiO}_{4}\right)$, el amarillo de praseodimio-circón ( $\left.\mathrm{Pr}-\mathrm{ZrSiO}_{4}\right)$, el coral de hierro-circón $\left(\mathrm{Fe}_{2} \mathrm{O}_{3}\right.$ $\left.\mathrm{ZrSiO}_{4}\right)$ y el rojo de sulfoseleniuro de cadmio-circón $\left(\mathrm{CdSe}_{1-\mathrm{x}} \mathrm{S}_{\mathrm{x}}-\mathrm{ZrSiO}_{4}\right)$.

Para profundizar en este tipo de pigmentos es esencial estudiar y ampliar conocimientos sobre la estructura circón y del mecanismo de formación del coral de hierro-circón. Por ello, a continuación se dan unas pinceladas acerca de este mineral y su estructura cristalina [23], [24].

El circón cristaliza en el sistema tetragonal (la estructura se describe en la figura 1.2). Es un silicato formado por tetraedros $\mathrm{SiO}_{4}$ aislados que se caracteriza porque cada unidad tetraédrica $\mathrm{SiO}_{4}$ está conectada a otras similares sólo a través de cationes diferentes del $\mathrm{Si}^{4+}$ denominados cationes externos. En la celda unidad se observa el catión central $\left(\mathrm{Zr}^{4+}\right)$ con un índice de coordinación de ocho ya que se trata de un catión grande.

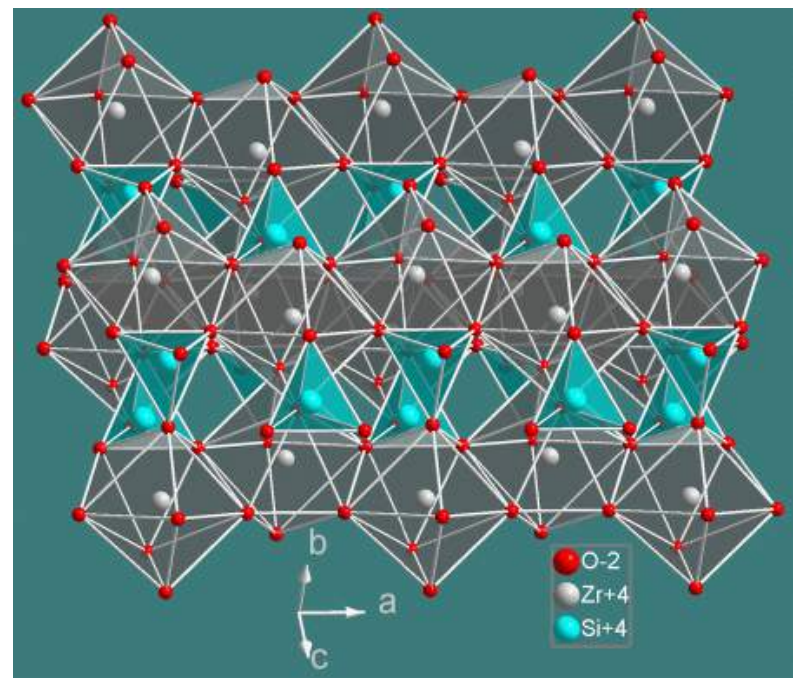

Figura 1.3 Estructura cristalina del circón (Imagen de Materialscientist, CC BY-SA 3.0) 
Debido a que puede dar origen a una gran variedad de tonalidades y colores, la estructura de circón tiene una gran aplicabilidad en el sector de los pigmentos y colores cerámicos, aunque las más utilizadas y conocidas son el turquesa de vanadio [25], el amarillo de praseodimio [26] y el coral de hierro [27,28].

Es conocido que los pigmentos del sistema $\mathrm{ZrO}_{2}-\mathrm{SiO}_{2}-\mathrm{Fe}_{2} \mathrm{O}_{3}$, fueron sintetizados por primera vez por Seabright en 1960 y desde entonces han sido numerosos los estudios e investigaciones que siguen profundizando en aspectos tecnológicos como implantación de métodos de síntesis alternativos al método cerámico tradicional, utilización de precursores de diferente naturaleza, así como estudio de las variables que afectan y pueden aumentar su poder colorante. Cabe destacar que cada uno de estos pigmentos basados en la estructura del circón sigue un mecanismo de reacción muy diferente, siendo el pigmento de hierro-circón el más complejo de sintetizar de los tres comentados anteriormente. Esto es debido esencialmente a que el hierro necesita estar presente en el sistema al inicio de la formación del circón. Puesto que el hierro es un elemento no volátil en las condiciones de operación habituales, el mecanismo de transporte del ion cromóforo no se produce a través de una fase vapor como ocurre con el turquesa de vanadio y el amarillo de praseodimio.

Los pigmentos basados en estructuras de circón no se producen a partir del mineral circón ni tampoco a partir del óxido de circonio que se encuentra en la naturaleza, puesto que contienen una gran cantidad de impurezas. El procesado es bastante inusual ya que, a partir del mineral circón se produce un óxido de circonio de alta pureza, que posteriormente se transforma en pigmentos de circón, pero a partir de este momento tiene un elevado poder colorante gracias a los elementos cromóforos que se incorporan a su estructura [11], [29]. Sin embargo, este material de partida es de dos a cuatro veces más caro que la baddeleyita natural y por este motivo, y porque la obtención del óxido de circonio a partir de arena de circón es un proceso complejo y caro, la síntesis de un pigmento utilizando circón o intermedios puede presentar ventajas económicas importantes.

Para la elaboración de circona a partir de circón, existen diferentes metodologías y las características de cada circona se basarán en el tamaño de partícula y la superficie específica, lo que va a condicionar su reactividad en las reacciones que tendrán lugar para la producción del pigmento. En concreto, para la fabricación de pigmentos con estructura circón (coral, azul turquesa, amarillo intenso y amarillo anaranjado) se emplea circona monoclínica que se obtiene mediante métodos de disociación química o térmica [30].

Hay que destacar que debido al elevado coste que puede presentar la circona para esta aplicación, están surgiendo nuevas líneas de investigación cuyo objetivo es el estudio de alternativas a la circona monoclínica. Una muestra de ello es la existencia de patentes que confirman que los productos intermedios obtenidos en el proceso de fabricación de circona a partir de circón pueden utilizarse para producir pigmentos con estructura circón. Por ejemplo, a partir 
de arena de circón por fusión a $1000^{\circ} \mathrm{C}$ con óxidos alcalinos se obtiene un material vítreo, que mezclada en las proporciones adecuadas con $\mathrm{SiO}_{2}$ y compuestos de hierro o vanadio dan lugar a pigmentos azules o rosa cuando son calcinadas a $800-1000^{\circ} \mathrm{C}$ [31], [32].

De igual forma, otros autores sintetizan pigmentos con estructura circón partiendo de circón como materia prima. Para ello, tras un proceso de descomposición con mezclas alcalinas $(\mathrm{KOH} / \mathrm{NaOH})$, los productos de descomposición son utilizados para producir pigmentos azul verdoso cuando se les añade $\mathrm{CrOOH}$ y $\mathrm{PbCrO}_{4}$ como precursores.

Otros estudios se dirigen hacia la síntesis de pigmentos de circón obtenidos con mezclas de precursores no convencionales, como por ejemplo mezclas de $\mathrm{FeOOH}$ y vidriados cuya composición se basa en el sistema $\mathrm{Li}_{2} \mathrm{O}-\mathrm{ZrO}_{2}-\mathrm{SiO}_{2}$ [33].

\subsubsection{Pigmento coral de hierro-circón}

En relación a las tonalidades que desarrollan los pigmentos, existe una gran variedad de pigmentos cerámicos con diferentes tonalidades y características físico-químicas. Sin embargo, el color rojo ha sido desde siempre un reto interesante para la industria de los pigmentos. En la actualidad no existe ningún pigmento rojo que presente características adecuadas para toda la gama de productos cerámicos (desde cerámica gresificada hasta porcelánicos técnicos o porcelanas) y que tenga una saturación de color y poder colorante intenso. El único pigmento que podría considerarse realmente rojo es el sulfoseleniuro de cadmio, pero presenta algunas desventajas al aplicarse en la industria cerámica, ya que su estabilidad térmica no supera los $900-1000^{\circ} \mathrm{C}$ y medioambientalmente presenta un riesgo importante [34-38]. Por este motivo, son muy interesantes las líneas de investigación dirigidas hacia el conocimiento de nuevos sistemas pigmentantes que mejoren las características de los pigmentos cerámicos rojos.

En la actualidad en el sector cerámico se utilizan diferentes pigmentos cerámicos que presentan tonalidades rojizas y que son producidos industrialmente [13]. Sus características más importantes como son la estabilidad térmica o la clasificación según CPMA [6] se detallan en la Tabla 1.1. Cabe recalcar que el pigmento basado en la estructura de sulfoseleniuro de cadmio no se contempla en la clasificación CPMA porque no es un óxido y además se ha clasificado como sustancia peligrosa por el cadmio presente en su composición [39,40].

Con respecto a los pigmentos rosa o coral, aquellos que son más utilizados en el sector cerámico son el pigmento estaño-cromo, el de alúmina-cromo y el de alúmina-manganeso, ahora bien, al tratarse de un pigmento encapsulado, el pigmento de hierro-circón presenta algunas ventajas frente al resto [41].

El pigmento de estaño-cromo ( $\mathrm{CaSnSiO}_{5}: \mathrm{Cr}_{2} \mathrm{O}_{3}$ ) con estructura de esfena presenta una estabilidad a la cocción baja y presenta un coste de producción 
elevado. Por otra parte, necesita de una atmósfera completamente oxidante durante su síntesis y utilización.

En cuanto al pigmento rosa de cromo-alúmina $\left((\mathrm{Al}, \mathrm{Cr})_{2} \mathrm{O}_{3}\right)$ es una disolución sólida de óxido de cromo trivalente en alúmina con estructura de corindón. Para que el desarrollo de color sea completo, éste necesita que los vidriados a los que es incorporado tengan una composición con proporciones de cinc y aluminio elevadas, así como una baja proporción de calcio.

El rosa de manganeso-alúmina $\left((\mathrm{Al}, \mathrm{Mn})_{2} \mathrm{O}_{3}\right)$ al igual que el pigmento anterior no tiene tampoco buena resistencia a los vidriados transparentes ya que disuelven la alúmina y el aspecto final del vidriado es de una superficie con una rugosidad elevada.

Adicionalmente, el pigmento rosa de cromo-alúmina presenta una curva de reflectancia con dos picos capaz de provocar un efecto metamérico (diferente tonalidad según se aplique una luz incandescente o luz natural), de forma que se hace más gris con luz natural y rosáceo con luz artificial. Este comportamiento no se presenta en el coral hierro-circón que tiene una curva de reflectancia muy regular [42].

Tabla 1.1 Características de algunos pigmentos con tonalidad rosaroja [13]

\begin{tabular}{|c|c|c|c|}
\hline Nombre & DCMA & $\begin{array}{l}\text { Estabilidad } \\
\text { térmica }\end{array}$ & $\begin{array}{l}\text { Tonalidad } \\
(\text { CIE L*a*b*) }\end{array}$ \\
\hline $\begin{array}{l}\text { Rosa de cromo-corindón } \\
\qquad\left(\mathrm{Cr}, \mathrm{Mn}-\mathrm{Al}_{2} \mathrm{O}_{3}\right)\end{array}$ & $\begin{array}{l}3-03-5(\mathrm{Cr}) \\
3-04-5(\mathrm{Mn})\end{array}$ & $1400^{\circ} \mathrm{C}$ & $\begin{array}{c}\text { Rojo-rosa } \\
\left(a^{*}=25 b^{*}=8\right)\end{array}$ \\
\hline $\begin{array}{l}\text { Rosa de cromo-espinela } \\
\qquad\left(\mathrm{Zn}(\mathrm{Al}, \mathrm{Cr})_{2} \mathrm{O}_{4}\right)\end{array}$ & $13-32-5$ & $1400^{\circ} \mathrm{C}$ & $\begin{array}{l}\text { Rosa-marrón } \\
\text { (no descrito) }\end{array}$ \\
\hline $\begin{array}{l}\text { Rosa de cromo-casiterita } \\
\qquad\left(\mathrm{Cr}-\mathrm{SnO}_{2}\right)\end{array}$ & $11-23-5$ & $1250^{\circ} \mathrm{C}$ & $\begin{array}{c}\text { Rosa-violeta } \\
\left(L^{*}=54,4 a^{*}=19,3\right. \\
\left.b^{*}=19,2\right)\end{array}$ \\
\hline $\begin{array}{l}\text { Rosa de cromo-esfena } \\
\quad\left(\mathrm{Cr}^{-} \mathrm{CaSnSiO}_{5}\right)\end{array}$ & $12-25-5$ & $1250^{\circ} \mathrm{C}$ & 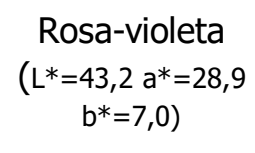 \\
\hline $\begin{array}{l}\text { Rosa de hierro-circón } \\
\left(\mathrm{Fe}-\mathrm{ZrSiO}_{4}\right)\end{array}$ & $14-44-5$ & $1300^{\circ} \mathrm{C}$ & $\begin{array}{c}\text { Rosa-marrón } \\
\left(L^{*}=58,7 a^{*}=22,7\right. \\
\left.b^{*}=17,9\right)\end{array}$ \\
\hline $\begin{array}{l}\text { Rojo de sulfoseleniuro de } \\
\text { cadmio } \\
\left(\mathrm{CdSe}_{x} \mathrm{~S}_{1-\mathrm{x}}-\mathrm{ZrSiO}{ }_{4}\right)\end{array}$ & $\begin{array}{c}\text { No } \\
\text { contemplado }\end{array}$ & $900^{\circ} \mathrm{C}$ & $\begin{array}{l}\text { Rojo-naranja } \\
\left(a^{*}=39 b^{*}=12\right)\end{array}$ \\
\hline
\end{tabular}


Como se ha comentado anteriormente, el sulfoseleniuro de cadmio es una disolución sólida de sulfuro de selenio en sulfuro de cadmio, la cual presenta una notable toxicidad ligada al $\mathrm{Cd}^{2+}$ y es considerado carcinógeno nivel $\mathrm{A} 2$, aunque esta limitación se solventó con la encapsulación de la disolución sólida en cristales de circón. Sin embargo, los pigmentos de sulfoseleniuro de cadmio encapsulados producen un color mucho más claro que su color original y su poder colorante va a depender mayoritariamente del método de síntesis y de la eficacia del proceso de encapsulación $[38,43]$.

Como contrapartida a las desventajas que presentan los pigmentos citados anteriormente frente al pigmento hierro-circón, debemos señalar que la síntesis de éste es compleja de implementar a nivel industrial, ya que son muchos los factores que influyen en el desarrollo del poder colorante. Estas variables están presentes durante todo el proceso de fabricación industrial, desde la selección de materias primas, el proceso de mezclado o el método de síntesis del pigmento. Pese a todo, los pigmentos con estructura de circón constituyen aproximadamente el $50 \%$ de la producción total de pigmentos cerámicos, y las tonalidades adquiridas con estos pigmentos no son sustituibles por otros compuestos, lo cual hace imprescindible al circón en la industria de los pigmentos cerámicos [30].

\subsubsection{Mecanismos de síntesis del pigmento coral de hierro-circón}

En relación al mecanismo de formación del pigmento de hierro-circón, existen numerosas investigaciones, como los estudios de Eppler, Both, Demiray, Bystrikov, Mattkovich y muchos otros autores. No obstante, sigue habiendo cierta controversia con respecto a las reacciones que tienen lugar en la formación de este pigmento, fundamentalmente porque el mecanismo de reacción va a depender en gran medida del método de síntesis, así como de los precursores utilizados.

En la síntesis del pigmento coral de hierro-circón mediante el método cerámico tradicional, se ha aceptado de forma general que la valencia con la que actúa el metal, en este caso el hierro, es una valencia de tres y este hecho se ha verificado con estudios de espectroscopia Mossbauer [44]. Sin embargo, la controversia reside en otros puntos como pueden ser:

- $\quad$ El papel que juega el hierro en la formación de la estructura de circón.

- Cómo se encuentra el hierro dentro de la estructura del pigmento, si como solución sólida, y en este caso, si es ocupando posiciones reticulares (solución sólida sustitucional) o posiciones intersticiales (solución sólida intersticial).

- $\quad$ Si el hierro está presente como hematites en forma de partículas libres o si las partículas de hematites están ocluidas en la estructura del circón. 
En cuanto a la formación de la estructura del pigmento, existen diferentes estudios, aunque uno de los primeros autores que comenzaron a investigar en el mecanismo de reacción fue Eppler [45] [46], demostrando que durante la formación del pigmento coral de hierro-circón la sílice es transportada hasta la circona como compuesto gaseoso, y todo este proceso se ve favorecido por la presencia del hierro, aunque existen etapas que limitan estas reacciones como son la velocidad de nucleación y la difusión de la sílice a través de la capa de circón que se va formando.

La técnica utilizada por Eppler fue la "técnica del marcador inerte de Kirkendall" que proporciona información sobre la difusión y el movimiento iónico durante la reacción observando la localización del producto coloreado después del tratamiento térmico, permitiendo seguir el proceso de la reacción dado el cambio de color que acompaña a la formación del pigmento [47]. Para ello, Eppler partió de una mezcla de sílice, circona, mineralizadores y una fuente de hierro. Tanto la sílice como la circona fueron colocados en un crisol separados por un alambre de platino que actuaría de marcador e interfase. Si existiera movimiento del $\mathrm{Zr}^{4+}$ y del $\mathrm{Si}^{4+}$ entonces, el circón aparecería a los dos lados del marcador. Además, si el proceso se llevaba a cabo en fase vapor, el producto aparecería no únicamente en la interfase sino en todas las paredes del crisol donde se estaba produciendo el tratamiento térmico.

Para el pigmento coral de hierro circón, Eppler [46] observó que:

i. Si el hierro y los mineralizadores estaban en las dos partes del crisol, se formaba una capa marrón de hierro-circón que se situaba en la interfase donde estaba situada la circona, pero no por toda la periferia del crisol.

ii. Se confirmaba la movilidad de la sílice a través de la formación de tetrafluoruro de silicio $\left(\mathrm{SiF}_{4}\right)$ por reacción entre la sílice y el mineralizador $\left(\mathrm{Na}_{2} \mathrm{SiF}_{6}\right)$ pero no del hierro.

iii. Cuando el hierro se introducía junto con la circona, el pigmento marrón se formaba en la zona donde estaba colocada la circona, independientemente de donde se había introducido el mineralizador.

iv. Si el hierro se introducía en la parte donde se encontraba la sílice, se formaba la estructura circón en la zona de la circona debido al transporte del $\mathrm{SiF}_{4}$. Sin embargo, la estructura de circón no contenía hierro y, por lo tanto, no aparecía la coloración marrón. 
( A)

( B )

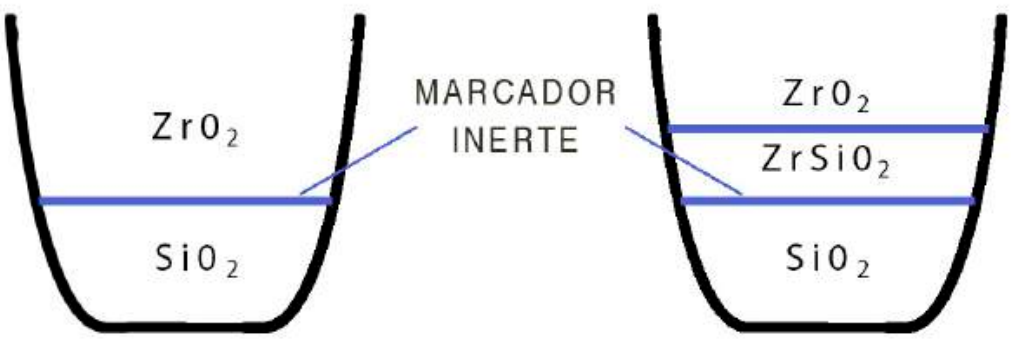

Figura 1.4 Técnica de marcador (A) antes de la reacción, (B) después de la reacción $[11,46]$

Todos estos hechos demostraban la inmovilidad del hierro durante la reacción y por tanto para que la estructura de pigmento se formara, el hierro tenía que estar presente donde se formase el circón, ya que éste no iba a ser transportado en fase vapor. La hematita íntimamente mezclada con la circona quedaría encapsulada en la red de circón.

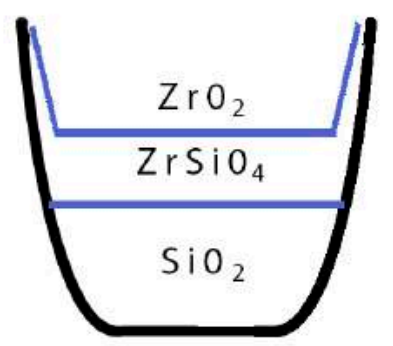

Figura 1.5 Capa de producto obtenida en reacciones gas-sólido con la técnica de marcador $[11,46]$

La reacción inicial tendría lugar entre la sílice y el mineralizador, produciendo especies volátiles como los tetrahaluros de silicio que transportaría el silicio hasta la interfase:

$$
\mathrm{SiO}_{2}+4 \mathrm{MX} \rightarrow \mathrm{SiX}_{4}(g)+2 \mathrm{M}_{2} \mathrm{O}
$$

(Ecuación 1)

A partir de aquí Eppler sugiere dos mecanismos para el transporte del silicio a través de la capa de reacción $[46,48]$ :

(1) Un modelo de difusión en el cual el tetrahaluro de silicio se descompone en la superficie de la capa de producto formado (circón) depositando silicio y electrones en defectos o imperfecciones de la red que se difunden a través de 
la capa de producto, permitiendo la reacción con la circona que está sin reaccionar.

$$
\begin{aligned}
& \mathrm{SiX}_{4} \rightarrow \mathrm{Si}^{4+}+4 e^{-}+2 \mathrm{X}_{2} \\
& \mathrm{Si}^{4+}+4 e^{-}+\mathrm{ZrO}_{2}+\mathrm{O}_{2} \rightarrow \mathrm{ZrSiO}_{4}
\end{aligned}
$$

(2) Un modelo de transporte en fase gas donde el tetrahaluro de silicio y el oxígeno se difunden a través de los poros de la capa de producto, y por tanto la reacción ocurre completamente en la interfase circón-circona sin reaccionar.

$$
\mathrm{SiX}_{4}+\mathrm{ZrO}_{2}+\mathrm{O}_{2} \rightarrow \mathrm{ZrSiO}_{4}+2 \mathrm{X}_{2}
$$

(Ecuación 4)

Con respecto al mecanismo de formación y tipología de pigmento, la mayor parte de los resultados obtenidos en el estudio de la síntesis del pigmento coral de hierro-circón dirigen sus conclusiones a que se trata de un pigmento de inclusión o encapsulado, ya que el pigmento no puede obtenerse a partir de circón mezclado con el precursor de hierro y los mineralizadores, sino que es necesario que los procesos de cristalización-sinterización-inclusión transcurran de forma sincronizada. Ahora bien, también se han propuesto mecanismos de formación basados en soluciones sólidas, lo que indica que puedan coexistir ambos mecanismos de formación siendo uno de ellos el mayoritario en función del método de síntesis y los precursores utilizados.

De hecho, los estudios realizados indican que el mecanismo que parece ser el determinante en el desarrollo del color coral en este pigmento cuando su síntesis se realiza mediante el método cerámico tradicional, es el de oclusión o inclusión de partículas de hematites en la matriz del circón. Autores como Berry $[49,50]$ o Gair [51], indican que el hierro se encuentra no solo como inclusiones de hematites sino también como $\mathrm{Fe}^{3+}$, formando una solución sólida en la red de circón. Sin embargo, estos autores discrepan en cuanto a las posiciones que ocupan los iones $\mathrm{Fe}^{3+}$ en la red de circón. Mientras que Berry afirma que se encuentran en posiciones intersticiales rómbicas y axiales, Gair concluye que los cationes $\mathrm{Fe}^{3+}$ sustituyen al silicio en posiciones tetracoordinadas en la estructura del circón.

En la misma dirección, Tartaj [52], utilizando el método de síntesis de pirolisis de aerosol, confirmó la formación de una solución sólida de $\mathrm{Fe}^{3+}$ en la red de circona tetragonal mediante medidas de parámetros reticulares. Por otra parte, con técnicas como la espectroscopia Mossbauer y XPS (espectroscopía de fotoelectrones emitidos por rayos $X$ ) se demostró que a pesar de que inicialmente existían pequeñas partículas de $\gamma-\mathrm{Fe}_{2} \mathrm{O}_{3}$, éstas se transformaban durante el tratamiento térmico en $\alpha-\mathrm{Fe}_{2} \mathrm{O}_{3}$ siendo esta estructura la responsable 
de aportar la coloración rojiza, cuyas partículas se encontraban distribuidas de forma homogénea en la matriz de circón.

Otros autores como Lahuerta [53], Airey [54] o Llusar [12] sugieren la presencia de inclusiones de hematites en la matriz de circón como principal responsable del poder colorante del pigmento basándose en la hipótesis del encapsulamiento, de forma que cuando mejor y más efectiva es la oclusión de las partículas de hematites, más intensa es la tonalidad coral. Si éste no es el caso, ya sea por un crecimiento demasiado rápido de la hematites o del circón, las partículas de hematites no quedarían protegidas o encapsuladas de manera eficiente por los cristales de circón recién formados (quedando como hematites libre) y se obtendrían coloraciones marrones en lugar del color rojizo o rosa característico.

Por tanto, recapitulando las conclusiones mostradas anteriormente, el mecanismo de formación que cobra más importancia en la síntesis del pigmento coral de hierro-circón, es el mecanismo de inclusión en el que las partículas de hematites estarían distribuidas junto con las partículas de sílice y circona y tras el tratamiento térmico, la sílice en contacto con la circona reaccionaría para forma circón, que encapsularían las partículas de hematites. Sin embargo, no se descarta que, en menor medida, se esté formando una solución sólida.

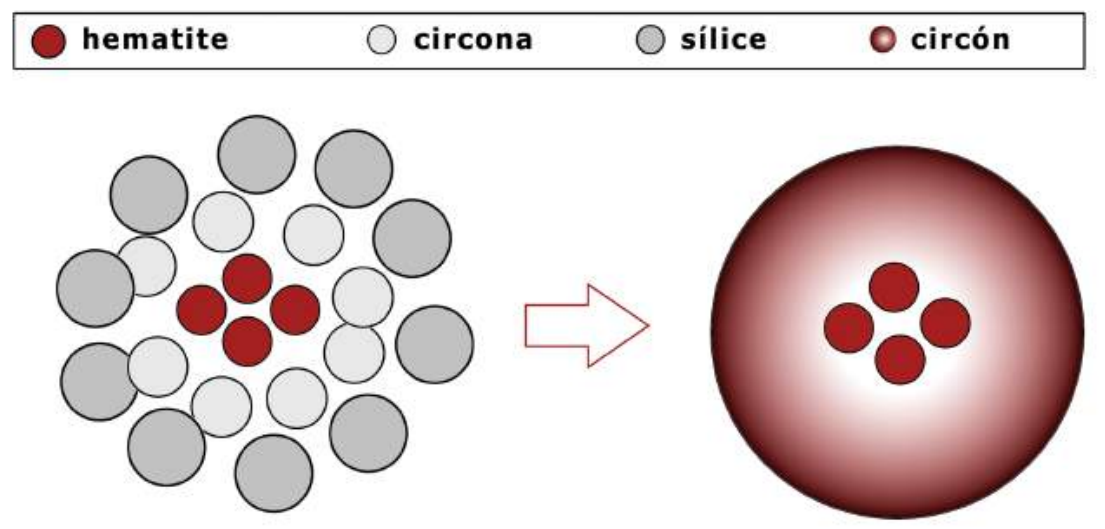

Figura 1.6 Distribución óptima de las partículas para la formación del pigmento coral de hierro-circón

Al mismo tiempo, según este modelo, los procesos difusivos involucrados entre las partículas de hematites, circona y sílice, así como el crecimiento de las partículas de circón, dependerán en gran medida del tipo de precursor de hierro utilizado, del tamaño de partícula de los materiales de partida, presencia de 
mineralizadores, así como del proceso de mezclado y síntesis teniendo estas variables una influencia muy relevante sobre el pigmento.

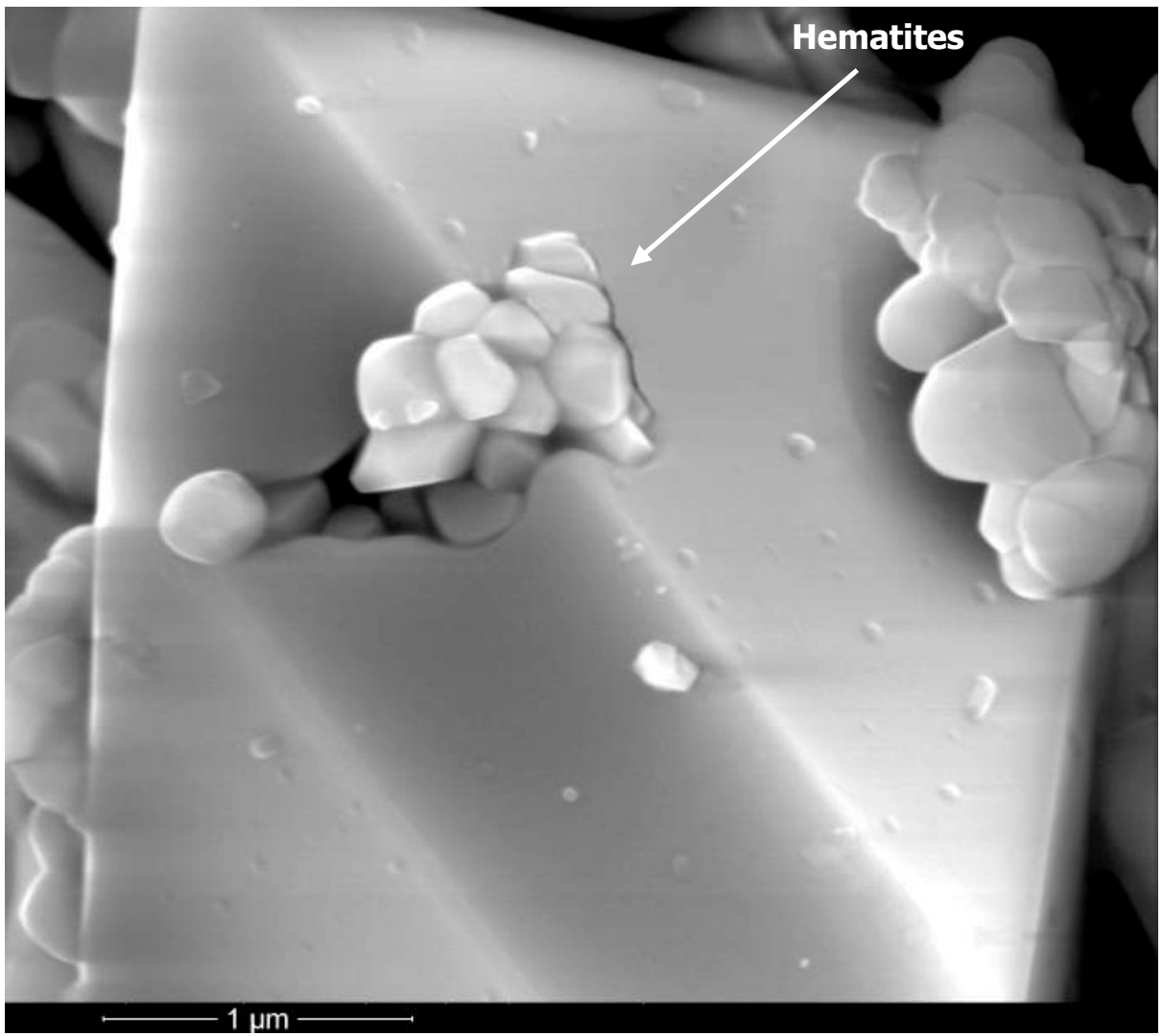

Figura 1.7 Micrografía de un cristal de circón del pigmento coral hierrocircón obtenida con la señal de electrones secundarios del MEB (x80000)

En la Figura 1.7 se muestra una micrografía realizada mediante microscopía electrónica de barrido durante el trabajo de investigación, en la que se observa perfectamente la inclusión de las partículas de hematites en el interior del cristal del circón.

Dejando atrás las investigaciones sobre el mecanismo de formación del pigmento, existen otras variables que van a influir de manera significativa en el poder colorante del pigmento y que se comentan a continuación.

En particular, algunos autores han evaluado como mejorar la eficiencia en el encapsulamiento de las partículas de hematites en la estructura de circón. Bondioli [55] ha profundizado en la activación mecánica de las materias primas utilizadas como precursores en este tipo de pigmentos. En concreto, esta activación mecánica aumentaba la reactividad de la mezcla de forma que, aumentando el tiempo de molienda, se disminuía la temperatura característica 
de formación del circón. Además, aumentando la temperatura de calcinación, se obtenía una mayor cantidad de partículas de hematites ocluidas en la matriz de circón consiguiendo una tonalidad roja más intensa.

Otros estudios indican la existencia de una interacción entre las partículas de hierro y la circona antes de la formación del pigmento [56]. Para ello se examinaron diferentes procesos de síntesis, utilizando metodologías de premolturación, tanto vía seca como vía húmeda y etapas de pre-calcinación. Merece la pena destacar que, en este estudio, el mayor poder colorante del pigmento se obtenía a partir del precursor $\mathrm{FeOOH}$, con tamaños de partícula más finos, etapas de molturación vía seca y etapas de pre-calcinación a $570^{\circ} \mathrm{C}$.

En conjunto, se puede concluir que a pesar de las numerosas investigaciones llevadas a cabo con los pigmentos coral de hierro-circón, existen discrepancias en cuanto a la naturaleza del pigmento y a su mecanismo de formación.

\subsection{Proceso de mezclado}

En lo que concierne a la síntesis del pigmento coral de hierro-circón, está influenciada por numerosas variables: la elección del método de síntesis, los precursores a utilizar, el procesado previo al tratamiento térmico, el mezclado o la molienda de los precursores, el tratamiento térmico...

Desde el punto de vista tecnológico, el coral de hierro-circonio es un pigmento problemático de sintetizar de un modo reproducible y esto es debido a la estructura que posee y su mecanismo de formación. Al tratarse de un pigmento del tipo encapsulado, cobra una gran importancia cómo se encuentran distribuidas las materias primas en la mezcla de reacción, ya que en el caso de que no se produjera un buen encapsulamiento de las partículas de hematites, podría sintetizarse el circón, pero el producto no tendría ningún valor como pigmento, ya que no poseería poder colorante. Por tanto, este trabajo intentará profundizar en la influencia que tiene el proceso de mezclado en la síntesis del pigmento coral de hierro-circón.

El proceso de mezclado en la síntesis de pigmentos tiene como objetivo principal conseguir una distribución homogénea de los precursores, intentando reducir la heterogeneidad del sistema antes de que se produzca la etapa de calcinación y cambiando la distribución de varios componentes que inicialmente se encuentran segregados, hasta conseguir una adecuada distribución. La distribución espacial de las partículas y su proximidad con las otras partículas resulta decisivo sobre todo en aplicaciones basadas en la reactividad de los compuestos [57].

El proceso de mezclado de sólidos y polvos es una de las operaciones básicas en la industria química donde las partículas a mezclar varían no solo en tamaño 
y densidad sino también en propiedades físico-químicas, estructurales y en composición [58].

El mezclado de partículas sólidas sigue principalmente tres procesos, el de convección, el de difusión y el de cizalla, y estos procesos siguen patrones muy diferentes. Las mezclas que crean patrones ordenados son el resultado de procesos convectivos, de forma que los grupos de partículas son desplazados uno con respecto al otro y este tipo de mezclado se logra en equipos que agitan o rotan la mezcla. Por otra parte, los procesos de difusión dan lugar a mezclas desordenadas en las que las partículas individuales se mueven unas respecto a las otras, de forma análoga a la difusión molecular que tiene lugar en los fluidos. Por último, existe un tercer mecanismo de mezclado que se denomina mezclado de cizalla en el que los componentes se mueven en planos de deslizamiento entre distintas zonas de la muestra [59]. En los equipos de mezclado es común que tenga lugar más de un mecanismo, por lo que el poder controlar este parámetro puede llegar a ser una tarea complicada.

Las reacciones sólido-sólido están controladas por mecanismos de transporte entre las fases implicadas y, por tanto, es de esperar que la reactividad de los sólidos sea función de los mismos factores que modifican los mecanismos de transporte de materia que controlan la velocidad del proceso. Sin embargo, muchos estudios han demostrado que la reactividad también está influenciada por las propiedades intrínsecas de los materiales, así como del método de preparación y si el material se encuentra en estado pulverulento o como partículas sólidas de tamaño apreciable.

Concretamente en este trabajo de investigación, cabe notar que existen numerosos factores que intervienen en el proceso de mezclado y afectarán posteriormente al proceso de síntesis y al poder colorante del pigmento. Entre estos factores hay que destacar [60]:

- El tamaño de las partículas que componen la mezcla, ya que cuanto menor tamaño tienen las partículas, las fuerzas de cohesión aumentan. Para evitar la segregación, las sustancias que se desea mezclar deben mostrar grados de movilidad parecidos, y si la movilidad de sus componentes es baja (componentes de pequeño tamaño de partícula), será complicado conseguir una mezcla homogénea. Sin embargo, este tipo de mezclas poseen una gran estabilidad. Por tanto, se podría concluir que, para poder optimizar el proceso de mezclado, las sustancias deberían poseer un tamaño de partícula lo más parecido posible.

- La forma y rugosidad de las partículas, porque van a influir en la capacidad de transmitir la energía cinética recibida de los componentes del mezclador o de otras partículas. 
- La proporción en la que se encuentran los componentes de la mezcla. La homogeneidad en el mezclado es más difícil de conseguir cuanto más diferentes son las cantidades de cada componente a mezclar.

- La formación de cargas eléctricas. Si a la hora de realizar el proceso de mezclado aparecieran cargas eléctricas, las partículas tenderían a agruparse 0 aglomerarse, lo que dificultaría el proceso. Para disminuir este efecto, podría aumentarse el contenido de humedad de la mezcla o bien usar algún tipo de fluidificante.

En cuanto al proceso de mezclado, existen diversos tipos de molinos, pero los más importantes son los de rulos y muelas, de discos, de barras, de bolas y de rodillos, siendo los más utilizados en el ámbito industrial cerámico los de bolas, los de barras y los de rodillos. Esquemáticamente, los dos primeros se conciben como un cilindro horizontal que gira alrededor de su eje longitudinal, conteniendo en su interior elementos moledores, los cuales se mueven libremente y el material es mezclado y molido por fricción y percusión de los elementos moledores. Los molinos de bolas consisten básicamente en recipientes cilíndricos en cuyo interior albergan bolas de material duro de distintos tamaños. El molino está dotado de un movimiento de rotación de forma que las bolas se desplazan en el interior de éste produciendo el mezclado por rozamiento con el material a mezclar o molturar. Existen instalaciones de molinos de bolas para molienda en vía seca o vía húmeda que permiten su utilización en continuo o de modo intermitente según su construcción y tipo de alimentación.

Las variables que influyen en el mezclado con molinos de bolas son [61]:

- $\quad$ Material utilizado (bolas y mezcla de materias primas). Tamaño y carga de las bolas.

- Cantidad de producto a molturar.

- Velocidad del molino.

- Tiempo de molienda.

- Cantidad de agua, densidad y viscosidad de la mezcla.

- Desfloculantes.

En cuanto a la cantidad de bolas, éstas deben ocupar el $40-55 \%$ del volumen interior de la jarra, siendo también importante vigilar el desgaste de las bolas, ya que va a influir considerablemente. En cuanto al tamaño y forma de las bolas hay dos factores a tomar en cuenta; la superficie de contacto con la que se produce la molienda (en este sentido, se prefieren las bolas pequeñas) y el movimiento de las bolas, ya sea girando entre sí o chocando, siendo en este caso más efectivas las bolas grandes. 
La velocidad de rotación del molino es también una variable a tener en cuenta ya que velocidades de rotación bajas generan un efecto de cascada de los materiales al rodar suavemente, produciendo principalmente un mecanismo de abrasión donde se genera gran cantidad de finos. Para una velocidad media, los elementos de molienda se separan en el punto más alto y al caer desarrollan una trayectoria parabólica de efecto "catarata" siendo el mecanismo más importante el de impacto y produciendo partículas más gruesas. Por otra parte, la utilización de una velocidad de rotación del molino alta (velocidad crítica), produce un efecto de centrifugado con las partículas y la carga tiende a pegarse en las paredes, siendo mayoritarios los mecanismos de abrasión y compresión, reduciendo drásticamente la ruptura por impacto. Por tanto, el molino deberá trabajar a velocidad inferiores a la crítica.

Asimismo, el mezclado y/o molienda de las materias primas que componen una mezcla puede realizarse por vía seca o con una tecnología en húmedo. En líneas generales se puede elegir una molienda en húmedo para obtener una mayor reducción granulométrica de los materiales que componen las mezclas y obtener una mayor homogeneización, mientras que una molienda en seco se suele utilizar cuando se trata de materias primas muy homogéneas desde el punto de visto morfológico o, como en el caso que nos aborda, cuando se quiere realizar un mezclado suave, modificando en la menor medida posible la granulometría de los materiales.

Por tanto, algunos aspectos a tener en cuenta a la hora de efectuar el proceso de mezclado será elegir el material de las bolas (sílex, alúmina de alta densidad) así como el tamaño y la carga de bolas y la velocidad del molino. Asimismo, también resulta elemental no utilizar tiempos de mezclado excesivamente largos, sino que habrá un tiempo de operación adecuado para cada material y molino. De otra forma estaríamos elevando el coste del proceso y desgastando el molino sin obtener el grado de mezcla adecuado [62].

\subsubsection{Grado de mezcla o índice de mezclado}

Para evaluar la efectividad del proceso de mezclado, se define un parámetro que es el grado de mezcla o índice de mezclado que estima el grado de homogeneidad del sistema [63]. En la bibliografía consultada se definen diferentes grados de mezcla fundamentados en aproximaciones estadísticas, desarrollados mayoritariamente para mezclas de dos componentes y basados en la desviación estándar o varianza de muestras extraídas de una mezcla al cabo de un cierto tiempo. Los índices de mezclado pocas veces se extraen en base a sistemas pulverulentos reales y, en estos casos, no suelen tratarse de metodologías prácticas a la hora de introducirlos en un proceso industrial. Sin embargo, este parámetro va a depender en gran medida del tamaño y número de muestras que se extraen de la mezcla que debe de ser representativo y no debe de provocar la segregación de los componentes. 
Algunos autores han revisado más de 30 índices de mezcla diferentes [60,64], sin embargo, resulta complicado poder relacionar los diferentes índices de mezcla entre ellos, de modo que comparar los resultados obtenidos en diferentes estudios de mezclas de sólidos resulta complejo. No obstante, algunos autores han realizado trabajos de investigación para facilitar la conversión de unos índices de mezcla en otros cuando se tratan de sistemas binarios con el mismo tamaño de partícula [64].

Para mezclas binarias, uno de los primeros índices de mezclado utilizados para evaluar la homogeneidad en mezclas fue propuesto por Miles [65] de la siguiente forma:

$$
M=1-\frac{\sigma^{2}}{\sigma_{0}^{2}}
$$

(Ecuación 5)

Donde $M$ es el grado de mezclado, $\sigma^{2}$ y $\sigma_{0}^{2}$ son la varianza de diferentes muestras extraídas y la varianza al inicio del mezclado respectivamente, que pueden ser determinadas de forma experimental.

Otros conceptos a tener en cuenta al hablar de índices de mezclado son la varianza teórica de una mezcla binaria en estado heterogéneo, lo que anteriormente hemos denominado como $\sigma 0^{2}$, y la varianza para una mezcla totalmente homogénea $\sigma R^{2}$ y que se definen como sigue:

$$
\begin{aligned}
& \sigma_{0}^{2}=p \cdot(1-p) \\
& \sigma_{R}^{2}=\frac{p \cdot(1-p)}{n}
\end{aligned}
$$

(Ecuación 6)

(Ecuación 7)

Donde $\mathrm{p}$ y (1-p) son las proporciones de los componentes en la mezcla, y $\mathrm{n}$ el número de partículas de cada muestra.

Utilizando estos parámetros estadísticos, en 1954 Lacey [66] definió un índice de mezcla para evaluar la homogeneidad de mezclas, utilizando la siguiente ecuación:

$$
M=\frac{\sigma_{0}^{2}-\sigma^{2}}{\sigma_{0}^{2}-\sigma_{R}^{2}}
$$

(Ecuación 8)

Según el índice de Lacey, una mezcla completamente segregada tendrá un valor de 0 , mientras que un índice de 1 indica que el sistema es totalmente homogéneo. En la mayoría de los casos el índice de mezclado cae en el rango 0,75-1, por lo tanto, se considera que el índice de Lacey no discrimina adecuadamente sistemas con diferentes grados de mezclado.

Algunos años más tarde, Poole [67] definió un índice de mezcla más discriminativo, de forma que cuando la mezcla es totalmente homogénea este índice tiende a la unidad. El índice de mezcla se define según la siguiente ecuación: 


$$
M=\frac{\sigma}{\sigma_{R}}
$$

Donde $\sigma$ es la desviación estándar observada y $\sigma_{R}$ es la desviación estándar para una mezcla completamente aleatoria.

Ahora bien, estos índices se utilizan para sistemas binarios, y cuando el número de componentes de la mezcla es mayor como es el caso que nos ocupa, el cálculo de los índices de mezcla se complica considerablemente, por lo que se hace necesario poder establecer algún método para evaluar la homogeneidad de las mezclas que no esté basado en conceptos estadísticos.

\subsubsection{Evaluación del grado de mezcla en pigmentos cerámicos}

El éxito en la síntesis de pigmentos cerámicos reside en lograr un buen mezclado de los diferentes componentes de una mezcla con partículas de diferente tamaño y densidad. Asimismo, debido a la naturaleza de los materiales cerámicos pulverulentos, a menudo sus partículas se hallan aglomeradas y, para poder romper estos aglomerados y dispersar las partículas individuales, es necesario el uso de equipos de mezclado que aumentan la uniformidad de la composición con el inconveniente de que los componentes pueden sufrir una reducción del tamaño de partícula que afecte posteriormente al proceso de síntesis.

Por tanto, una de las claves en la obtención de pigmentos a nivel industrial reside en la mezcla inicial de materias primas. Por este motivo, una de las líneas de investigación seguidas durante el desarrollo de este trabajo fue proponer un método para evaluar el grado de mezcla en la síntesis del pigmento coral de hierro-circón y así poder optimizar el proceso.

Uno de los aspectos fundamentales a tener en cuenta a la hora de desarrollar un método para evaluar el grado de mezcla y poder aplicarlo al proceso industrial de síntesis del pigmento, consistía en poder trabajar sobre las materias primas directamente, es decir, antes de la etapa de calcinación.

Los resultados obtenidos en la revisión bibliográfica, mostraban mayoritariamente métodos basados en aspectos estadísticos [68-70], sin embargo, en uno de los trabajos [71] se hacía referencia a un método en el que no se utilizaban parámetros estadísticos y en principio podría aplicarse a la determinación del índice de mezcla en la síntesis del pigmento coral hierrocircón de una forma práctica. Esta metodología consistiría en extraer el índice de mezcla a partir de la transformada de Fourier de imágenes reales de la mezcla de materias primas. 
Según los autores, la transformada de Fourier permitía interpretar las imágenes obtenidas de una mezcla de componentes. Además, el espectro de potencia obtenido a partir de la transformada de Fourier discreta (TFD) mostraba un significado físico más interesante que algunos parámetros estadísticos nombrados anteriormente, como la desviación estándar. Los resultados obtenidos a partir de simulaciones computacionales demostraban como la componente máxima del espectro de potencia de una imagen podía ser empleado como índice de mezcla, ya que existía una relación entre la homogeneidad de las mezclas de sólidos y el espectro de su TFD. Asimismo, este índice permitía distinguir entre mezclas cuyos componentes se encontraban distribuidos aleatoriamente y mezclas ordenadas. No obstante, el artículo consultado estaba basado en modelos matemáticos y casos teóricos, sin hacer referencia a su aplicación en sistemas reales.

A pesar de que existen numerosos parámetros de la TFD que podrían ser utilizados como índice de mezcla, los autores seleccionaron el parámetro $\mathrm{M}_{1}$ (componente máximo del espectro de potencia), como índice de mezcla. Esta selección se basaba en su estabilidad a los cambios en la composición media y en su eficiencia. A modo ilustrativo, se presenta la Tabla 1.2, que ayuda a comprender el significado del parámetro $\mathrm{M}_{1}[71]$.

Tabla 1.2 Componente máxima del espectro de potencia $\left(M_{1}\right)$ de una mezcla ordenada unidimensional

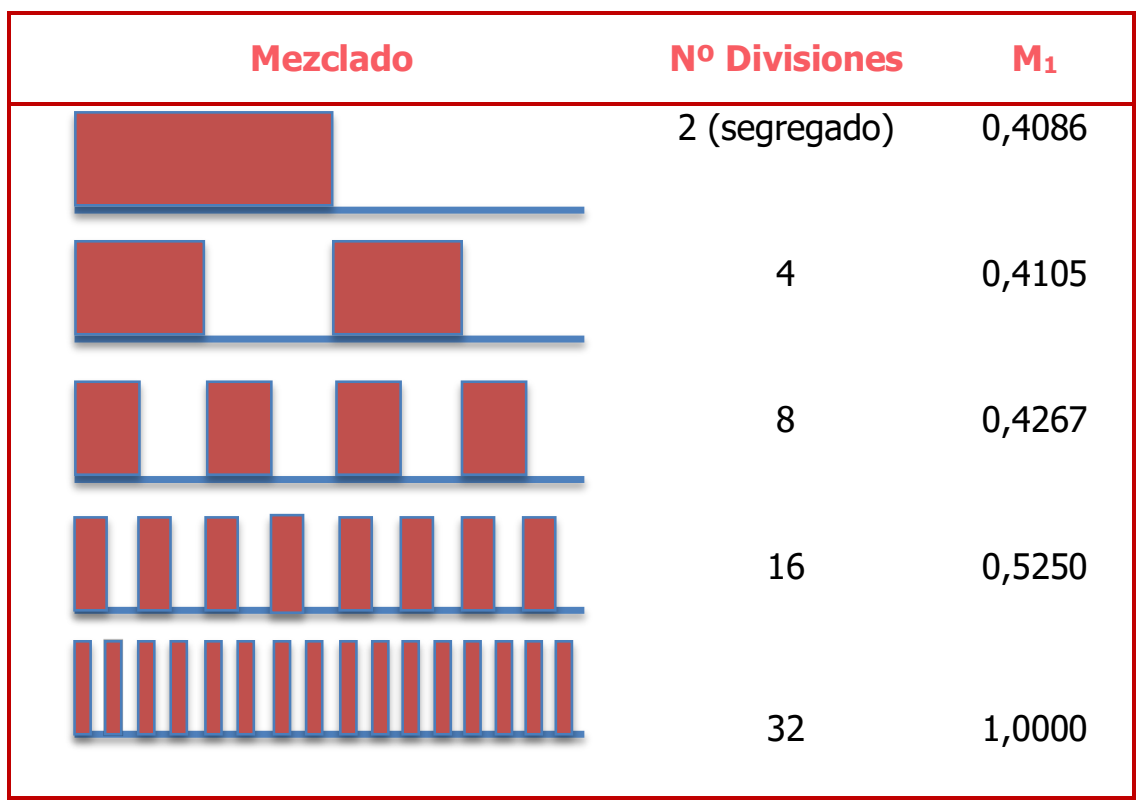


El trabajo de investigación consultado permitía extraer las siguientes conclusiones:

- Mezclas ordenadas: El parámetro $M_{1}$ aumentaba a medida que progresaba el proceso de mezclado hacia una mezcla ordenada. El espectro de potencia de una mezcla ordenada presentaba una forma particular, ya que tenía un espectro de potencia simétrico.

- Mezclas aleatorias: Un proceso de mezclado suele ir acompañado de movimientos aleatorios de partículas individuales, por tanto, el espectro de potencia de una mezcla aleatoria debía tener una estructura totalmente diferente a la de una mezcla ordenada. De este modo, a medida que el proceso de mezclado avanzaba o la aleatoriedad aumentaba, $M_{1}$ disminuía y conforme la mezcla se iba aproximando a un estado completamente aleatorio, $\mathrm{M}_{1}$ tendía a cero. Este hecho permitía diferenciarlas de las mezclas ordenadas, en las que $\mathrm{M}_{1}$ aumentaba con un aumento de la homogeneidad o uniformidad.

- Se comprobaba que existía una relación lineal entre $\ln \left(\mathrm{M}_{1}\right)$ y $\ln \left(\sigma^{2}\right)$ (siendo $\sigma$ la desviación estándar). De esta forma se demostraba que este parámetro permitía distinguir entre patrones ordenados y aleatorios incluyendo el concepto de homogeneidad de la mezcla.

A pesar de ser un estudio meramente teórico, los conceptos que se evaluaban parecían interesantes y podían ser aplicados para afrontar la problemática de la evaluación del grado de mezcla en la síntesis de pigmentos.

Por tanto, una idea inicial para desarrollar esta metodología consistiría en:

I. Preparación de las muestras a estudiar.

II. Obtener imágenes de la mezcla de materias primas utilizando un microscopio electrónico de barrido, aprovechando el contraste de composición implícito en las imágenes.

III. Aplicar la transformada de Fourier discreta a las imágenes (TFD) mediante un software de análisis de imagen.

IV. Obtener el espectro de potencia de la transformada de Fourier.

V. Evaluar la homogeneidad de las mezclas utilizando diferentes parámetros del espectro de potencia TFD para definir un índice de mezclado. 


\subsection{Transformada de Fourier Discreta (TFD)}

Con el fin de poder desarrollar la metodología expuesta anteriormente, se hace necesario realizar una introducción a la transformada de Fourier y cómo opera esta función matemática [72], [73].

La idea del análisis de Fourier comienza a principios del siglo XIX, cuando Joseph Fourier afirma que toda función periódica puede ser expresada como una suma infinita de senos y cosenos. Considerando que las imágenes digitales presentan cierta regularidad y tienen periodicidad, éstas se pueden descomponer en una función periódica como suma infinita de senos y cosenos, y por tanto el análisis de Fourier puede ser utilizado en multitud de aplicaciones en diversas ramas de la ingeniería. Extrapolando este concepto a las imágenes digitales, éstas pueden ser representadas en una matriz con filas y columnas en función de la posición de los píxeles y los niveles de gris de la imagen (intensidad de la señal).

Por este motivo, la transformada de Fourier se ha convertido en una herramienta matemática utilizada en el procesado y retocado de imágenes incluyendo el análisis de imágenes, filtrado, reconstrucción y compresión de imágenes. Se trata de una transformación matemática empleada para transformar señales entre el dominio del tiempo (o espacial) y el dominio de la frecuencia. Se puede considerar básicamente como el espectro de frecuencias de una función, ya que toda función periódica de período $\mathrm{T}$ puede ser expresada como una suma trigonométrica de senos y cosenos del mismo período $\mathrm{T}$ [74], [75].

La transformada de Fourier descompone una señal compleja en una suma ponderada de varios términos. En primer lugar, un término de frecuencia cero (que está relacionado con el valor medio de la señal), en segundo lugar, una sinusoide con la frecuencia mínima (también denominada término fundamental), y a continuación una serie términos sinusoidales, en la cual cada sinusoide posee una frecuencia múltiplo de la frecuencia del término fundamental. Habitualmente al término fundamental se le denomina primer armónico, y el resto de las sinusoides se indican como armónicos del término fundamental. De este modo es posible recrear la señal original sumando al término de frecuencia cero, el término fundamental y sus armónicos, cada uno de ellos multiplicado por el factor de peso, que son los coeficientes de la transformada [72], [73]. 
La expresión de la transformada de Fourier para una función continua $f$ de una variable $\boldsymbol{c}$ viene dada por la ecuación 10.

$$
F_{t}(v)=\int_{-\infty}^{\infty} f(c) \cdot e^{-i 2 \pi v c} d c=\int_{-\infty}^{\infty} f(c) \cdot[\cos (2 \pi v c)-i \cdot \operatorname{sen}(2 \pi v c)] d c
$$

(Ecuación 10)

Donde $\boldsymbol{i}$ es la unidad imaginaria, y $v$ la frecuencia.

Aunque inicialmente la transformada de Fourier se desarrolló para funciones continuas, posteriormente se amplió al tratamiento de funciones discretas, situación a la que corresponde la ecuación 11.

$$
F_{t}(v)=\frac{1}{N} \sum_{c=0}^{N-1} f(c) \cdot e^{-i \frac{2 \pi v c}{N}}=\frac{1}{N} \sum_{c=0}^{N-1} f(c) \cdot\left[\cos \left(\frac{2 \pi v c}{N}\right)-i \cdot \operatorname{sen}\left(\frac{2 \pi v c}{N}\right)\right]
$$

(Ecuación 11)

Donde $\mathrm{N}$ son los puntos donde está definida la función discreta.

En la Figura 1.8 se muestra el resultado de la descomposición de una onda cuadrada aplicando la transformada de Fourier.

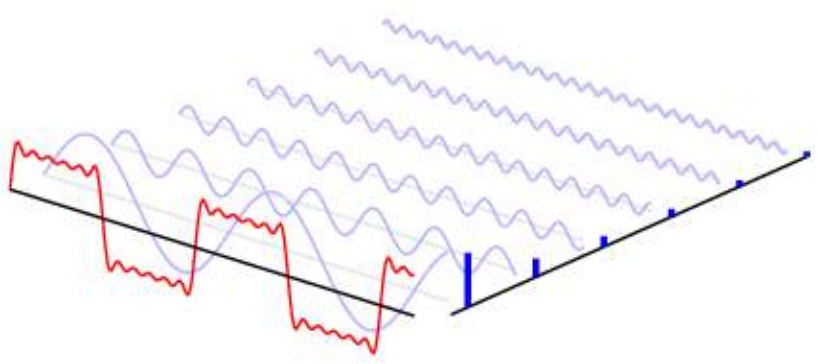

Figura 1.8 Onda cuadrada y reconstrucción con diferentes armónicos (Imagen de pgfplots.net con licencia CC BY-SA 3.0)

La transformada de Fourier se puede extender a funciones de dos variables, tanto continuas como discretas. El último caso es el utilizado en el análisis de imágenes, y se expresa mediante la ecuación 12 (supuesta una función discreta de dos variables $\boldsymbol{r}$ y $\boldsymbol{c}$, que se transforma en una función discreta de dos frecuencias $\boldsymbol{u}$ y $\boldsymbol{v}$ ). 


$$
F_{t}(u, v) \frac{1}{N} \sum_{r=0}^{N-1} \sum_{c=0}^{N-1} f(r, c)\left\{\cos \left[\frac{2 \pi}{N}(u r+v c)\right]-i \cdot \operatorname{sen}\left[\frac{2 \pi}{N}(u r+v c)\right]\right\}
$$

(Ecuación 12)

Para este trabajo, en el cual vamos a trabajar con imágenes digitales, la transformada de Fourier se enfoca en el análisis de señales discretas, y por tanto la herramienta que utilizaremos será la transformada de Fourier discreta (TFD).

Su utilidad en el análisis de imágenes se debe a que éstas se pueden considerar como funciones discretas de dos variables, donde el valor de la función es el nivel de gris de cada píxel, y las variables de la función la posición de cada píxel en la imagen. De este modo la transformada de Fourier traduce la imagen a un espacio matemático distinto vía la ecuación de transformación. En términos matemáticos, se transforma la función desde el dominio espacial al domino de frecuencias (también llamado dominio espectral), de forma que todos los píxeles de la imagen original contribuyen a cada píxel de la imagen en el dominio espectral. Dado que cada píxel en la transformada tiene asociado un número complejo, en realidad se obtendrían dos imágenes, una correspondiente a la magnitud del número complejo y otra correspondiente a su fase, que vendrían dadas por las siguientes ecuaciones ( $\boldsymbol{R}$ e $\boldsymbol{I}$ son las componentes real e imaginaria del número complejo).

$$
\begin{aligned}
& \text { magnitud }=\left|F_{t}(u, v)\right|=\sqrt{[R(u, v)]^{2}+[I(u, v)]^{2}} \\
& \text { fase }=\phi(u, v)=\arctan \left[\frac{I(u, v)}{R(u, v)}\right]
\end{aligned}
$$

(Ecuación 14)

La transformada de Fourier de las imágenes en blanco y negro son los espectros de potencia o densidad espectral, que se representan como otra imagen en tonos de gris, donde las frecuencias con mayor peso en el espectro aparecen como puntos blancos (nivel de gris 255 en binario), y las frecuencias con menos peso en forma de puntos negros (nivel 0 de gris en binario).

A fin de clarificar la teoría de la transformada de Fourier aplicada a imágenes, se muestra un cuadrado y un círculo y los espectros de potencia de su transformada de Fourier [76]. 


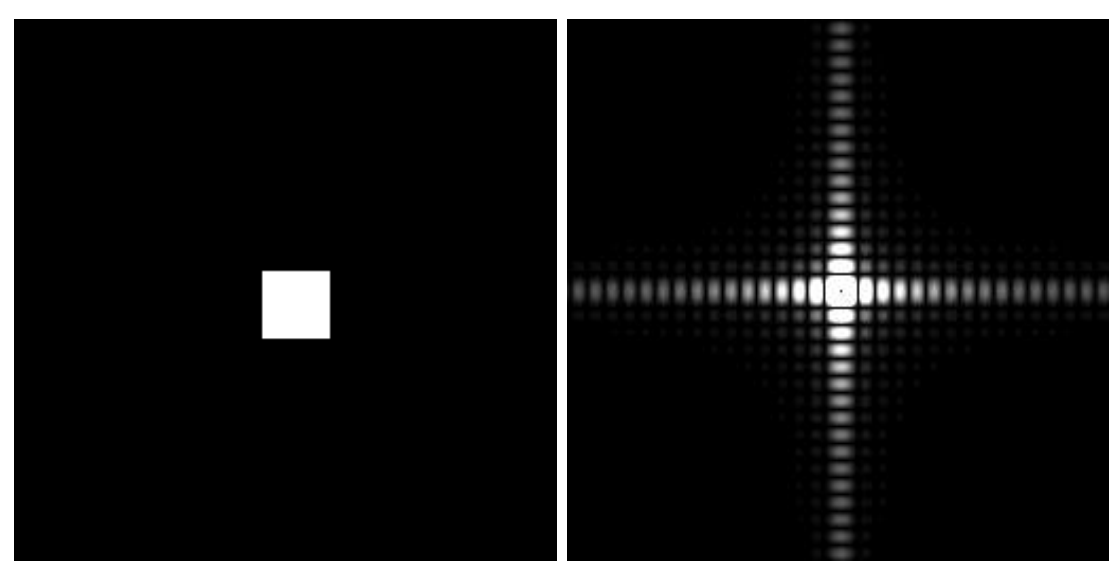

Figura 1.9 Cuadrado y TFD del cuadrado (2D sinc function) [76]
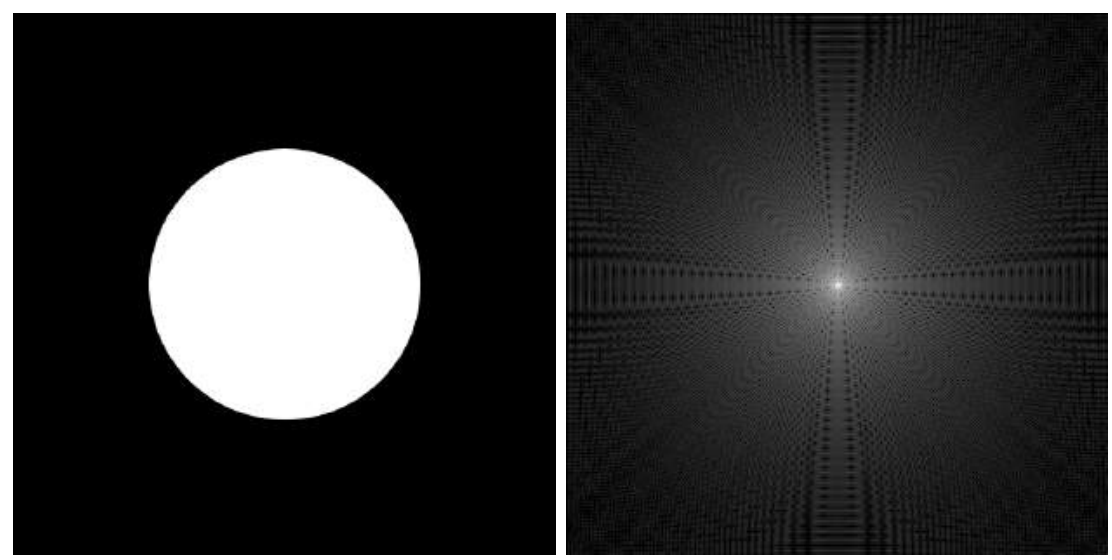

Figura 1.10 Círculo y TFD del círculo (2D sinc function) [76]

Por otra parte cabe mencionar que los intervalos que abarcan los valores de la magnitud en el espectro de potencia de una imagen, pueden ser mucho mayores que el intervalo 0-255 que corresponden a los píxeles de una imagen binaria, por ello se realiza un escalado en los valores de la magnitud para ajustarlos al intervalo binario, es decir, para una mejor visualización se puede utilizar el logaritmo de la transformada y escalarlo a 255 de forma que se normaliza la matriz en el intervalo 0-255, utilizando el factor de escalado k:

$$
\log (u, v)=k \cdot \log \left[1+\left|F_{t}(u, v)\right|\right]
$$


El espectro de frecuencias de una imagen puede calcularse de varias maneras, pero el método Fast Fourier Transform (FFT) es rápido, práctico y el que suelen utilizar la mayoría de software para realizar la transformada. La imagen original debe estar compuesto de $\mathrm{N}$ filas y $\mathrm{N}$ columnas, donde $\mathrm{N}$ es una potencia de dos, es decir, 256, 512, 1024, etc... Si el tamaño de la imagen original no es una potencia de dos, se añaden píxeles con un valor de cero para que sea del tamaño correcto. Se denomina matriz bidimensional a aquella que contiene la imagen de la matriz real. Además, se necesita otra matriz del mismo tamaño, que se denomina matriz imaginaria.

Para el cálculo de la transformada de Fourier de una imagen se toma la FFT unidimensional de cada una de las filas, seguidas por la FFT unidimensional de cada una de las columnas. Dado que las direcciones verticales y horizontales son equivalentes en una imagen también se puede realizar primero el algoritmo con las columnas y posteriormente con las filas. Independientemente del orden que se utilice, el resultado será el mismo [74].

A pesar de la complejidad que supone la comprensión y utilización de estas herramientas matemáticas, el algoritmo matemático FFT que se utiliza para calcular la TFD de las imágenes digitales en este estudio se resuelve con el software de análisis de imagen MicroImage, que transforma la imagen en escala de grises en su forma espectral (espectro de potencia). Otro tipo de software como el MathCad también permite la manipulación de tablas de datos, así como implementación de algoritmos del tipo FFT y debido a su disponibilidad también se abordará la TFD utilizando este programa matemático. 


\section{OBJETIVOS}



Las principales razones que han motivado la selección del trabajo de investigación, así como la elaboración del plan de trabajo, objeto de esta Tesis, son, entre otros, los siguientes:

- El coral de hierro-circón, es un pigmento cerámico con una dificultad intrínseca a la hora de implementar a nivel industrial, ya que al tratarse de un pigmento encapsulado o de inclusión son muchos los factores que influyen en el desarrollo del poder colorante. Estas variables son numerosas y están implicadas en todo el proceso industrial, desde la selección de materias primas, el proceso de mezclado o el método de síntesis del pigmento. Pese a todo, estos pigmentos con estructura de circón presentan unas propiedades inmejorables con la presencia de estructuras estables a elevadas temperaturas, con una elevada resistencia al ataque de los vidriados y una amplia gama de tonalidades que incluyen el melocotón, el coral o el rosa.

- Al tratarse de mecanismos de síntesis complejos, existen diferentes etapas durante la reacción que requieren ser controladas como son los procesos de difusión entre las partículas de hematites, circona y sílice, así como la etapa de crecimiento de las partículas de circón. Como evolucionen estos procesos dependerá en gran medida del tipo de precursor de hierro utilizado, del tamaño de partícula de los materiales de partida, presencia de mineralizadores, así como del proceso de mezclado y método de síntesis, teniendo estas variables una influencia muy relevante sobre la formación del pigmento y en su poder colorante final.

- Al considerarse un pigmento del tipo encapsulado, resulta imprescindible hacer hincapié en conocer cómo se encuentran distribuidas espacialmente las materias primas en la mezda de reacción, ya que en caso de que la efectividad del encapsulamiento de las partículas de hematites en la matriz de circón no sea elevada, podría formarse circón, pero éste no presentaría poder colorante.

- Por otra parte, a pesar de las numerosas investigaciones llevadas a cabo con los pigmentos coral de hierro-circón, existen discrepancias en cuanto a la naturaleza del pigmento y a su mecanismo de formación.

Así pues, el objetivo general de este trabajo es, por una parte, intentar profundizar en la influencia que tiene el proceso de mezclado en la síntesis del pigmento coral de hierro-circón. Por otra parte, se propondrá un índice de mezclado que describa el grado de homogeneidad del sistema utilizando el algoritmo de transformada de Fourier discreta (TFD), el cual posteriormente se pueda correlacionar con las coordenadas cromáticas del pigmento final para poder ser introducido en el proceso industrial. 
Con esta finalidad, se planificaron una serie de experimentos que permitieran analizar los factores que influyen realmente en el mecanismo de síntesis del pigmento, así como estimar esta influencia desde un punto de vista mineralógico, microestructural y colorimétrico. Se evaluaron las variables que se describen a continuación:

- Influencia de las materias primas.

- Influencia del método de mezclado.

- Influencia del tiempo de mezclado.

- Influencia del orden de adición de las materias primas.

- Influencia de la velocidad de calentamiento en el tratamiento térmico.

- $\quad$ Efecto de la temperatura máxima de síntesis.

- $\quad$ Efecto del tiempo de permanencia a temperatura máxima.

Finalmente, también se realizarían experimentos para corroborar los mecanismos de formación del pigmento propuestos con los resultados obtenidos en el trabajo de investigación. 
3. MATERIALES
Y MÉTODOS 

En este apartado se describe la metodología experimental empleada para realizar los diferentes estudios comprendidos en el presente trabajo.

La metodología utilizada incluye una breve descripción de las materias primas utilizadas, el equipamiento y las técnicas de caracterización empleadas.

\subsection{Materiales y reactivos}

Para llevar a cabo la síntesis del pigmento coral de hierro circón, se seleccionaron las diferentes materias primas para posteriormente preparar las mezclas.

Para la obtención del pigmento se seleccionaron dos circonas, dos óxidos de hierro, un cuarzo, un mineralizador utilizado habitualmente en la síntesis de este pigmento como es el hexafluorosilicato sódico y un fluidificante como es la sílice pirogénica para favorecer el mezclado entre las partículas. En la Tabla 3.1 se muestran los materiales seleccionados, así como la referencia comercial y el proveedor.

Tabla $3.1 \quad$ Materias primas utilizadas

\begin{tabular}{|cccc|}
\hline Referencia & Materia prima & Referencia comercial & Proveedor \\
\hline FZr & Circona & $\mathrm{CCO}$ & Saint Gobain \\
GZr & Circona & $\mathrm{CC} 10$ & Saint Gobain \\
AFe & Óxido de hierro & 3097 & Huntsman Corp. \\
BFe & Óxido de hierro & 485 & Huntsman Corp. \\
Q & Cuarzo & $\mathrm{SE}-500$ & Sibelco \\
Min & Mineralizador & $\mathrm{Na}_{2} \mathrm{SiF}_{6}$ & Sigma Aldrich \\
Flu & Fluidificante & Aerosil 200 & Evonik \\
\hline
\end{tabular}

Algunas de las propiedades de estas materias primas que presumiblemente ejercerían un efecto significativo en la reactividad, como son el diámetro medio de partícula $\left(\mathrm{d}_{50}\right)$ y la superficie específica $\left(\mathrm{S}_{\mathrm{e}}\right)$ fueron caracterizadas, recogiéndose en la Tabla 3.2. 
Tabla 3.2 Características de las materias primas utilizadas

\begin{tabular}{|cccc|}
\hline Referencia & Materia prima & $\begin{array}{c}\mathrm{d}_{50} \\
(\mu \mathrm{m})\end{array}$ & $\begin{array}{c}\text { Se } \\
\left(\mathrm{m}^{2} / \mathrm{g}\right)\end{array}$ \\
\hline $\mathrm{FZr}$ & Circona (CC02) & 0,75 & 3,72 \\
$\mathrm{GZr}$ & Circona (CC10) & 3,02 & 2,38 \\
$\mathrm{AFe}$ & Óxido de hierro (3097) & 0,37 & 11,4 \\
$\mathrm{BFe}$ & Óxido de hierro (485) & 0,42 & 9,68 \\
$\mathrm{Q}$ & Cuarzo & 2,79 & 4,46 \\
$\mathrm{Flu}$ & Fluidificante & 0,012 & 200 \\
\hline
\end{tabular}

La distribución de tamaño de partícula de las circonas, óxidos de hierro y cuarzo se muestran desde la Figura 3.1 a la Figura 3.5. Las circonas y el cuarzo fueron medidos utilizando la técnica de difracción láser vía húmeda, mientras que los óxidos de hierro, debido a su naturaleza se midieron con dispersión dinámica de luz (DLS).

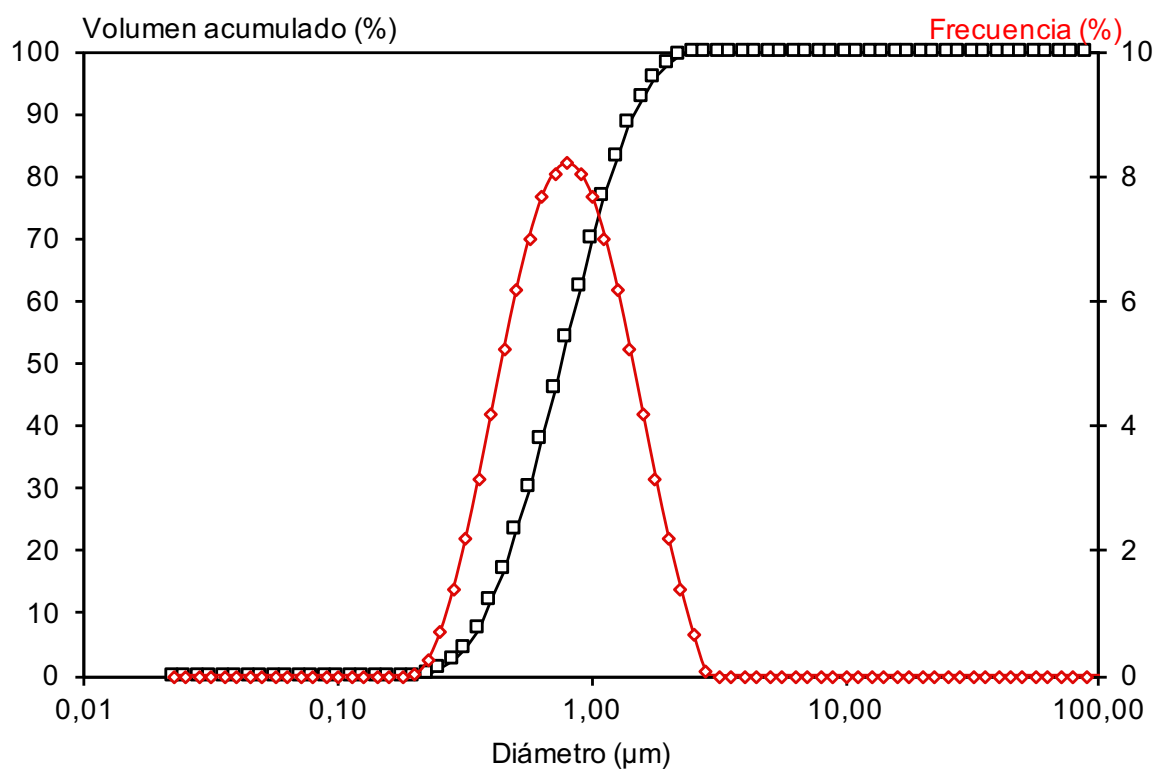

Figura 3.1 Distribución de tamaño de partícula de la circona FZr 


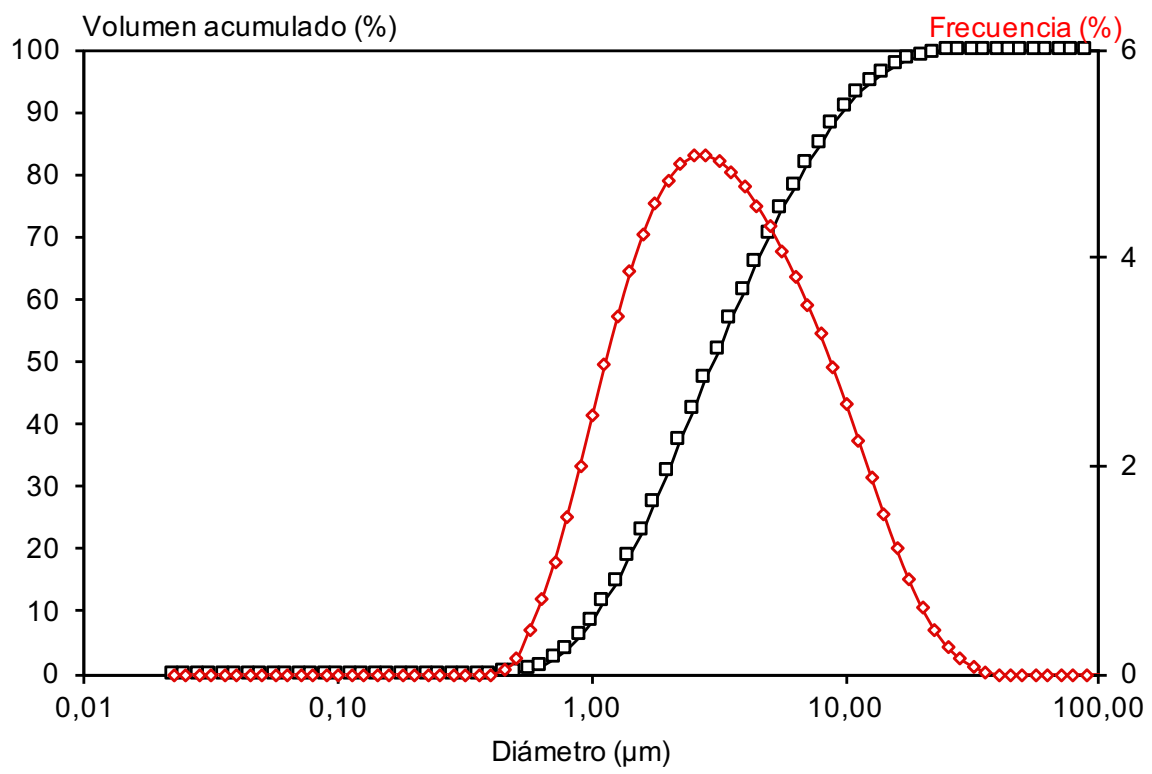

Figura 3.2 Distribución de tamaño de partícula de la circona GZr

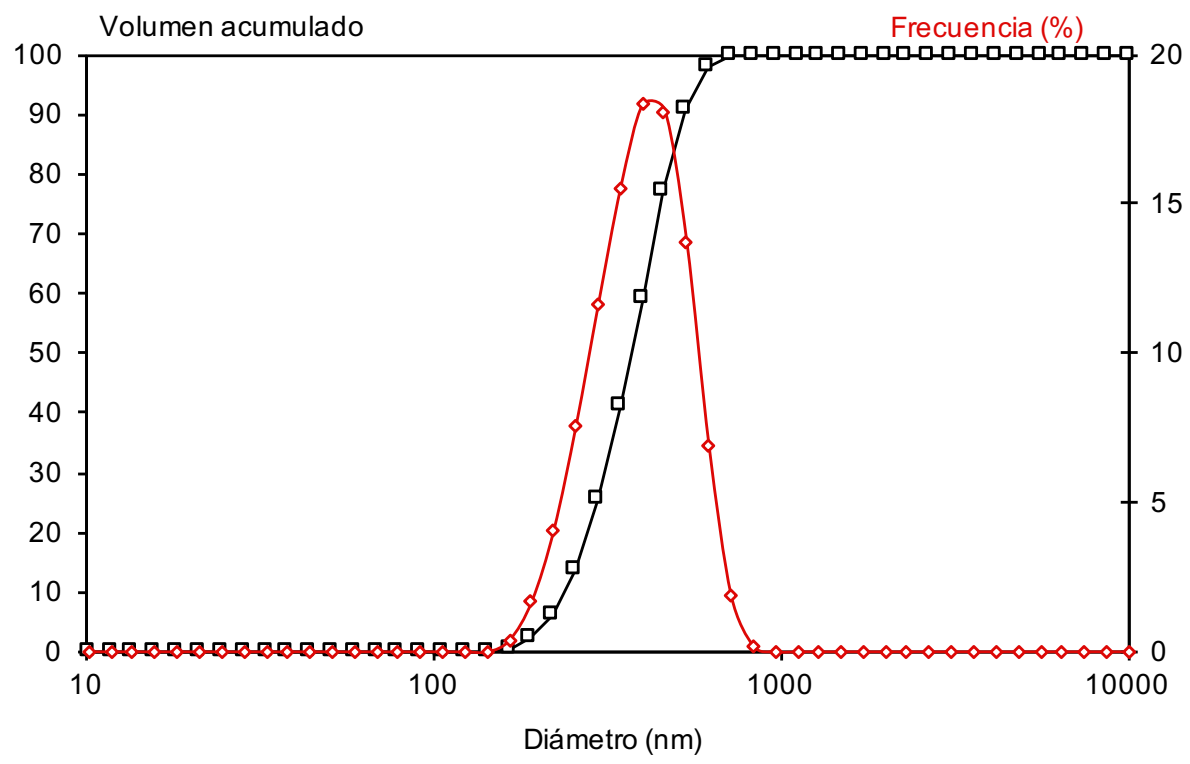

Figura 3.3 Distribución de tamaño de partícula del óxido de hierro AFe 


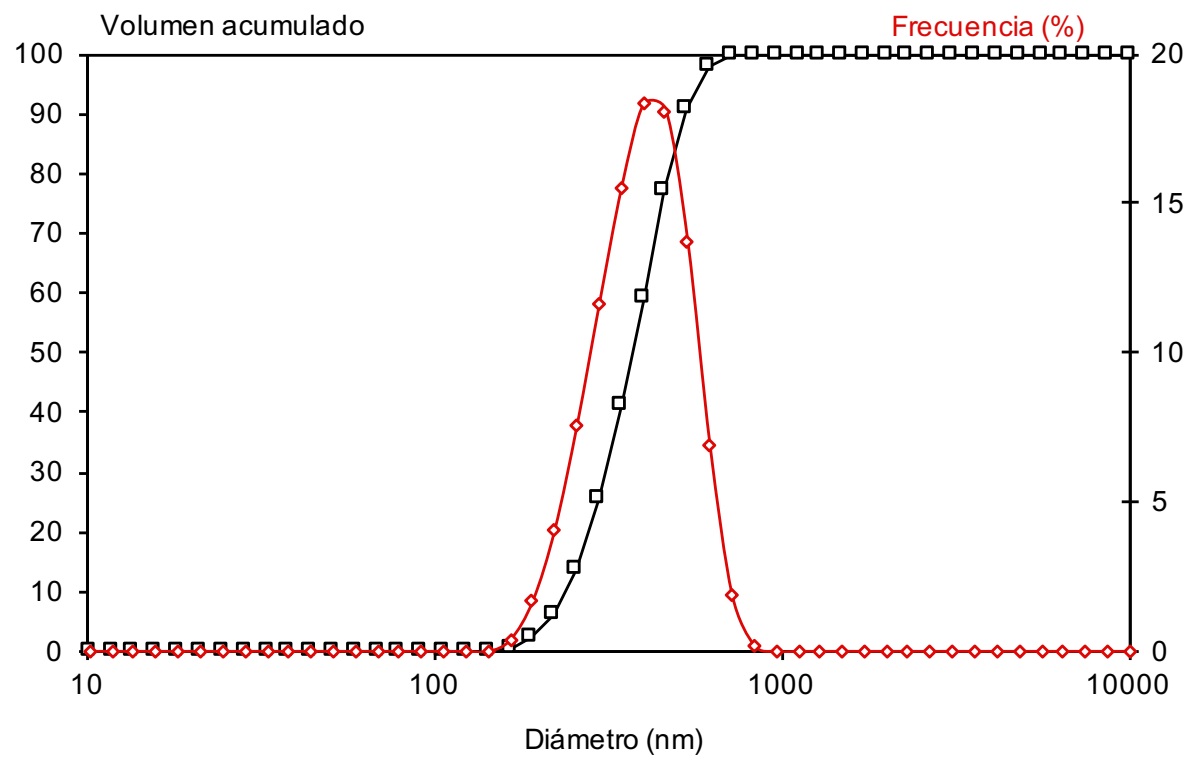

Figura 3.4 Distribución de tamaño de partícula del óxido de hierro BFe

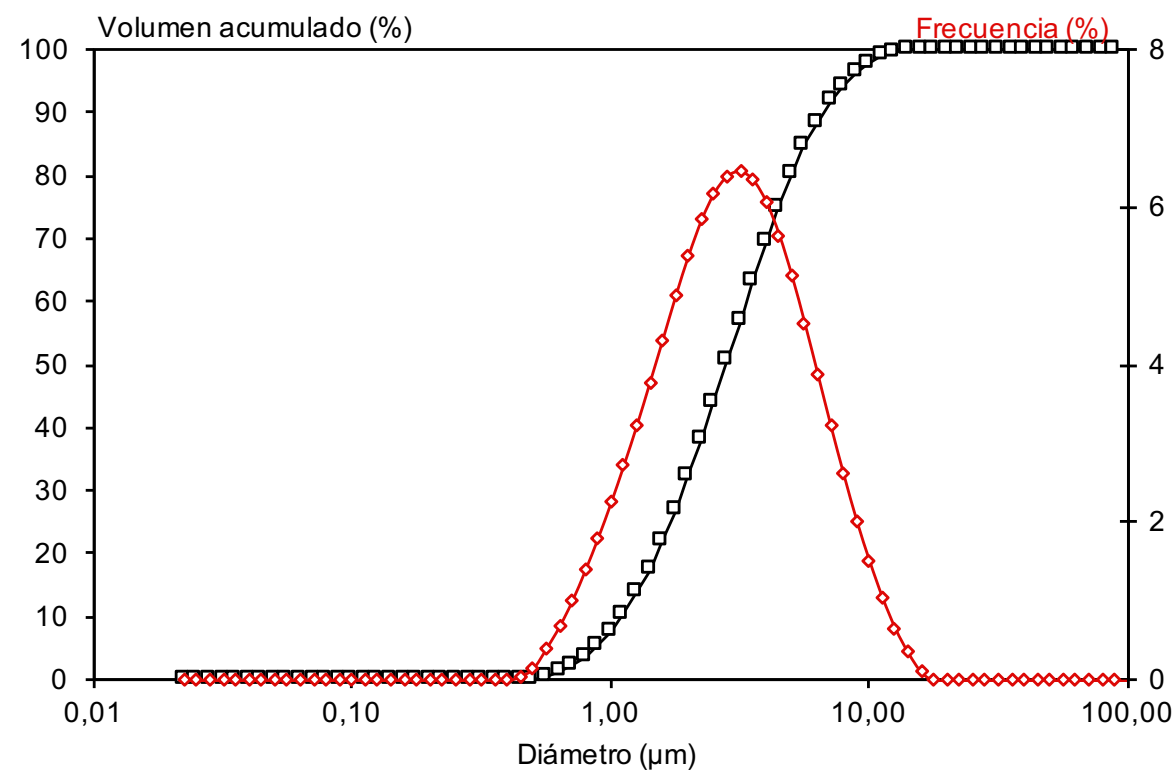

Figura 3.5 Distribución de tamaño de partícula del cuarzo SE-500 
Para verificar la mineralogía de las materias primas, se realizó una caracterización mediante difracción de rayos $X$. Tal y como se observa en las Figura 3.6 a Figura 3.11, las materias primas no presentan fases minoritarias que puedan interferir en la reacción de la síntesis del pigmento. A continuación, en la Tabla 3.3 se indican las fases identificadas en cada una de las materias primas utilizadas.

Tabla 3.3 Fases cristalinas de las materias primas utilizadas

\begin{tabular}{|ccc|}
\hline Referencia & Fase cristalina & Fórmula \\
\hline $\mathrm{FZr}$ & Baddeleyita & $\mathrm{ZrO}_{2}$ \\
$\mathrm{GZr}$ & Baddeleyita & $\mathrm{ZrO}_{2}$ \\
$\mathrm{AFe}$ & Hematites & $\mathrm{Fe}_{2} \mathrm{O}_{3}$ \\
$\mathrm{BFe}$ & Hematites & $\mathrm{Fe}_{2} \mathrm{O}_{3}$ \\
$\mathrm{Q}$ & Cuarzo & $\mathrm{SiO}_{2}$ \\
Min & Malladrita & $\mathrm{Na}_{2} \mathrm{SiF}_{6}$ \\
\hline
\end{tabular}

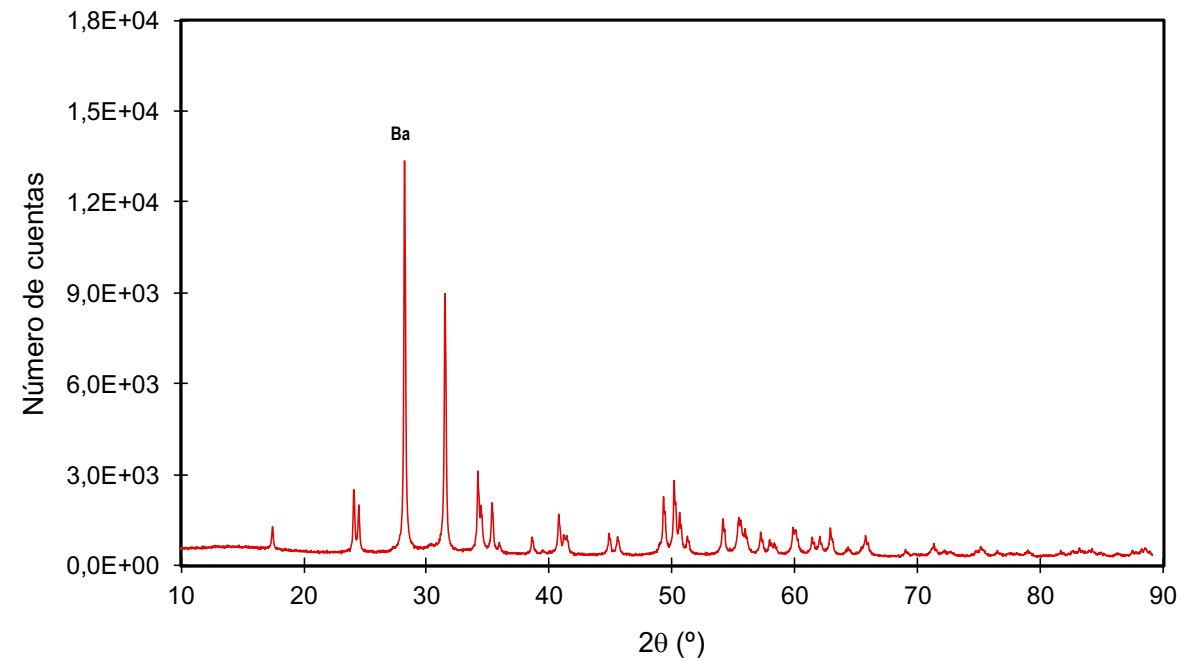

Figura 3.6 Identificación de fases cristalinas. Difractograma de la muestra FZr junto con las fases cristalinas identificadas (Ba:Baddeleyita) 


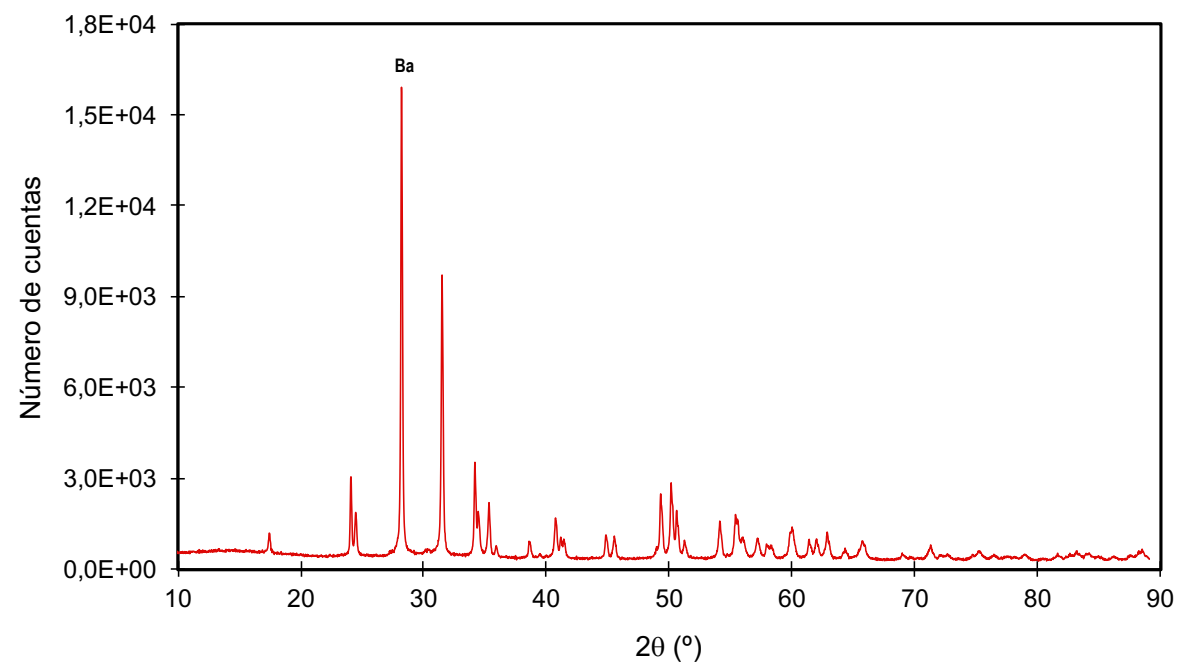

Figura 3.7 Identificación de fases cristalinas. Difractograma de la muestra GZr junto con las fases cristalinas identificadas (Ba:Baddeleyita)

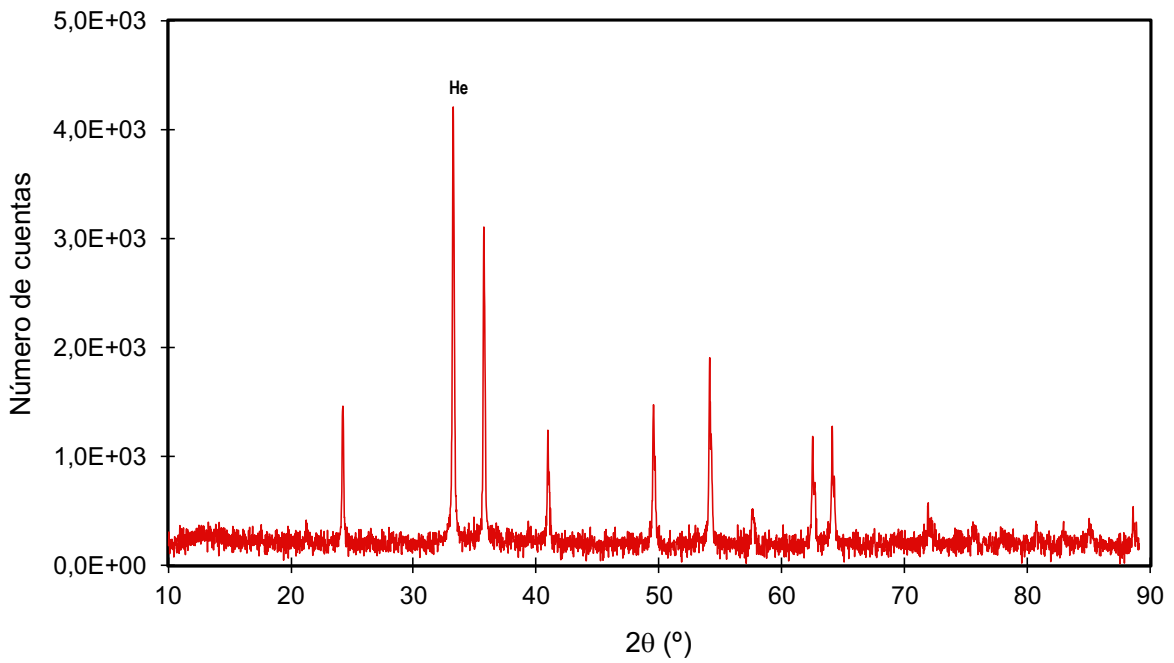

Figura 3.8 Identificación de fases cristalinas. Difractograma de la muestra AFe junto con las fases cristalinas identificadas (He:Hematites) 


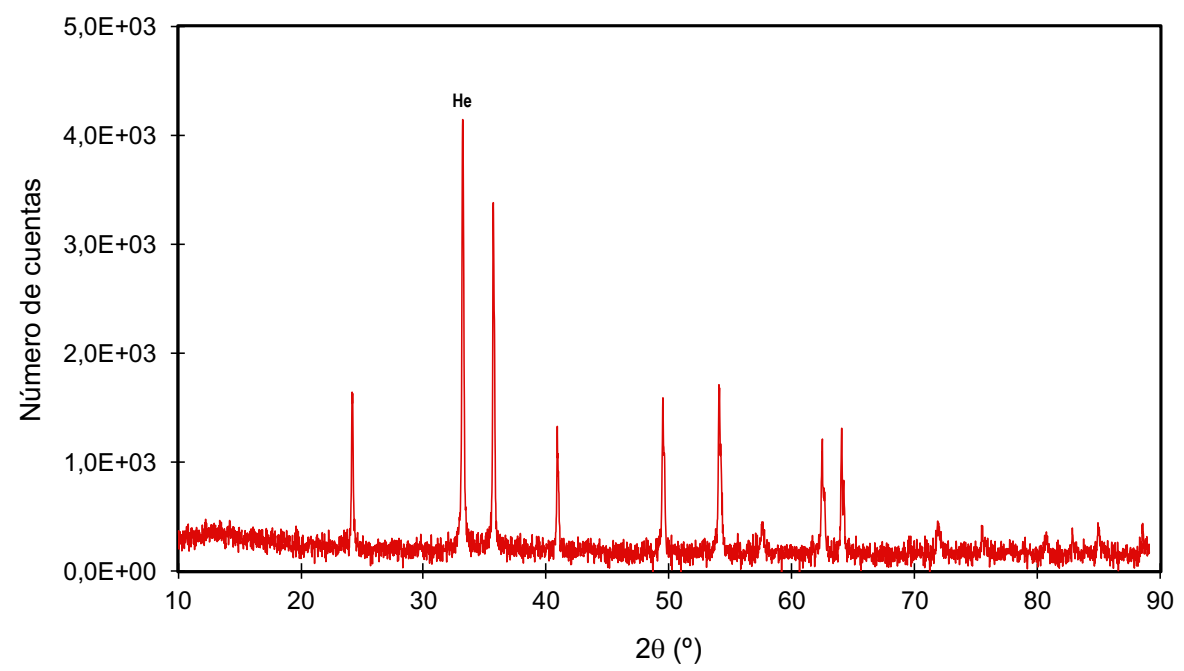

Figura 3.9 Identificación de fases cristalinas. Difractograma de la muestra BFe junto con las fases cristalinas identificadas (He:Hematites)

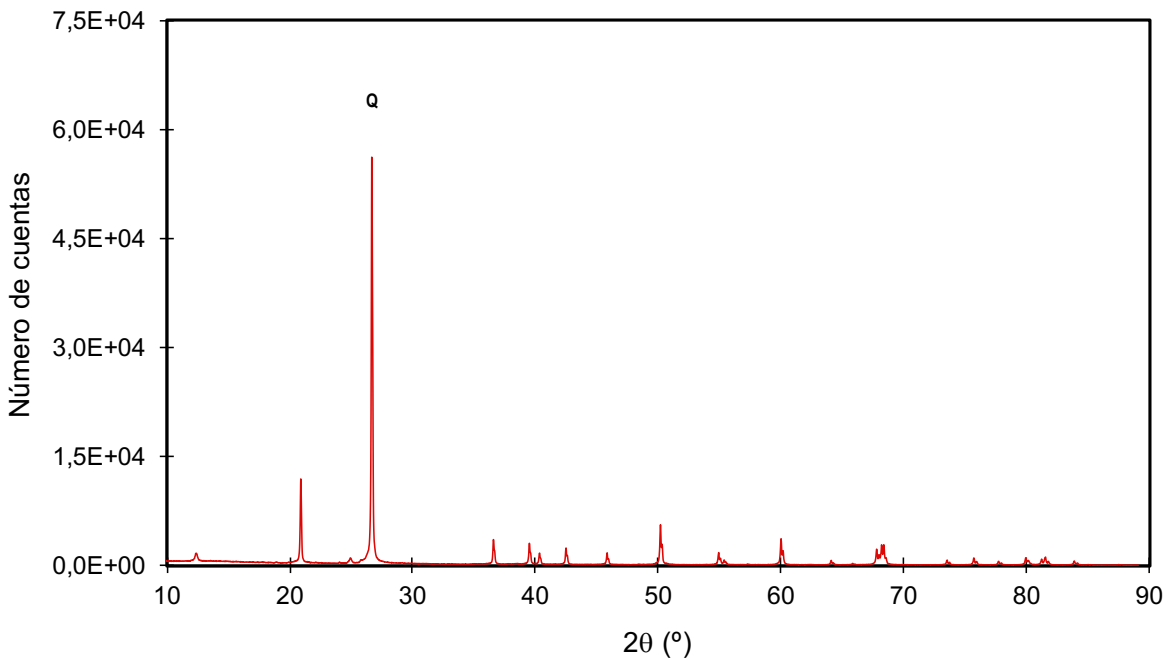

Figura 3.10 Identificación de fases cristalinas. Difractograma de la muestra Cuarzo SE-500 junto con las fases cristalinas identificadas

(Q:Cuarzo) 


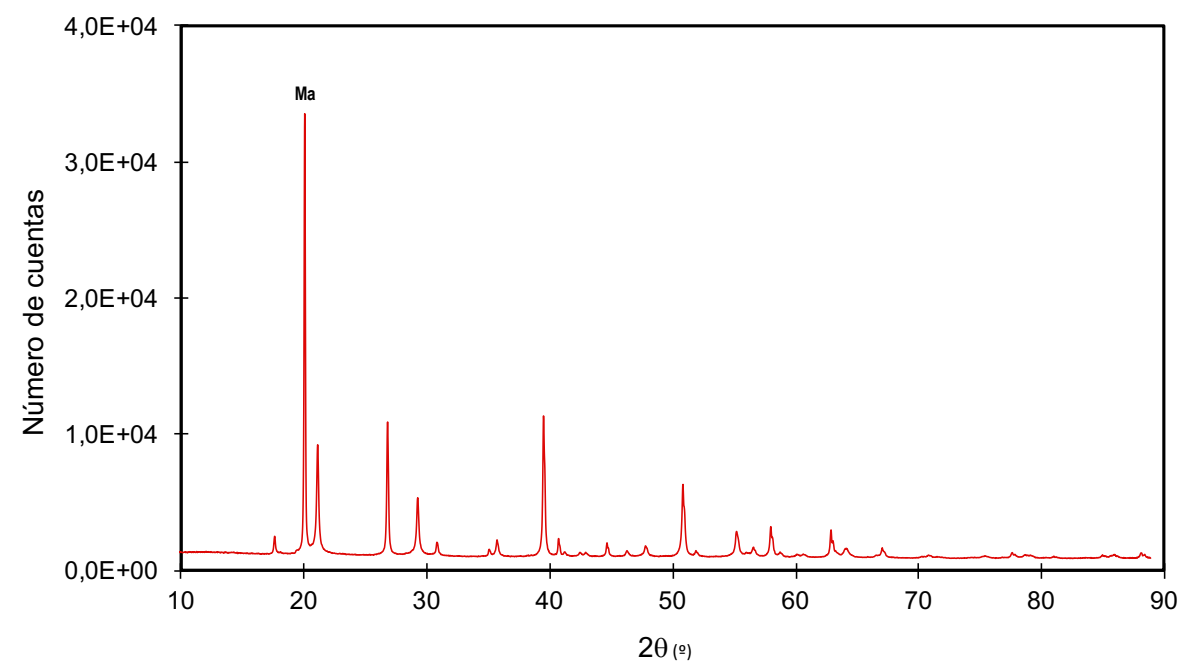

Figura 3.11 Identificación de fases cristalinas. Difractograma del mineralizador $\mathrm{Na}_{2} \mathrm{SiF}_{6}$ junto con las fases cristalinas identificadas (Ma:Malladrita)

Para realizar los experimentos se partió de una composición similar a la utilizada industrialmente en la síntesis del pigmento coral. Los porcentajes en peso de cada tipo de materia prima en las diferentes mezclas se muestran en la Tabla 3.4 .

Tabla 3.4 Porcentajes en peso (\%) de las materias primas en las composiciones

\begin{tabular}{|ccccc|}
\hline $\mathrm{ZrO}_{2}$ & $\mathrm{SiO}_{2}$ & $\mathrm{Fe}_{2} \mathrm{O}_{3}$ & Mineralizador & Fluidificante \\
\hline 50,0 & 20,2 & 23,6 & 4,6 & 1,0 \\
\hline
\end{tabular}

Con las materias primas seleccionadas, se formularon cuatro mezclas iniciales, según la circona y óxido de hierro utilizado, que servirán de base para realizar el diseño de experimentos y que se muestran en la Tabla 3.5. 
Tabla 3.5 Materias primas utilizadas en la preparación de las composiciones

\begin{tabular}{|ccccc|}
\hline Componente & $\begin{array}{c}\text { Fórmula } \\
\mathrm{N}^{0} 1\end{array}$ & $\begin{array}{c}\text { Fórmula } \\
\mathrm{N}^{0} 2\end{array}$ & $\begin{array}{c}\text { Fórmula } \\
\mathrm{N}^{0} 3\end{array}$ & $\begin{array}{c}\text { Fórmulla } \\
\mathrm{N}^{0} 4\end{array}$ \\
\hline $\mathrm{ZrO}_{2}$ & $\mathrm{GZr}$ & $\mathrm{GZr}$ & $\mathrm{FZr}$ & $\mathrm{FZr}$ \\
$\mathrm{SiO}_{2}$ & $\mathrm{Q}$ & $\mathrm{Q}$ & $\mathrm{Q}$ & $\mathrm{Q}$ \\
$\mathrm{Fe}_{2} \mathrm{O}_{3}$ & $\mathrm{BFe}$ & $\mathrm{AFe}$ & $\mathrm{BFe}$ & $\mathrm{AFe}$ \\
Mineralizador & $\mathrm{Na}_{2} \mathrm{SiF}_{6}$ & $\mathrm{Na}_{2} \mathrm{SiF}_{6}$ & $\mathrm{Na}_{2} \mathrm{SiF}_{6}$ & $\mathrm{Na}_{2} \mathrm{SiF}_{6}$ \\
Fluidificante & Aerosil & Aerosil & Aerosil & Aerosil \\
\hline
\end{tabular}

Adicionalmente se seleccionaron dos esmaltes en polvo para evaluar el poder colorante de los pigmentos que se fueran sintetizando a lo largo de la investigación, con las siguientes referencias y características:

- $\quad$ Esmalte transparente (Ref. ETR), con una temperatura de maduración de $1120^{\circ} \mathrm{C}$, que dará lugar a un vidriado brillante y transparente.

- $\quad$ Esmalte blanco opaco (Ref. EB), con una temperatura de maduración de $1040^{\circ} \mathrm{C}$, que dará lugar a un vidriado de aspecto opaco y brillante.

\subsection{Procedimientos de mezclado}

Los procesos de mezclado o molienda se suelen realizar mediante dos metodologías alternativas, bien vía húmeda o bien sea vía seca. Las ventajas que presenta el método vía húmeda es que no hay problema de emisión de polvo, no existen tampoco problemas de compactación lo que hace que sea una molienda muy homogénea y se obtienen tamaños de partícula más bajos a igualdad de tiempo de molturación. Sin embargo, la molienda o mezclado vía seca disminuye el grado de contaminación con las bolas utilizadas y se eliminan posibles reacciones con el líquido dispersante, aunque pueden aparecer problemas de homogeneidad debido a la formación de agregados.

Debido a la diversidad de molinos y metodologías de mezclado disponibles, a continuación, se detalla cada uno de los procedimientos de mezclado utilizados en este trabajo de investigación. 


\subsubsection{Preparación de las mezclas en molino planetario de bolas (vía húmeda/vía seca)}

Los molinos planetarios utilizan la fragmentación como método de molienda a través de impactos de alta energía proporcionados por bolas de molienda dentro de una jarra en rotación. La elevada eficacia del proceso de mezclado o molturación reside en la velocidad de giro de las jarras que pueden alcanzar hasta $1100 \mathrm{rpm}$.

El procedimiento llevado a cabo para la preparación de las mezclas de materias primas del pigmento coral de hierro-circón fue mediante mezclado en molino planetario de bolas (Pulverisette 5, Fritsch $\mathrm{Gmbh}$ ), vía húmeda o vía seca, con jarras y bolas de ágata. La metodología de mezclado constaba de las siguientes etapas:

- Dosificación de las materias primas por pesada en una balanza de laboratorio según la Tabla 3.4.

- Homogeneización en el molino, vía húmeda o vía seca, con jarras y bolas de ágata. En función del experimento concreto se modificó la naturaleza del fluido, la velocidad del molino, el tiempo de homogeneización, carga de bolas... Asimismo, en algunos casos las materias primas se introdujeron por etapas en la jarra. Todas estas variables se encuentran detalladas para cada serie de experimentos.

- En el caso del mezclado vía húmeda se procedió al secado de la suspensión obtenida bajo lámparas de infrarrojos.

- Finalmente, el polvo seco se tamizó en una malla de $600 \mu \mathrm{m}$ de luz de malla para romper los aglomerados de gran tamaño.

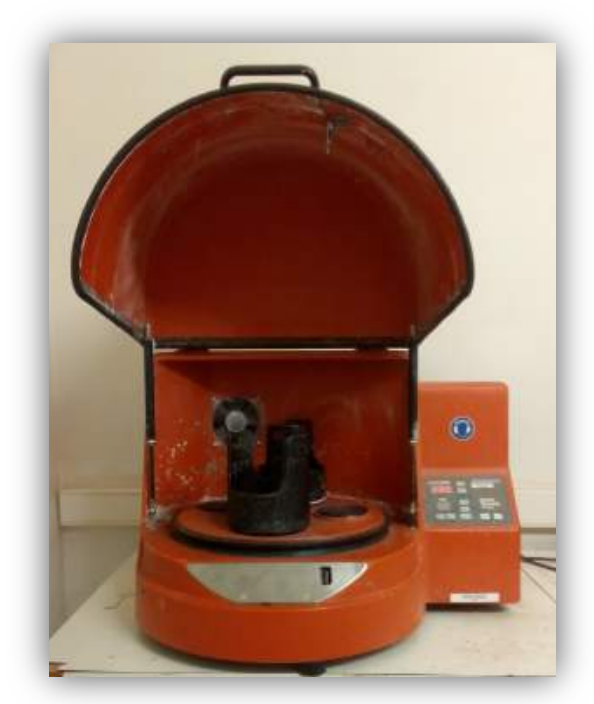

Figura 3.12 Molino Pulverisette 5 


\subsubsection{Preparación de las mezclas en un molino horizontal de bastidores o tipo Alsing}

Otro equipamiento utilizado en el estudio del mezclado vía seca consistió en un molino de bastidores horizontal, utilizando jarras de porcelana de $380 \mathrm{~cm}^{3}$ de capacidad y una carga de bolas estándar compuesta por 244 gramos de bolas grandes y 163 gramos de bolas pequeñas (con 12 y $6 \mathrm{~mm}$ de diámetro aproximado respectivamente) y una carga útil de 100 gramos de materias primas. En este molino la velocidad de rotación era una constante del equipo, siendo las variables para considerar el tiempo de mezclado y la carga de bolas (estándar o modificada). Durante la molienda, tanto las bolas como el material que se encuentran en la jarra se hacen rotar sobre su eje horizontal de modo que la fuerza centrífuga hace que alcancen una cierta altura. Debido a la gravedad, el material y las bolas caen desde la pared de la jarra produciendo un impacto, y el mezclado y/o molturación se producen por fricción y cizalla.

En determinados experimentos el cuarzo se adicionó tras el tiempo de mezclado estipulado para el resto de las materias primas, y dependiendo del experimento la adición se realizó directamente en la jarra, o bien antes de la adición se extrajo y tamizó la mezcla a medio procesar. Tras completar la composición diseñada, se homogeneizó con un tiempo adicional de mezclado de 10 minutos. Finalmente, la mezcla se tamizó en una malla de $600 \mu \mathrm{m}$ antes de someterla al tratamiento térmico.

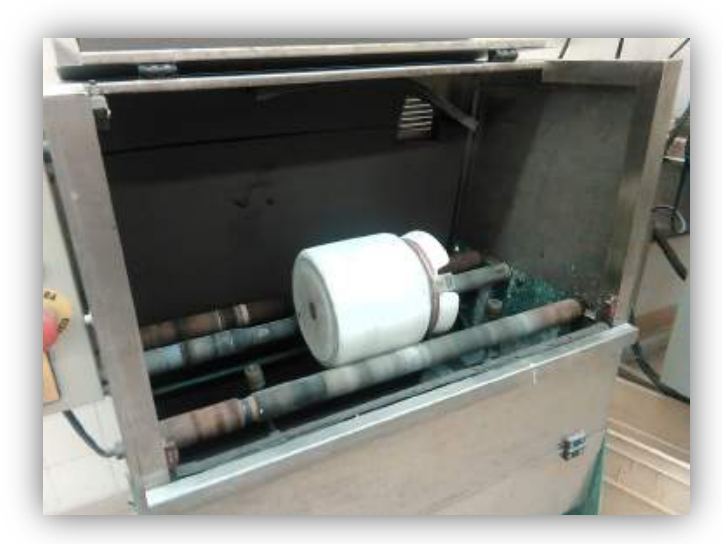

Figura 3.13 Molino horizontal de bastidores

\subsubsection{Preparación de las mezclas en un molino de cuchillas}

Puesto que en el laboratorio se disponía de un molino de cuchillas, se decidió realizar un diseño de experimentos que también incluyera esta tipología de molino para evaluar cómo afectaba a las propiedades del pigmento este tipo de proceso de mezclado. 
Los molinos a cuchillas fragmentan la muestra empleando el corte y el cizallamiento. En nuestro caso, el molino utilizado fue el un molino Moulinex Multitrio, que presenta dos cuchillas afiladas que realizan un movimiento circular (Figura 3.14).

\subsubsection{Preparación de las mezclas en un molino de mortero}

La molienda o mezclado en el molino de mortero vía seca se realiza mediante presión y fricción. El material es empujado por una cuchilla o espátula entre el mortero en movimiento y la mano. Esta alimentación forzada garantiza que todo el material sea sometido constantemente al proceso de molienda y fricción, y además mezclado intensamente. La mano no se encuentra en el centro del mortero, y rota automáticamente debido al contacto con el mortero rotatorio y el material. El peso propio de la mano y la presión graduable del contrapeso sobre el eje ejercen la fuerza necesaria para la molienda.

En el caso de la preparación de las mezclas de materias primas para la síntesis del pigmento coral de hierro-circón, se empleó un mortero eléctrico de laboratorio (modelo PULVERISETTE 2 de Fritsch Gmbh).

En este caso se operó mezclando en primer lugar todos los componentes de la mezcla excepto el cuarzo, y tras el tiempo de homogeneización establecido, se incorporó dicha materia prima, finalizando el proceso con un segundo tratamiento de homogeneización. Para concluir, la mezcla se tamizó en una malla de $600 \mu \mathrm{m}$ antes de someterla al tratamiento térmico.

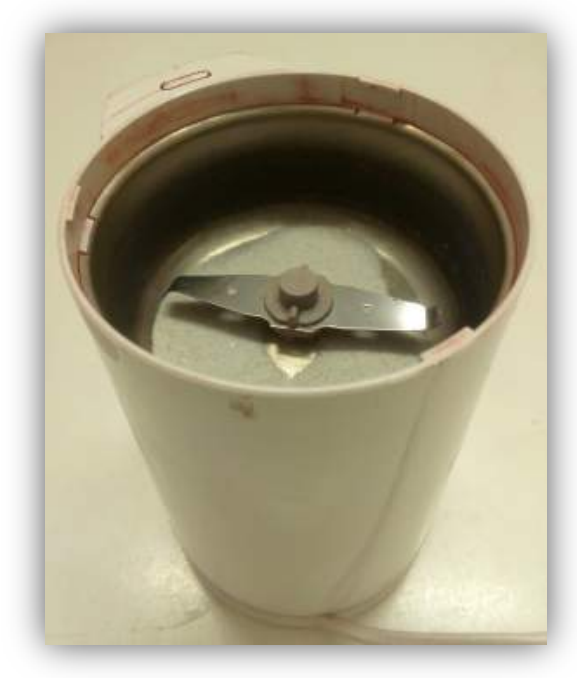

Figura 3.14 Molino de cuchillas

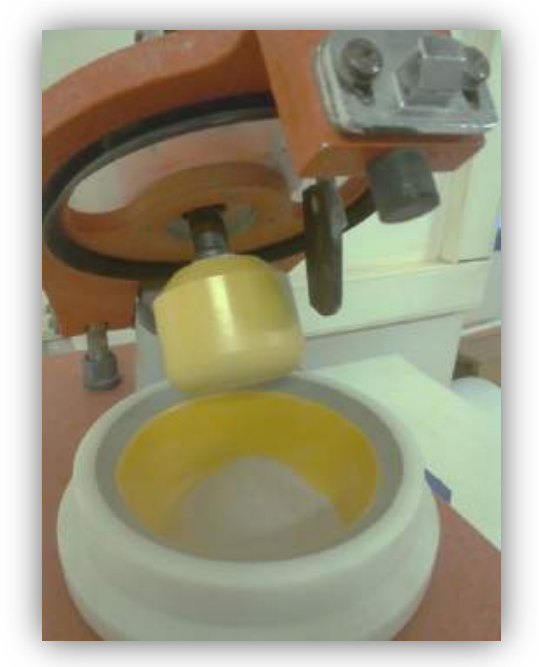

Figura 3.15 Molino de mortero 


\subsection{Síntesis del pigmento}

La síntesis de los pigmentos cerámicos, tal y como se ha comentado anteriormente se puede realizar utilizando diferentes metodologías. En concreto, el pigmento coral de hierro-circón se suele sintetizar mediante el método cerámico $[49,50,77-80]$ o bien con métodos sol-gel $[51,79-83]$.

Para este trabajo de investigación, los pigmentos se obtuvieron mediante el método cerámico, es decir, con un tratamiento térmico de las mezclas de materias primas, previamente preparadas utilizando la metodología de mezclado vía húmeda o vía seca.

El ciclo térmico utilizado en la mayoría de los experimentos fue un ciclo típico industrial, en adelante denominado Ciclo STD (con 6 horas de permanencia a temperatura máxima de $1000^{\circ} \mathrm{C}$ ), que se muestra en la Figura 3.16. Algunos experimentos se realizaron con ciclos diferentes para evaluar los efectos de los parámetros del ciclo, y éstos se indican en los apartados correspondientes.

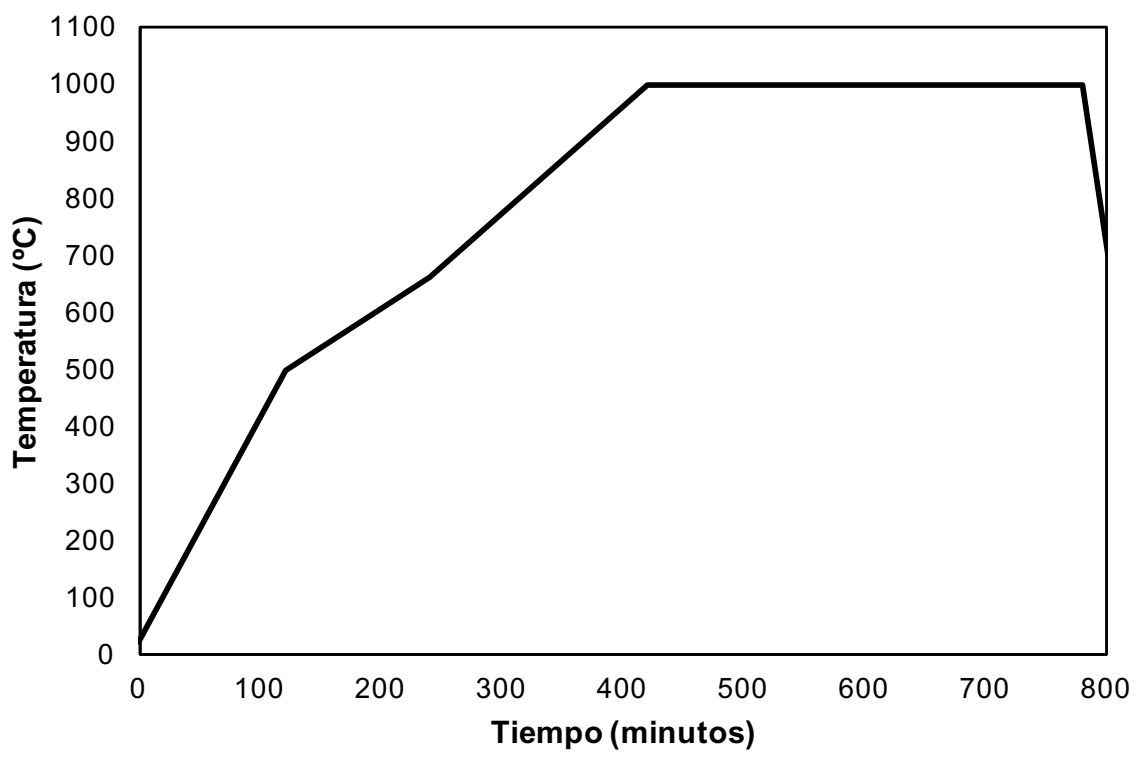

Figura 3.16 Ciclo STD utilizado para la síntesis de pigmentos

Todas las síntesis se realizaron en crisoles de mullita, con una carga de 20 gramos por crisol, y tapados con un fragmento de fibra cerámica.

Tras la síntesis, los pigmentos se disgregaron en un mortero de ágata hasta atravesar una malla de $600 \mu \mathrm{m}$. Una pequeña fracción del cernido se guardó inalterada para caracterizar su microestructura mediante microscopía electrónica. El resto se molturó en el molino planetario (Pulverisette 5, ya 
descrito previamente), vía húmeda con acetona, con un tiempo de molienda de una hora y una velocidad del molino de $260 \mathrm{rpm}$. La suspensión obtenida se secó bajo lámparas de infrarrojos, y el material seco se tamizó en una malla de $200 \mu \mathrm{m}$ para evitar la presencia de partículas sin molturar. El cernido se guardó en recipientes cerrados hasta que se realizaron los ensayos de caracterización.

\subsection{Desarrollo de color}

La variable que realmente permite evaluar el grado de avance de la síntesis del pigmento es su capacidad colorante, ya que se pueden conseguir grados de conversión muy elevados de la circona y el cuarzo a circón, pero si no se produce simultáneamente el encapsulado de las partículas de hematites, el producto final poseerá un poder colorante muy reducido. En consecuencia, sólo se incorporaron a los vidriados aquellos pigmentos que contuviesen una elevada cantidad de circón, ya que una reducida proporción de esta fase era una indicación clara de que el pigmento no se había sintetizado correctamente.

Para ello, se prepararon suspensiones de esmalte con un porcentaje del pigmento de 3\% en peso. El contenido en sólidos de las suspensiones fue del $62 \%$ en el caso del esmalte transparente y del $60 \%$ en el caso del esmalte blanco. Los esmaltes se aplicaron con un patín de galga 0,8 mm sobre soportes de revestimiento blanco industriales previamente cocidos, preparando las probetas por duplicado.

Una vez secas, las piezas aplicadas se cocieron con el ciclo térmico detallado en la Figura 3.17 en un horno de laboratorio.

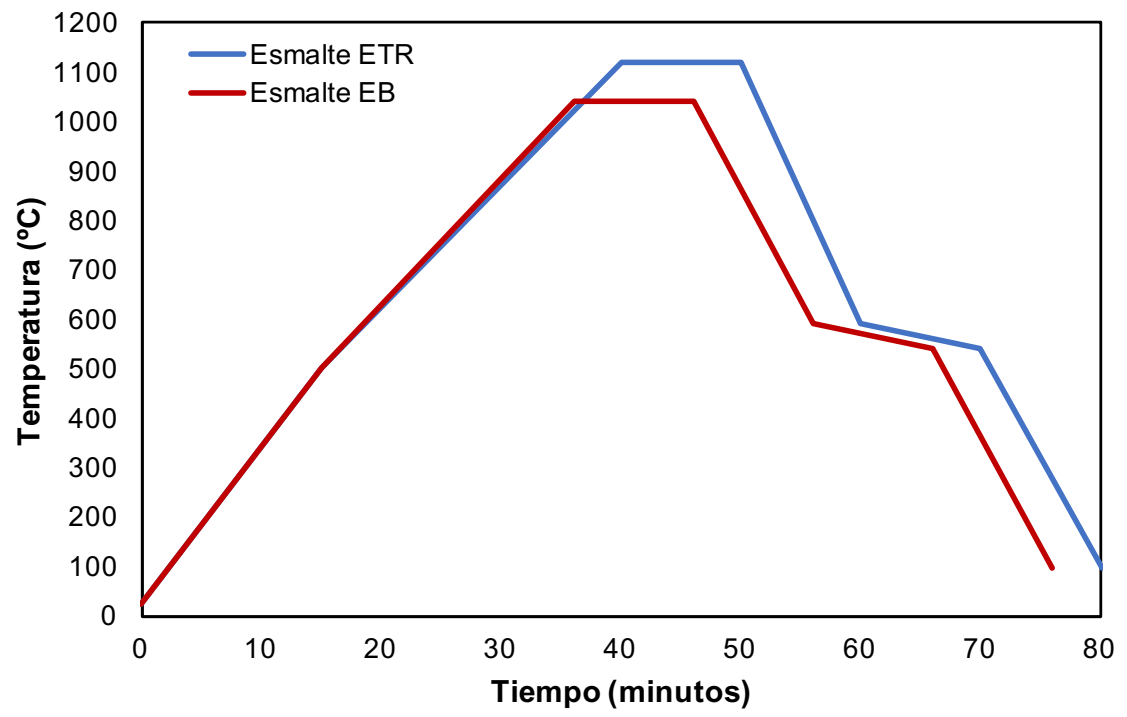

Figura 3.17 Ciclo térmico utilizado para el desarrollo de color 
Tras la cocción se midieron las coordenadas cromáticas de cada probeta con un espectrofotómetro de reflectancia difusa (Color-Eye 7000A, X-Rite, USA).

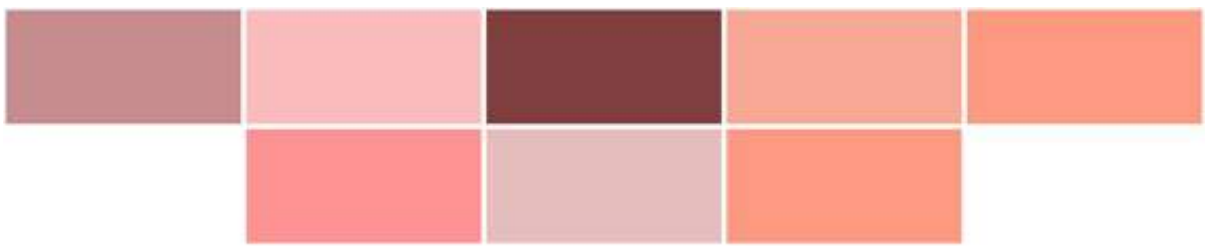

Figura 3.18 Desarrollo de color del pigmento coral hierro-circón

\subsection{Técnicas de caracterización}

A continuación, se detallarán las técnicas analíticas utilizadas para la caracterización de las materias primas empleadas como precursores, así como para el estudio del pigmento coral de hierro-circón.

\subsubsection{Distribución de tamaño de partícula}

La distribución de tamaño de partícula de los materiales que intervienen en una reacción sólido-sólido como es el caso del pigmento coral de hierro-circón tiene una gran influencia en su reactividad, por lo que resulta esencial conocer esta característica en las materias primas que intervendrán en la reacción [84,85]. De hecho, la cinética del proceso depende en gran medida del tamaño de partícula.

La forma de las partículas de las materias primas suele ser irregular, sin embargo, la medida del tamaño debe referirse a una forma ideal. Esta medida puede realizarse utilizando procedimientos basados en diferentes principios físicos (absorción de rayos $\mathrm{X}$, difracción de un haz de luz, dispersión dinámica de luz, análisis de imagen...). Por tanto, seleccionar la técnica más adecuada para determinar el tamaño de partícula es complejo y va a depender de las propiedades del material (tamaño, forma, densidad, índice de refracción, coeficiente de absorción...).

Los óxidos de hierro, debido a su naturaleza y a su tamaño de partícula casi nanométrico se analizaron utilizando el equipo ZETASIZER NANO de la firma MALVERN. El método utilizado se basa en la dispersión dinámica de luz (Dynamic Light Scattering, DLS). Esta técnica mide la difusión de partículas en movimiento Browniano, y convierte este valor a tamaño y a una distribución de tamaño utilizando la relación de Einstein-Stokes [86-88]. El equipo DLS está formado por un láser monocromático que emite luz a una longitud de onda determinada. Esta luz, una vez que interacciona con las partículas es disipada en todas las direcciones, recogiéndose únicamente aquella fracción que forma 
un ángulo de $90^{\circ}$ con respecto al haz incidente. Las variaciones en la intensidad de la luz son transformadas a pulsos eléctricos y éstos a los valores de diámetro hidrodinámico.

Para realizar la medida, el óxido de hierro se dispersó utilizando como medio una disolución acuosa de 2 gramos de citrato de amonio en 1 litro de agua $[89,90]$. A continuación, se sometió a la acción de ultrasonidos para lograr la total dispersión de las partículas y eliminar la posible presencia de aglomerados en la muestra. Los cálculos se efectuaron considerando el índice de refracción del óxido de hierro 3,1 y un valor del coeficiente de absorción de 0,1 [90]. La viscosidad del dispersante (agua) fue $0,8872 \mathrm{cP}$, con un índice de refracción de $1,33[23]$.

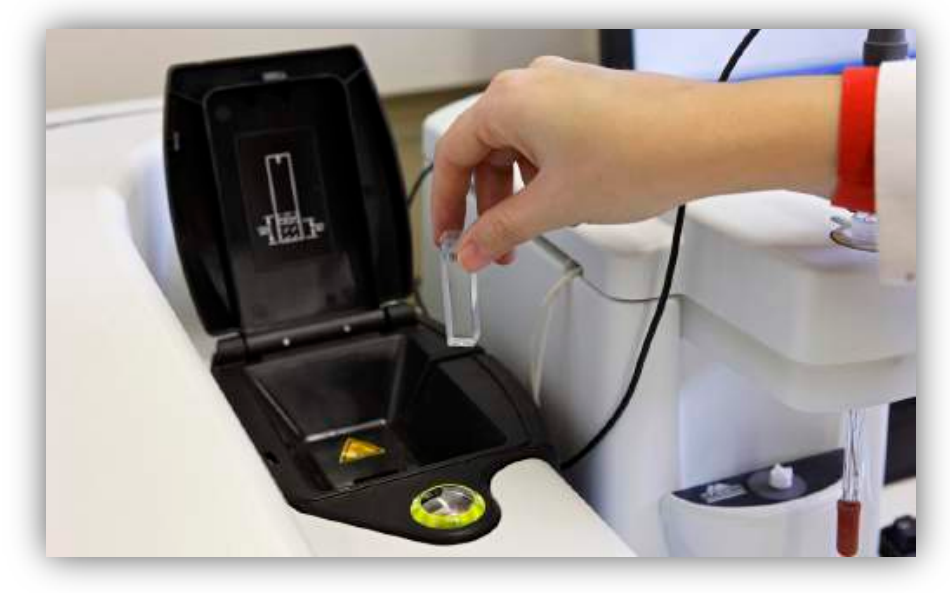

Figura 3.19 Equipo Zetasizer Nano

Para las circonas y el cuarzo, la distribución de tamaños de partícula se determinó utilizando un equipo de difracción de láser MASTERSIZER 2000 de la firma MALVERN según la norma ISO 13320-1:2009. Particle Size Analysis. Laser Diffraction Methods. Part 1. General Principles. Las muestras fueron dispersadas en agua y sometidas a ultrasonidos y agitación mecánica. La técnica de difracción láser para medir el tamaño de las partículas mide la intensidad de la luz que se dispersa cuando el haz del láser pasa a través de una muestra de partículas individualizadas [91]. Utilizando la teoría de dispersión Mie para interpretar la señal de dispersión de luz recogida por los detectores. Se consideró el índice de refracción de 2,2 y un valor del coeficiente de absorción de 0,1 para las circonas mientras que para el cuarzo se utilizó un índice de refracción de 1,55 y un coeficiente de absorción de 0,001 [23,90,92].

Los parámetros utilizados para describir la distribución del tamaño de partícula fueron $\mathrm{d}_{90}, \mathrm{~d}_{50}$ y $\mathrm{d}_{10}$, que son aquellos diámetros por debajo de los cuales queda, respectivamente, un $90 \%$, un $50 \%$ y un $10 \%$ de las partículas totales. 
El parámetro $d_{50}$ se corresponde con el tamaño medio de la distribución de tamaños de partículas individualizadas de cada una de las muestras [84,93].

Además de estos parámetros característicos, las distribuciones de tamaño de partícula se representan en forma de gráficos siendo las más visuales las curvas de frecuencia de tamaño diferencial y de frecuencia acumulada. La curva de frecuencia diferencial representa la frecuencia relativa de las partículas frente al tamaño de estas, en un intervalo de tamaño. Por otro lado, la curva de frecuencia acumulada representa el porcentaje de partículas menores que un determinado tamaño frente a dicho tamaño.

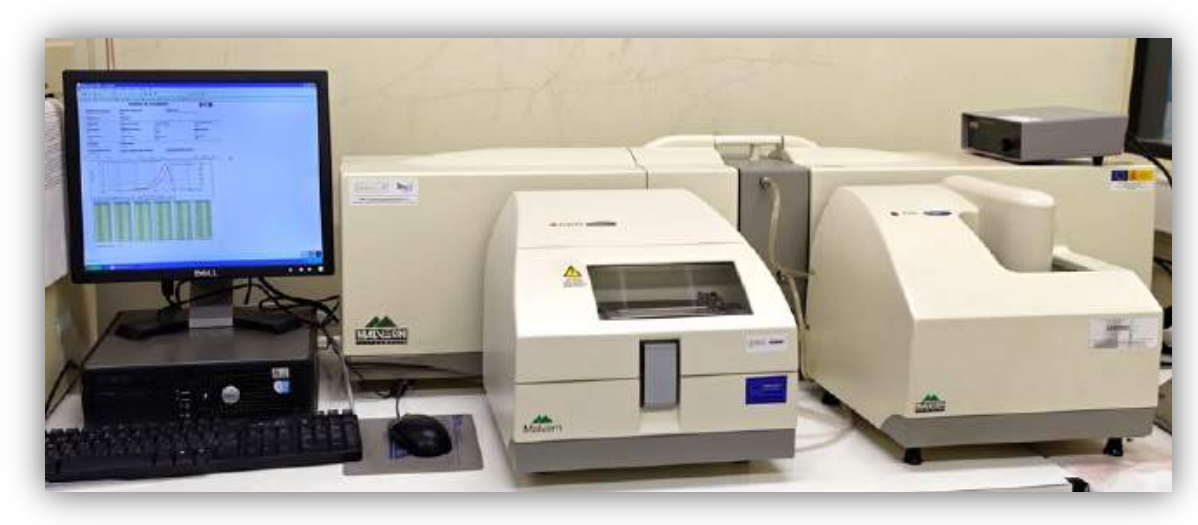

Figura 3.20 Equipo Mastersizer 2000

\subsubsection{Superficie específica}

En las reacciones sólido-sólido la superficie específica juega un importante papel en la cinética de reacción de modo que cuanto mayor es la superficie específica de la partícula, mayor puede ser la superficie de contacto y por tanto mayor la reactividad.

Para la determinación de la superficie específica se utilizó el método BET de acuerdo con la norma ISO 9277:2010 Determination of the specific surface area of solids by gas adsorption using the BET method. La base del método BET es que conocida la cantidad de gas adsorbido necesaria para formar una monocapa y el área que ocupa una de estas moléculas adsorbidas, es posible estimar la superficie específica del sólido [84,93,94].

En el caso que nos ocupa, se consideró determinante para estimar la reactividad de la mezcla la obtención de la superficie específica de las materias primas. Existe una gran variedad de adsorbatos disponibles: $\mathrm{N}_{2}, \mathrm{O}_{2}, \mathrm{Ar}, \mathrm{Kr}, \mathrm{CO}_{2}$, algunos hidrocarburos aromáticos, como el benceno, y algunos alcanos y alcoholes de cadena corta. Sin embargo, la adsorción de $\mathrm{N}_{2}$ a $77 \mathrm{~K}$ es la más utilizada ya que cubre todo el rango de porosidad e interacciona débilmente con la mayoría de los sólidos. 
La superficie específica se determinó por adsorción de nitrógeno con un equipo TriStar 3000 de Micromeritics, de acuerdo con el método multipunto, mediante la ecuación:

$$
S_{B E T}\left(m^{2} \cdot g^{-1}\right)=n_{m} \cdot a_{\text {nitrógeno }} N A
$$

Donde $\mathrm{n}_{\mathrm{m}}$ es la cantidad de gas adsorbido necesario para la formación de una monocapa que recubre toda la superficie del material, anitrógeno la sección transversal de la molécula de nitrógeno $\left(0,162 \mathrm{~nm}^{2}\right)$ y $\mathrm{NA}$ el número de Avogadro [84]. La cantidad de nitrógeno adsorbido se midió mediante un método volumétrico estático.

La capacidad de la monocapa $\mathrm{n}_{\mathrm{m}}$ se calcula por regresión lineal determinando la pendiente y la ordenada en el origen de la ecuación que resulta al representar los datos experimentales de acuerdo con el método $B E T, n_{m}=(1 /(a+b))$, donde $a$ es la pendiente y $b$ es la ordenada en el origen.

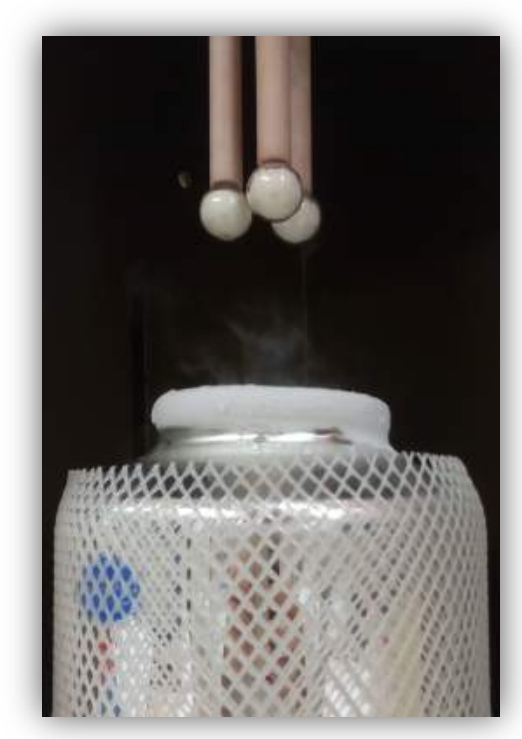

Figura 3.21 Analizador de superficie específica por adsorción de gas

Antes de realizar el ensayo, las muestras se secaron en estufa a $110^{\circ} \mathrm{C}$ durante 2 horas $y$, a continuación, fueron sometidas a desgasificación por corriente de nitrógeno. Los óxidos de hierro se desgasificaron a $300^{\circ} \mathrm{C}$, mientras que las circonas y el cuarzo fueron desgasificadas a $150^{\circ} \mathrm{C}$. 


\subsubsection{Difracción de rayos $X$}

La identificación de estructuras cristalinas se realizó por difracción de rayos $X$ de la muestra en polvo, usando un difractómetro BRUKER Theta-Theta modelo D8 Advance y un detector sensible a la posición Vantec-1, que permite una elevada sensibilidad, ausencia de fondo y resolución óptima para la identificación y cuantificación de fases cristalinas en materias primas y pigmentos cerámicos.

La técnica consiste en hacer incidir un haz de rayos $X$, de longitud de onda conocida, sobre una muestra en polvo. El haz se difracta y se refleja con ángulos característicos de los planos de los cristales, obteniéndose el correspondiente difractograma, a partir del cual se identifican las fases cristalinas presentes utilizando las fichas desarrolladas por el International Centre for Diffraction Data (ICDD) para fases cristalinas puras (Powder Diffraction File, PDF-4 2017) [95].

Las medidas se efectuaron con cátodo de cobre y filtro de níquel, con un voltaje de $30 \mathrm{kV}$ y una intensidad de $45 \mathrm{~mA}$, en un intervalo de $2 \theta$ de $5^{\circ}$ a $90^{\circ}$ para todas las muestras, con la velocidad correspondiente a $0,015^{\circ}$ de tamaño de paso y 1,2 segundos por paso. En relación a la óptica, se utilizó una rendija de divergencia de $0,3^{\circ}$ así como rendijas Soller en los haces incidente y difractado para reducir la asimetría a bajos ángulos además de mejorar la resolución de las medidas.

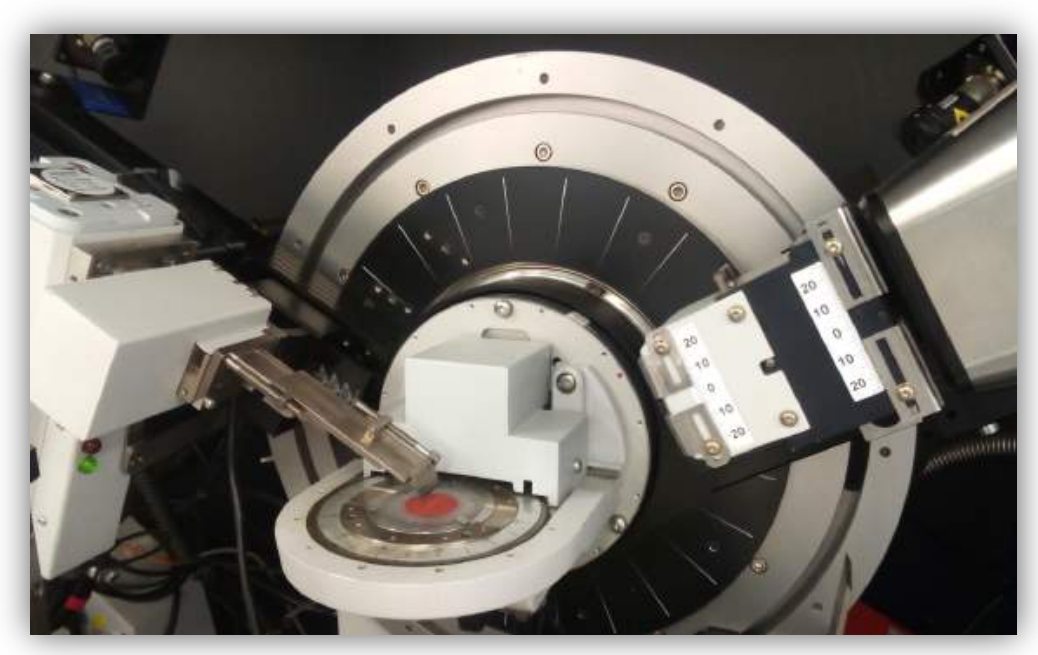

Figura 3.22 Difractómetro de rayos $\mathrm{X}$ 


\subsubsection{Cuantificación de fases cristalinas y fase amorfa}

Existen numerosos métodos de cuantificación de fases cristalinas, no obstante, el más utilizado es el método de Rietveld que fue publicado por Hugo Rietveld en 1969 [96]. Este método consiste en un ajuste multiparamétrico del diagrama de difracción experimental y requiere que se disponga de los datos cristalográficos de todas las fases cristalinas presentes. Éste se ha impuesto como el método de cuantificación más utilizado en los últimos años y fue el elegido para llevar a cabo el estudio de fases cristalinas en este trabajo de investigación. El método de Rietveld [97-103] es una potente herramienta para la obtención de información estructural, microestructural y el análisis cuantitativo de fases a partir de difractogramas de polvo, ya que permite solventar problemas en el análisis cuantitativo de mezclas polifásicas como son el solapamiento de picos y la orientación preferente de planos de difracción.

El método consiste en ajustar teóricamente los parámetros estructurales (o parámetros de red, deslizamientos atómicos, anisotropía, tensiones de la red, etc.,) así como aquellos que dependen de las condiciones de experimentación, al perfil completo del difractograma en polvo, suponiendo que el difractograma es la suma de un número de reflexiones de Bragg centradas en sus posiciones angulares respectivas. Los factores que influyen en la intensidad de los picos de difracción son muy variables pero aquellos que van a afectar considerablemente al refinamiento de la estructura son factores estructurales (factor de dispersión atómica, factor de estructura, polarización, temperatura...), factores instrumentales que dependen del equipo de medida (intensidad del haz de rayos $\mathrm{X}$, óptica de divergencia y del detector...), factores relacionados con la naturaleza de la muestra (absorción, tamaño de cristalito, grado de cristalización, orientación de los cristales...) así como factores de la propia medida (cálculo del área del pico, fondo, radiación $\mathrm{K} \alpha 2 \ldots$ ).

Por tanto, en primer lugar, se identificará la posición de cada una de las reflexiones del difractograma y se ajustarán para cada reflexión su anchura, posición e intensidad integrada. Estas reflexiones se asignan a una fase cristalina de la que se conoce su estructura cristalina (parámetros de celda, simetría y posiciones atómicas).

Utilizando el software DiffracPlus TOPAS 4.2, los parámetros estructurales e instrumentales van siendo ajustados en un proceso iterativo hasta que se alcanza una condición de convergencia entre los valores de las intensidades experimentales y el modelo teórico. Los valores ajustados de los factores de escala junto con las densidades de las fases presentes permiten obtener sus fracciones en peso.

Los difractogramas han sido ajustados utilizando una función pseudo-Voight que considera una mezcla de función Gaussiana y Lorentziana, teniendo además en cuenta las correcciones debidas a la asimetría de los picos. Cuando 
se han observado orientaciones preferentes, estas han sido corregidas utilizando el algoritmo March-Dollase. Otros parámetros refinados han sido los parámetros de celda, corrección del cero y desplazamiento de picos, parámetros de la forma del pico y corrección del fondo. Ésta última corrección ha sido necesaria debido a la elevada fluorescencia que presentaban los difractogramas y por la presencia de importantes cantidades de material amorfo.

En lo que corresponde al difractómetro, se han tenido en cuenta parámetros como las longitudes de onda correspondientes a las líneas $\mathrm{K}_{\alpha_{1}}$ y $\mathrm{K}_{\alpha_{2}}$ del espectro de rayos $X$ del cobre y la razón de sus intensidades, la geometría del difractómetro, así como un coeficiente para la corrección de la absorción.

Una vez realizado el refinamiento o ajuste del difractograma se estima la validez del ajuste utilizando algunos criterios numéricos, aunque el más comúnmente utilizado y que desde un punto de vista puramente matemático refleja la evolución del refinamiento es Rwp. El Rwp también denominado factor del difractograma ponderado (weight profile $R$-factor) es probablemente el más utilizado ya que evalúa la calidad del ajuste con la diferencia entre el modelo refinado y los datos experimentales para todos y cada uno de los puntos del difractograma. Debido a que el objetivo de este trabajo es la cuantificación de las fases cristalinas y no la resolución de parámetros estructurales se ha considerado como óptimo aquel ajuste con Rwp inferior a 5 para cada uno de los difractogramas evaluados [103-105].

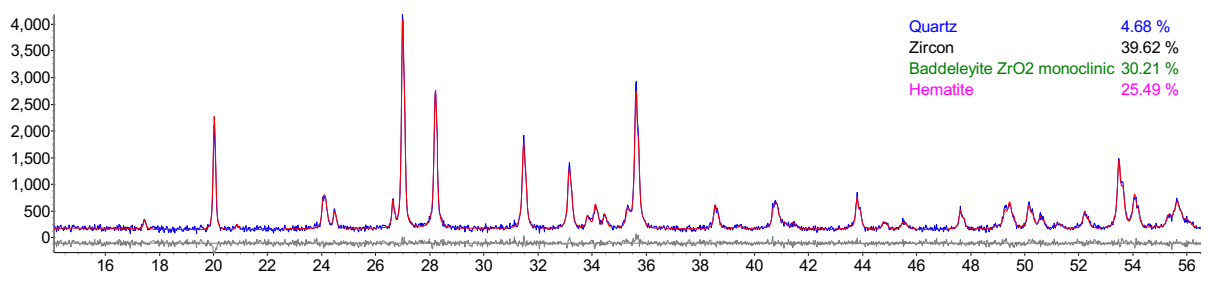

Figura 3.23 Ejemplo de cuantificación de fases cristalinas mediante el método Rietveld

Inicialmente se supuso que los pigmentos sintetizados estaban exentos de material amorfo, no obstante, debido a los mecanismos de formación del pigmento, existía la posibilidad de que estuviera presente alguna fase no cristalina o amorfa. El método de Rietveld ajusta a $100 \%$ las fases cristalinas identificadas, por lo que para realizar la cuantificación de la fase amorfa, se utilizó el método del estándar interno $[106,107]$ añadiendo a la muestra original un $5 \%$ de fluorita. Añadir un estándar interno a la muestra implicaba una dilución de la muestra por el estándar, por lo que para obtener el contenido de 
cada fase en la muestra original se corrigieron los valores obtenidos por Rietveld teniendo en cuenta la presencia del estándar interno, lo que también permitía determinar la cantidad de fase amorfa.

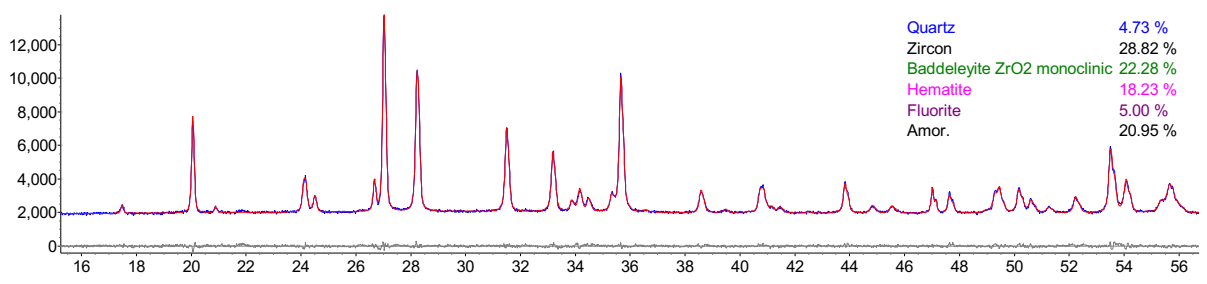

Figura 3.24 Ejemplo de cuantificación de fases cristalinas y fase amorfa mediante el método Rietveld con adición de patrón interno

Para estimar la exactitud y precisión de este método aplicado al pigmento coral de hierro-circón se analizaron por separado las materias primas utilizadas como precursores, así como un circón natural como referencia. Posteriormente se prepararon mezclas sintéticas con diferentes porcentajes de las materias primas y de circón y se analizaron mediante difracción de rayos $\mathrm{X}$ para establecer unos patrones de referencia $[108,109]$. Utilizando esta metodología se obtuvieron errores del orden del $5 \%$ relativo para las fases mayoritarias ( $>5 \%$ en peso) y del $10 \%$ relativo para las fases minoritarias ( $<5 \%$ en peso).

Las fases típicas en los pigmentos corales de hierro-circón son el cuarzo, la baddeleyita, el circón y la hematites, por lo tanto, el interés del estudio mineralógico no es tanto el identificar las fases presentes, sino el estimar la evolución en la proporción de cada una, especialmente en el caso del circón, que es la fase que permite estimar el grado de avance del proceso de síntesis, al menos en lo que respecta a la reacción de la sílice con la circona.

Ya que el método Rietveld requiere el conocimiento de las estructuras cristalinas de todas las fases presentes en la muestra, se estudiaron las siguientes fases cristalinas $[24,30,110]$ :

- Hematites (Ficha 04-003-2900 del PDF-4). La estructura de la hematites, $\alpha-\mathrm{Fe}_{2} \mathrm{O}_{3}$, es semejante a la del corindón donde cada átomo de $\mathrm{Fe}$ está rodeado por 6 oxígenos, constituyendo un octaedro no regular, ya que tres oxígenos están más cerca del Fe que los otros tres. Cada oxígeno está rodeado por cuatro átomos de Fe y el sistema cristalino es romboédrico ( $R-3 c)$.

- Baddeleyita (Ficha 04-004-4339). La baddeleyita es la forma natural del óxido de circonio y tiene simetría monoclínica (P21/a). Es una fase estable a temperaturas inferiores a $1170-1200^{\circ} \mathrm{C}$. En su estructura los cationes $\mathrm{Zr}{ }^{4+}$ están situados en planos paralelos al 001 y separados por los planos de aniones 
$\left(\mathrm{O}^{2-}\right)$. Cada ion $\mathrm{Zr}^{4+}$ está rodeado por siete iones de oxígeno, de tal forma que está coordinado triangularmente con los iones de oxígeno de un plano $\mathrm{O}_{\mathrm{I}}$ y tetraédricamente con los iones de oxígeno de un segundo plano $\mathrm{O}_{\text {II. }}$.

- Cuarzo (Ficha 04-005-4718). La estructura del cuarzo consiste en un armazón tridimensional de tetraedros de $\mathrm{Si}$ en coordinación con el oxígeno, esto es, los tetraedros comparten los cuatro vértices para desarrollar la estructura que está compuesta por anillos de 6 y 8 tetraedros. Con sus dos polimorfos, la fase $\beta$ es estable por encima de los $573^{\circ} \mathrm{C}$ (simetría hexagonal P3221) y la fase $\alpha$ estable por debajo de dicha temperatura y con simetría trigonal.

- Circón (Ficha 04-007-5058). Como se ha comentado en el apartado 1.1.2 se trata de un neosilicato formado por tetraedros $\mathrm{SiO}_{4}$ aislados unidos por octaedros de $\mathrm{ZrO}_{6}$ con simetría tetragonal centrado en el cuerpo (I41/amd) en la celda unidad.

Los parámetros de red de las fases cristalinas $(a, b, c, \alpha, \beta$ y $\gamma$ ) así como los picos de difracción de máxima intensidad se muestran en las Tabla 3.6 y Tabla 3.7.

Tabla 3.6

Parámetros de red de las fases cristalinas presentes

\begin{tabular}{|ccccccc|}
\hline Fase & $\mathrm{a}(\AA)$ & $\mathrm{b}(\AA)$ & $\mathrm{c}(\AA)$ & $\alpha\left(^{\circ}\right)$ & $\beta\left(^{\circ}\right)$ & $\gamma\left(^{\circ}\right)$ \\
\hline Hematites & 5,038 & - & 13,772 & 90 & 90 & 120 \\
Baddeleyita & 5,150 & 5,212 & 5,317 & 90 & 99,2 & 90 \\
Cuarzo & 4,914 & - & 5,405 & 90 & 90 & 120 \\
Circón & 6,607 & - & 5,982 & 90 & 90 & 90 \\
\hline
\end{tabular}

Tabla 3.7

Picos de máxima intensidad de difracción $\left(\mathrm{I} / \mathrm{I}_{0}\right)$

\begin{tabular}{|ccccccc|}
\hline Fase & \multicolumn{2}{c}{$\mathrm{I} 1$} & \multicolumn{2}{c}{$\mathrm{I} 2$} & \multicolumn{2}{c|}{$\mathrm{I3}$} \\
\hline \multirow{3}{*}{ Hematites } & $\AA$ & $\mathrm{I} / \mathrm{I}_{0}$ & $\AA$ & $\mathrm{I} / \mathrm{I}_{0}$ & $\AA$ & $\mathrm{I} / \mathrm{I}_{0}$ \\
Baddeleyita & 3,69 & 1 & 1,69 & 0,6 & 2,51 & 0,5 \\
Cuarzo & 3,34 & 1 & 2,82 & 0,8 & 2,61 & 0,6 \\
Circón & 3,30 & 1 & 2,51 & 0,4 & 4,43 & 0,4 \\
\hline
\end{tabular}




\subsubsection{Cálculo de la composición de la fase amorfa}

La presencia de una fase no cristalina o amorfa en el pigmento podría ser crucial a la hora de intentar dilucidar el mecanismo de formación de éste, por lo que se hizo necesaria una estimación de la composición de la fase amorfa en óxidos, ya que parte del cuarzo, baddeleyita, hematites y mineralizador podrían pasar a formar parte de ésta.

Para ello, teniendo en cuenta la composición inicial de las mezclas y los resultados del análisis de Rietveld, se definió un sistema de ecuaciones a partir de los balances a cada uno de los elementos. Dicho sistema contenía más ecuaciones que variables, por lo que se resolvió por minimización del cuadrado de las diferencias entre los valores experimentales y los calculados de las proporciones de cada una de las fases detectadas. De este modo se obtuvo un valor óptimo para el porcentaje de cada uno de los óxidos que forman parte de la fase amorfa detectada en cada muestra.

\subsubsection{Coordenadas cromáticas}

La variable que permite evaluar el grado de avance de la síntesis del pigmento objeto de estudio es su capacidad colorante, ya que se pueden conseguir grados de conversión muy elevados de la circona y el cuarzo a circón, pero si no se produce simultáneamente el encapsulado de las partículas de hematites, el producto final poseerá un poder colorante muy reducido.

El color se define como la sensación causada por la luz visible, la radiación comprendida entre $400 \mathrm{~nm}$ y $700 \mathrm{~nm}$ del espectro electromagnético, es decir, el rango de radiación al que es sensible el ojo humano. De esta forma, los colores del espectro de la radiación electromagnética son el resultado de cada una de las longitudes de onda, presentando tonalidad violeta de 400 a $430 \mathrm{~nm}$, azules de 430 a $485 \mathrm{~nm}$, los verdes de 485 a $570 \mathrm{~nm}$, los amarillos de 570 a $585 \mathrm{~nm}$, de 585 a $610 \mathrm{~nm}$ los anaranjados y por encima de $610 \mathrm{~nm}$ los rojos [13].

Por otra parte, los colores, desde el punto de vista sensorial, vienen definidos por tres características; la luminosidad, el tono y la saturación, y el conjunto formado entre el tono y la saturación son los responsables de las características colorimétricas de un color y reciben el nombre de cromaticidad.

Con el objeto de poder cuantificar el estímulo del color mediante números, la Commission Internationale de l'Éclairage (CIE) desarrolló dos importantes sistemas para la evaluación de color en términos de números basados en la medición de reflectancia espectral de la muestra. El primer sistema fue definido en 1931 e introdujo los valores triestímulo (XYZ) para describir el estímulo luminoso. El segundo sistema fue definido en 1976 e introdujo el espacio de 
color compuesto por tres coordenadas cromáticas ( $\left.L^{*} a^{*} b^{*}\right)$, las cuales poseen una mayor correlación con las magnitudes percibidas visualmente. Ambos sistemas son los más utilizados en la actualidad por los instrumentos de medición de color.

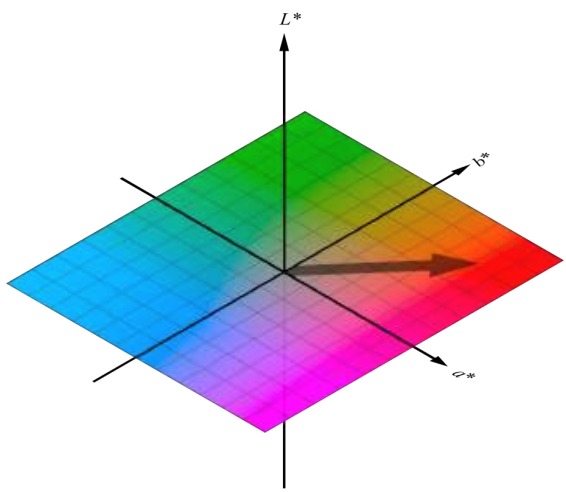

Figura 3.25 Diagrama de cromaticidad CIE (Imagen de Wikipedia con licencia CC BY-SA 4.0)

El espacio de color CIE 1976 L*, a*, b* (CIELab) [111], es actualmente uno de los más populares para evaluar el color de un objeto. Este espacio de color es ampliamente empleado porque correlaciona los valores numéricos de color consistentemente con la percepción visual humana. El espacio de color L*a*b* fue modelado en base a una teoría del color oponente que establece que dos colores no pueden ser rojo y verde al mismo tiempo o amarillo y azul al mismo tiempo. De esta forma los resultados colorimétricos se expresan en forma de coordenadas cromáticas CIELab y cuyo significado es:

- $\quad$ La coordenada $L^{*}$ indica la posición en el eje de luminosidad ( $L^{*}=0$ corresponde al negro y $L^{*}=100$ al blanco).

- La coordenada a* indica la posición en el eje rojo-verde (a* $>0$ indica componente roja y $a^{*}<0$ componente verde).

- La coordenada $b^{*}$ indica la posición en el eje amarillo-azul ( $b^{*}>0$ indica componente amarilla y $b^{*}<0$ componente azul).

Por otra parte, en el sistema CIELab la diferencia de color entre dos muestras se puede expresar como el módulo del vector que une los puntos del espacio de color, correspondientes a dichas muestras. Dicho parámetro se denomina $\Delta \mathrm{E}^{*} \mathrm{y}$ viene dado por:

$$
\Delta E^{*}=\sqrt{\left(L_{2}^{*}-L_{1}^{*}\right)^{2}+\left(a_{2}^{*}-a_{1}^{*}\right)^{2}+\left(b_{2}^{*}-b_{1}^{*}\right)^{2}} \quad \text { (Ecuación 17) }
$$


De modo general se considerará que aquellos colores con una diferencia menor de 0,5 unidades en $\Delta \mathrm{E}^{*}$ no son diferenciables por el observador humano medio.

Para obtener los valores CIEL*a*b* se utiliza un espectrofotómetro de reflectancia que consiste básicamente en iluminar la muestra con luz blanca y calcular la cantidad de luz que refleja dicha muestra en una serie de intervalos de longitudes de onda. Lo más usual es que los datos se recojan en intervalos de longitudes de onda desde $400 \mathrm{~nm}$ a $700 \mathrm{~nm}$ haciendo pasar la luz a través de un dispositivo monocromador que fracciona la luz en distintos intervalos de longitudes de onda $[112,113]$.

A modo de ejemplo, en la Tabla 3.8 se presentan los valores CIEL*a*b* medios de tres colores triaxiales cerámicos utilizados habitualmente [114] como son el coral de hierro-circón (rojo primario), el amarillo de praseodimio-circón (amarillo primario) y el azul turquesa de vanadio-circón (azul primario) [115].

Tabla 3.8 Coordenadas CIEL*a*b* de los colores triaxiales [116]

\begin{tabular}{|c|c|c|c|}
\hline Pigmento & L* & a* & b* \\
\hline Coral $\left(\mathrm{Fe}-\mathrm{ZrSiO}{ }_{4}\right)$ & 68,9 & 12,8 & 12,4 \\
\hline Azul $\left(\mathrm{V}-\mathrm{ZrSiO}_{4}\right)$ & 74,2 & $-6,6$ & $-18,6$ \\
\hline Amarillo $\left(\mathrm{Pr}-\mathrm{ZrSiO}{ }_{4}\right)$ & 91,1 & $-10,2$ & 40,7 \\
\hline
\end{tabular}

Tal y como se comentó en el apartado 3.4, para evaluar el poder colorante de las muestras de pigmento, se incorporaron a un esmalte transparente y uno blanco, con un contenido del $3 \%$ de pigmento, y se aplicaron sobre soportes de revestimiento blanco que fueron cocidos en un horno de laboratorio a las temperaturas máximas óptimas para cada esmalte. Sobre las probetas esmaltadas se midieron las coordenadas cromáticas con un espectrofotómetro Macbeth Color-Eye 7000A en base a la norma ISO 11664-4:2008. Colorimetría. Parte 4: Espacio cromático L*a*b* CIE 1976. Las condiciones de medida del equipo fueron:

- Iluminante estándar CIE D65.

- Observador estándar CIE $10^{\circ}$.

- Componente especular incluida.

Para cada pigmento, se realizaron varias medidas en diferentes probetas, calculando el valor medio $(X)$ y la desviación estándar $(\sigma)$ para cada coordenada cromática. 

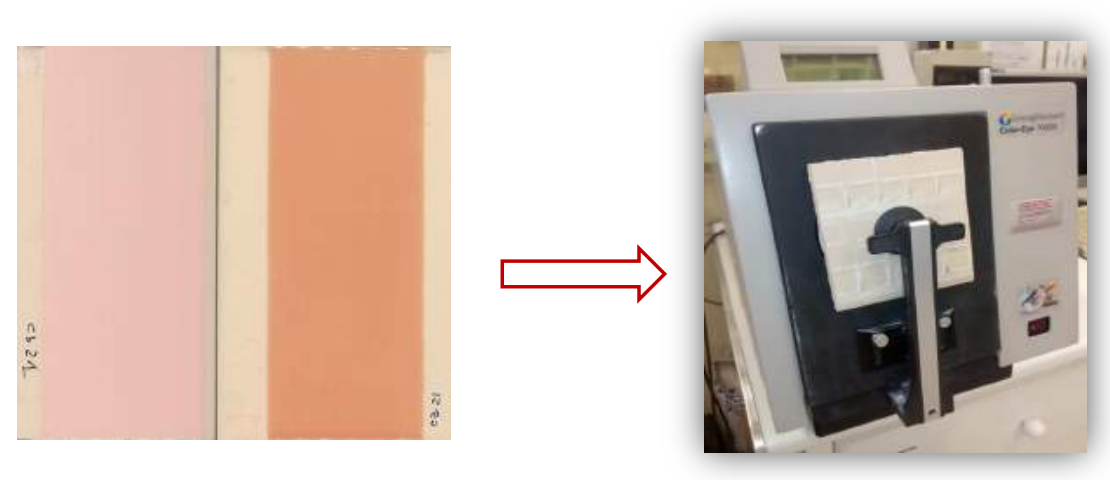

Figura 3.26 Medida de las coordenadas cromáticas

Otro parámetro que permite caracterizar los pigmentos cerámicos según su poder colorante es la curva de reflectancia y se puede obtener con el espectrofotómetro. La relación entre la luz reflejada y la luz incidente se conoce como reflectancia o factor de iluminancia, y se expresa como un porcentaje entre 0 y $100 \%$, o como una relación entre 0 y 1 . Cuando el factor de iluminancia es medido para las diferentes longitudes de onda y se traza un gráfico de reflectancia en función de las longitudes de onda, se forma una curva que es característica denominada curva de reflectancia u espectro de reflectancia.

Los datos espectrales de luz reflejada (espectros de reflectancia), se adquirieron en el espectrofotómetro nombrado anteriormente y fueron representados en el rango espectral de $360 \mathrm{~nm}$ a $750 \mathrm{~nm}$ para cada una de las piezas esmaltadas (ASTM C 609-07. Standard Test Method for Measurement of Light Reflectance Value and Small Color Differences between Pieces of Ceramic Tile). Debido a que todos los pigmentos presentan una tonalidad similar, las curvas de reflectancia no aportan información esencial en este trabajo de investigación, sin embargo, se han incluido aquellas curvas correspondientes a la caracterización inicial de los pigmentos.

\subsubsection{Mícroscopía electrónica de barrido (MEB)}

El microscopio electrónico de barrido es un equipo que permite la observación y caracterización superficial de muestras, proporcionando información morfológica y de composición del material analizado. En el microscopio electrónico de barrido, se genera un haz de electrones, que atraviesa la columna e incide sobre la muestra. De la interacción entre los electrones incidentes con los átomos que componen la muestra se generan diferentes señales como son electrones secundarios, electrones retrodispersados, rayos $\mathrm{X}$ característicos, electrones Auger, catodoluminiscencia... (Figura 3.28). Todas estas señales, que se producen simultáneamente, son captadas con los correspondientes detectores, proporcionando distinto tipo de información. 
Entre las señales producidas están los electrones secundarios que son de baja energía y proceden de las inmediaciones de la superficie de la muestra y aportan información topográfica, los electrones retrodispersados o de alta energía que dan imágenes de composición y topografía de la superficie, y los rayos $\mathrm{X}$ característicos que permiten el análisis de la muestra y obtener imágenes de distribución de elementos (mapping).

Las muestras preparadas durante este trabajo se observaron y fotografiaron con la señal de electrones retrodispersados y con la señal de electrones secundarios de un microscopio electrónico de barrido (FEG-ESEM Quanta 200F, FEI, USA). EI microscopio integra un sistema para realizar microanálisis por dispersión de energías de rayos X (Genesis 7000 SUTW, EDAX, USA), que permite realizar diversos análisis de composición química e imágenes de distribución de elementos.

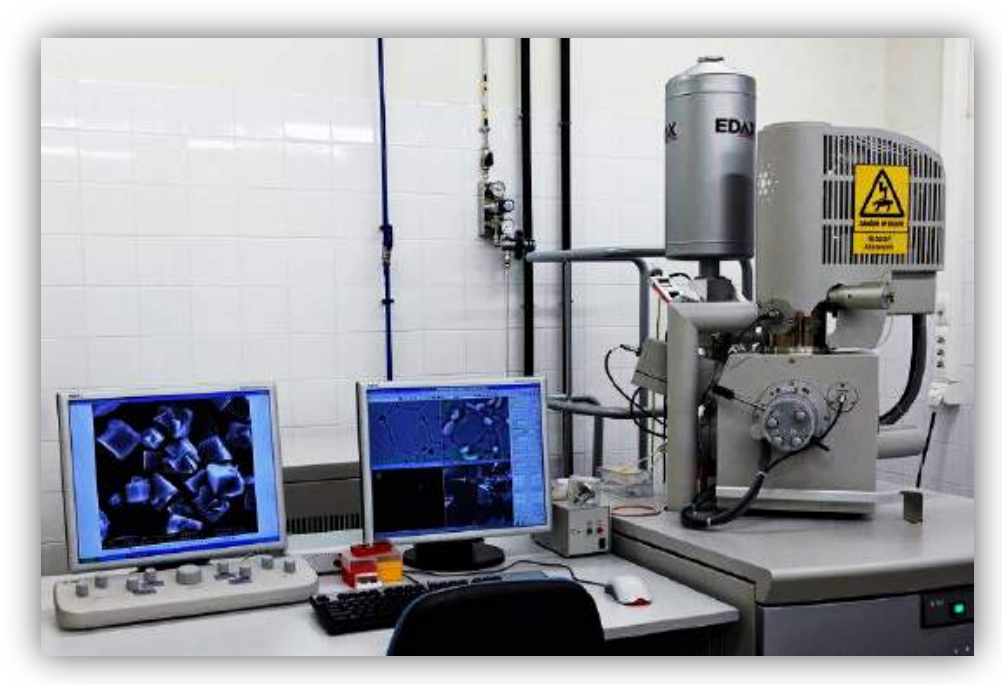

Figura 3.27 Microscopio electrónico de barrido FEG-ESEM QUANTA 200F

El microscopio electrónico de barrido ha permitido realizar diferentes tipos de análisis $[117,118]$ :

- La señal de electrones retrodispersados es sensible al número atómico de los componentes de la muestra y presenta contraste de composición, de modo que la señal es más intensa cuanto mayor es el número atómico medio, con lo cual las zonas más claras y brillantes contienen elementos más pesados y las zonas más oscuras elementos más ligeros. El contraste composicional puede explicarse considerando que los electrones retrodispersados son electrones del haz primario que interaccionan elásticamente con los núcleos atómicos de los elementos de la muestra y sufren una desviación de trayectoria de manera que vuelven a salir de la muestra. Cuanto mayor es el número atómico mayor es la probabilidad de interacción de los electrones del haz 
primario y mayor es la generación de electrones retrodispersados. Así pues, el nivel de grises que se obtiene mediante esta señal dependerá de la composición química de las fases.

- Por otra parte, la señal de electrones secundarios es más superficial (provienen de una zona de la muestra cuya profundidad es de unos 50 a 500 angstrom) ya que son electrones de baja energía y sólo pueden salir de la muestra los que proceden de las inmediaciones de la superficie. Esta señal proporciona información sobre la morfología de la muestra, resaltando las irregularidades de la superficie, como grietas, poros, bordes de grano o de cristales.

- Utilizando la emisión de radiación X que se genera al excitar una muestra con una fuente primaria (que es el haz de electrones utilizado en el SEM) se han podido realizar microanálisis por energía dispersiva EDX. La radiación primaria expulsa electrones de las capas interiores de los átomos del material a analizar. Los electrones de capas más externas de esos átomos ocupan los lugares vacantes y el exceso de energía resultante de esta transición se disipa en forma de fotones (radiación X). Esta radiación es característica para cada elemento químico. Por lo tanto, es posible identificar los elementos de una muestra midiendo la energía de esa radiación. El resultado de un análisis EDX, es un espectro que muestra la intensidad de radiación $X$ en función de la energía. Este espectro se genera en muy pocos segundos y la identificación del elemento que genera cada uno de los picos es inmediata, de modo que el análisis cualitativo y semicuantitativo de todos los elementos químicos (a partir del número atómico igual o mayor que 6, el carbono) presentes en la muestra por encima del límite de detección del método puede realizarse en escasos segundos.

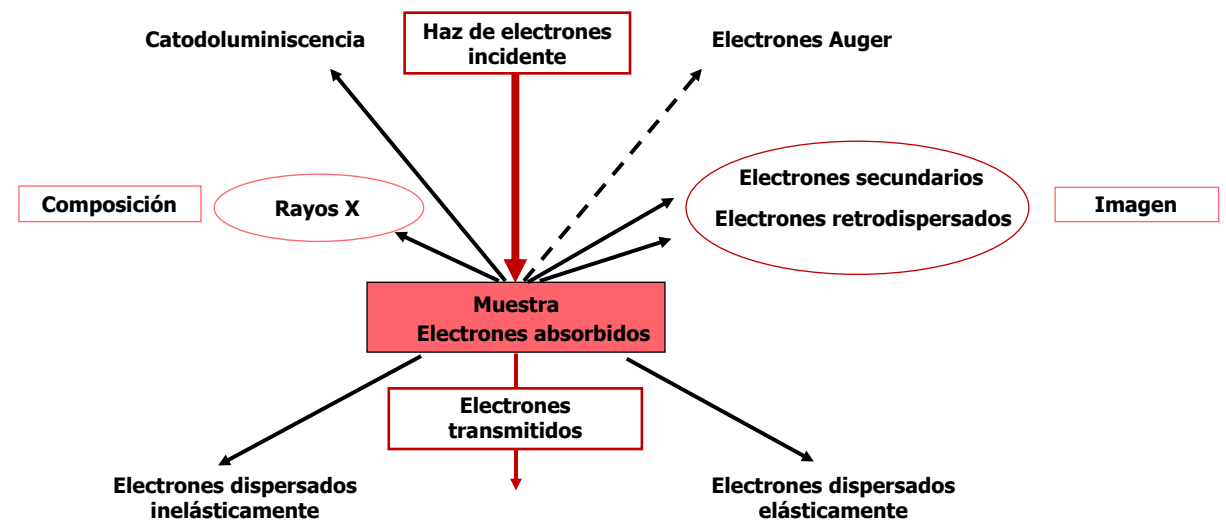

Figura 3.28 Interacción haz de electrones-muestra 


\subsubsection{Análisis de imagen y obtención de la Transformada de Fourier Discreta (TFD)}

El estudio del índice de mezcla mediante Transformada de Fourier está basado fundamentalmente en la obtención de imágenes con el microscopio electrónico de barrido. Sin embargo, la obtención de imágenes de materiales pulverulentos sueltos en un microscopio electrónico no resulta adecuada y se hace necesario fijar las partículas de cada mezcla que se analiza. La solución adoptada para mejorar esta problemática fue prensar probetas a partir de los polvos obtenidos durante el mezclado de las materias primas. Por otra parte, estas probetas presentaban muy baja resistencia mecánica, por lo que se optó por someter las probetas a un tratamiento suave de sinterización. Con esta aproximación se corría el riesgo de alterar la microestructura de la mezcla, pero de este modo las probetas resultaron mucho más fáciles de manipular, y lo que resultaba más importante, permitieron obtener imágenes más nítidas.

Las probetas se prepararon directamente con el polvo seco de las mezclas, utilizando una carga de 0,5 gramos en un molde de $8 \mathrm{~mm}$ de diámetro utilizando una prensa manual Expert-System, con la que se ejerció una fuerza de $20 \mathrm{~N}$.

Con este procedimiento se obtuvieron probetas con suficiente resistencia mecánica para poder ser manipuladas con cuidado, pero que desprendían partículas con facilidad. Por este motivo, se realizó un tratamiento térmico a las probetas introduciéndolas en un horno de laboratorio con una velocidad de calentamiento de $25^{\circ} \mathrm{C} /$ min hasta alcanzar la temperatura de $600{ }^{\circ} \mathrm{C}$, permaneciendo cinco minutos a dicha temperatura, y enfriamiento libre hasta temperatura ambiente. La temperatura máxima fue escogida por ser inferior a la temperatura de fusión de cualquiera de los componentes de las mezclas, incluido el mineralizador. Tras este tratamiento, las probetas adquirieron suficiente resistencia mecánica para poder ser introducidas sin riesgos en el microscopio electrónico de barrido (ver Figura 3.29).

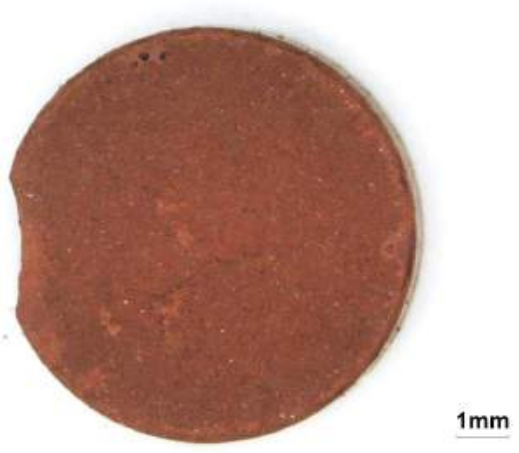

Figura 3.29 Probeta ligeramente sinterizada de la composición A06 
Las probetas sinterizadas se visualizaron con MEB utilizando electrones retrodispersados, tanto en superficie como en fractura fresca, si bien en estas últimas imágenes la microestructura dependía notablemente del camino seguido por la grieta, y la falta de planaridad de la superficie analizada complicaba el estudio de la mezcla de materias primas. Por ello se decidió utilizar las micrografías de la superficie de las probetas para realizar las evaluaciones del grado de mezcla.

Con las imágenes obtenidas con el microscopio, se realizó un estudio de homogeneidad de las muestras utilizando dos vías alternativas:

- MicroImage. Software de análisis de imagen que permite utilizar el algoritmo FFT (Fast Fourier Transform) para calcular la TFD editando la imagen en escala de grises en su forma espectral (Figura 3.30). Este software permitirá evaluar la homogeneidad o grado de mezcla de las imágenes obtenidas por microscopía (formato jpeg).

- Mathcad. Software matemático que permite resolver y analizar cálculos matemáticos de forma que se puede utilizar directamente la matriz de datos correspondiente a la transformada de Fourier, en lugar de analizar su representación gráfica. Este programa permitirá evaluar la homogeneidad de las mezclas a partir de los valores del espectro de potencia de la TFD [119].

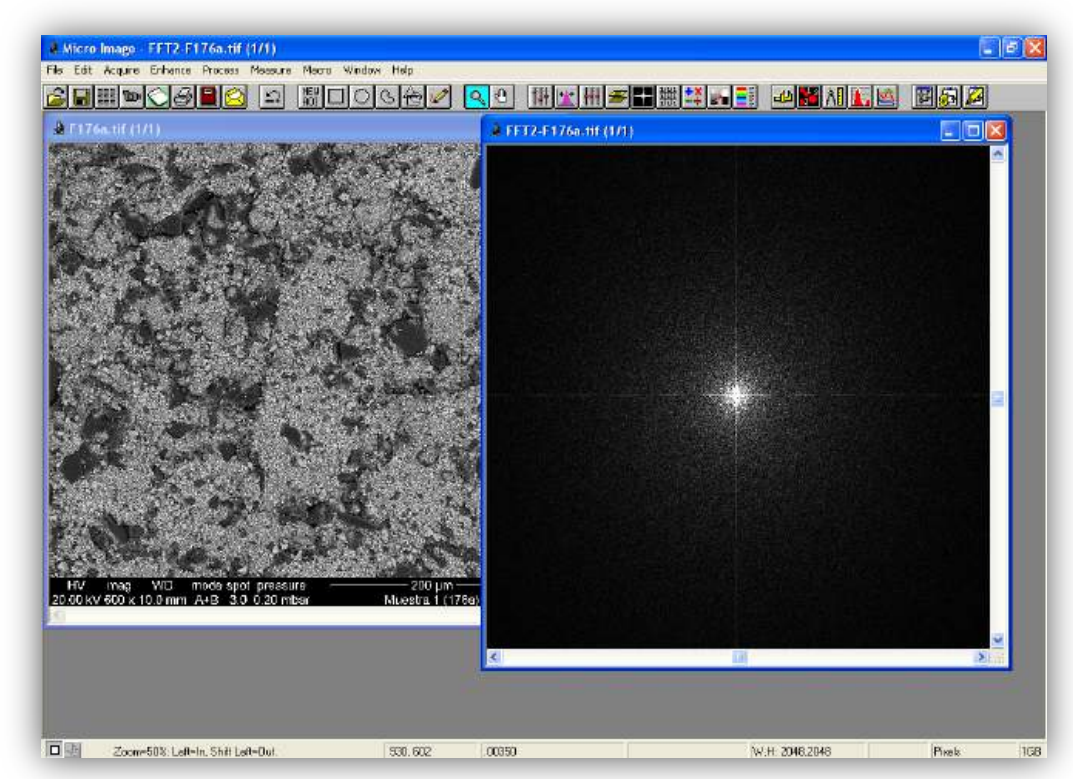

Figura 3.30 Obtención de la TFD a partir de una micrografía de MEB 
De forma general, la asignación de color a cada píxel en cada imagen digital, en nuestro caso micrografías con el microscopio electrónico de barrido, se realiza por medio de bits, siendo un bit la mínima unidad de medida de información de los archivos informáticos. Si a una imagen se le asigna un bit por píxel, tendrá sólo dos colores, usualmente blanco y negro. Si se asignaran dos bits por píxel se podrían definir cuatro colores y así podríamos seguir con imágenes de tres, cuatro o más bits por píxel, con una creciente cantidad de tonos de gris. Sin embargo, la mayoría de las imágenes digitales tienen asignadas ocho bits por píxel que permite definir 256 tonos de gris, desde el blanco hasta el negro.

En la Figura 3.31 se observa dos escalas del blanco al negro. La primera escala corresponde a los colores que pueden obtenerse en un archivo de 1 bit por píxel de forma que los píxeles de la imagen sólo pueden ser blancos o negros. Conforme aumenta el número de bits por píxel, la cantidad de grises aumenta hasta obtener la escala de 8 bits por píxel que es la paleta utilizada para las imágenes en "escala de grises" [75].

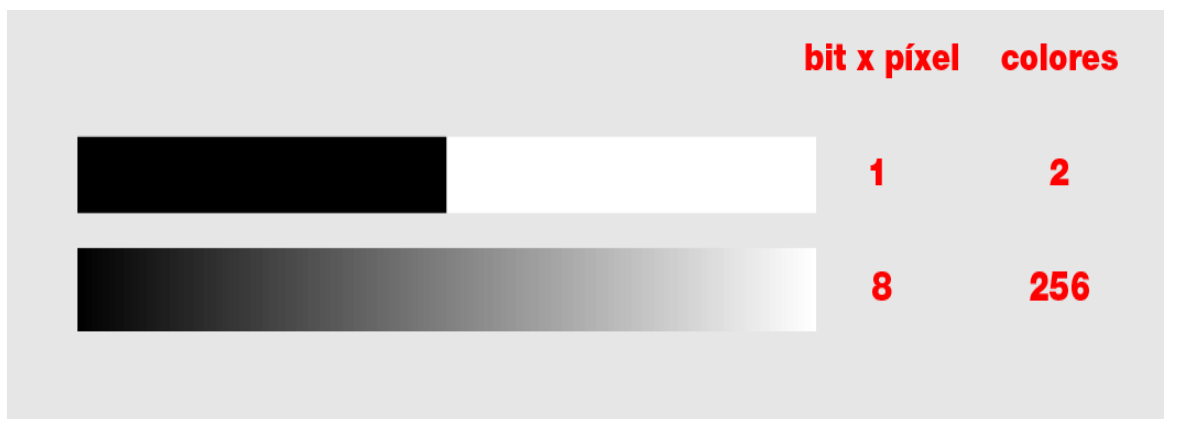

Figura 3.31 Bits por píxeles (Imagen depixelnauta.com con licencia CC BY-NC 3.0)

Para poder comparar los espectros de potencia de la TFD de cada imagen de una forma más cuantitativa, es necesario seleccionar un parámetro que defina la imagen digital obtenida. Entre los parámetros más comúnmente utilizados en el procesamiento digital de imágenes, se encuentran el nivel de gris o el número de píxeles y en consecuencia, estos conceptos son los seleccionados posteriormente para evaluar un índice de mezcla [120]. 
4. RESULTADOS
Y DISCUSIÓN 



\subsection{Comparación inicial de los métodos de mezclado vía húmeda y vía seca}

A lo largo de la investigación se han utilizado numerosos procedimientos para preparar las diferentes mezclas de materias primas, tanto de mezclado vía húmeda como vía seca, con el fin de evaluar los efectos sobre las propiedades y poder colorante del pigmento final.

El método general de optimización de condiciones experimentales para la obtención de pigmentos en un laboratorio puede utilizar una metodología de mezclado de las materias primas vía húmeda o vía seca, dependiendo del equipamiento disponible y de los mecanismos de formación del pigmento.

Para el desarrollo de este trabajo de investigación se consideró interesante disponer de composiciones industriales para la síntesis del pigmento coral de hierro-circón y poder utilizarlas como referencia en el estudio de las diferentes variables del proceso. Por este motivo, se seleccionaron cuatro muestras procedentes de un fabricante de pigmentos ubicado en la provincia de Castellón. Las materias primas habían sido mezcladas en las instalaciones de la empresa mediante mezclado vía seca utilizando las materias primas que se describen en el apartado 3.1 e incorporando el cuarzo en una etapa de mezclado posterior al resto de materias primas [56]. Las muestras fueron referenciadas como A01, A02, A03 y A04 y corresponden a la composición de la Tabla 3.4, con las materias primas descritas en la Tabla 3.5.

Estas composiciones fueron tratadas térmicamente en un horno de laboratorio utilizando el Ciclo STD que se detalla en la Figura 3.16. Se obtuvieron materiales de color granate oscuro intenso en todos los casos. En este experimento, los pigmentos sintetizados habían sufrido una ligera contracción durante la cocción, si bien parecían estar disgregados o sueltos.

Por otra parte, se realizaron los experimentos con una molienda vía húmeda con el molino de bolas Pulverisette 5, siguiendo el procedimiento descrito en el apartado 3.2.1. Se introdujo la mezcla de todas las materias primas en un crisol de mullita y se realizó un tratamiento térmico utilizando el Ciclo STD. Las muestras fueron referenciadas como A05, A06, A07 y A08. Aparentemente no se apreciaban visualmente diferencias de color entre los pigmentos generados, pero poseían una elevada contracción tras la cocción y una resistencia considerable frente a la disgregación. Por lo tanto, se podría suponer que los aglomerados de materias primas eran bastante compactos.

En este apartado se realiza una comparación inicial de los pigmentos obtenidos mediante mezclado vía húmeda y vía seca incluyendo las imágenes de los polvos de pigmento obtenidos (Figura 4.1). Sin embargo, no se aprecian diferencias significativas entre ellos. 

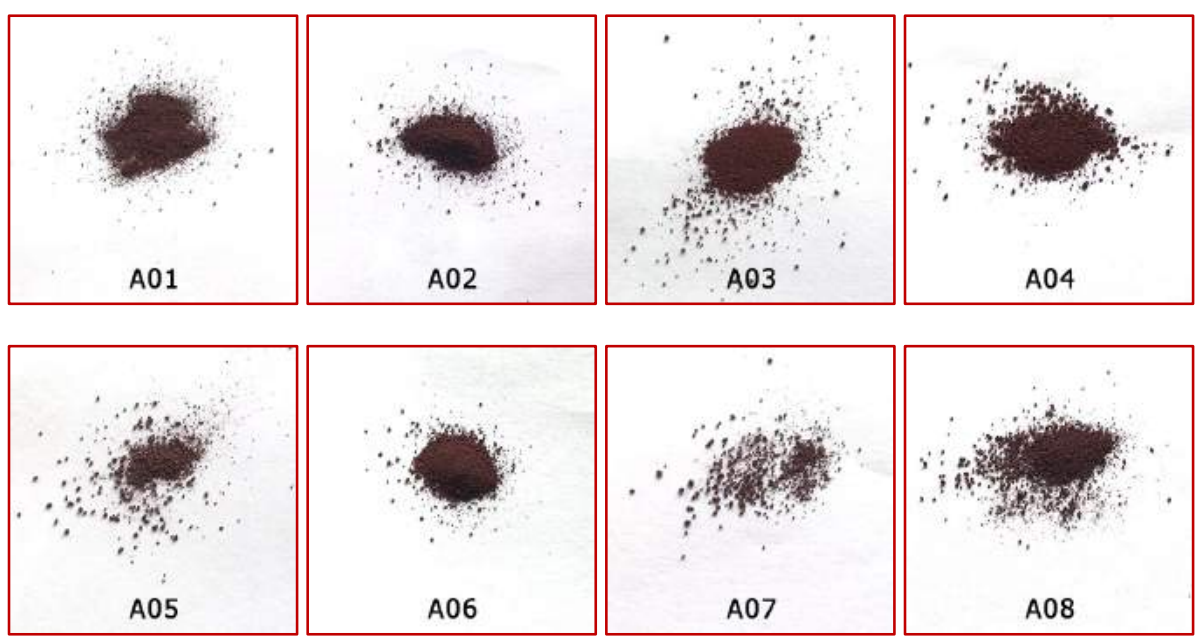

Figura 4.1 Pigmentos obtenidos en la caracterización inicial mediante mezclado vía seca (A01 a A04) y vía húmeda (A05 a A08)

\subsubsection{Caracterización mineralógica}

Tras el tratamiento térmico, todos los materiales sintetizados se molturaron y se caracterizaron desde el punto de vista de la composición mineralógica. Los pigmentos que contenían una cantidad apreciable de circón, también se incorporaron posteriormente a los vidriados para evaluar su poder colorante.

Cabe destacar que la composición utilizada poseía un exceso de circona con respecto a la sílice $y$, en consecuencia, los pigmentos generados siempre contuvieron una fracción apreciable de baddeleyita, incluso si todo el cuarzo se hubiese incorporado al circón y, por tanto, completado la reacción.

En las Tabla 4.1 y Tabla 4.2 se detallan los porcentajes de fases cristalinas obtenidas cuando el mezclado de las materias primas o precursores se realiza mediante vía seca y vía húmeda. Tal y como se comentó en el apartado 3.5.3, los porcentajes que se muestran a continuación y sucesivamente durante todo el trabajo de investigación llevan asociados errores del $5 \%$ relativo para las fases mayoritarias ( $>5 \%$ en peso) y del $10 \%$ relativo para las fases minoritarias ( $<5 \%$ en peso).

Asimismo, se ha realizado una estimación de la composición de la fase amorfa en óxidos, ya que parte del cuarzo, baddeleyita, hematites, así como el mineralizador introducido inicialmente $\left(4,6 \%\right.$ en peso de $\left.\mathrm{Na}_{2} \mathrm{SiF}_{6}\right)$ pasarán a formar parte de ésta. 
Tabla 4.1 Composición industrial: Porcentaje de las fases cristalinas identificadas y composición de la fase amorfa (\% peso)

\begin{tabular}{|c|c|c|c|c|c|c|}
\hline & & & A01 & A02 & A03 & A04 \\
\hline \multirow{4}{*}{\multicolumn{2}{|c|}{ 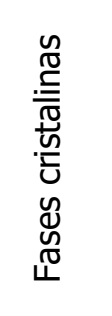 }} & Cuarzo & 5 & 4 & 4 & 3 \\
\hline & & Baddeleyita & 23 & 20 & 19 & 16 \\
\hline & & Hematites & 19 & 20 & 20 & 21 \\
\hline & & Circón & 30 & 37 & 32 & 45 \\
\hline & & Fase amorfa total & 22 & 19 & 26 & 17 \\
\hline \multirow{3}{*}{\multicolumn{2}{|c|}{ 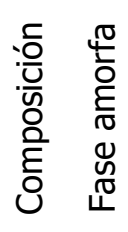 }} & $\% \mathrm{Fe}_{2} \mathrm{O}_{3}$ & 4 & 3 & 4 & 3 \\
\hline & & $\% \mathrm{SiO}_{2}$ & 7 & 6 & 7 & 6 \\
\hline & & $\% \mathrm{ZrO}_{2}$ & 6 & 5 & 10 & 4 \\
\hline
\end{tabular}

Tabla 4.2 Composición preparada en laboratorio: Porcentaje de las fases cristalinas identificadas y composición de la fase amorfa (\% peso)

\begin{tabular}{|c|c|c|c|c|c|c|}
\hline & & & A05 & A06 & A07 & A08 \\
\hline \multirow{4}{*}{\multicolumn{2}{|c|}{ 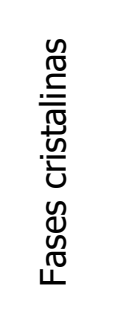 }} & Cuarzo & 9 & 11 & 10 & 9 \\
\hline & & Baddeleyita & 40 & 47 & 42 & 38 \\
\hline & & Hematites & 21 & 22 & 20 & 21 \\
\hline & & Circón & 10 & 5 & 5 & 15 \\
\hline & & Fase amorfa total & 20 & 15 & 23 & 18 \\
\hline \multirow{3}{*}{\multicolumn{2}{|c|}{ 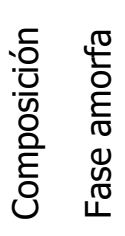 }} & $\% \mathrm{Fe}_{2} \mathrm{O}_{3}$ & 3 & 1 & 3 & 3 \\
\hline & & $\% \mathrm{SiO}_{2}$ & 9 & 9 & 10 & 8 \\
\hline & & $\% \mathrm{ZrO}_{2}$ & 3 & $<1$ & 4 & 2 \\
\hline
\end{tabular}


Para seguir de forma más sencilla la reacción de formación del circón, se definió el grado de avance de la reacción $\varsigma$. De esta forma fue posible determinar como avanza la reacción química con las diferentes condiciones de síntesis. En general el grado de avance viene definido como el cociente entre el cambio total en el número de moles de una especie y su coeficiente estequiométrico y permite estudiar como evoluciona la concentración de alguno de los reactivos o productos que intervienen en la misma. [121].

En el caso que nos ocupa, la reacción de formación de circón es una reacción química irreversible, puesto que los reactivos forzosamente sólo pueden transformarse en productos, y no al revés. Por tanto, el grado de avance $\varsigma$ inicialmente es nulo y va aumentando hasta que alguno de los reactivos se agota. En la formación del circón el reactivo limitante es el cuarzo, ya que la baddeleyita se encuentra en exceso y el porcentaje de hematites se ha supuesto constante en el transcurso de la reacción.

A partir de los porcentajes de fases cristalinas calculados mediante difracción de rayos $X$, así como de la estimación de la composición de la fase vítrea, se definieron dos parámetros para evaluar el grado de avance de la reacción:

- $\quad \zeta 1$ como la fracción de cuarzo que reacciona para formar circón.

- $\quad$ \$2 como la fracción de cuarzo que pasa a formar parte de la fase vítrea.

A partir de las representaciones gráficas de los valores obtenidos tanto de los porcentajes de fases cristalinas y fase amorfa como de los dos parámetros que definen el grado de avance $\varsigma_{1}$ y $\varsigma_{2}$ (Figura 4.2, Figura 4.3, Figura 4.4 y Figura 4.5), se pudieron extraer las relaciones que se comentan a continuación.

- El porcentaje de hematites (Figura 4.2) obtenido en los ocho pigmentos analizados es bastante similar, en torno al 19-22\%, lo cual indica que el óxido de hierro no tiene tendencia a formar una solución sólida con las otras fases presentes (o si lo hace es en proporción similar en todos los casos) y no parecen existir diferencias significativas con el cambio en el método de preparación de la mezcla de materias primas. Es lógico ya que el óxido de hierro puede ser encapsulado o quedar libre, pero en principio no debe reaccionar para generar otra sustancia diferente, y por tanto mantiene su naturaleza. 


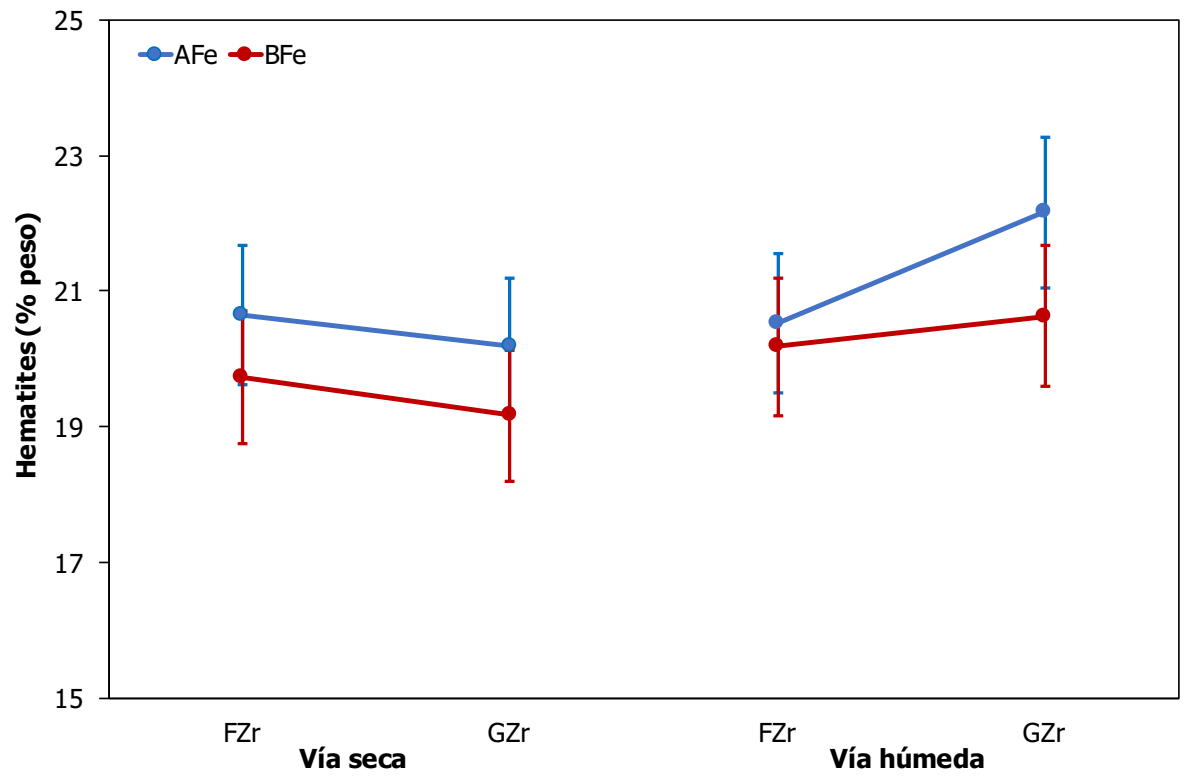

Figura 4.2 Evolución del porcentaje de hematites en función de las materias primas y método de preparación de las mezclas

- Los pigmentos sintetizados a partir de las mezclas preparadas mediante mezclado vía húmeda presentan un porcentaje de baddeleyita (Figura 4.3) mucho más elevado que sus homólogos sintetizados a partir de las mezclas preparadas por vía seca (en torno a un 30 o 40\% más de baddeleyita), lo cual indica que la reacción de síntesis del circón no alcanzó conversiones elevadas cuando el mezclado se realizó vía húmeda.

- El porcentaje de cuarzo (Figura 4.4) en los pigmentos presenta una evolución coherente con los resultados correspondientes a la baddeleyita. A igualdad de composición, los pigmentos sintetizados a partir de mezclas procesadas vía seca siempre poseen un porcentaje de cuarzo más bajo, debido a un mayor grado de avance de la reacción, lo cual es acorde con las apreciaciones descritas en el párrafo anterior en relación a los porcentajes de baddeleyita. 


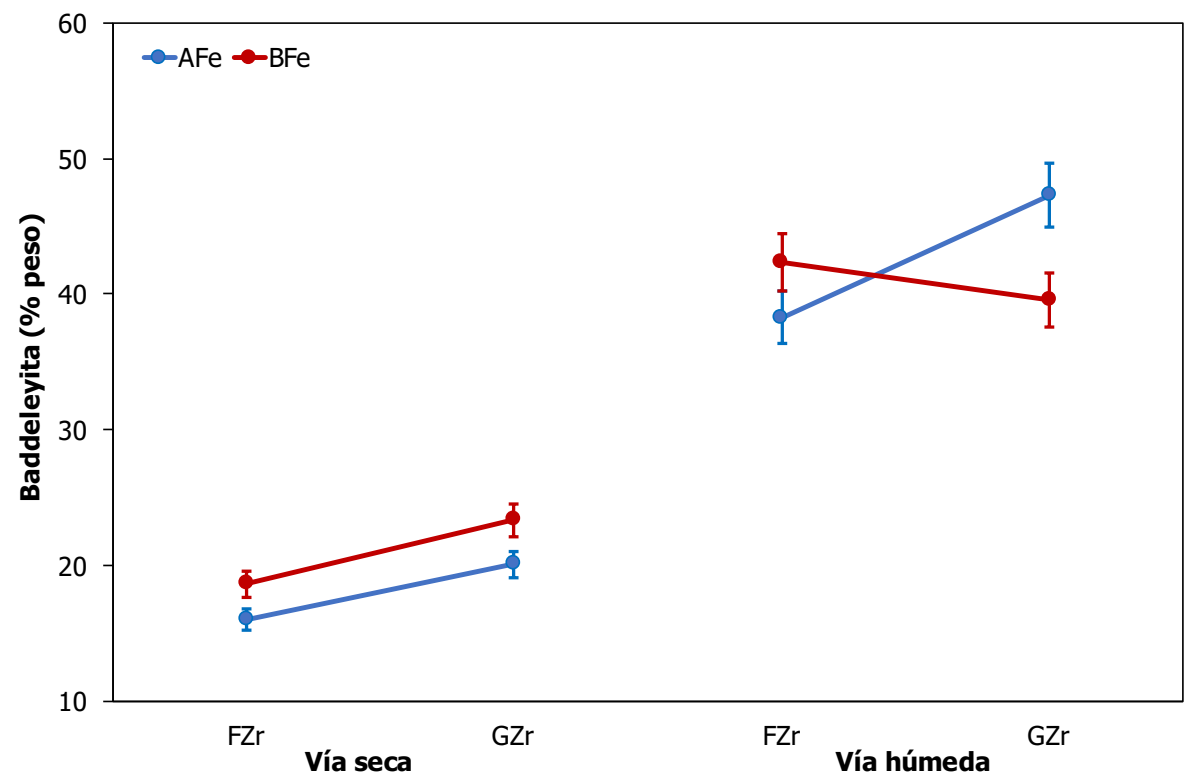

Figura 4.3 Evolución del porcentaje de baddeleyita en función de las materias primas y método de preparación de las mezclas

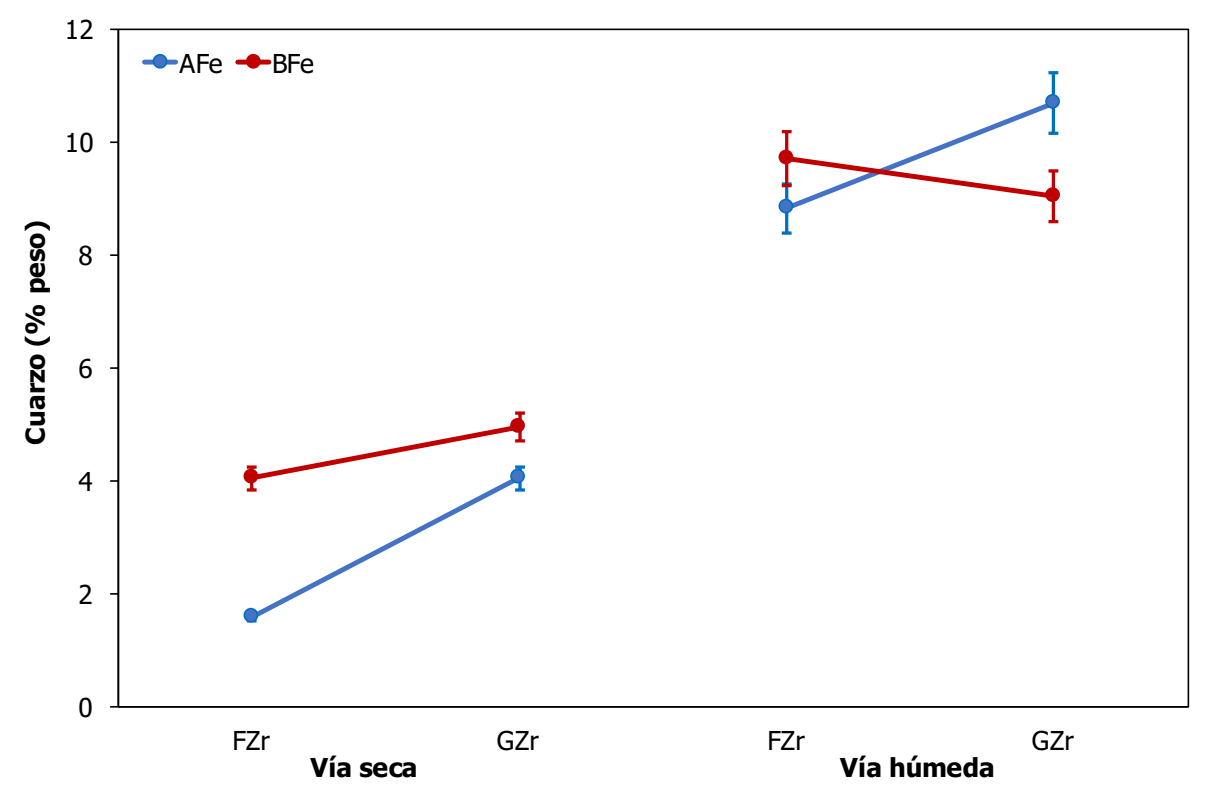

Figura 4.4 Evolución del porcentaje de cuarzo en función de las materias primas y método de preparación de las mezclas

- Evaluando los pigmentos preparados con ambos métodos, se observa como el que mayor cantidad de circón es capaz de formar es aquel preparado con la circona FZr y el óxido de hierro AFe y consecuentemente los que menor cantidad de cuarzo y baddeleyita contienen en su composición. 
- Del mismo modo, se observa la relación directa que existe entre el porcentaje de circón formado y el grado de avance $\varsigma_{1}$ (Figura 4.5), obteniendo valores de 0,7 para el pigmento sintetizado mediante vía seca utilizando la circona FZr. Los valores de $\varsigma_{1}$ para los pigmentos sintetizados a partir de un mezclado vía húmeda presentan valores entre 0,1 y 0,25 lo que indica un menor grado de avance de la reacción.

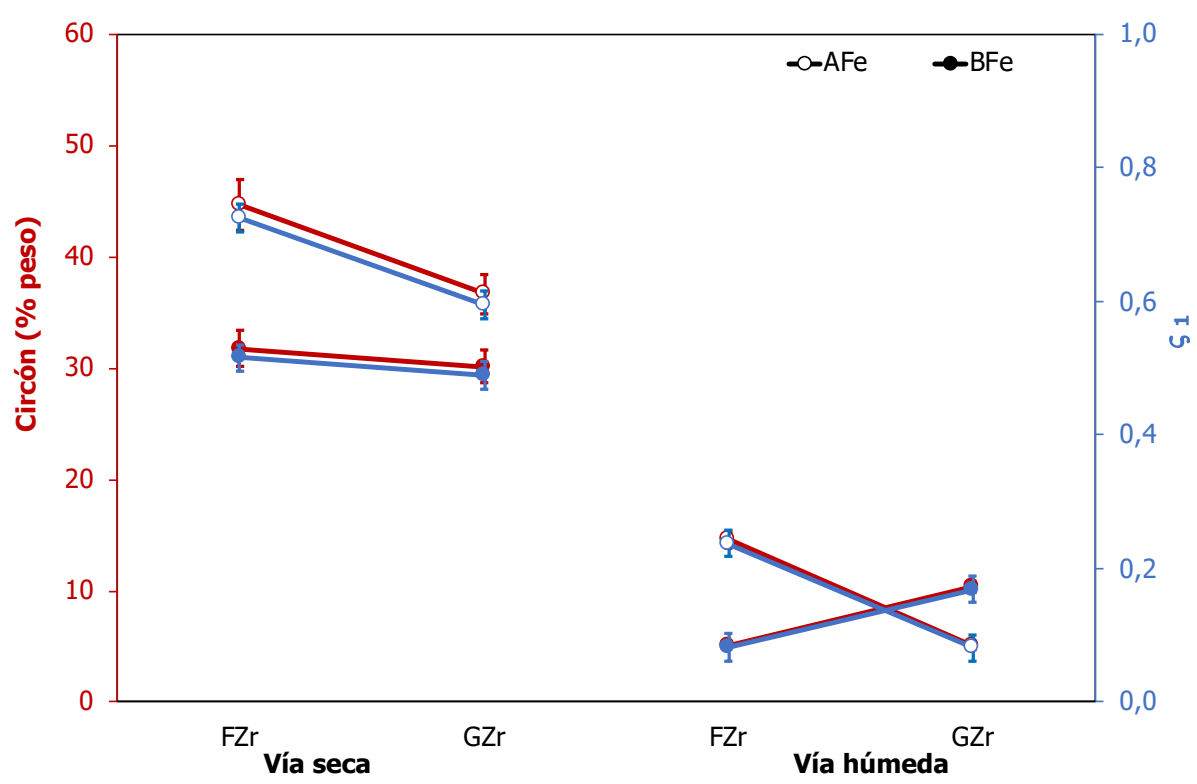

Figura 4.5 Evolución del porcentaje de circón y grado de avance $\left(\varsigma_{1}\right)$ en función de las materias primas y método de preparación de las mezclas

- Los valores de fase amorfa calculados por el método Rietveld indican que las composiciones procesadas vía seca contienen un mayor porcentaje de amorfo, siendo mayor cuando se utiliza el óxido de hierro BFe.

- En el caso del grado de avance $\varsigma_{2}$, éste manifiesta una mayor variabilidad con respecto al porcentaje de fase amorfa presente en cada uno de los pigmentos sintetizados. Esto es debido a que, en la formación de la fase vítrea o amorfa, el cuarzo no es el único componente que estará presente en su composición. 


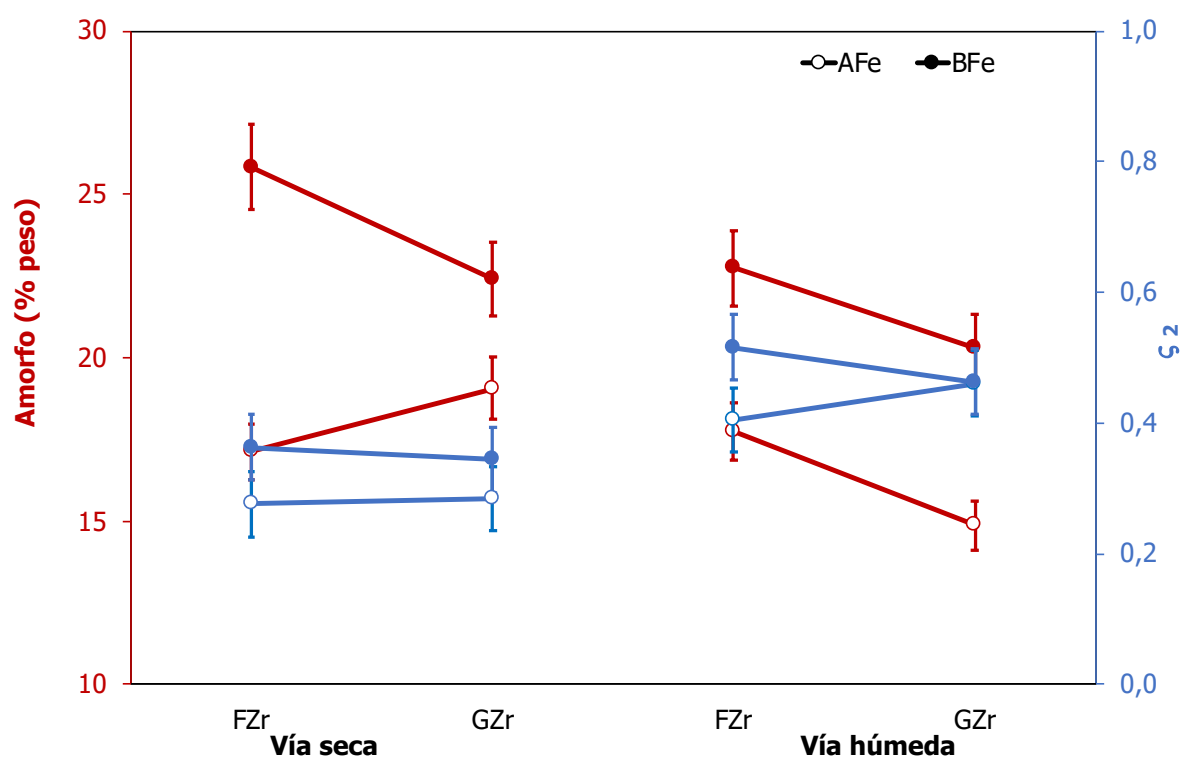

Figura 4.6 Evolución del porcentaje de fase amorfa y grado de avance $\left(\varsigma_{2}\right)$ en función de las materias primas y método de preparación de las mezclas

Teniendo en cuenta la evolución de las diferentes fases cristalinas, de la fase amorfa y los parámetros $\zeta_{1}$ y $\zeta_{2}$, se aprecian algunas irregularidades, que pueden indicar un desacoplamiento entre la reacción del cuarzo con el mineralizador para formar fase vítrea y/o el compuesto gaseoso $\mathrm{SiF}_{4}$, y la reacción con la baddeleyita para generar circón. Concretamente, la relación entre la formación del circón y la desaparición de la baddeleyita no es tan directa como cabría esperar si toda la baddeleyita presente participase en la génesis de circón. Los resultados parecen indicar que los mecanismos de formación del circón siguen caminos diferentes según si el proceso de mezclado se realiza vía húmeda o vía seca.

En ambos métodos de procesado, vía húmeda y vía seca, la relación circón/cuarzo es mayor en las composiciones que contienen la circona FZr y el óxido de hierro AFe (composiciones A04 y A08), con un máximo de formación de circón y un mínimo de cuarzo libre sin reaccionar.

En el caso del proceso de mezclado vía húmeda, con la misma circona $\mathrm{FZr}$ (A07 y A08), el cambio de óxido de hierro hace que el cuarzo sin reaccionar aumente en gran medida y las diferencias sean máximas. Por otra parte, en el procesado vía húmeda, se observa como la utilización de la circona GZr (A05 y A06) hace que la formación del circón no dependa tanto del óxido de hierro incorporado como cuando se utiliza la circona FZr, en la que el óxido de hierro adicionado afectará de forma importante al porcentaje de circón formado. Este efecto no se observa en los pigmentos procesados por vía seca. 
El porcentaje de circón es notablemente más elevado en los pigmentos sintetizados a partir de las mezclas preparadas vía seca, que en sus homólogos generados partiendo de mezclas elaboradas vía húmeda, lo cual es acorde con los datos sobre la presencia de baddeleyita sin reaccionar. En el caso de las composiciones que han sido mezcladas vía seca empleando la circona FZr (A03 y A04), se consigue una mayor formación de circón utilizando el óxido de hierro AFe (A04) y a igualdad en el óxido de hierro, se consigue una mayor cantidad de circón con la circona más fina FZr. Sin embargo, en los pigmentos sintetizados a partir de las composiciones mezcladas vía húmeda, no se mantiene la misma tendencia.

Los resultados indicaron claramente que el método de preparación de las mezclas por vía húmeda generaba un material con menor reactividad que la preparación por vía seca, al menos en lo que a la síntesis del circón se refiere.

Dado que no se apreciaba una correlación muy precisa entre los porcentajes de las fases cristalinas y el comportamiento que teóricamente cabría esperar, se realizó un ajuste lineal de los datos disponibles (Figura 4.7), tomando como fase de referencia la baddeleyita, ya que estaba en exceso en las composiciones utilizadas tal y como se indicó en el apartado de materiales. Los resultados se pueden resumir del siguiente modo:

- La evolución del porcentaje de cuarzo y circón con respecto a la baddeleyita es el que cabría esperar, creciente respecto al cuarzo y decreciente con el circón. Además, el valor de la pendiente de la regresión lineal sugiere una relación directa entre el porcentaje de baddeleyita y circón, hecho que no ocurre entre las fases cristalinas cuarzo y baddeleyita. Este resultado supondría que la desaparición del cuarzo no implica directamente la síntesis del circón, ya que parte del cuarzo puede formar fase vítrea, mientras que en el caso de la baddeleyita una disminución de ésta indicaría tanto la formación de la fase cristalina circón como su incorporación a la fase vítrea, aunque en una proporción inferior a la de sílice.

- El porcentaje de hematites es prácticamente independiente del de la baddeleyita, lo cual indica que esta fase no sufre cambios durante el proceso de síntesis del pigmento y, por tanto, no interviene en el mecanismo de la reacción, o si lo hace es de forma minoritaria. 


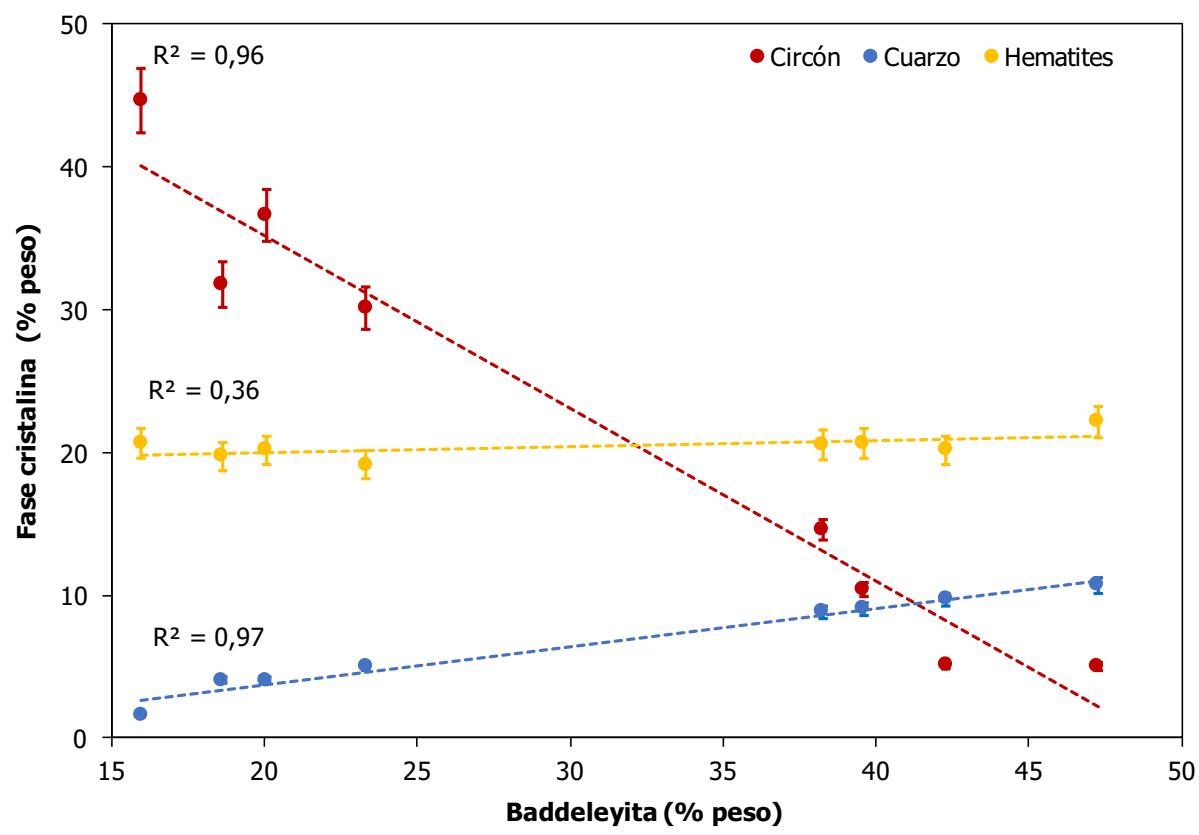

Figura 4.7 Correlación entre las cuatro fases cristalinas presentes en los pigmentos

Estos resultados indicaban que la baddeleyita y el circón eran las fases más recomendables para evaluar el grado de avance de la reacción de síntesis del pigmento, ya que el contenido en cuarzo estaba influenciado por más variables, y la fase hematites apenas presentaba dependencia respecto a las condiciones del proceso. 


\subsubsection{Desarrollo de color}

Se ensayó el poder colorante de los ocho pigmentos sintetizados, cuatro por vía húmeda y cuatro por vía seca. Para ello se utilizó un vidriado transparente y un vidriado opaco sobre soportes de revestimiento blanco según el ciclo térmico detallado en la Figura 3.17.
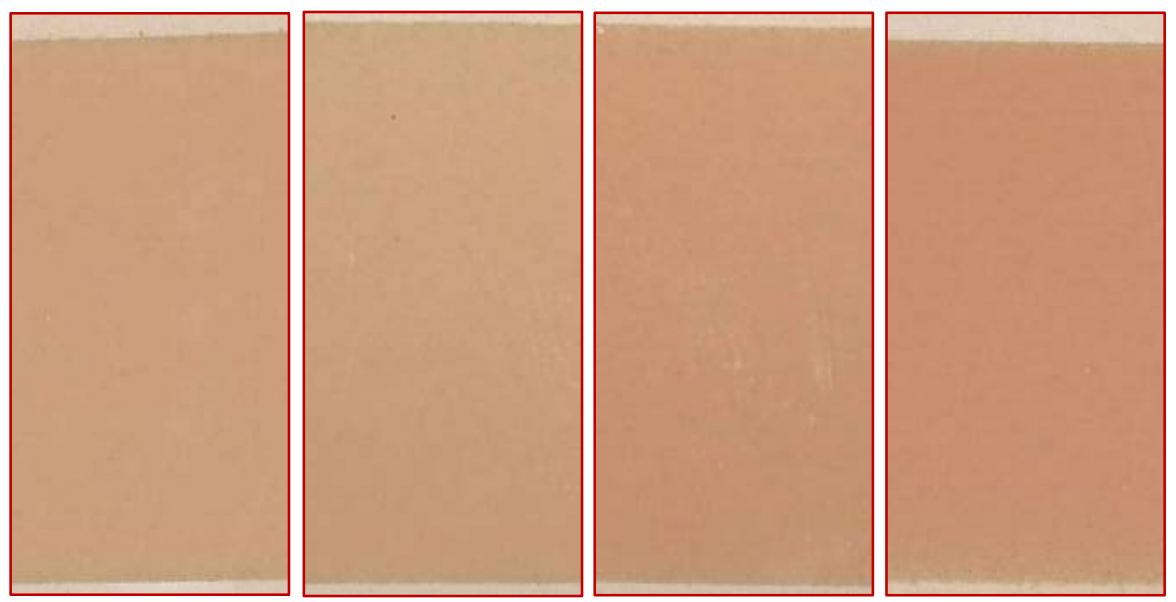

Figura 4.8 Probetas esmaltadas que incorporaban los pigmentos A01, A02, A03 y A04 con el vidriado transparente
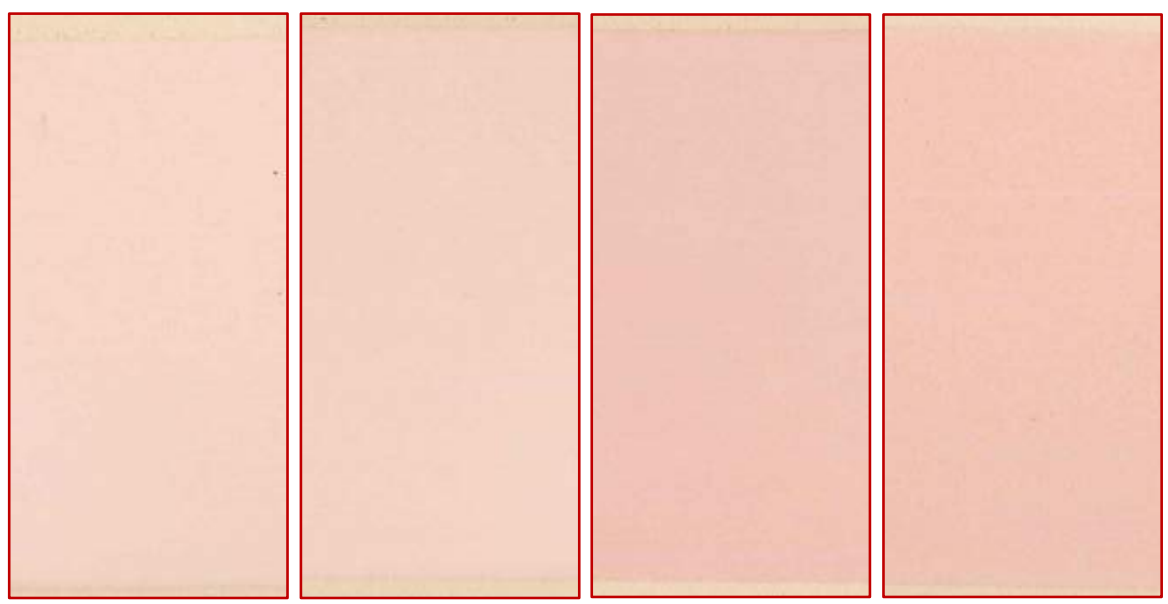

Figura 4.9 Probetas esmaltadas que incorporaban los pigmentos A01, A02, A03 y A04 con el vidriado opaco

Tras la aplicación y cocción de los vidriados, se observó cómo los pigmentos preparados mediante el proceso de mezclado vía húmeda de laboratorio apenas habían desarrollado poder colorante, mientras que los pigmentos sintetizados mediante el proceso vía seca industrial poseían un tono coral con una intensidad elevada. 
Por este motivo, únicamente se determinaron las coordenadas cromáticas de los pigmentos sintetizados mediante mezclado vía seca. Los resultados obtenidos, media de tres valores, se detallan en la Tabla 4.3 y Tabla 4.4 junto con la desviación estándar.

Tabla 4.3 Coordenadas cromáticas de los vidriados transparentes que contenían los pigmentos sintetizados $\left(1120^{\circ} \mathrm{C}\right)$

\begin{tabular}{|ccccccc|}
\hline Referencia & \multicolumn{2}{c}{ L* $^{*}$} & \multicolumn{3}{c}{$\mathrm{a}^{*}$} & \multicolumn{2}{c|}{$\mathrm{b} *$} \\
\hline & $\mathrm{X}$ & $\sigma$ & $\mathrm{X}$ & $\sigma$ & $\mathrm{X}$ & $\sigma$ \\
$\mathrm{A} 01$ & 69,51 & 0,07 & 11,33 & 0,18 & 18,84 & 0,02 \\
$\mathrm{~A} 02$ & 69,68 & 0,09 & 11,04 & 0,20 & 18,81 & 0,07 \\
A03 & 67,01 & 0,06 & 13,89 & 0,25 & 19,59 & 0,06 \\
A04 & 66,05 & 0,18 & 14,94 & 0,19 & 19,41 & 0,15 \\
\hline
\end{tabular}

Tabla 4.4 Coordenadas cromáticas de los vidriados opacos que contenían los pigmentos sintetizados $\left(1040^{\circ} \mathrm{C}\right)$

\begin{tabular}{|ccccccc|}
\hline Referencia & \multicolumn{2}{c}{$\mathrm{L}^{*}$} & \multicolumn{3}{c}{ a* } & \multicolumn{2}{c|}{$\mathrm{b}^{*}$} \\
& $\mathrm{X}$ & $\sigma$ & $\mathrm{X}$ & $\sigma$ & $\mathrm{X}$ & $\sigma$ \\
$\mathrm{A} 01$ & 84,86 & 0,09 & 7,83 & 0,09 & 7,86 & 0,16 \\
$\mathrm{~A} 02$ & 84,93 & 0,18 & 7,82 & 0,18 & 7,79 & 0,28 \\
$\mathrm{~A} 03$ & 81,32 & 0,12 & 10,57 & 0,08 & 7,98 & 0,05 \\
$\mathrm{~A} 04$ & 81,85 & 0,08 & 10,41 & 0,12 & 8,42 & 0,16 \\
\hline
\end{tabular}

El estudio de la relación de las coordenadas cromáticas medidas en los vidriados y las materias primas utilizadas en la síntesis de los pigmentos incorporados a los mismos permitió extraer las siguientes tendencias:

- La ausencia de poder colorante en los pigmentos sintetizados a partir de las mezclas preparadas vía húmeda se correlaciona bien con la escasa proporción de circón formado, el cual habría resultado insuficiente para encapsular el óxido de hierro y protegerlo de la disolución en la fase vítrea durante la cocción del vidriado. 
- La luminosidad (Figura 4.10) de los colores generados en los vidriados opaco y transparente es mayor en el caso de incorporar los pigmentos sintetizados a partir de la circona GZr, mientras que es apreciablemente menor si el pigmento está sintetizado con la circona FZr. No se detecta una influencia clara por parte del óxido de hierro utilizado en la síntesis, ya que apenas se aprecian diferencias.

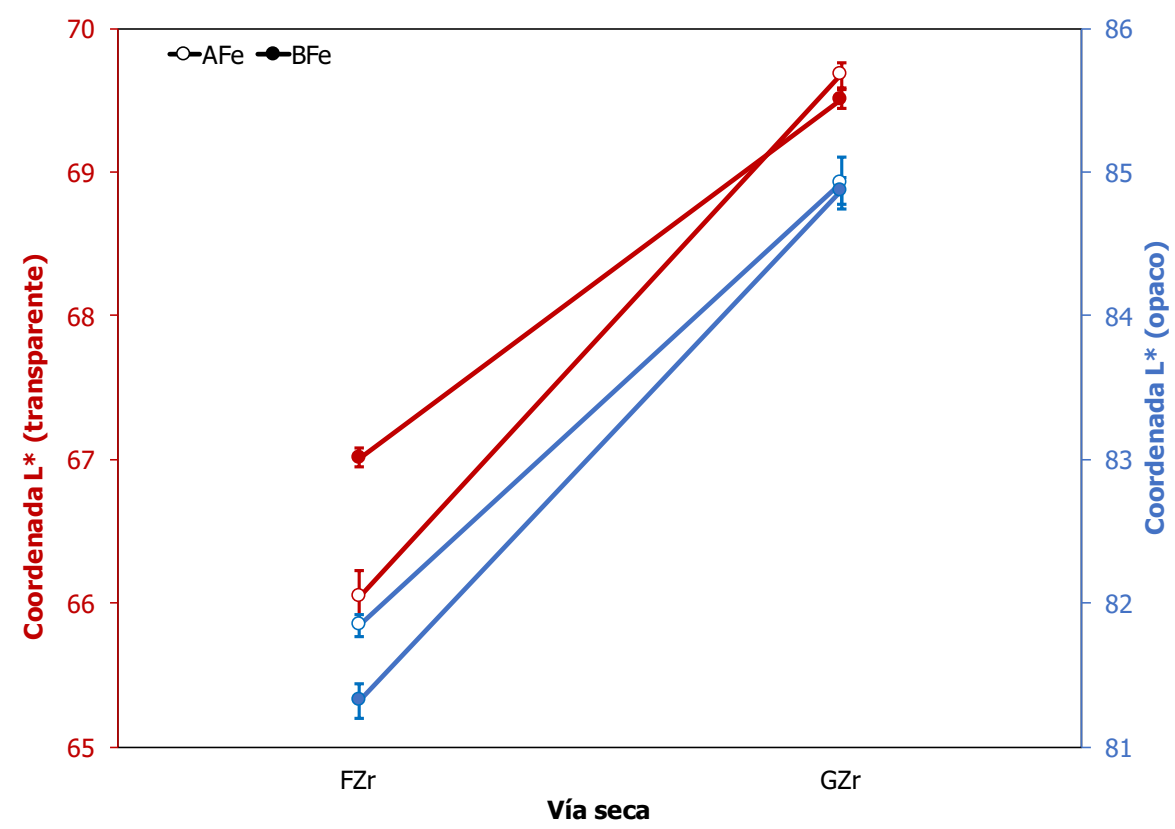

Figura 4.10 Evolución de la coordenada L*en los vidriados ensayados

- La componente roja (Figura 4.11) muestra que los valores más elevados de $a^{*}$ en los dos vidriados se obtienen con los pigmentos sintetizados a partir de la circona $\mathrm{FZr}$, mientras que los más reducidos se consiguen con los pigmentos sintetizados a partir de la circona GZr. En cuanto al óxido de hierro, tampoco se detecta un efecto definido, ya que en los pigmentos sintetizados a partir de la circona GZr apenas se producen variaciones en la componente roja cuando se cambia el óxido de hierro. En el caso de la circona FZr se aprecia que el efecto del óxido de hierro depende del vidriado al que se incorpora. 


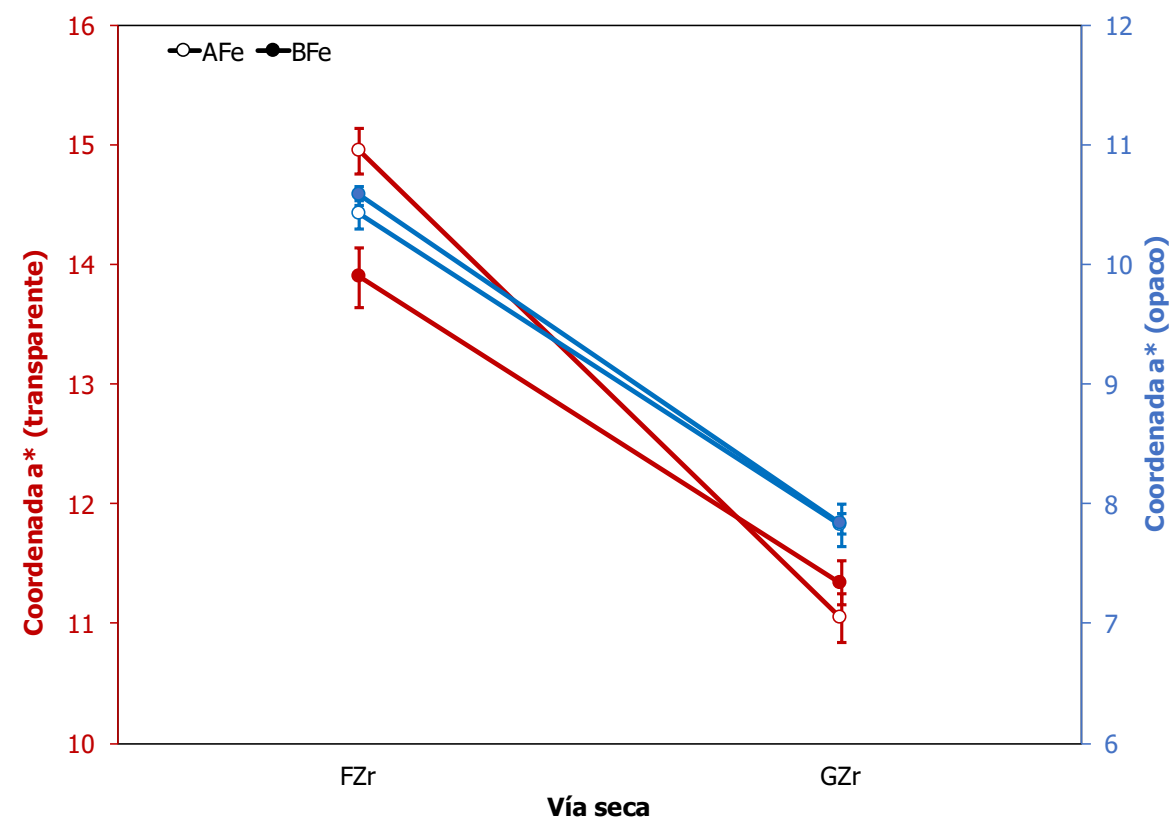

Figura 4.11 Evolución de la coordenada a*en los vidriados ensayados

- La componente amarilla (Figura 4.12) presenta un intervalo de variación muy reducido en ambos vidriados, por lo que no se puede describir una tendencia clara, a diferencia de lo que ocurre con las otras dos coordenadas, sobre todo en el vidriado opaco. Aparentemente, los pigmentos sintetizados a partir de la circona FZr tienden a generar colores ligeramente más amarillentos, sobre todo en el vidriado transparente. En esta coordenada se mantiene que el efecto del cambio en el óxido de hierro es muy escaso en los pigmentos sintetizados a partir de la GZr, y en los pigmentos sintetizados con la FZr depende del vidriado al que se incorpora. 


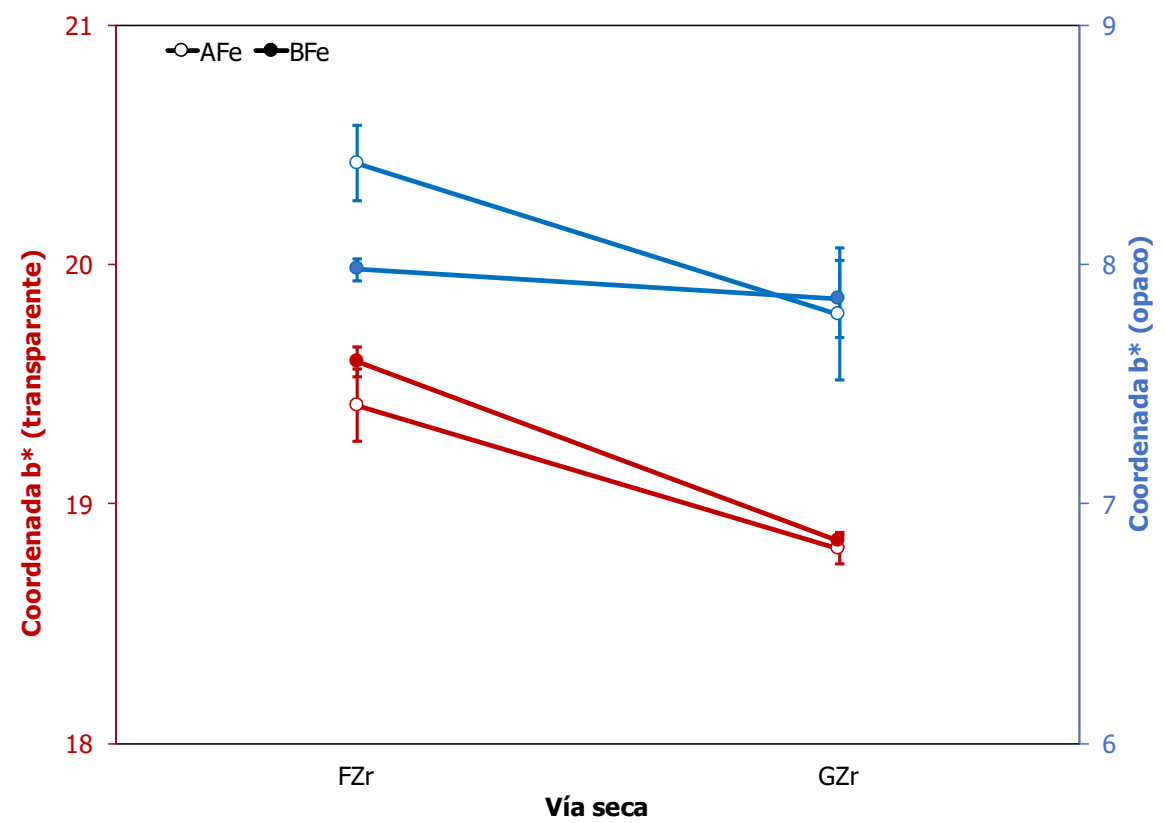

Figura 4.12 Evolución de la coordenada b*en los vidriados ensayados

Los resultados indicaban claramente que la circona FZr era la más adecuada para sintetizar el pigmento a partir de las materias primas mezcladas por vía seca, si bien en dicho caso el poder colorante dependía del tipo de óxido de hierro incorporado como cromóforo. Por el contrario, la circona GZr permitía sintetizar pigmentos con un poder colorante inferior, pero menos sensibles a las características del cromóforo.

En las Figura 4.13 y Figura 4.14 se muestran las curvas de reflectancia medidas para las probetas esmaltadas correspondientes a los pigmentos A01 a A04 para el vidriado transparente y el vidriado opaco. Las curvas muestran como el comportamiento es similar para los pigmentos A01 y A02 por un lado y para los pigmentos A03 y A04 por otro, ya estén incorporados a un vidriado transparente o un vidriado blanco, por lo que esta característica podría estar relacionado con la circona utilizada. 


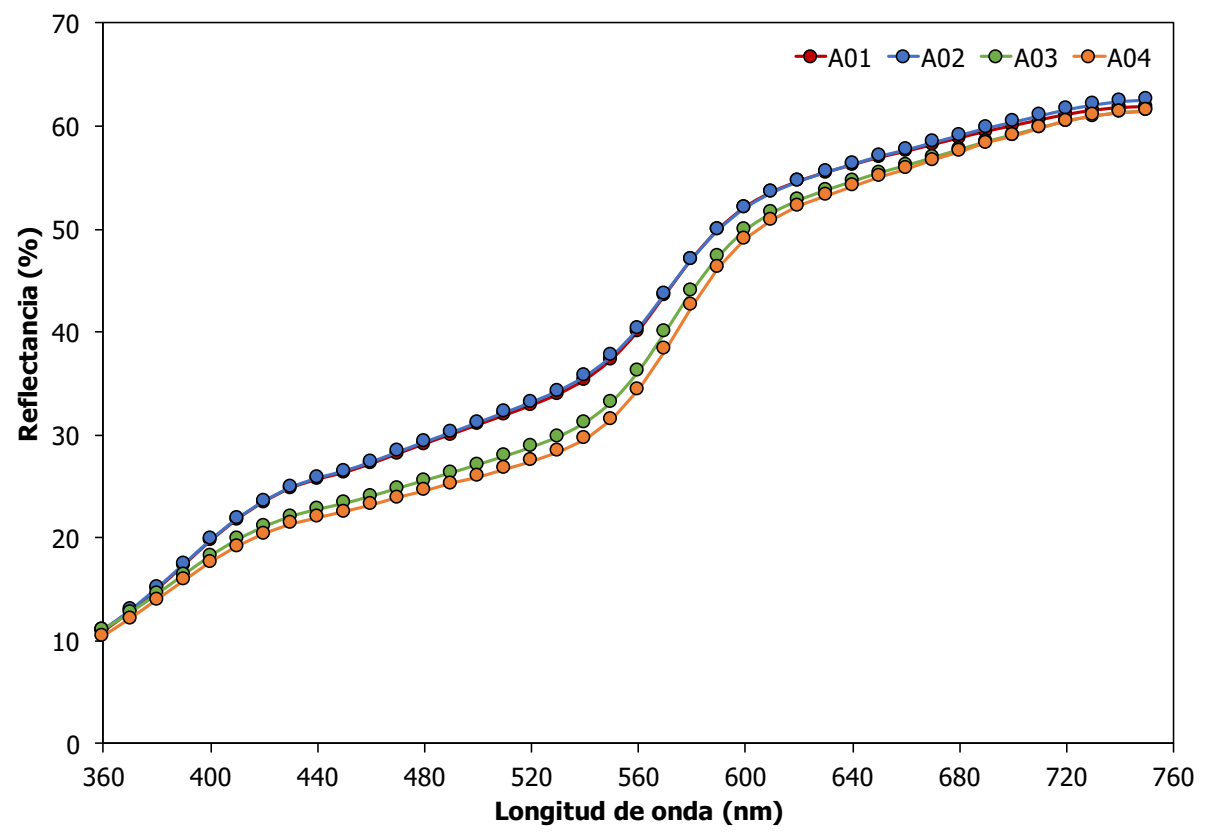

Figura 4.13 Curvas de reflectancia de los vidriados transparentes que incorporaban los pigmentos sintetizados vía seca

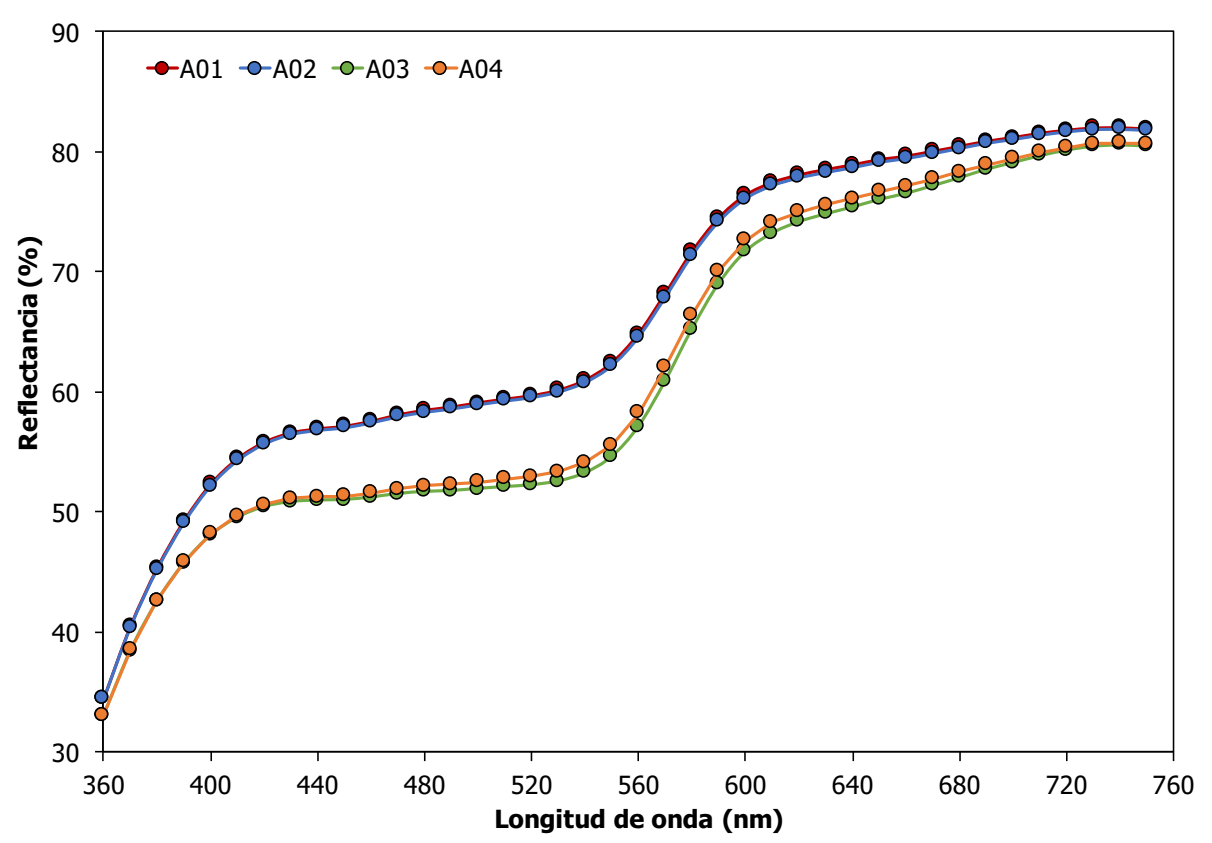

Figura 4.14 Curvas de reflectancia de los vidriados opacos que incorporaban los pigmentos sintetizados vía seca 


\subsubsection{Caracterización microestructural}

Los pigmentos sintetizados a partir de las mezclas elaboradas mediante procesos de mezclado vía húmeda y vía seca dieron lugar a resultados muy diferentes en lo que respecta a su poder colorante. Por tanto, se decidió investigar la microestructura de los pigmentos, para determinar si estas diferencias se debían únicamente al reducido avance en la reacción de síntesis del circón alcanzado en las mezclas preparadas por vía húmeda, o si existía otra causa adicional relacionada con morfología o microestructura de las partículas.

Para realizar el estudio se seleccionaron dos muestras de pigmento sin molturar, concretamente la A02 y A06, que correspondían a la mezcla N02 preparada por mezclado vía seca y vía húmeda y en los cuales se había formado un $37 \%$ y un $5 \%$ en peso de circón respectivamente. Dichos pigmentos se analizaron con el microscopio electrónico de barrido.

En el caso del pigmento A06, obtenido por mezclado vía húmeda, se detectaron las siguientes características microestructurales:

- Los aglomerados de pigmento obtenidos presentaron pequeñas partículas de óxido de circonio y sílice sin reaccionar, y de forma muy minoritaria pequeños cristales bipiramidales de circón. (Figura 4.15 y Figura 4.17). Las imágenes en electrones secundarios (Figura 4.16 y Figura 4.18) indicaron que las partículas podrían estar unidas por una fase vítrea, que sería un vidrio formado a partir de la sílice y el mineralizador.

- La proporción de grandes partículas ricas en sílice parecía elevada, lo cual parecía apuntar a que la reacción se hallaba en un estado poco avanzado, con poca sílice reaccionada para formar circón. 


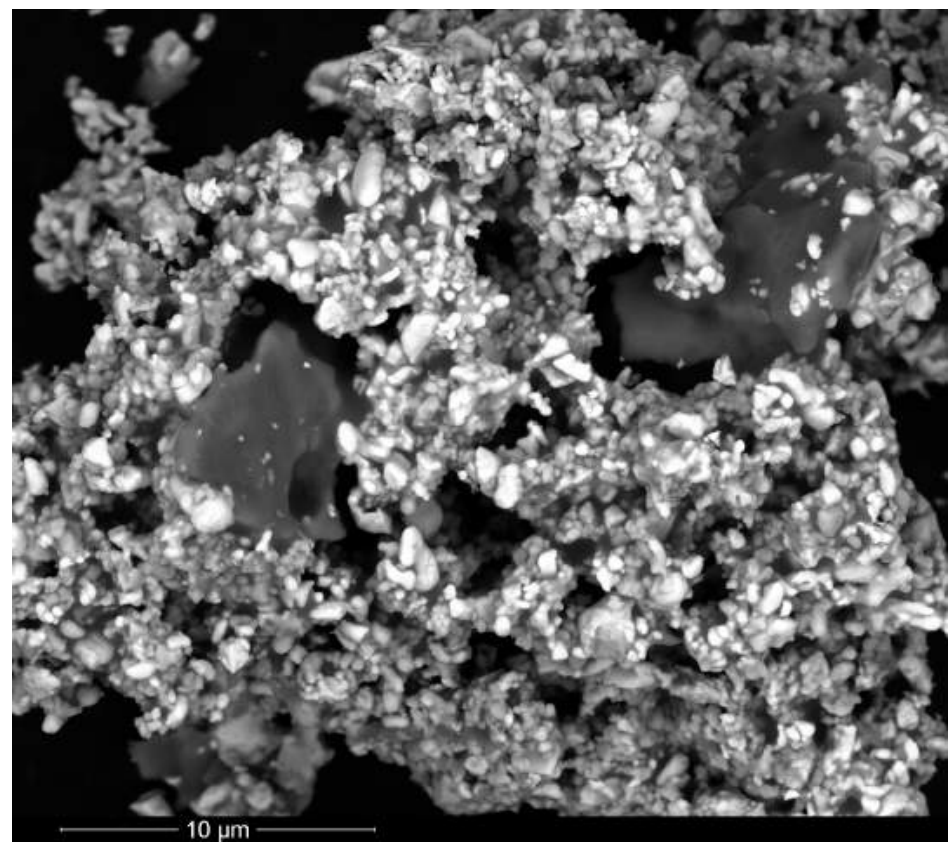

Figura 4.15 Micrografía de una partícula del pigmento A06 obtenida con la señal de electrones retrodispersados del MEB (x10000)

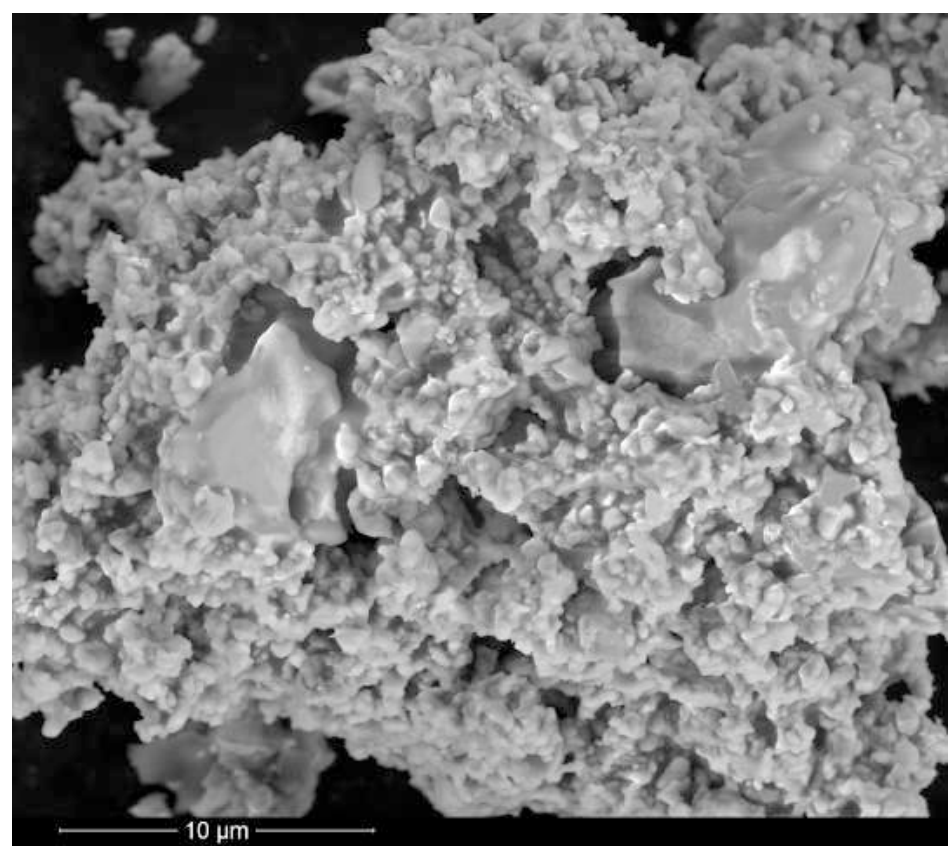

Figura 4.16 Micrografía de una partícula del pigmento A06 obtenida con la señal de electrones secundarios del MEB (x10000) 


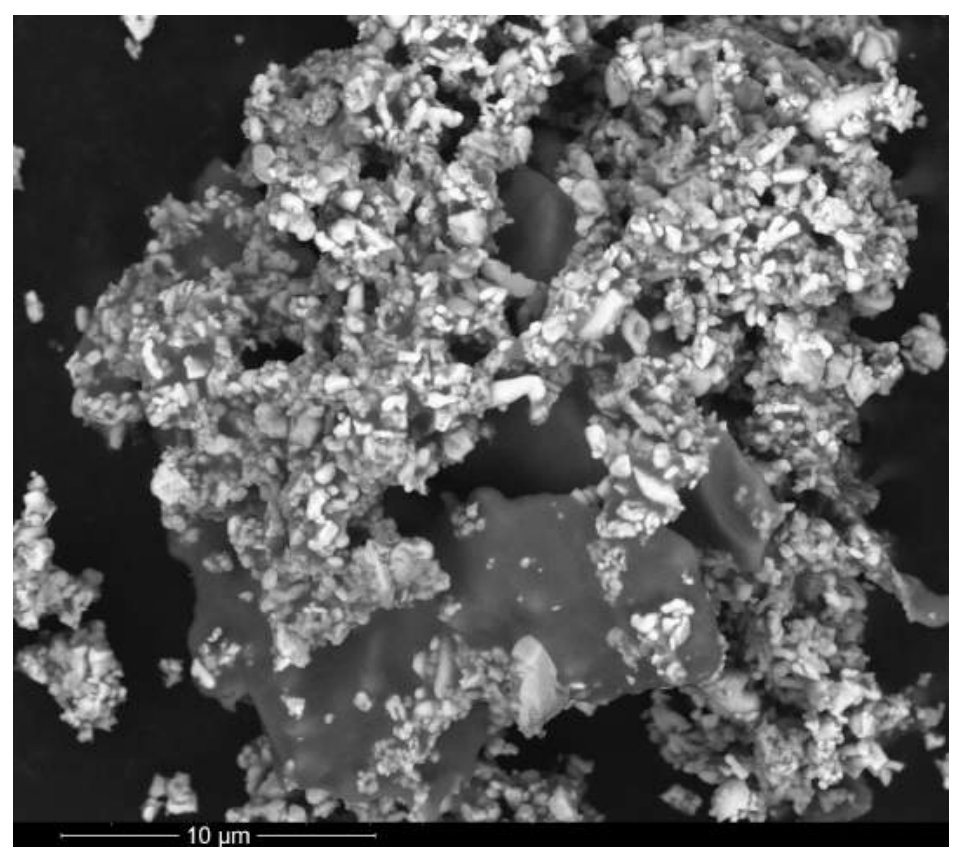

Figura 4.17 Micrografía de una partícula del pigmento A06 obtenida con la señal de electrones retrodispersados del MEB (x10000)

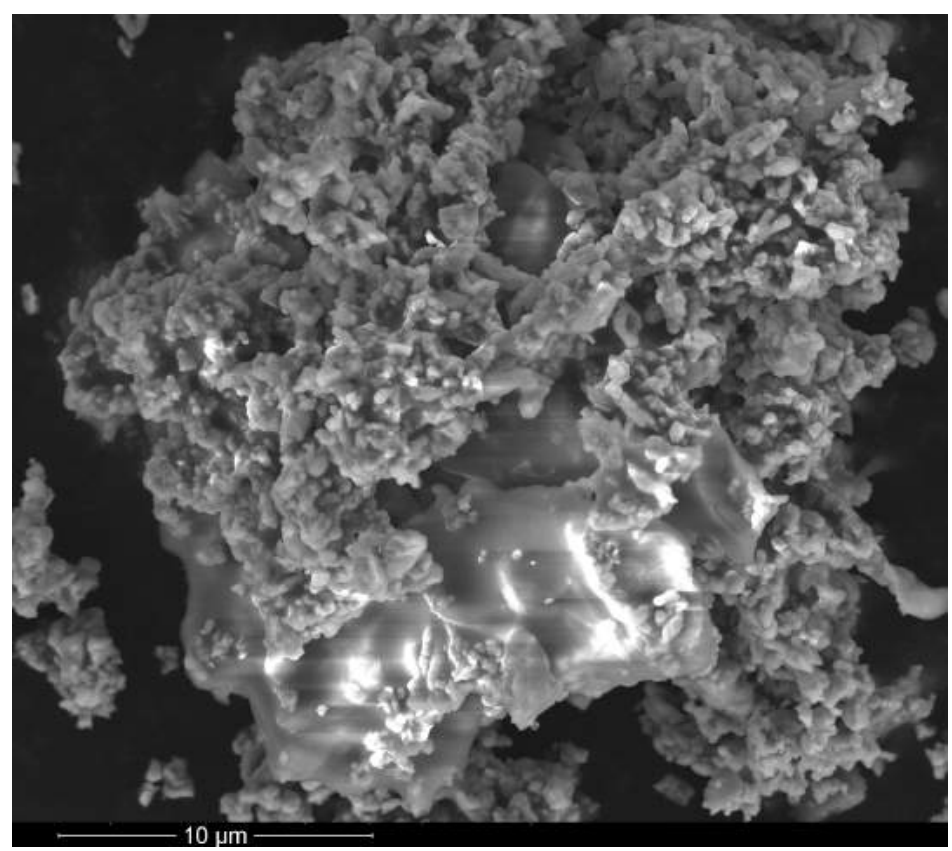

Figura 4.18 Micrografía de una partícula del pigmento A06 obtenida con la señal de electrones secundarios del MEB (x10000) 
El pigmento A02 preparado por mezclado vía seca industrialmente, presentó una microestructura bastante diferente a la mostrada anteriormente (ver las micrografías en la Figura 4.19 y la Figura 4.20), tal y como se indica a continuación:

- Se detectaron grandes cristales bipiramidales con el hábito típico del circón, junto con masas de partículas sinterizadas de aspecto redondeado, entre las cuales se apreciaban tanto partículas de óxido de circonio (las más claras), como sílice sin reaccionar.

- En la imagen obtenida con electrones secundarios parecía que las partículas estaban unidas por una fase vítrea, que podría proceder de la combinación del mineralizador con la sílice. De hecho, en la Figura 4.21, se apreció lo que parecía haber sido una gran partícula de sílice, sobre la cual estaban creciendo cristales de circón.

- En esta muestra también se detectó una etapa intermedia de la formación del pigmento coral, donde un cristal de circón en crecimiento engulle pequeñas partículas ricas en hierro (Figura 4.22). Además, en la imagen de electrones secundarios se apreciaron ciertas irregularidades superficiales en la composición del cristal de circón, que pueden indicar la posición de otras partículas de óxido de hierro atrapadas en etapas previas de su crecimiento (Figura 4.23).

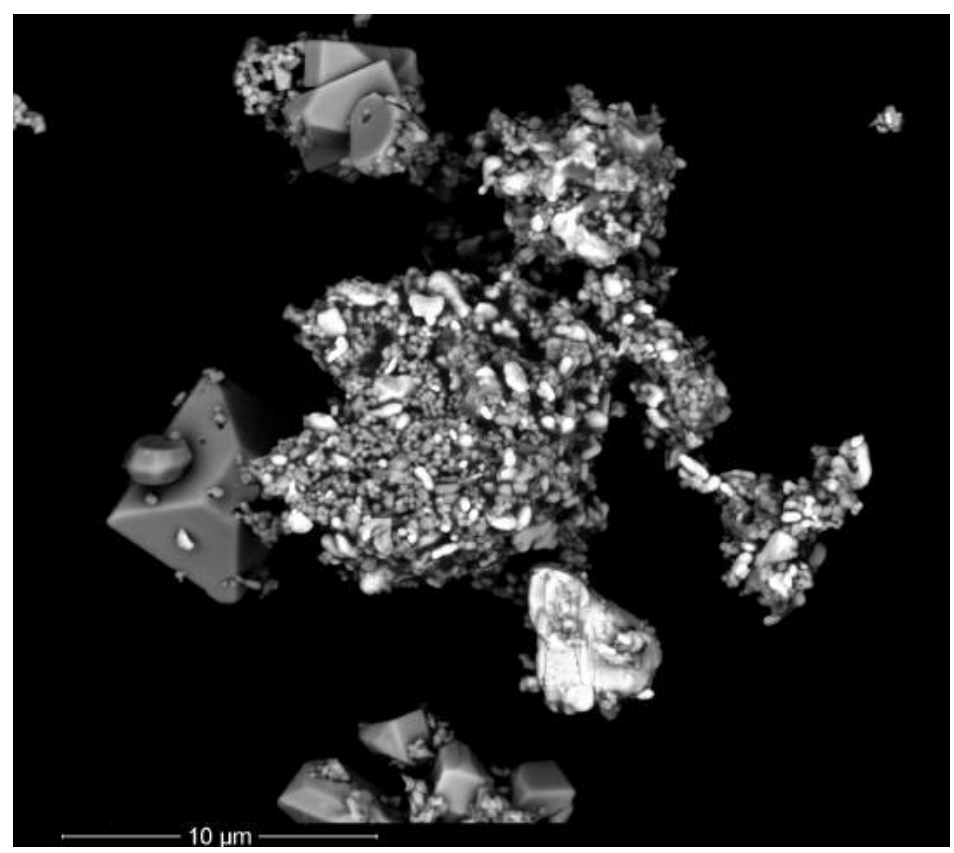

Figura 4.19 Micrografía de una partícula del pigmento A02 obtenida con la señal de electrones retrodispersados del MEB (x10000) 


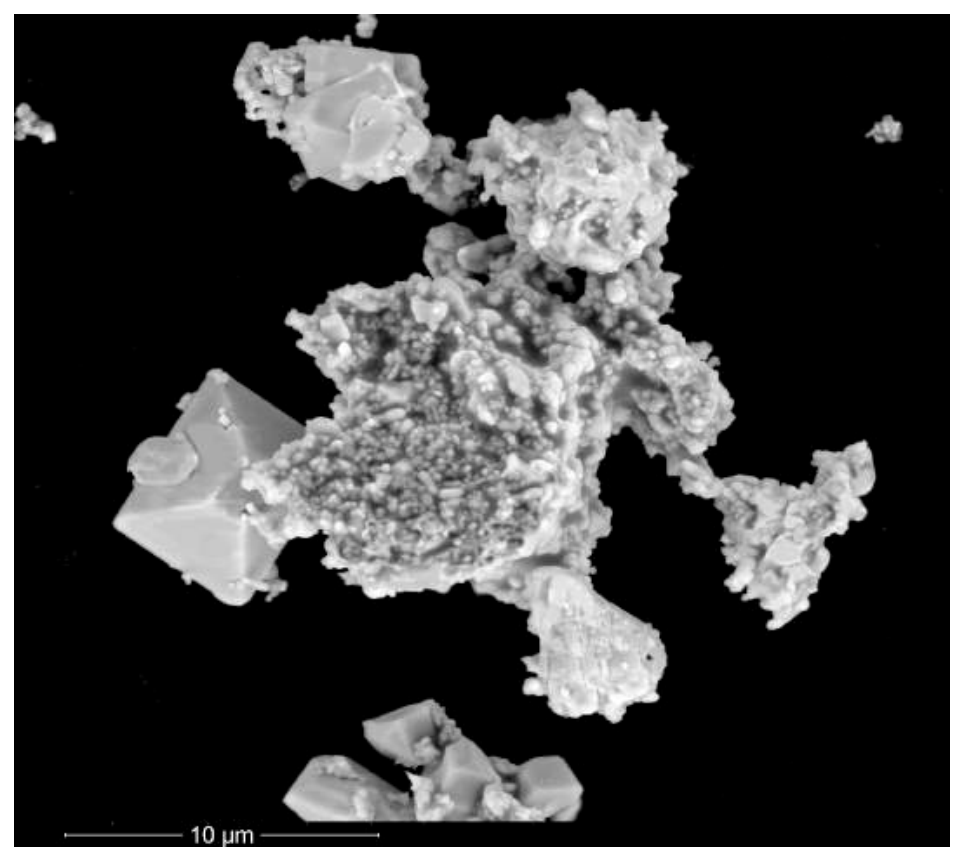

Figura 4.20 Micrografía de una partícula del pigmento A02 obtenida con la señal de electrones secundarios del MEB (x10000)

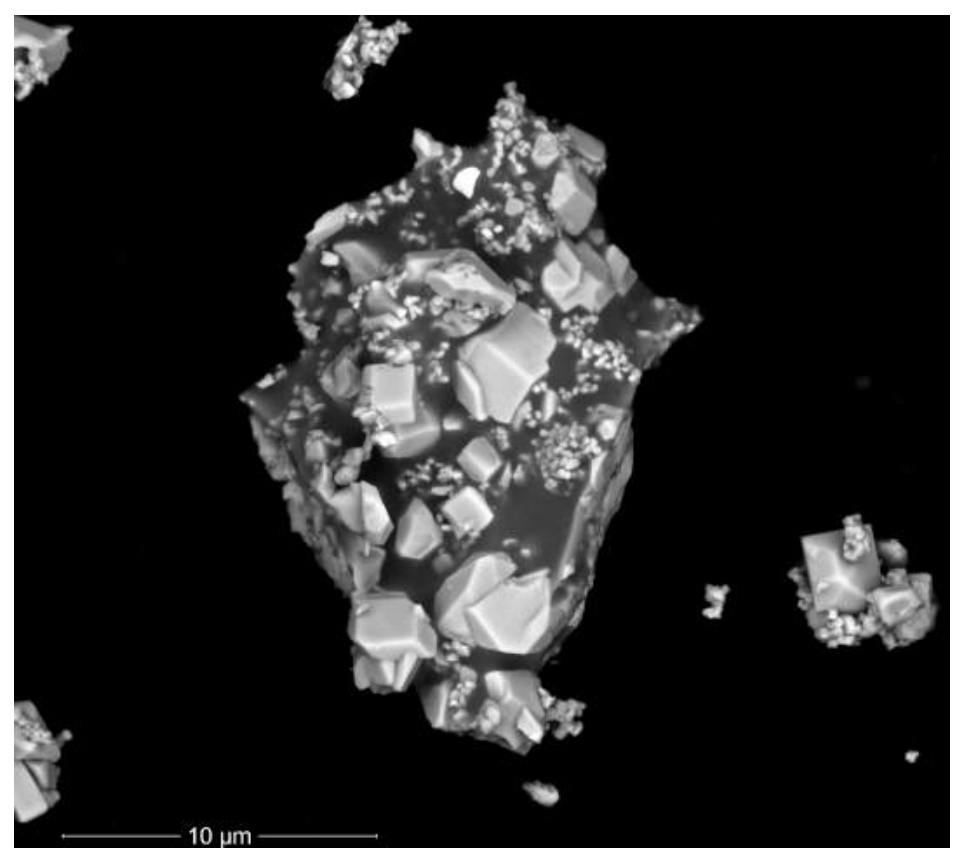

Figura 4.21 Micrografía de una partícula del pigmento A02 obtenida con la señal de electrones retrodispersados del MEB (x10000) 


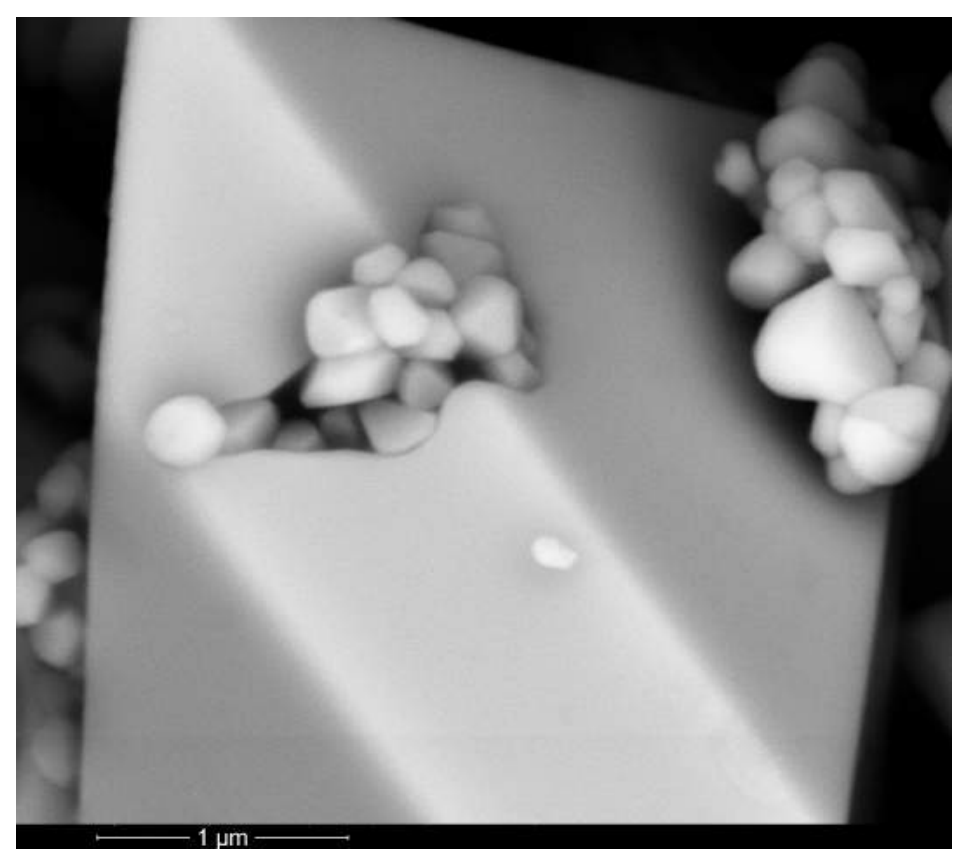

Figura 4.22 Micrografía de un cristal de circón del pigmento A02 obtenida con la señal de electrones retrodispersados del MEB (x80000)

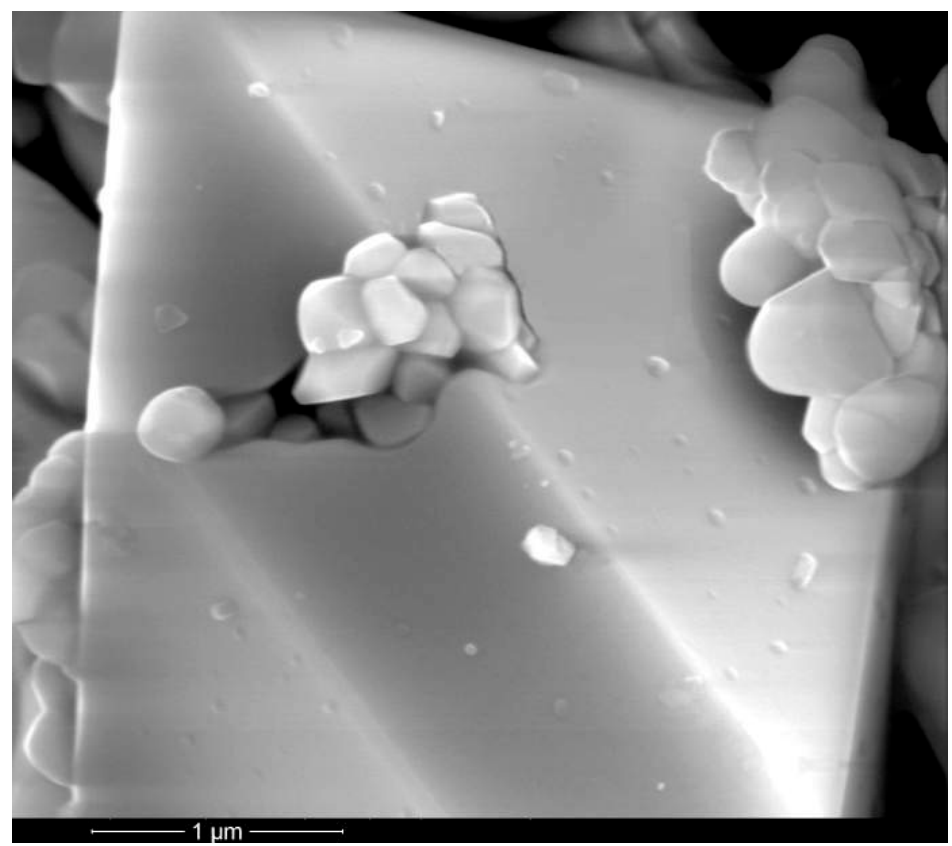

Figura 4.23 Micrografía de un cristal de circón del pigmento A02 obtenida con la señal de electrones secundarios del MEB (x80000) 
El análisis microestructural apuntaba a que las mezclas preparadas vía seca reaccionaban según un mecanismo diferente. Dado que la característica específica del pigmento A02 era la presencia de cristales de circón bien formados, que son las cápsulas que protegen al cromóforo, y dichos cristales suelen ser el resultado de un crecimiento a partir de una fase gaseosa, y no de la desvitrificación de un líquido, cabía plantear como hipótesis de partida que las composiciones mezcladas vía seca eran más favorables a que la reacción de síntesis del circón tuviese lugar vía intermedios gaseosos. Por el contrario, la reacción en las mezclas preparadas vía húmeda tendría lugar en presencia de una fase líquida.

Combinando la hipótesis planteada con la distribución espacial de los reactantes teóricamente más favorable para obtener el pigmento (Figura 1.6) se podría deducir que las mezclas preparadas vía seca industrialmente tendían a separar el cuarzo del mineralizador, impidiendo la formación de una fase líquida viscosa, y forzando a que la reacción transcurriese mediante intermedios gaseosos. Por el contrario, la mayor homogeneidad que cabía esperar en un mezclado vía húmeda con todas las materias primas presentes, permitiría que la sílice se combinase con el mineralizador para generar una fase vítrea viscosa, de modo que la reacción sería más lenta, no se formarían cristales de circón tan definidos y, además, se dificultaría el encapsulado del hematites, ya que el cristal no podría crecer alrededor de las partículas de hematites con tanta facilidad (lo cual es coherente con el poder colorante prácticamente nulo que poseían los pigmentos sintetizados a partir de las mezclas preparadas vía húmeda). 


\subsection{Propuesta de un índice de mezclado en mezclas de materias primas}

Tal y como se comentó en el apartado de introducción, el pigmento coral de hierro-circón, de tipo encapsulado, es complejo de sintetizar a escala industrial. Por ello es importante conocer cómo se encuentran distribuidas espacialmente las materias primas en la mezcla que se calcina, ya que en el caso de que no se produjera un buen encapsulamiento de las partículas de hematites, podría sintetizarse el circón, pero podría ocurrir que el producto no presentara poder colorante alguno. Por tanto, se hace necesario definir un índice de mezclado que describa el grado de homogeneidad del sistema, el cual posteriormente se pueda correlacionar con las coordenadas cromáticas del pigmento final.

En consecuencia, en este apartado se propone un índice de mezcla basado en determinados parámetros extraídos a partir de la transformada de Fourier de imágenes reales de la mezcla de materias primas [71].

Para poner a punto el método de medida y la aplicación de la transformada de Fourier a las imágenes reales de las muestras, resultaba imprescindible disponer de imágenes de las mezclas con muy buena resolución. Por este motivo, se decidió utilizar un microscopio electrónico de barrido (MEB), ya que esta técnica incorpora una buena definición de los contornos de las partículas (gracias a su elevada profundidad de campo), y permite diferenciar partículas de diferentes componentes debido al contraste de composición de la señal de electrones retrodispersados entre las partículas (la circona y la sílice principalmente) que se reflejan en diferentes niveles de gris. De esta forma, fue posible obtener imágenes con buena definición, sin necesidad de que las muestras presentaran una superficie perfectamente plana, que es uno de los problemas que presenta la microscopía óptica.

Las micrografías realizadas en el MEB fueron analizadas posteriormente con un software de análisis de imagen (MicroImage) y un software matemático (Mathcad) que permitieron realizar la transformada de Fourier, concretamente mediante el algoritmo Fast Fourier Transform (FFT).

A continuación, se muestra el diagrama de flujo seguido para desarrollar el índice de mezcla. 


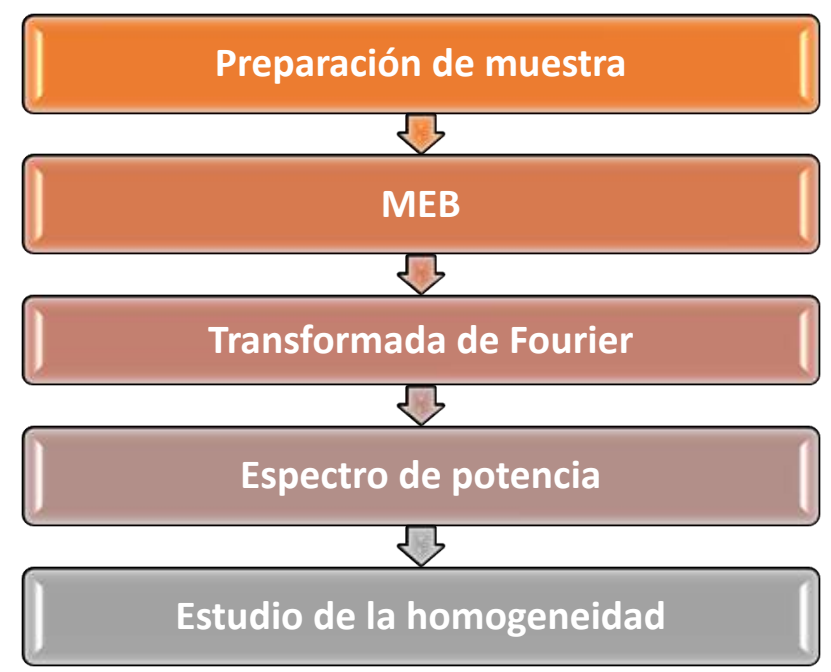

Figura 4.24 Metodología propuesta para el estudio del índice de mezcla por TFD

Para evaluar el índice de mezcla, se seleccionaron seis de las composiciones preparadas en el apartado 4.1, cuatro de ellas procedentes del mezclado vía seca industrial (A01, A02, A03 y A04) y dos de ellas mezcladas vía húmeda (A06 y A08) y se prepararon tal y como se indica en el apartado 3.5.5. Para extraer un índice de mezcla se analizaron varias aproximaciones a partir de la matriz de datos que supone la transformada de Fourier de las fotografías obtenidas por MEB.

De esta forma, sería posible evaluar diferentes variables que podrían afectar a la homogeneidad de la muestra:

- $\quad$ El método de mezclado utilizado, esto es, vía húmeda o vía seca.

- Las características de la circona utilizada, ya que la circona FZr presenta una distribución de tamaño de partícula mucho más fina que la circona GZr.

- Los óxidos de hierro empleados en las mezclas con superficie específica y distribución de tamaño de partícula distintos. 


\subsubsection{Estudio del grado de mezcla a partir de las micrografías obtenidas por el microscopio electrónico de barrido}

A partir de las probetas preparadas de las seis mezclas objeto de análisis, se realizaron micrografías en superficie de cada una de las probetas utilizando el MEB. Dado la heterogeneidad de las mezclas, se decidió analizar seis imágenes de cada muestra.

La comparación visual de estas imágenes indicaba que las seis muestras poseían un nivel de mezclado distinto, pero no permitía cuantificar si esas diferencias eran importantes o no.

Realizando un estudio cualitativo, en las micrografías se pudieron observar diferentes tipos de partículas que diferían tanto en el tono de gris como en la morfología y tamaño. En un primer paso resultó importante identificar cada tipo de partícula para poder correlacionarlas en las diferentes mezclas. Por tanto, analizando visualmente las micrografías y con ayuda del microanálisis, se pudo identificar los siguientes tipos de partículas:

- Partículas oscuras, gruesas y de forma angulosa que correspondían a la materia prima cuarzo.

- Partículas pequeñas de color blanco y brillante que correspondían a la circona utilizada para realizar las mezclas.

- Partículas muy pequeñas y muy numerosas distribuidas por toda la matriz de color claro que se encontraban aglomeradas y que correspondían a óxido de hierro.

Visualmente, se observaron diferencias significativas en función de la circona utilizada. Las composiciones que contenían la circona gruesa presentaban un aspecto más heterogéneo, mientras que aquellas composiciones en las que se había incorporado la circona fina presentaban una apariencia más homogénea.

En la Figura 4.25 se muestra una zona de la superficie de las probetas A01 y A03 donde se observan estas diferencias de forma evidente. En estas composiciones se utilizó el mismo óxido de hierro (BFe) y el mismo método de mezclado (vía seca), pero diferente granulometría de circona (GZr y FZr). 

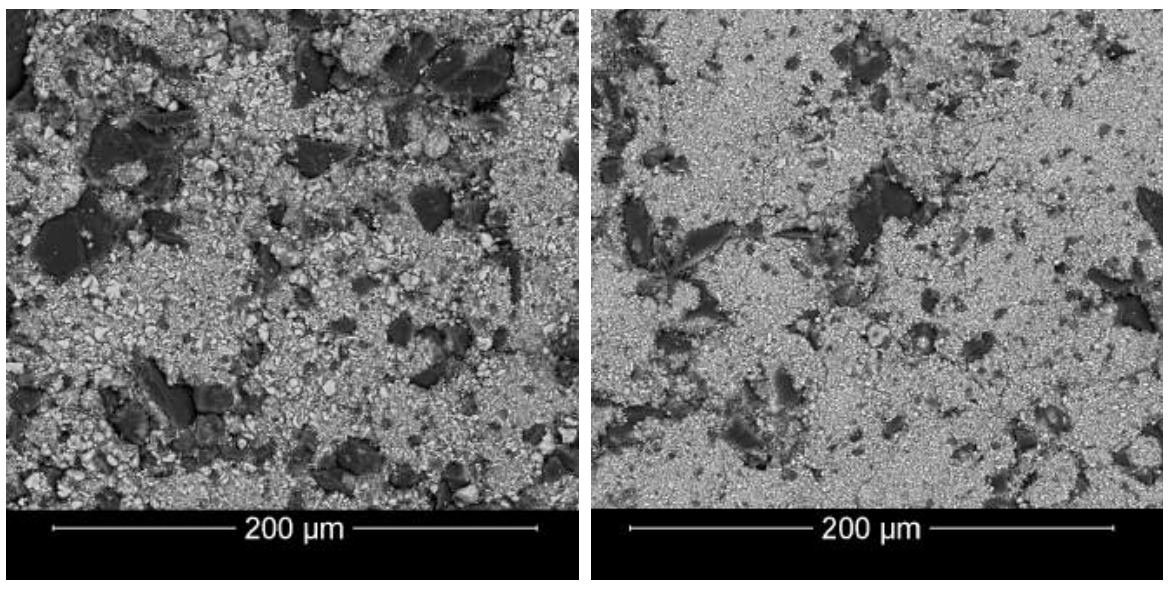

Figura 4.25 Micrografías de la superficie de las probetas: A01 (GZr-vía seca-BFe) y A03 (FZr-vía seca-BFe)

De la misma forma también se perciben diferencias cuando se comparan muestras con la misma composición, pero diferente método de mezclado, es decir, mezclado vía seca y vía húmeda (A02 y A05), aunque cabe destacar que estas diferencias son más importantes cuando se utiliza la circona más gruesa (GZr).

En la Figura 4.26, se presentan las micrografías obtenidas con el MEB de las muestras que tienen en su composición la circona GZr más gruesa y óxido de hierro AFe, donde se observa una mayor heterogeneidad de la mezcla A02 preparada mediante mezclado vía seca.
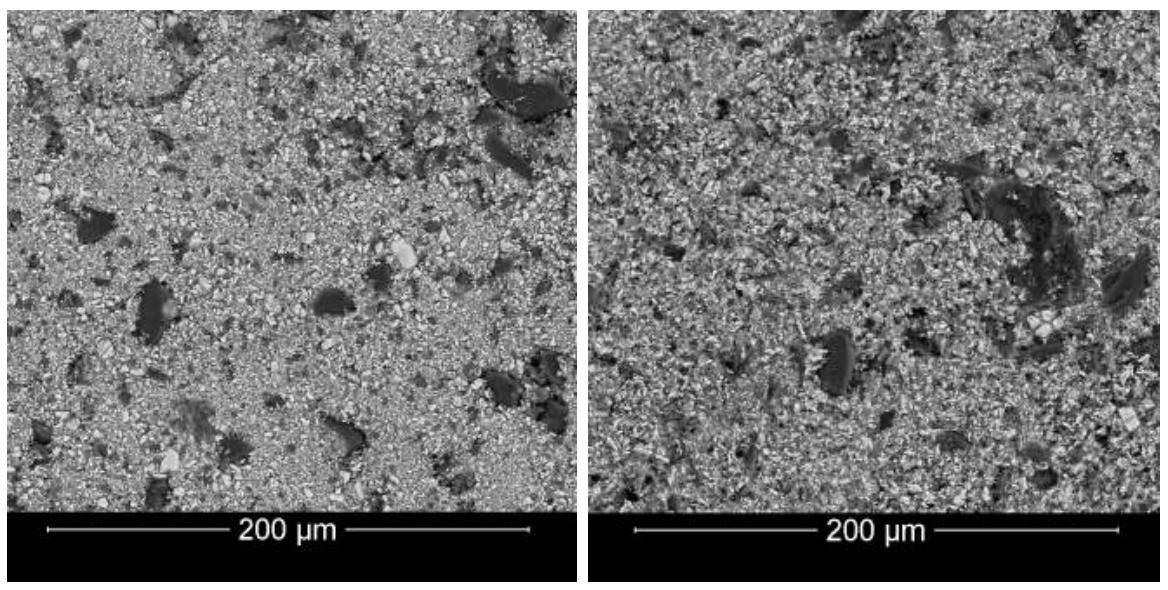

Figura 4.26 Micrografías de la superficie de las probetas: A02 (GZr-vía seca-AFe) y A05 (GZr-vía húmeda-AFe) 
Este efecto, aunque más atenuado, también se observa en la Figura 4.27 donde se han comparado las imágenes de las muestras A04 y A08, preparadas a partir de circona FZr con un tamaño de partícula menor, óxido de hierro AFe y diferente proceso de mezclado.
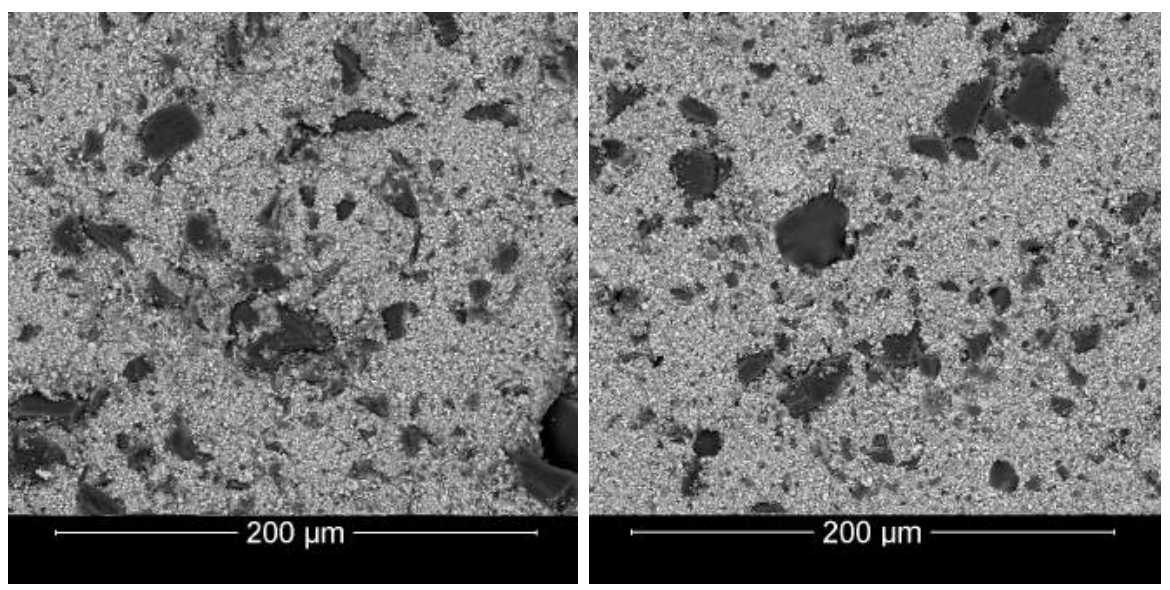

Figura 4.27 Micrografías de la superficie de las probetas: A04 (FZr-vía seca-AFe) y A08 (FZr-vía húmeda-AFe)

Tal y como se ha comentado anteriormente, se realizaron seis micrografías de cada una de las probetas en superficie para intentar reducir en lo posible el efecto de la heterogeneidad de las mezclas. Dos de las micrografías obtenidas para cada mezcla se muestran en las Figura 4.28 a Figura 4.33 .
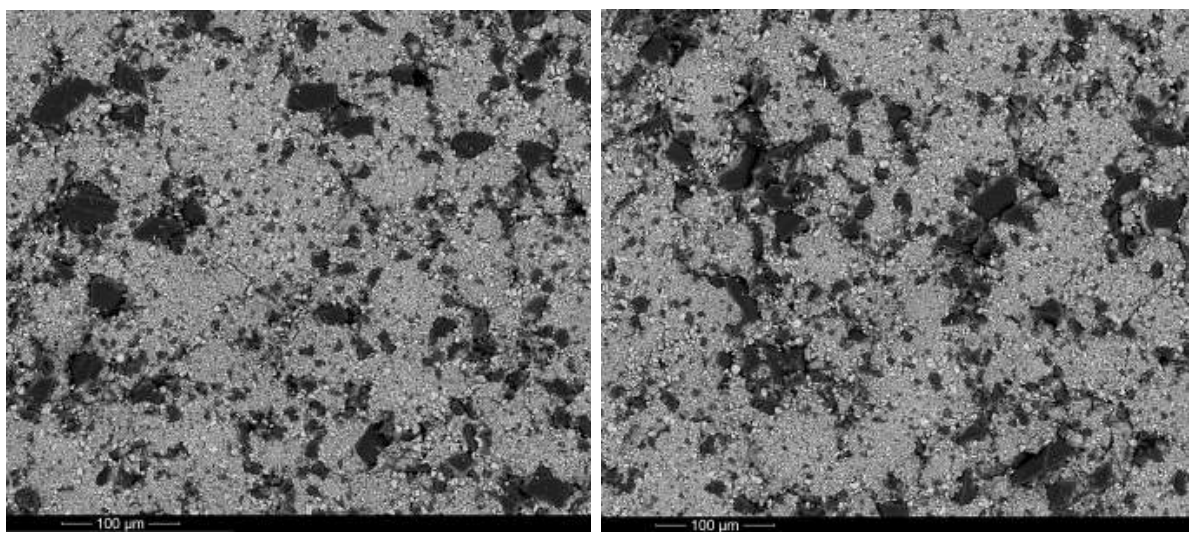

Figura 4.28 Micrografías de la probeta A01 (600x) 

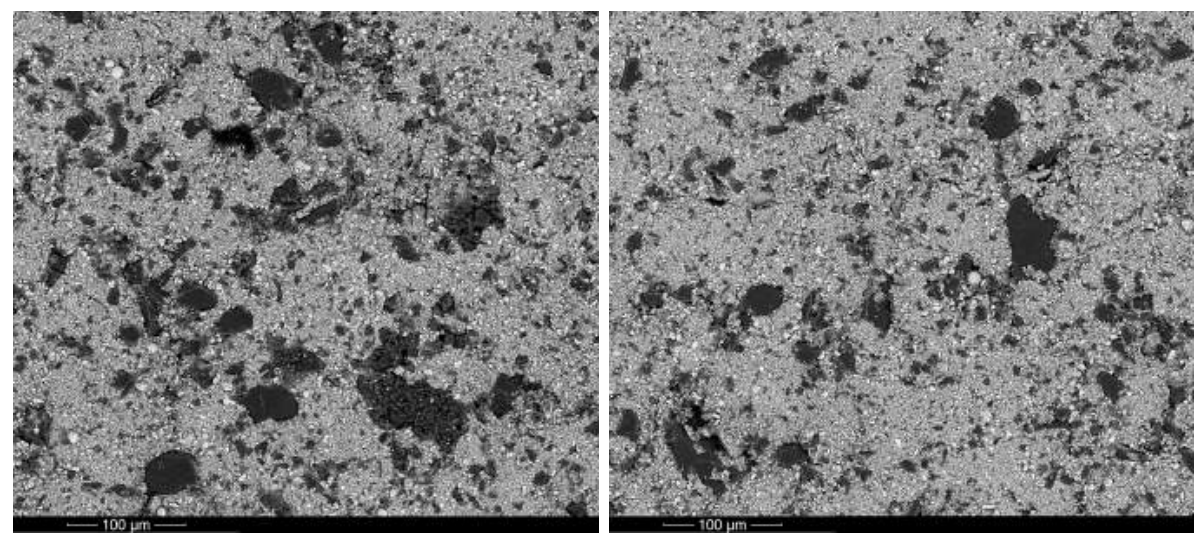

Figura 4.29 Micrografías de la probeta A02 (600x)
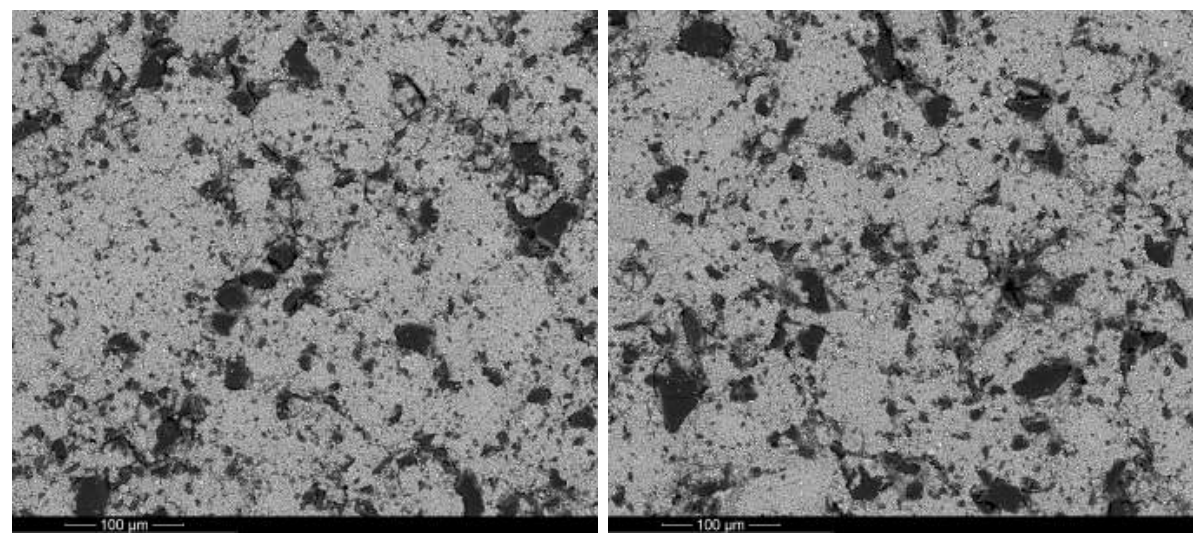

Figura 4.30 Micrografías de la probeta A03 (600x)
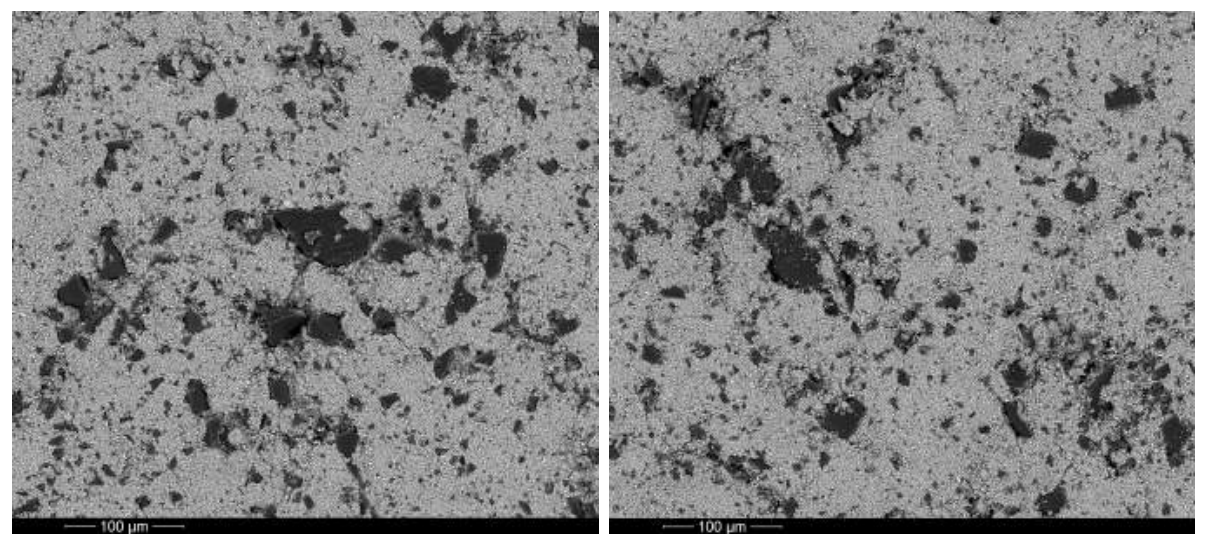

Figura 4.31 Micrografías de la probeta A04 (600x) 

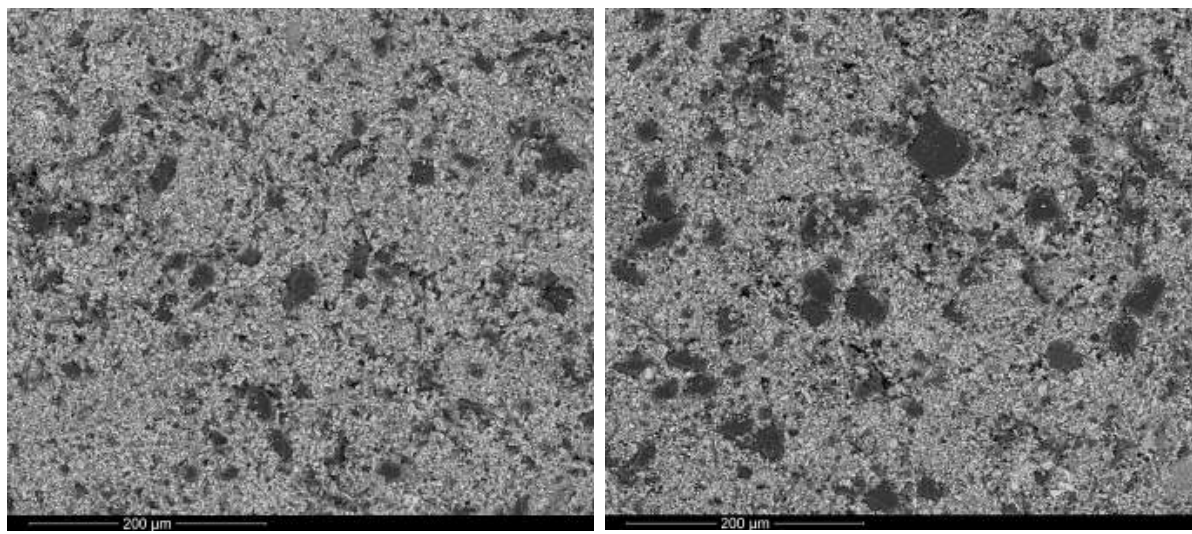

Figura 4.32 Micrografías de la probeta A06 (600x)
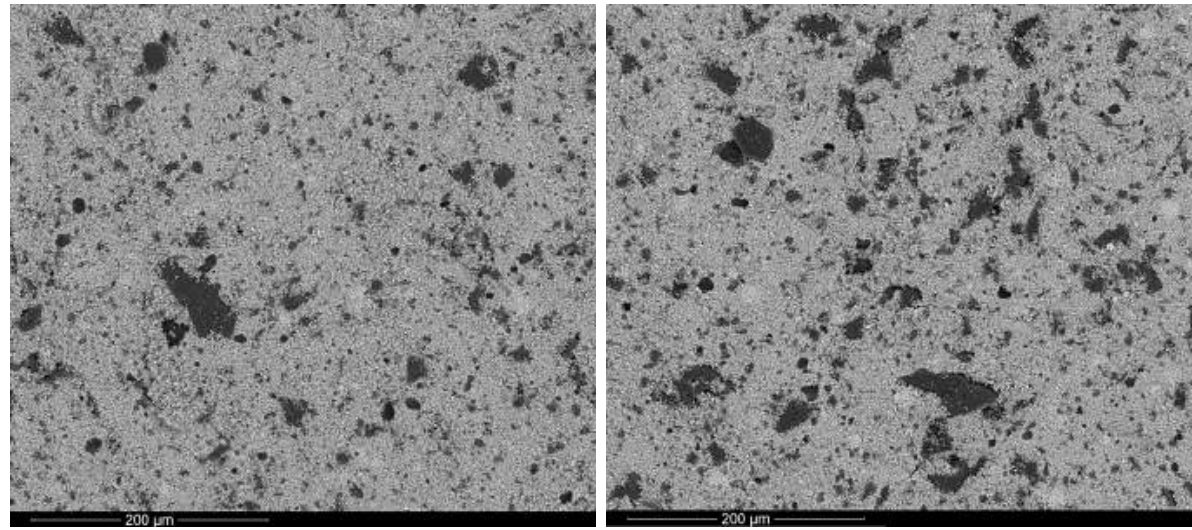

Figura 4.33 Micrografías de la probeta A08 (600x)

\subsubsection{Obtención del espectro de potencia de la TFD}

Sobre las imágenes obtenidas en el microscopio de cada una de las mezclas, se aplicó la transformada de Fourier utilizando el software de análisis de imagen MicroImage, obteniendo de esta forma el espectro de potencia de la TFD.

Los espectros de potencia de las imágenes de MEB permiten clarificar las diferencias observadas visualmente. Cada uno de los espectros de potencia posee una representación gráfica en forma de estrella, pero en aquellas muestras más heterogéneas, la estrella abarca un área mayor, es decir, tiene mayor dispersión de puntos alrededor del centro. Sin embargo, aquellas mezclas más homogéneas tienen una mayor periodicidad, por tanto, su transformada necesita menos puntos significativos, con lo que el área observada es menor. De hecho, los espectros de potencia con una estrella menor coinciden con las mezclas A06 y A08 que corresponderían a las composiciones que se han mezclado en húmedo y que en principio deberían ser más homogéneas. 
Realizando la TFD de dos zonas de la superficie de la muestra A01 (Figura 4.34 y Figura 4.35), se aprecia la diferencia entre un área más homogénea, en la que se observa mayoritariamente circona, óxido de hierro y algunas partículas de cuarzo de pequeño tamaño y su espectro de potencia, y otra área más heterogénea, donde se observan partículas de cuarzo más gruesas. La micrografía con una composición más homogénea tiene un espectro de potencia con una estrella más pequeña. Sin embargo, el espectro de potencia correspondiente a la micrografía con las partículas de cuarzo grandes tiene una estrella mayor, más blanca en el centro y con una nube de puntos más dispersos.

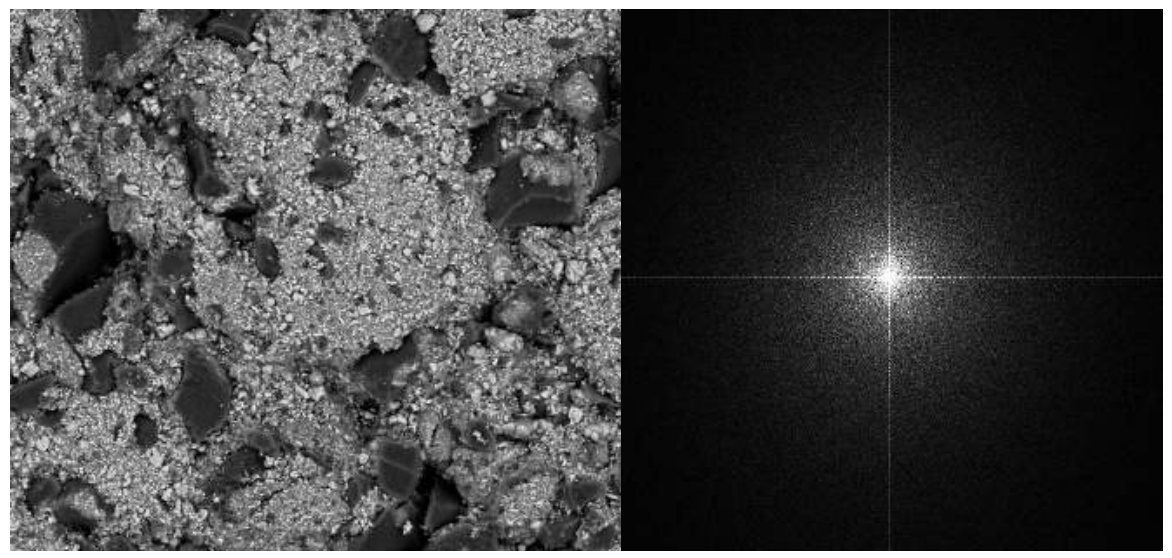

Figura 4.34 TFD de una zona de una de las micrografías de la muestra A01 más homogénea

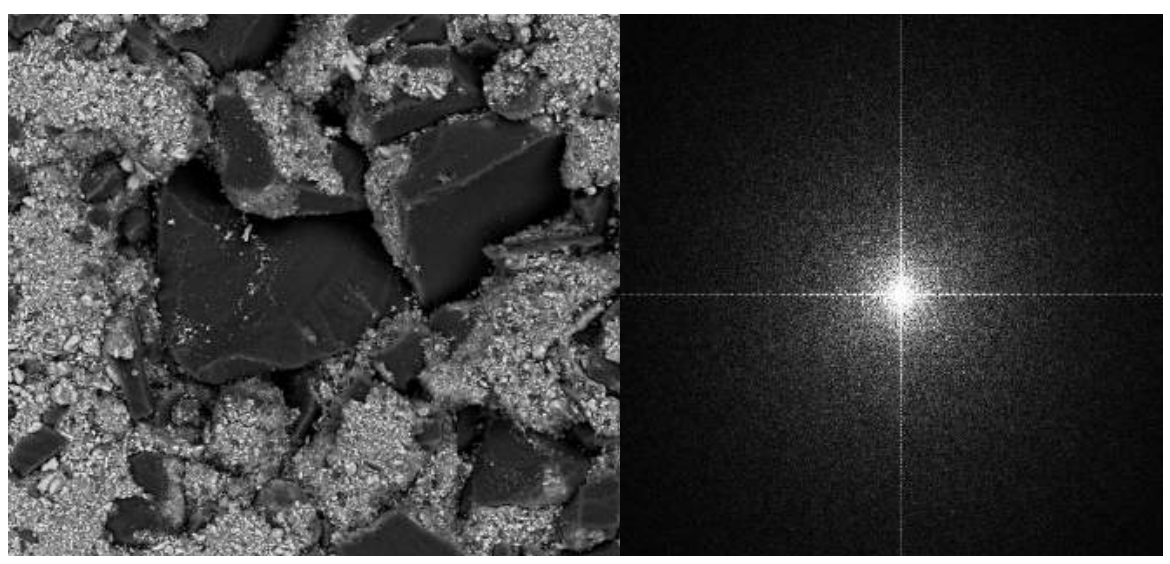

Figura 4.35 TFD de una zona de una de las micrografías de la muestra A01 más heterogénea

A continuación, se comparan visualmente los espectros de potencia de la transformada de Fourier de una micrografía realizada en el MEB de cada una de las mezclas. 
En la Figura 4.36 se comparan los espectros de potencia de las muestras A02 y A06 que tendrían en su composición la circona más gruesa y el óxido de hierro AFe, diferenciándose únicamente por el proceso de mezclado. Se observa como el mezclado vía húmeda proporciona un espectro de potencia con los píxeles más concentrados en el centro de la estrella, mientras que el mezclado vía seca proporciona una nube de puntos mucho más amplia y dispersa.
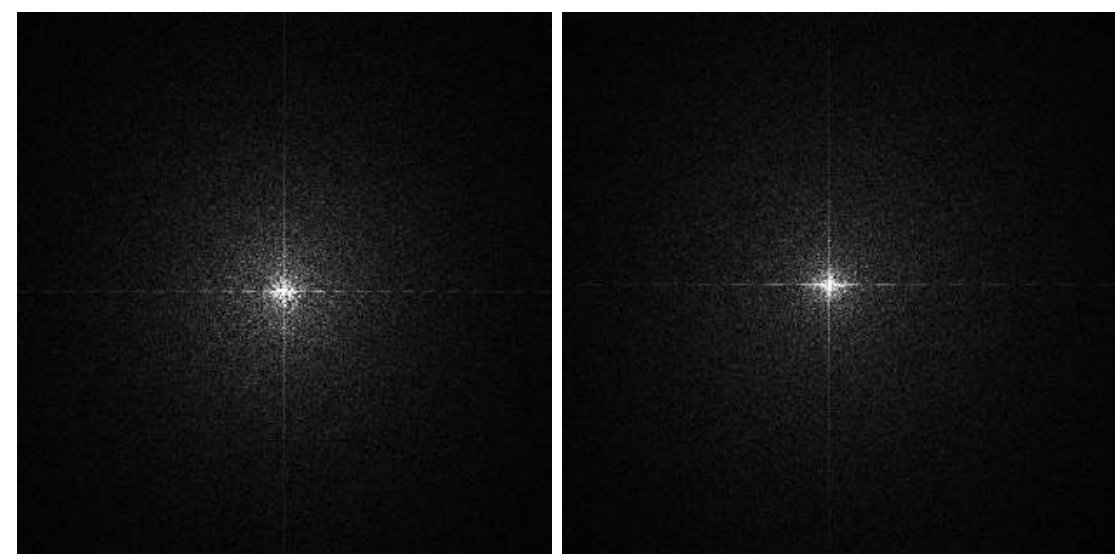

Figura 4.36 Espectros de potencia de la micrografía de las muestras: A02 (GZr-vía seca-AFe) vs A06 (GZr-vía húmeda-AFe)

En la Figura 4.37, se comparan las muestras M4 y M6 con la circona más fina (FZr) y el óxido de hierro AFe, teniendo como única variable el proceso de mezclado. En este caso, al tratarse de una circona muy fina, visualmente se aprecian menos diferencias en el espectro de potencia de las mezclas.
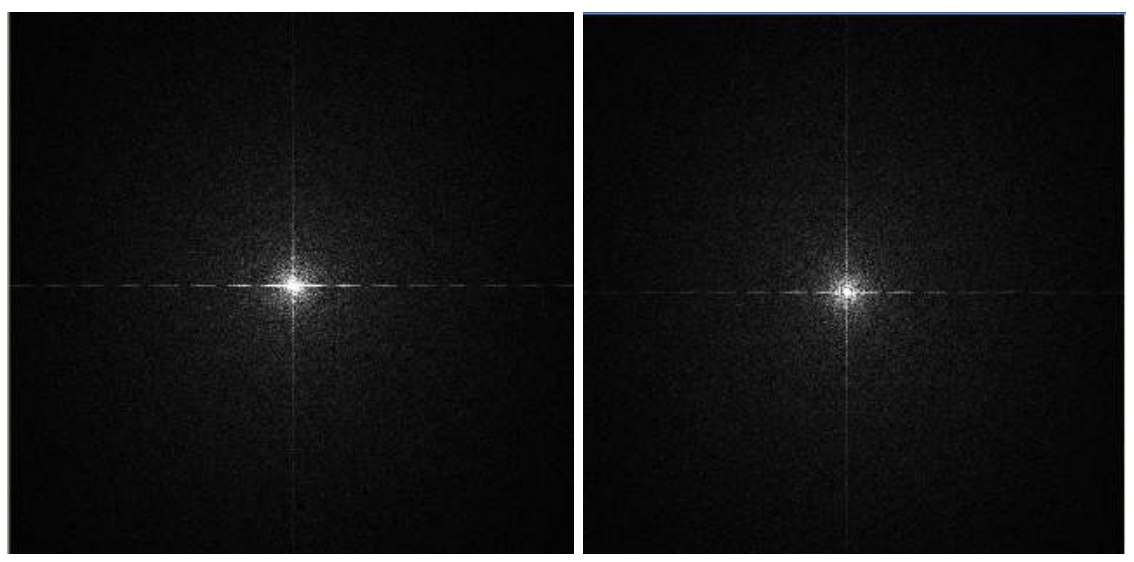

Figura 4.37 Espectros de potencia de la micrografía de las muestras: A04 (FZr-vía seca-AFe) vs A08 (FZr-vía húmeda-AFe) 
Comparando los espectros de potencia de las muestras A01 y A03 (Figura 4.38), mezcladas por vía seca y utilizando el óxido de hierro BFe, se observa que el espectro de potencia de la muestra con una circona de mayor tamaño (GZr) proporciona un espectro de potencia con los píxeles más dispersos, mientras que la muestra con la circona más fina ( $F Z r)$ muestra una mayor concentración de píxeles en el centro de la estrella y que, además, es más pequeña.
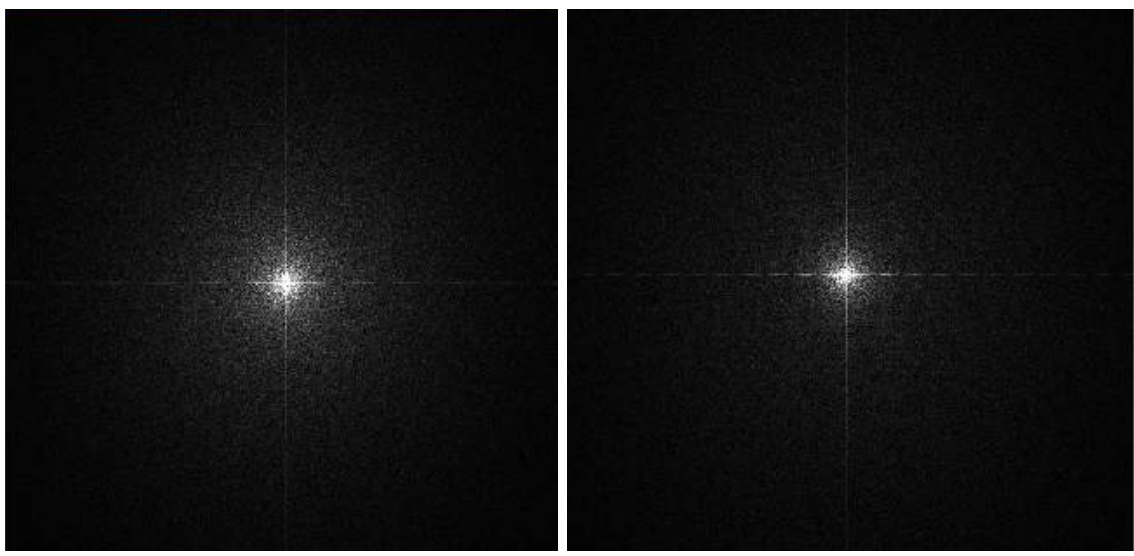

Figura 4.38 Espectros de potencia de la micrografía de las muestras: A01 (GZr-vía seca-BFe) vs A03 (FZr-vía seca-BFe)

En último lugar, en la Figura 4.39 se comparan los espectros de potencia correspondientes a las muestras A06 y A08 donde se han mezclado los componentes en ambos casos mediante vía húmeda. Sin embargo, la circona utilizada en la primera imagen es más gruesa (A06) y, por tanto, el espectro de potencia resulta más disperso.
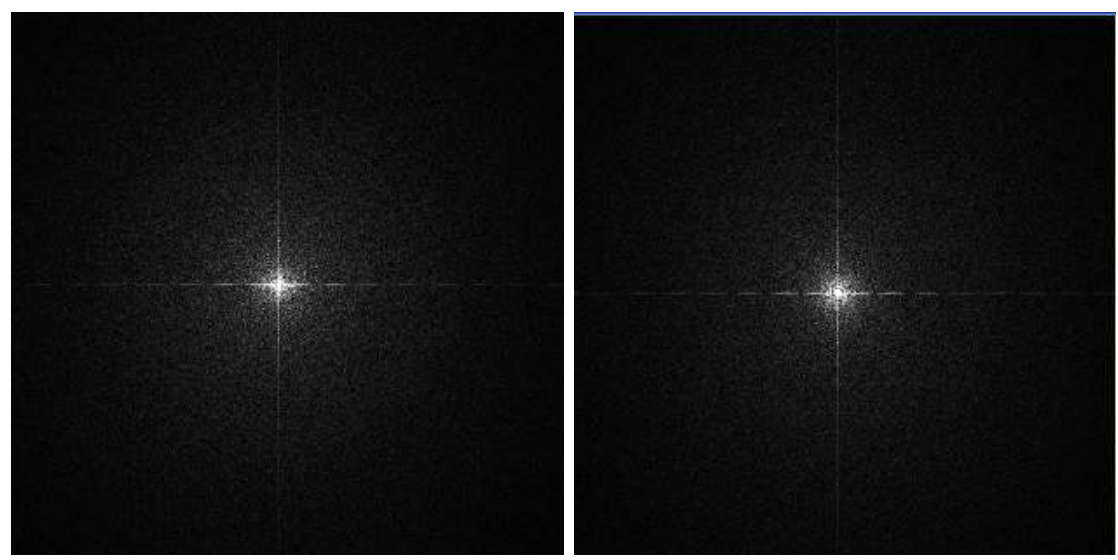

Figura 4.39 Espectros de potencia de la micrografía de las muestras: A06 (GZr-vía húmeda-AFe) vs A08 (FZr-vía húmeda-AFe) 
De esta forma, se comprueba que, con un proceso de mezclado más eficaz, el espectro de potencia de la TDF presenta una estrella menor, con una menor dispersión de puntos.

\subsubsection{Estudio del grado de mezcla a partir de los valores del espectro de potencia de la TFD}

Con la finalidad de realizar un análisis cuantitativo de los espectros de potencia y poder establecer un índice de mezcla, se decidió tratar directamente la matriz de datos correspondiente a la transformada de Fourier de las imágenes. El software MathCad permite tratar las micrografías obtenidas en el microscopio como una matriz de datos y aplicar un tratamiento matemático a dicho conjunto de datos.

Tal y como se comentó en la introducción la transformada de Fourier de cada imagen obtenida en el MEB, se transforma en una matriz. Cada elemento de la matriz contiene información relativa a los valores de intensidad o de gris, e información sobre la posición de los píxeles en la imagen.

A partir de la matriz de datos de la transformada de Fourier, se definió el componente máximo del espectro de potencia como $M_{1}$ y el término de frecuencia cero como $M_{0}$ [71]. De esta forma se calculó la razón $M_{1} / M_{0}$ para cada uno de los espectros de potencia de las micrografías realizadas en el MEB.

En la Tabla 4.5, se muestran los promedios de $\mathrm{M}_{1} / \mathrm{M}_{0}(X)$ así como la desviación estándar $(\sigma)$ en las transformadas de Fourier de las seis micrografías realizadas con el microscopio electrónico de barrido para cada mezcla. Para comprobar si existe algún tipo de relación con el proceso de mezclado o con las características de las materias primas se muestran los valores ordenados en orden creciente de $\mathrm{X}$.

Tabla 4.5 Valor medio $(X)$ y desviación estándar $(\sigma)$ de la razón

M1/M0 en las transformadas de Fourier de las micrografías de microscopía electrónica

\begin{tabular}{|cccccc|}
\hline Referencia & $\mathrm{X}$ & $\sigma$ & Circona & $\mathrm{Fe}_{2} \mathrm{O}_{3}$ & Mezclado \\
\hline $\mathrm{A} 06$ & 0,0163 & 0,0013 & $\mathrm{GZr}$ & $\mathrm{AFe}$ & Húmeda \\
$\mathrm{A} 08$ & 0,0204 & 0,0012 & $\mathrm{FZr}$ & $\mathrm{AFe}$ & Húmeda \\
$\mathrm{A} 03$ & 0,0239 & 0,0007 & $\mathrm{FZr}$ & $\mathrm{BFe}$ & Seca \\
$\mathrm{A} 01$ & 0,0266 & 0,0018 & $\mathrm{GZr}$ & $\mathrm{BFe}$ & Seca \\
$\mathrm{A} 02$ & 0,0299 & 0,0016 & $\mathrm{GZr}$ & $\mathrm{AFe}$ & Seca \\
$\mathrm{A04}$ & 0,0312 & 0,0034 & $\mathrm{FZr}$ & $\mathrm{AFe}$ & Seca \\
\hline
\end{tabular}


Con los datos obtenidos se pueden extraer las siguientes conclusiones:

- Las muestras A06 y A08, es decir, las composiciones mezcladas por vía húmeda proporcionan valores de $\mathrm{M}_{1} / \mathrm{M}_{0}$ más bajos. El resto de las composiciones, mezcladas por vía seca, presentan valores más altos. Este comportamiento en principio permitiría distinguir entre los métodos de mezclado utilizados.

- Cuando se realiza el mezclado vía seca, las mezclas que incluyen el óxido de hierro AFe (con una superficie específica más elevada) proporcionan un valor más elevado de $M_{1} / M_{0}$ que sus homólogas que incluyen el óxido de hierro BFe, independientemente de la circona utilizada en las composiciones.

- $\quad$ No se detecta una tendencia clara en función de la circona empleada para preparar las mezclas y es posible que se deba a que los aglomerados de circona se comportan de forma diferente según el resto de las materias primas presentes y el método de preparación, con lo que el índice de mezcla empleado no tendría una relación directa con el tipo de circona utilizado.

- Los resultados obtenidos indican que la relación $M_{1} / M_{0}$ podría ser un parámetro utilizable como índice de mezcla, aunque para un estudio más completo sería necesario obtener más datos experimentales para confirmar su idoneidad para clasificar las mezclas de materias primas utilizadas para sintetizar el pigmento coral de hierro-circón.

\subsubsection{Estudio del grado de mezcla a partir de la imagen del espectro de potencia de la TFD}

\subsubsection{Nivel medio de gris}

Atendiendo al concepto expuesto anteriormente, en un primer paso, las micrografías realizadas en el MEB fueron tratadas con el software MicroImage para obtener la TFD y su espectro de potencia. A partir de cada espectro de potencia se obtuvo el correspondiente histograma, es decir, el porcentaje de píxeles que tiene la imagen para cada tono de gris. Posteriormente, se seleccionó el nivel medio de gris como parámetro para poder evaluar los espectros obtenidos, de forma que, cuanto mayor sea la estrella del espectro de potencia, tendrá mayor cantidad de tonos blancos y el valor del parámetro será más elevado. Por tanto, aquellas mezclas con aspecto más heterogéneo, con una mayor estrella en el espectro de potencia, tendrán un nivel medio de gris más elevado.

En la Tabla 4.6, se muestran los valores de nivel medio de gris (X) para cada mezcla. Puesto que se realizaron seis micrografías para cada una de las 
mezclas, los resultados obtenidos se muestran como valor medio y desviación estándar de las medidas, ordenados de forma creciente.

Tabla 4.6 Valor del nivel medio de gris $(X)$ y desviación estándar

$(\sigma)$ en los espectros de potencia de las transformadas de Fourier de las micrografías de microscopía electrónica

\begin{tabular}{|cccccc|}
\hline Referencia & $\mathrm{X}$ & $\sigma$ & Circona & $\mathrm{Fe}_{2} \mathrm{O}_{3}$ & Mezclado \\
\hline A08 & 0,1791 & 0,0121 & $\mathrm{FZr}$ & AFe & Húmeda \\
A06 & 0,1889 & 0,0001 & $\mathrm{GZr}$ & AFe & Húmeda \\
A04 & 0,2023 & 0,0024 & $\mathrm{FZr}$ & AFe & Seca \\
A03 & 0,2066 & 0,0026 & FZr & BFe & Seca \\
A01 & 0,2588 & 0,0023 & GZr & BFe & Seca \\
A02 & 0,2763 & 0,0036 & GZ & AFe & Seca \\
\hline
\end{tabular}

Las conclusiones que se pueden extraer de la Tabla 4.6 se presentan a continuación:

- Los valores obtenidos para el nivel medio de gris de la transformada de Fourier indican que se obtienen valores más pequeños para las muestras A08 y A06 que corresponderían al proceso de mezclado vía húmeda.

- En cuanto a las mezclas obtenidas utilizando un mezclado vía seca, se aprecia que aquellos valores más elevados, es decir, las muestras más heterogéneas son A01 y A02 que están preparadas a partir de la circona GZr, con un tamaño de partícula mayor.

Estas dos conclusiones se correlacionan adecuadamente con la evaluación visual de las micrografías del MEB y los espectros de potencia comentados anteriormente.

Ya que los resultados obtenidos a partir de las seis micrografías realizadas a cada una de las probetas parecían prometedores, se decidió realizar cinco micrografías adicionales de cada muestra en el MEB. De este modo se podría evaluar la variabilidad que puede presentar la superficie de las probetas.

Del mismo modo que se ha procedido anteriormente, se realizaron cinco micrografías en el MEB y sobre cada micrografía se determinó la transformada de Fourier utilizando el software MicroImage y se obtuvo el histograma. Los valores promedio del nivel medio de gris correspondiente a esta segunda serie de micrografías, así como la desviación estándar de las medidas en orden creciente, se muestran en la Tabla 4.7. 
Tabla 4.7 Valor del nivel medio de gris $(X)$ y desviación estándar $(\sigma)$ en los espectros de potencia de las transformadas de Fourier de las micrografías de microscopía electrónica

\begin{tabular}{|cccccc|}
\hline Referencia & X & $\sigma$ & Circona & $\mathrm{Fe}_{2} \mathrm{O}_{3}$ & Mezclado \\
\hline A04 & 0,1578 & 0,0025 & $\mathrm{FZr}$ & $\mathrm{AFe}$ & Seca \\
A03 & 0,1584 & 0,0005 & $\mathrm{FZr}$ & $\mathrm{BFe}$ & Seca \\
A01 & 0,1811 & 0,0074 & $\mathrm{GZr}$ & $\mathrm{BFe}$ & Seca \\
A08 & 0,1827 & 0,0011 & $\mathrm{FZr}$ & AFe & Húmeda \\
A02 & 0,1940 & 0,0015 & $\mathrm{GZr}$ & AFe & Seca \\
A06 & 0,1971 & 0,0018 & GZr & AFe & Húmeda \\
\hline
\end{tabular}

En la Figura 4.40 se muestra un gráfico con los valores del nivel medio de gris para cada una de las micrografías MEB realizadas sobre cada probeta (seleccionando dos micrografías de la primera serie y cinco micrografías de la segunda serie), donde se observa la variabilidad de estos valores. Los valores obtenidos dan una idea de la heterogeneidad de las muestras. Las micrografías realizadas sobre las mezclas A06 y A08 (mezclado vía húmeda), presentan una menor variabilidad de este parámetro mientras que las mezclas A01 y A02, preparadas por vía seca, presentan una mayor heterogeneidad y por tanto una mayor variabilidad de los valores de gris entre las micrografías realizadas.

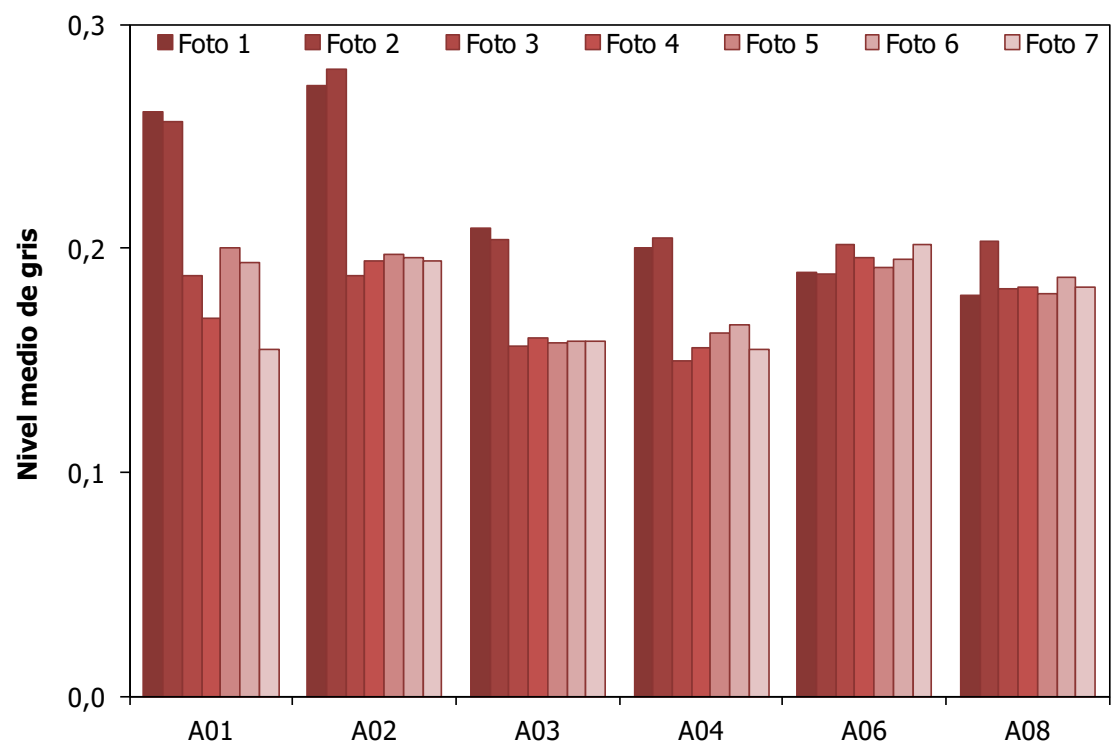

Figura 4.40 Valores del nivel medio de gris en los espectros de potencia de TFD en las dos series de micrografías MEB para las 6 mezclas 
En la Figura 4.41, se han representado los valores promedio de nivel medio de gris en las dos series de micrografías realizadas. Se observa una misma tendencia entre las mezclas preparadas por vía seca, es decir, el valor más alto y, por tanto, la que presenta una mayor heterogeneidad es la mezcla A02, seguida de la A01, es decir aquellas que contienen la circona GZr. Además, en las mezclas preparadas por vía húmeda (A06 y A08) el nivel medio de gris entre las dos series de micrografías no varía de forma significativa debido a la mayor homogeneidad de las mezclas.

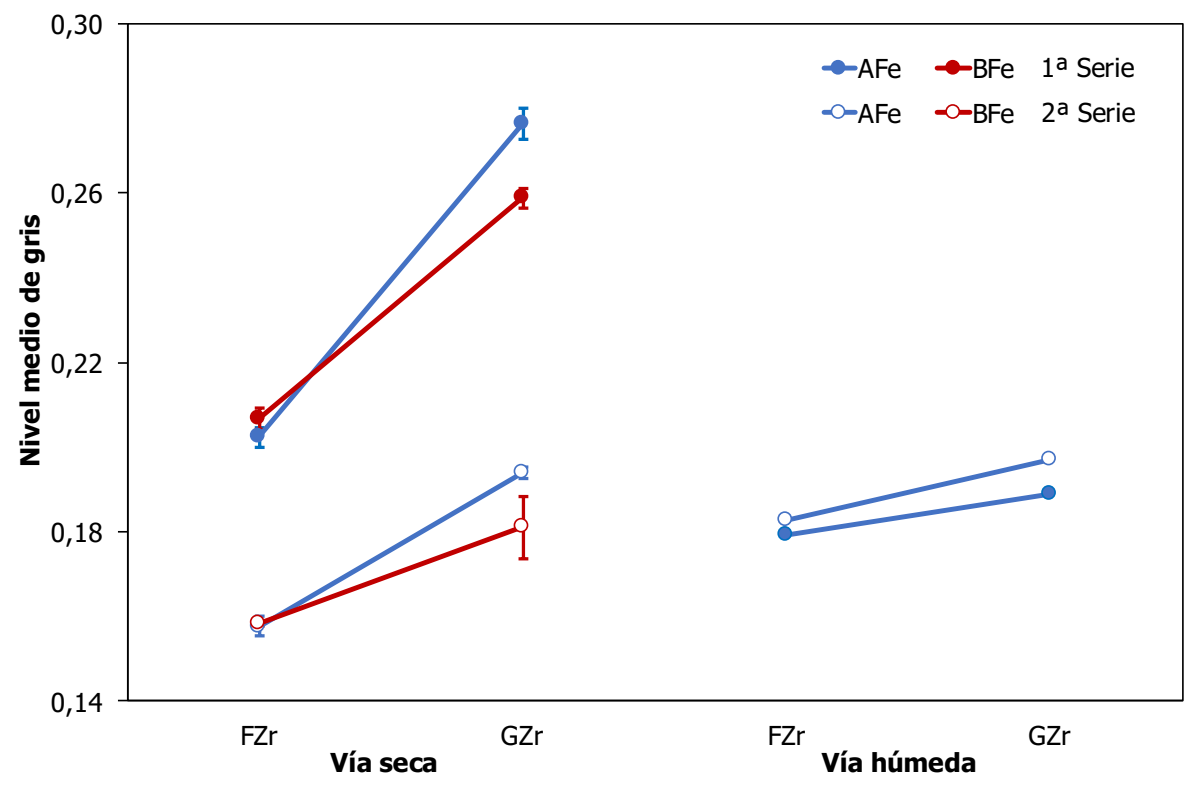

Figura 4.41 Valores del nivel medio de gris en los espectros de potencia de TFD en las dos series de micrografías MEB para las 6 mezclas

Las conclusiones que se obtienen al valorar los resultados obtenidos se enuncian a continuación:

- $\quad$ El valor de nivel medio de gris obtenido en la transformada de Fourier presenta una variabilidad importante en las dos series de micrografías realizadas. Este hecho se explica debido a que las condiciones de medida de las dos series de micrografías utilizando el microscopio electrónico de barrido varían ligeramente, no solo en el brillo y contraste que presentan las micrografías, sino que también interviene un parámetro instrumental como es el filamento del microscopio electrónico, ya que éste se va desgastando con el tiempo y, por tanto, las condiciones de medida son ligeramente diferentes.

- Los datos de nivel medio de gris obtenidos en la primera serie de micrografías realizadas a la superficie de las muestras indican que las muestras más heterogéneas corresponderían con la muestra A02 y A01, en las que se ha utilizado la circona más gruesa y el método de mezclado ha sido vía seca. La composición A08 mezclada vía húmeda y con la circona más fina presenta un 
nivel de gris menor seguida de A06 que también ha sido mezclada por vía húmeda. Este hecho demuestra que aquellas que presentan un valor bajo de nivel medio de grises son muestras más homogéneas y los niveles de grises más altos corresponden a mezclados más imperfectos.

- Sin embargo, cuando se realiza una segunda serie de micrografías (cinco micrografías adicionales), no se observa una ordenación lógica en cuanto a la homogeneidad de las muestras y no es posible distinguir entre las mezclas obtenidas por vía seca y las obtenidas mediante vía húmeda.

- El nivel medio de gris resulta ser muy sensible a las condiciones en las que se realizan las micrografías en el microscopio electrónico de barrido. Por tanto, se concluye que el parámetro elegido para evaluar el grado de mezcla no es el adecuado, si se considera que las condiciones de obtención de las imágenes son difíciles de replicar exactamente.

\subsubsection{Número de píxeles}

Dado que en la transformada de Fourier los puntos con mayor peso en la reconstrucción de la imagen son los que poseen un valor de gris más elevado (el máximo es 255), y el escalado en la asignación de tonos de gris es logarítmico, son precisamente los puntos con mayor valor los que más contribuyen a definir la imagen y, por tanto, los que incluyen mayor parte de la información de la micrografía original. Con todo esto, se decidió ensayar como índice de mezcla el número de píxeles en el espectro de potencia de la TFD que poseen valores próximos a 255.

Para ello se seleccionaron dos micrografías realizadas en la primera serie de experimentos y las cinco micrografías tomadas en la segunda serie, es decir, se analizaron un total de siete micrografías realizadas en el MEB para cada una de las seis probetas. A partir del histograma de cada uno de los espectros de potencia de las micrografías, se seleccionaron seis intervalos de niveles de gris para tratar de identificar el más adecuado para calcular el índice de mezcla. A continuación, se extrajo el número de píxeles de cada imagen para cada intervalo seleccionado.

El valor medio obtenido $(X)$ así como la desviación estándar $(\sigma)$ de estos valores se muestran en la Tabla 4.8 
Tabla 4.8 Número medio de píxeles del espectro de potencia de la

TFD en los intervalos seleccionados para las micrografías de las seis muestras analizadas $(X \pm \sigma)$

\begin{tabular}{|ccccccc|}
\hline \multicolumn{7}{c|}{ Intervalo de nivel de grises } \\
& $255-240$ & $255-220$ & $255-200$ & $255-150$ & $255-100$ & $255-50$ \\
\hline A01 & $71 \pm 1$ & $92 \pm 2$ & $119 \pm 3$ & $234 \pm 4$ & $508 \pm 7$ & $1409 \pm 14$ \\
A02 & $75 \pm 2$ & $89 \pm 2$ & $113 \pm 2$ & $212 \pm 6$ & $444 \pm 9$ & $1262 \pm 19$ \\
A03 & $79 \pm 2$ & $99 \pm 1$ & $129 \pm 2$ & $245 \pm 5$ & $505 \pm 12$ & $1379 \pm 24$ \\
A04 & $77 \pm 2$ & $97 \pm 2$ & $126 \pm 3$ & $222 \pm 5$ & $477 \pm 13$ & $1236 \pm 28$ \\
A06 & $63 \pm 1$ & $76 \pm 1$ & $100 \pm 2$ & $183 \pm 4$ & $396 \pm 13$ & $1206 \pm 31$ \\
A08 & $81 \pm 1$ & $100 \pm 3$ & $128 \pm 4$ & $230 \pm 10$ & $481 \pm 18$ & $1335 \pm 30$ \\
\hline
\end{tabular}

Para poder comparar los resultados que aparecen en la tabla de una forma más visual y cómoda, a continuación, se presenta un gráfico donde se ha representado la desviación del número de píxeles en cada uno de los intervalos escogidos, con respecto al valor medio de todas las muestras en dicho intervalo, y normalizada con respecto a dicho valor medio, de forma que los valores se encuentran a la misma escala (ver Figura 4.42).

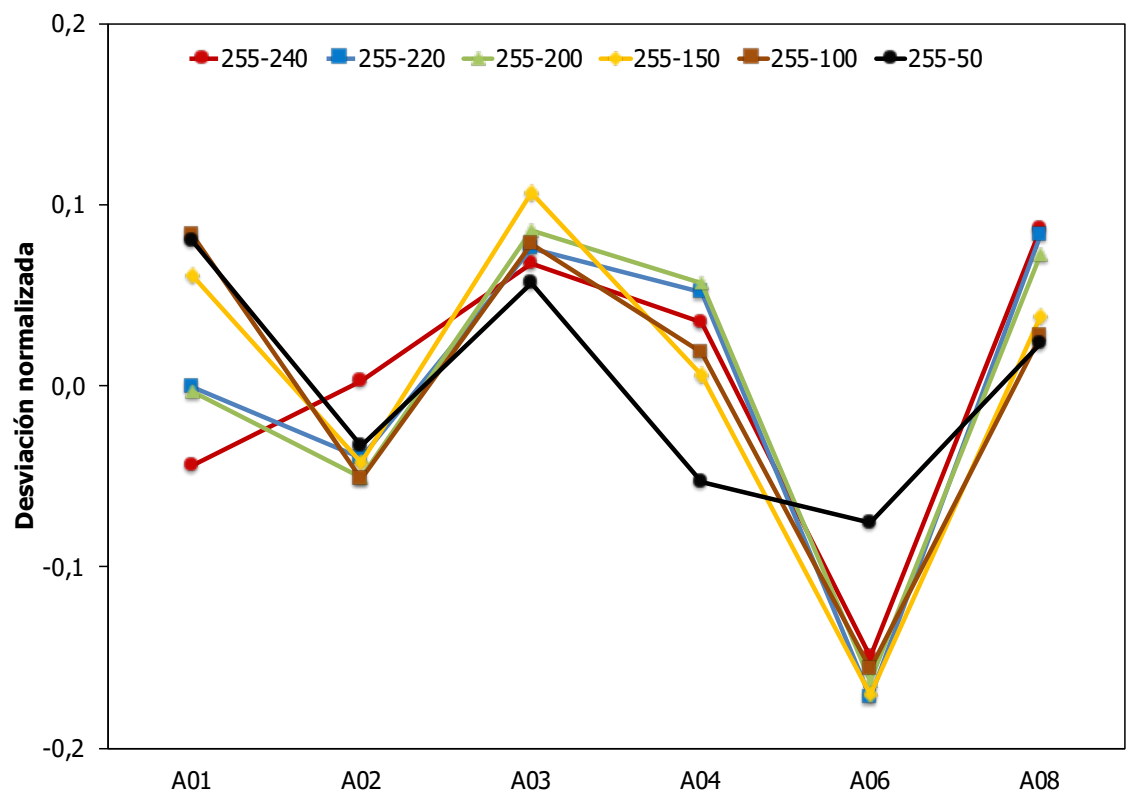

Figura 4.42 Evolución del número medio de píxeles en los intervalos seleccionados para cada muestra analizada 
De la evaluación de los datos se pueden extraer algunas conclusiones:

- Los cinco primeros intervalos de grises seleccionados tienen la misma tendencia en cada una de las seis muestras analizadas, sin embargo, el intervalo 255-50 parece que se desvía del resto de intervalos. Por tanto, este intervalo se desestima para definir un índice de mezcla.

- Las diferencias entre los cinco primeros intervalos seleccionados son pequeñas, pero no siguen una misma ordenación de las muestras para evaluar la homogeneidad de éstas. Por este motivo, se tomó el valor medio de las desviaciones para cada muestra, intentando reducir las diferencias, y se obtuvo que este valor medio conducía a la ordenación de las muestras que presenta el intervalo 255-200. Como consecuencia, para evaluar la homogeneidad de las muestras y poder ordenarlas en función del grado de mezcla, se decidió seleccionar el número medio de píxeles del intervalo 255-200. Asimismo, se introdujeron otras variables que pueden influir en la homogeneidad de las mezclas como son la circona y el óxido de hierro utilizados, así como el proceso de mezclado. Todos estos datos se reflejan en la Tabla 4.9.

Tabla 4.9 Resultado de la ordenación de las mezclas según el índice de mezcla propuesto

\begin{tabular}{|ccccc|}
\hline Referencia & $\begin{array}{c}\text { No píxeles } \\
{[255-200]}\end{array}$ & Circona & $\mathrm{Fe}_{2} \mathrm{O}_{3}$ & Mezclado \\
\hline $\mathrm{A} 06$ & $100 \pm 2$ & $\mathrm{GZr}$ & $\mathrm{AFe}$ & Húmeda \\
$\mathrm{A} 02$ & $113 \pm 2$ & $\mathrm{GZr}$ & $\mathrm{AFe}$ & Seca \\
$\mathrm{A} 01$ & $119 \pm 3$ & $\mathrm{GZr}$ & $\mathrm{BFe}$ & Seca \\
$\mathrm{A} 04$ & $126 \pm 3$ & $\mathrm{FZr}$ & $\mathrm{AFe}$ & Seca \\
$\mathrm{A} 08$ & $128 \pm 4$ & $\mathrm{FZr}$ & $\mathrm{AFe}$ & Húmeda \\
$\mathrm{A03}$ & $129 \pm 2$ & $\mathrm{FZr}$ & $\mathrm{BFe}$ & Seca \\
\hline
\end{tabular}

El parámetro definido como número de píxeles debe evaluarse de forma que aquellas mezclas que generan una imagen más compleja, y por tanto un espectro de potencia con una estrella mayor y más puntos blancos, tendrán un número de píxeles más elevado. 
Observando la tabla anterior y tomando como índice de mezcla el número de píxeles en el intervalo 255-200, se deduce que:

- Las mezclas A04, A08 y A03 que están preparadas con una circona más fina, tienen un número más elevado de píxeles, ya que, al tener un tamaño de partícula más pequeño, genera una imagen más compleja.

- A su vez, las mezclas A06, A02 y A01 preparadas con una circona con un tamaño de partícula más grueso, presenta menor número de píxeles.

- Entre las muestras mezcladas por vía húmeda, es decir, A06 y A08, la muestra A06 presenta un menor número de píxeles, debido a la utilización de una circona más gruesa.

- Por tanto, parece que el índice de mezcla definido podría ordenar las mezclas en función de la circona utilizada.

- Por otra parte, la utilización del óxido de hierro BFe genera un número de píxeles mayor y este hecho se ha observado independientemente de la circona utilizada. Por lo que a priori el índice de mezcla seleccionado también puede clasificar las mezclas según el óxido de hierro utilizado.

- La ordenación de las mezclas en las que se utiliza la circona más fina (FZr) no es muy clara debido a que los valores obtenidos son muy similares.

- $\quad$ Cuando en la composición se introduce la circona GZr, la muestra M5 mezclada mediante procesado vía húmeda resulta ser la mezcla con un menor número de píxeles.

- Con las medidas experimentales llevadas a cabo, el índice de mezcla seleccionado no permite separar las composiciones en función del proceso de mezclado, ya que las muestras A06 y A08 (vía húmeda) aparecen intercaladas entre el resto de las muestras. Este hecho puede deberse a que las diferencias en el número de píxeles de las mezclas A04, A08 y A03 son mínimas y hay que tener en cuenta que las desviaciones estándar de estas medias son del mismo orden que las diferencias encontradas.

En consecuencia, los resultados obtenidos parecen indicar que el índice de mezcla definido como número de píxeles en el intervalo 255-200, permite separar las mezclas en función de las materias primas utilizadas en su preparación, ya que alcanza los valores más elevados para la circona más fina (que por tanto genera una imagen más compleja), y a igualdad de circona parece separar en función del óxido de hierro incorporado. 
Como resumen general de este apartado del trabajo de investigación, se puede concluir que se ha propuesto un índice de mezclado que permite diferenciar mezclas de materias primas en función de los precursores utilizados, aunque se considera necesario profundizar en esta línea de trabajo aplicando la metodología a pigmentos cuyo mecanismo de formación no presenten una complejidad tan elevada como es el caso del pigmento coral de hierro-circón. Por otra parte, con el objetivo de optimizar las horas de uso del microscopio electrónico de barrido, sería interesante analizar la posibilidad de emplear imágenes de microscopía óptica para facilitar la transferencia del método al entorno industrial. 


\subsection{Influencia del tratamiento térmico}

Las grandes diferencias encontradas entre los pigmentos sintetizados a partir de las mezclas preparadas vía seca y los generados a partir de las mezclas elaboradas vía húmeda, apuntaban a una diferencia notable en la reactividad de las composiciones en función del método de preparación. Sin embargo, ya que la evolución del sistema en reacciones entre sólidos depende enormemente del tratamiento térmico, se decidió estudiar su influencia disminuyendo la temperatura máxima del tratamiento térmico y el tiempo de permanencia para comprobar que el ciclo térmico aplicado era el adecuado, ya que una elevada temperatura máxima o un elevado tiempo de permanencia a la misma, podría hacer que el mineralizador comenzase una acción de ataque al circón que revertiese la reacción, eliminando parcialmente la nueva fase formada [122].

\subsubsection{Efecto de la temperatura máxima}

Para comparar el efecto de la temperatura máxima del ciclo se partió de dos mezclas con la composición correspondiente a la fórmula N04, una preparada vía seca y la otra preparada vía húmeda (B01 y B02 respectivamente), y se sometieron a un tratamiento térmico manteniendo el esquema del Ciclo STD, pero reduciendo la temperatura máxima a $950^{\circ} \mathrm{C}$. El aspecto de los pigmentos sintetizados no mostró diferencias, ya que se obtuvieron materiales de color rojizo en los dos casos. La cuantificación de fases cristalinas de ambos pigmentos condujo a los resultados que se detallan en la Tabla 4.10.

Tabla 4.10 Porcentaje de las fases cristalinas identificadas y composición de la fase amorfa (\% peso)

\begin{tabular}{|c|c|c|c|c|}
\hline & & & B01 & BO2 \\
\hline \multirow{4}{*}{\multicolumn{2}{|c|}{ 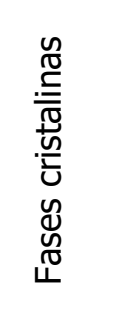 }} & Cuarzo & 9 & 12 \\
\hline & & Baddeleyita & 30 & 43 \\
\hline & & Hematites & 17 & 21 \\
\hline & & Circón & 11 & 1 \\
\hline & & Fase amorfa total & 34 & 22 \\
\hline \multirow{3}{*}{\multicolumn{2}{|c|}{ 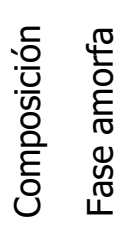 }} & $\% \mathrm{Fe}_{2} \mathrm{O}_{3}$ & 7 & 3 \\
\hline & & $\% \mathrm{SiO}_{2}$ & 9 & 9 \\
\hline & & $\% \mathrm{ZrO}_{2}$ & 13 & 6 \\
\hline
\end{tabular}


El análisis de los datos y su comparación con los obtenidos partiendo de las mismas mezclas, pero sometidas al Ciclo STD (pigmentos A04 y A08) indicaron que la reducción en la temperatura máxima del tratamiento térmico provocaba una ralentización en la reacción de síntesis del pigmento, independientemente del proceso de mezclado de materias primas, y este hecho se reflejaba en mayores porcentajes para las fases de cuarzo y baddeleyita, y menor para el circón (la hematites apenas variaba). Así, con la temperatura máxima a 1000 C se obtenían $45 \%$ y $15 \%$ de circón, y las mismas composiciones disminuyendo la temperatura máxima a $950{ }^{\circ} \mathrm{C}$, disminuía el porcentaje de circón a $11 \%$ y $1 \%$ respectivamente.

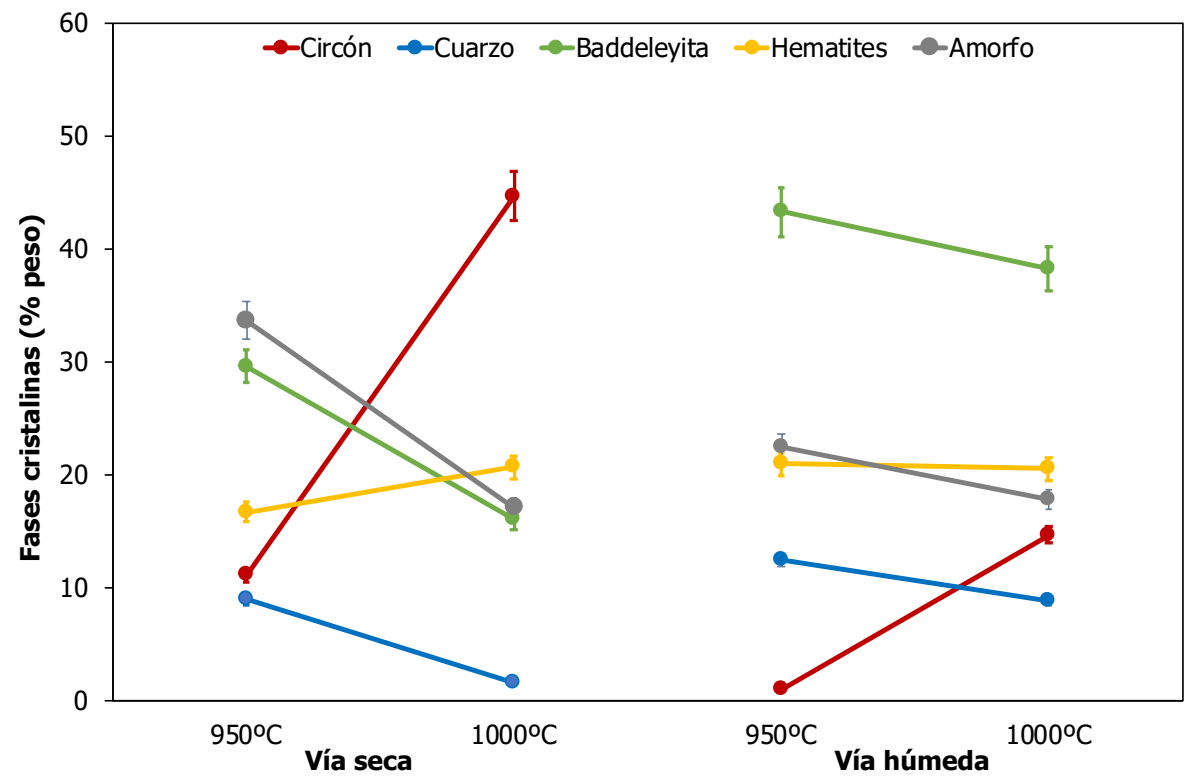

Figura 4.43 Evolución de las fases cristalinas presentes en los pigmentos, frente a la temperatura máxima del tratamiento térmico y el método de preparación de la mezcla de materias primas

Del mismo modo, en la Figura 4.44 se observa como el grado de avance representado como $\varsigma_{1}$ (sílice que reacciona para formar circón) y $\varsigma_{2}$ (sílice que forma parte de la fase vítrea) evoluciona con la temperatura máxima del tratamiento térmico y el proceso de mezclado de forma que $\varsigma_{1}$ va aumentando al aumentar la temperatura máxima y es mayor en el mezclado mediante vía seca debido a una mayor formación de circón. Sin embargo, \$2 evoluciona de modo contrario, es decir, la sílice que pasa a formar parte de la fase vítrea es mayor cuando la temperatura máxima del tratamiento térmico es $950^{\circ} \mathrm{C}$. Para ambos parámetros, se observa que con el mezclado vía seca los cambios en estos parámetros se producen de forma más aguda. 


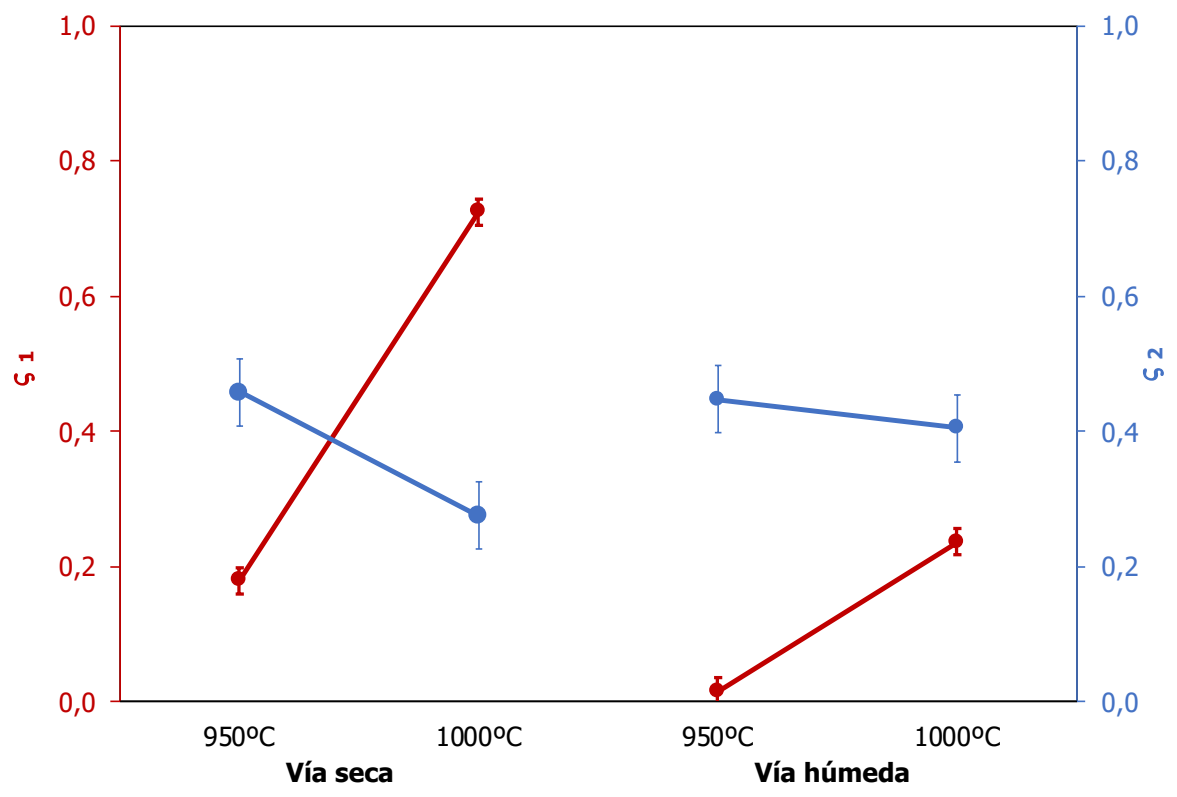

Figura 4.44 Evolución de los parámetros $\varsigma_{1}$ y $\varsigma 2$, frente a la temperatura máxima del tratamiento térmico y el método de preparación de la mezcla de materias primas

El resultado obtenido parecía coherente con lo esperado, sin embargo, al comparar la variación del porcentaje de cada fase con la temperatura, se apreció que este efecto era más notable para los pigmentos sintetizados a partir de las mezclas preparadas vía seca, lo que parecía indicar que la reactividad en dichas mezclas es mucho más sensible a los cambios de temperatura que en las homólogas preparadas vía húmeda.

Una posible interpretación de este efecto podría explicarse de forma que la reducción en la temperatura máxima del tratamiento térmico provocase un cambio en el mecanismo predominante por el cual transcurre la reacción de síntesis del circón, pasando de un transporte de la sílice mediante intermedios gaseosos a un transporte a través de una fase líquida viscosa. La disposición de las partículas en las mezclas procesadas vía seca favorecería el cambio de mecanismo, cosa que no ocurriría en la mezcla preparada vía húmeda. Esta explicación sería coherente con el hecho de que el punto de fusión del mineralizador utilizado $\left(\mathrm{Na}_{2} \mathrm{SiF}_{6}\right)$ es de $847^{\circ} \mathrm{C}$, de modo que operando a la temperatura de $1000{ }^{\circ} \mathrm{C}$ el $\mathrm{Na}_{2} \mathrm{SiF}_{6}$ podría liberar el $\mathrm{SiF}_{4}$ gaseoso, mientras que a $950^{\circ} \mathrm{C}$ sólo estaría presente como fase líquida o, al menos, la proporción de $\mathrm{SiF}_{4}$ generada sería mucho menor, con lo que el transporte en fase gas se vería muy limitado. Por otra parte, la mayor homogeneidad de la muestra preparada vía húmeda, favorecería una interacción temprana entre el mineralizador y la sílice para formar la fase vítrea, en lugar de interaccionar a mayor temperatura, cuando se pudiese formar el $\mathrm{SiF}_{4}$. 


\subsubsection{Tiempo de permanencia a temperatura máxima}

La evaluación del efecto del tiempo de permanencia se realizó sintetizando el pigmento partiendo de las fórmulas $\mathrm{N}^{0} 1$ y N03 preparadas mediante procesado vía húmeda (A05 y A07 respectivamente), utilizando un tratamiento térmico con una estructura idéntica al Ciclo STD, pero en el que se acortó el tiempo de permanencia a $1000{ }^{\circ} \mathrm{C}$, reduciéndolo de seis a una hora. Se escogieron dos fórmulas diferentes a la utilizada en el apartado anterior para confirmar o descartar con mayor base experimental la posibilidad de que la reacción de síntesis del circón retrocediese. Las referencias de los nuevos pigmentos fueron B03 y B04 respectivamente.

Los materiales obtenidos se caracterizaron mediante difracción de rayos $\mathrm{X}$ obteniendo los porcentajes de fases cristalinas indicadas en la Tabla 4.11.

Tabla 4.11 Porcentaje de las fases cristalinas identificadas y composición de la fase amorfa (\% peso)

\begin{tabular}{|c|c|c|c|}
\hline & & B03 & B04 \\
\hline \multirow{4}{*}{ 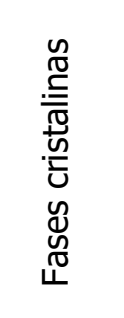 } & Cuarzo & 12 & 12 \\
\hline & Baddeleyita & 49 & 49 \\
\hline & Hematites & 23 & 22 \\
\hline & Circón & 3 & $<1$ \\
\hline & Fase amorfa total & 13 & 17 \\
\hline \multirow{3}{*}{ 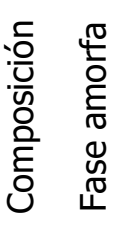 } & $\% \mathrm{Fe}_{2} \mathrm{O}_{3}$ & $<1$ & 2 \\
\hline & $\% \mathrm{SiO}_{2}$ & 9 & 10 \\
\hline & $\% \mathrm{ZrO}_{2}$ & $<1$ & 1 \\
\hline
\end{tabular}

Los datos obtenidos se han representado en la Figura 4.45, junto con los correspondientes a los pigmentos sintetizados a partir de las mismas mezclas, pero tratadas con el Ciclo STD. Asimismo, se han representado los parámetros $\varsigma_{1}$ (sílice que reacciona para formar circón) y $\varsigma_{2}$ (sílice que forma parte de la fase vítrea) que darán una idea de la evolución del grado de avance en las diferentes condiciones de síntesis. 


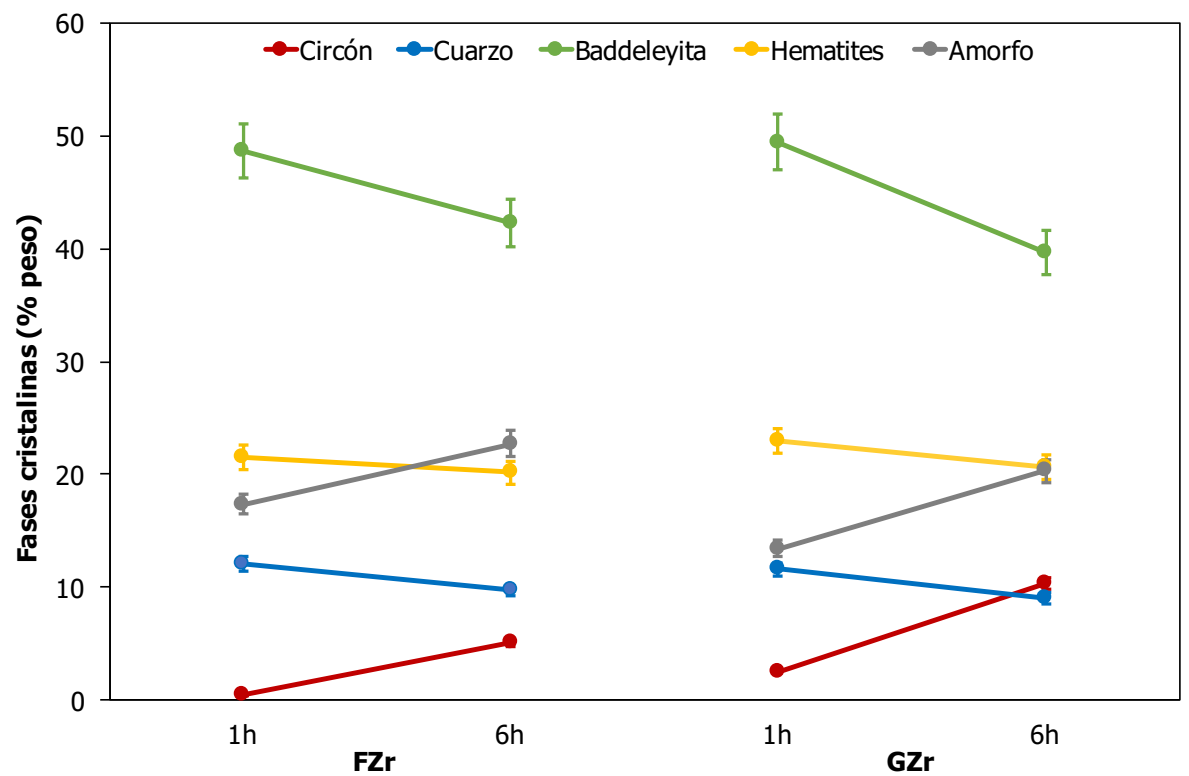

Figura 4.45 Evolución de las fases cristalinas presentes en los pigmentos, frente al tiempo de permanencia a la temperatura máxima del tratamiento térmico y la fórmula de la mezcla de partida (mezclado vía húmeda)

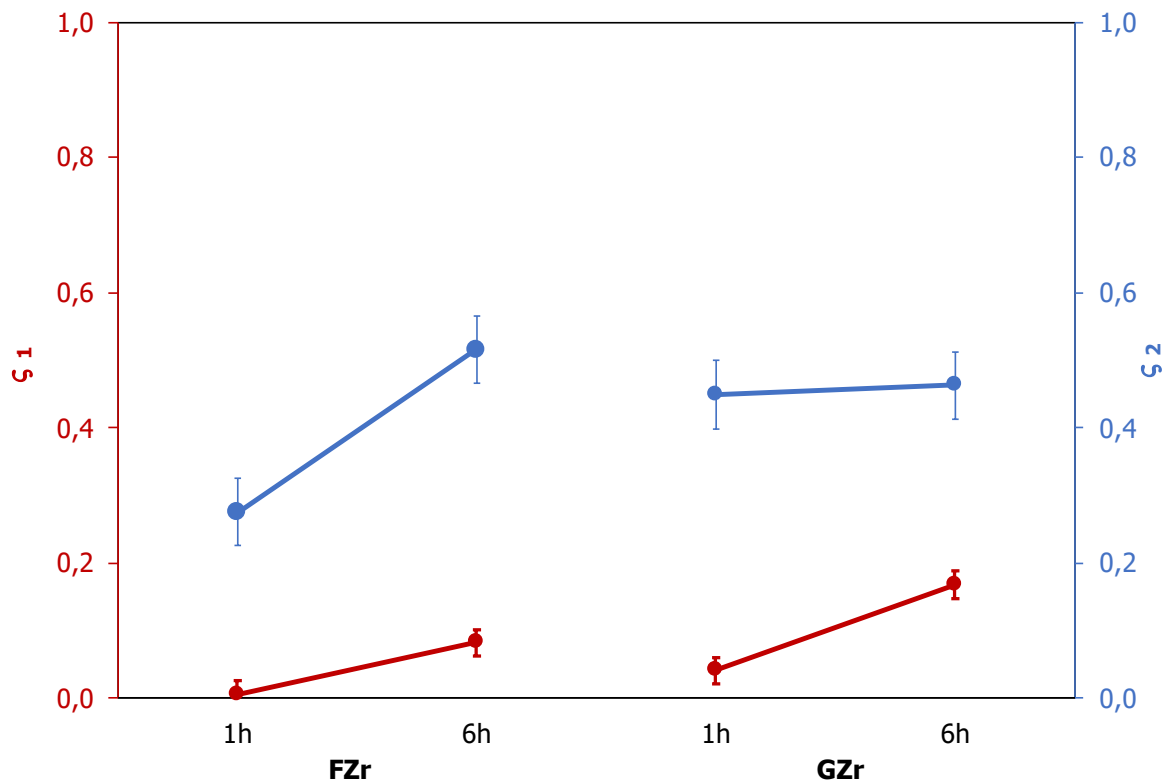

Figura 4.46 Evolución de los parámetros $\varsigma_{1}$ y $\varsigma 2$, frente al tiempo de permanencia a la temperatura máxima del tratamiento térmico y la fórmula de la mezcla de partida (mezclado vía húmeda) 
Los resultados del análisis se resumen en los siguientes puntos:

- $\quad$ La evolución de las fases cristalinas corresponde a un menor avance en la reacción de síntesis del circón. En las dos composiciones seleccionadas se advierte que al reducir el tiempo de permanencia a la temperatura máxima de $1000^{\circ} \mathrm{C}$ se reduce el porcentaje de circón, y en cambio aumentan los de cuarzo y baddeleyita. Así, el porcentaje de circón pasa de un $10 \%$ y $5 \%$ en las muestras A05 y A07 a un 3\% y menor de 1\% para las muestras B03 y B04 respectivamente.

- $\quad$ El porcentaje de fase amorfa o vítrea es mucho menor cuando el tiempo de permanencia a la temperatura máxima es de una hora, lo que indica que un mayor tiempo de permanencia generará una mayor cantidad de fase vítrea.

- $\quad$ El tamaño de partícula de la circona parece ejercer cierto efecto sobre la reacción. Concretamente, la composición con la circona más fina tiende a generar menos circón y más fase vítrea que su homóloga con la circona más gruesa, en las mismas condiciones de operación. Ello apunta a que una circona menos reactiva (más gruesa), al reaccionar más lentamente favorece que el resto de la mezcla alcance las condiciones favorables para la síntesis del circón, es decir, que el mecanismo de transporte en fase gas sea el predominante.

- $\quad$ El parámetro $\varsigma_{1}$ que corresponde a la fracción de sílice que reacciona para formar circón, apenas alcanza el valor de 0,2 lo que indica que la reacción se encuentra en una etapa inicial en lo que se refiere a la formación del circón. Por otra parte, un tiempo de permanencia a temperatura máxima menor, revela el escaso porcentaje de cuarzo reaccionado para formar el silicato de circonio.

- $\quad$ El parámetro $\$ 2$ nos muestra como un elevado porcentaje de sílice está formando parte de la fase amorfa.

Los datos indican que tras una hora de permanencia a $1000^{\circ} \mathrm{C}$ estas mezclas apenas generan circón, de lo cual se deduce que la reacción en dichas condiciones es lenta $y$, por tanto, la preparación de la mezcla de materias primas en el molino planetario vía húmeda ejerce algún efecto desfavorable sobre la reactividad de ésta.

Estos resultados indicarían que el escaso porcentaje de circón obtenido en los pigmentos sintetizados con el Ciclo STD a partir de mezclas preparadas vía húmeda, no se debe a que la reacción esté retrocediendo, sino que ésta es muy lenta en comparación con las preparadas vía seca.

Los resultados obtenidos en este apartado y en el anterior, indican que las composiciones mezcladas vía húmeda poseen una reactividad mucho más baja que sus homólogas preparadas vía seca, a pesar de que las primeras tendrían mayor homogeneidad en cuanto a la distribución espacial de los reactantes. Por lo tanto, se decidió investigar con mayor profundidad el proceso del mezclado de las materias primas, y su influencia en la reactividad. 


\subsection{Métodos de mezclado y ciclos térmicos alternativos}

Los resultados preliminares obtenidos con la comparación de los procesos de mezclado y diferentes tratamientos térmicos mostraban diferencias muy notables en la reactividad de las mezclas. Por ello se decidió sintetizar el pigmento a partir de composiciones procesadas mediante diferentes metodologías, intentando correlacionar las diferentes variables del proceso con la evolución de las fases cristalinas formadas durante la síntesis y el poder colorante del pigmento final.

\section{4:4.1 Modificación del proceso de mezclado}

Los experimentos se realizaron con la composición correspondiente a la fórmula No4, e incluyeron las siguientes variantes:

- C01: Mezcla de materias primas preparada por mezclado vía seca con molino planetario Pulverisette. Seguidamente se volvería a mezclar en el molino planetario vía húmeda con acetona (15 minutos de tratamiento a $230 \mathrm{rpm}$ ).

- C02: Mezcla de materias primas, excepto el mineralizador, preparada en el molino planetario Pulverisette vía húmeda con acetona (15 minutos de tratamiento a $230 \mathrm{rpm}$ ). El $\mathrm{Na}_{2} \mathrm{SiF}_{6}$ se incorporó posteriormente homogeneizando manualmente en un mortero de ágata.

- C03: Mezcla de materias primas preparada íntegramente en un mortero mecánico vía seca, donde la molienda se realiza mediante presión y fricción.

- C04: Mezcla de materias primas obtenida en un molino de cuchillas vía seca, donde el mezclado se realiza mediante corte y cizalla.

Tras el tratamiento térmico con el Ciclo STD, se obtuvieron materiales de color rojizo en los cuatro casos, si bien el tono era más regular en el C01 y algo más irregular en los otros tres, lo cual era coherente con la menor homogeneidad que se presuponía con los métodos de mezclado utilizados.

La caracterización mineralógica y cuantificación de fases cristalinas mediante difracción de rayos $\mathrm{X}$ mostraban la formación de diferentes porcentajes de circón en los cuatro pigmentos, tal como se refleja en la Tabla 4.12. 
Tabla 4.12 Porcentaje de las fases cristalinas identificadas y composición de la fase amorfa (\% peso)

\begin{tabular}{|c|c|c|c|c|c|}
\hline & & C01 & $\mathrm{CO} 2$ & $\mathrm{CO3}$ & C04 \\
\hline \multirow{4}{*}{ 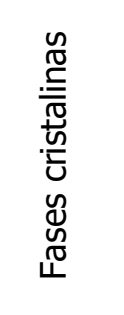 } & Cuarzo & 7 & 11 & 13 & 13 \\
\hline & Baddeleyita & 31 & 43 & 43 & 45 \\
\hline & Hematites & 20 & 19 & 19 & 20 \\
\hline & Circón & 18 & 4 & 1 & 1 \\
\hline & Fase amorfa total & 23 & 22 & 23 & 21 \\
\hline \multirow{3}{*}{ 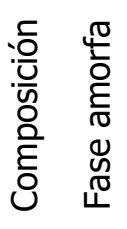 } & $\% \mathrm{Fe}_{2} \mathrm{O}_{3}$ & 3 & 4 & 5 & 3 \\
\hline & $\% \mathrm{SiO}_{2}$ & 9 & 10 & 8 & 8 \\
\hline & $\% \mathrm{ZrO}_{2}$ & 6 & 4 & 6 & 4 \\
\hline
\end{tabular}

Comparando estos datos con los correspondientes a la fórmula N04 preparada inicialmente vía seca industrialmente y vía húmeda en el molino Pulverisette (pigmentos A04 y A08 respectivamente), se identificaron los siguientes fenómenos:

- El reprocesado de la fórmula N04 elaborada inicialmente vía seca en el molino planetario (C01) ralentiza notablemente la reacción de síntesis del circón, dejando la cantidad de circón generado en un nivel algo superior al del pigmento sintetizado a partir de la mezcla preparada inicialmente vía húmeda (A08, con $15 \%$ de circón), y muy lejos del pigmento sintetizado directamente a partir de la mezcla preparada industrialmente mediante vía seca (A04, con $45 \%$ de circón). Evidentemente, el mezclado vía húmeda en las condiciones utilizadas influye negativamente en la reactividad, reduciéndola notablemente en el caso de una mezcla que se podía considerar óptima (Figura 4.47).

- La combinación del mezclado de materias primas en el molino planetario vía húmeda, con la incorporación posterior del mineralizador vía seca procesando en mortero de ágata (C02), genera menor cantidad de circón si cabe que la preparación de la mezcla completa vía húmeda (A08). Obviamente la dispersión del mineralizador había sido deficiente.

- Un mixturado poco enérgico, como el proporcionado por el mortero mecánico (C03), también es perjudicial, ya que en este caso apenas se produce la formación de circón. Por otra parte, el mezclado proporcionado por el molino de cuchillas (C04), conduce a unos resultados prácticamente similares, es decir, con escasa formación de circón. 


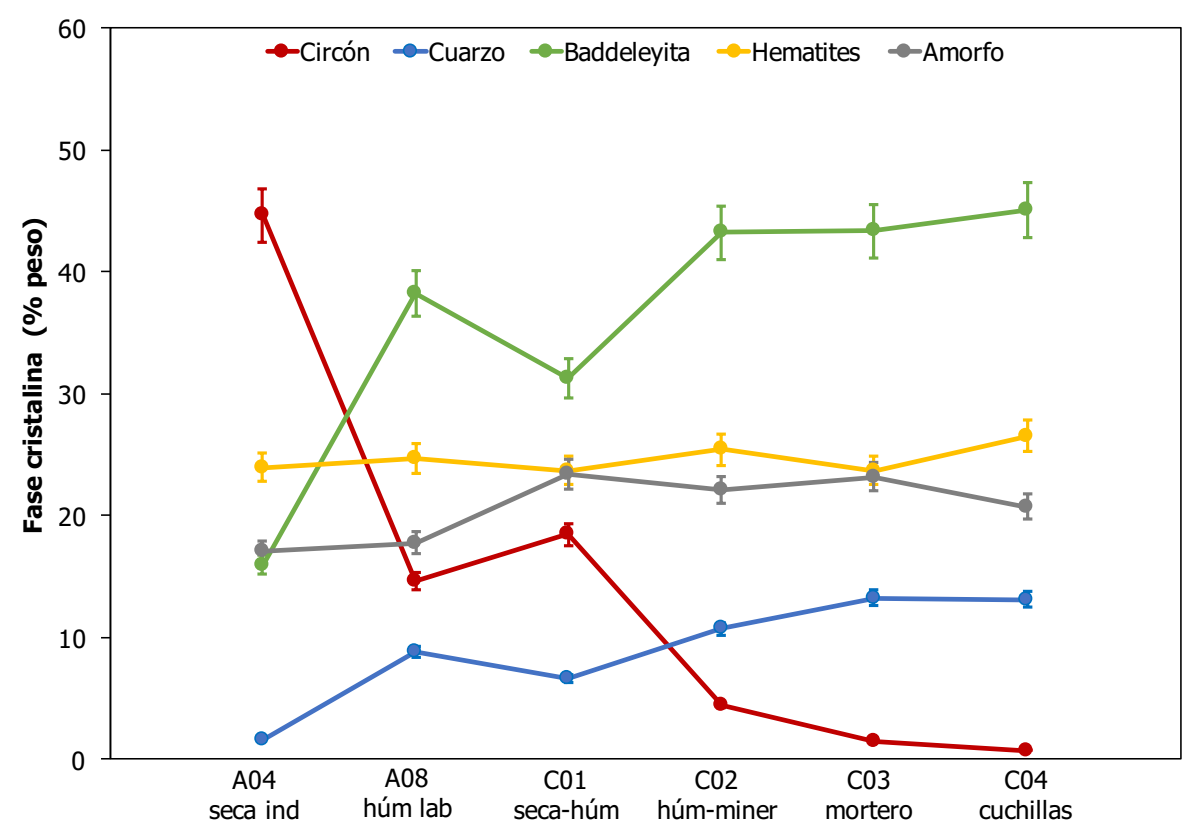

Figura 4.47 Evolución de las fases cristalinas presentes en los pigmentos

Los resultados demostraron que el mezclado de las materias primas es una etapa decisiva en la preparación del pigmento, ya que, al reforzar la preparación vía seca con el reprocesado en el molino planetario vía húmeda, se obtienen resultados casi parejos a los obtenidos inicialmente mediante procesado vía húmeda. Por otra parte, parece que son las características específicas de la mezcla obtenida en el molino planetario las que reducen la velocidad de síntesis, puesto que la adición posterior de mineralizador también conduce a una escasa formación de circón (lo cual elimina la posibilidad de que la ralentización de la reacción se deba a una reducción en el tamaño de partícula del mineralizador). Finalmente, un proceso de mezclado poco enérgico como los realizados en el molino de cuchillas y en el mortero mecánico, conducen a los resultados más desfavorables.

En cuanto a los parámetros $\varsigma_{1}$ (fracción de sílice que reacciona para formar circón) y $\varsigma_{2}$ (fracción de sílice que formará parte de la fase vítrea), los métodos de mezclado vía seca con mortero y cuchillas, sugieren que un escaso porcentaje de cuarzo ha contribuido en la formación del circón, y además también se ralentiza la transformación de cuarzo en fase vítrea. Es decir, estos mezclados menos enérgicos resultan claramente desfavorables para los dos mecanismos de transporte de materia que se están considerando. 


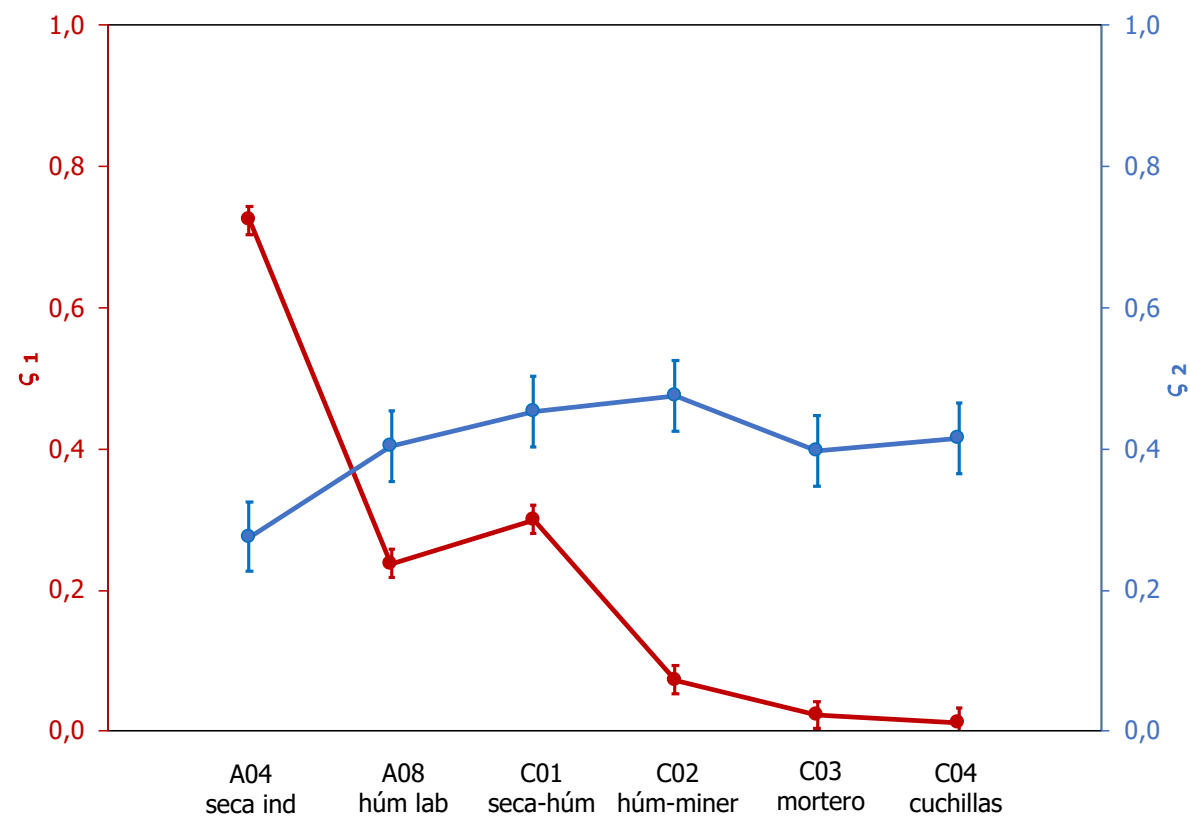

Figura 4.48 Evolución de los parámetros $\varsigma 1$ y $\varsigma 2$ en función del tipo de mezclado

Por tanto, el análisis de estos resultados indicaría que:

- Aparentemente existe un punto óptimo en la estructura de la mezcla, que de no ser alcanzado implica una reducción en la velocidad de reacción de síntesis del circón, a igualdad en la composición de partida. Dadas las características de los procesos empleados en la preparación de las mezclas, se plantearon las siguientes hipótesis: El mezclado vía húmeda en el molino planetario genera una mezcla muy homogénea, y tal vez por ello no se alcanza la estructura en teoría más favorable, en la cual las partículas de hematites estarían rodeadas preferentemente de partículas de circona, y las partículas de cuarzo se hallarían dispuestas en el exterior. La posición del mineralizador sería la más favorable para acelerar la reacción.

- El mezclado realizado vía seca industrialmente se caracterizaba por no introducir inicialmente el cuarzo en el molino, sino que se introducía una vez homogeneizados la circona, la hematites y el mineralizador (A04). Es posible que dicho método se asemeje a un proceso tipo rebozado de las partículas de hematites, con lo cual la mezcla se aproximaría en mayor medida a la estructura deseada. Además, la incorporación final del cuarzo, provocaría que éste se hallase relativamente alejado tanto de la circona como del mineralizador, dificultando la formación inicial de fases vítreas.

- Los pigmentos mezclados en mortero de ágata y en molino de cuchillas conducirían a una mezcla de consistencia muy esponjosa, con contactos escasos entre las partículas, si bien con un grado de homogeneidad que no se 
puede determinar, pero que en principio podría ser más próximo al correspondiente al mezclado vía húmeda. Estas dos condiciones de homogeneidad y escasos contactos entre partículas serían coherentes con la escasa formación de circón y la menor proporción de fase vítrea.

En este esquema conceptual no es posible establecer a priori la posición más favorable del mineralizador $\left(\mathrm{Na}_{2} \mathrm{SiF}_{6}\right)$, ya que como se ha indicado anteriormente, existen dos posibles mecanismos de actuación del mineralizador, por medio de intermedios gaseosos y por medio de una fase líquida viscosa. Según la caracterización por microscopía electrónica de barrido, la mezcla preparada vía seca es más proclive al primer mecanismo, mientras que la mezcla preparada por vía húmeda sería más favorable al segundo.

Con respecto al mecanismo de actuación del mineralizador, también hay que considerar que el ciclo térmico también puede influir sobre el mismo, ya que el calentamiento lento que caracteriza el Ciclo STD, favorece en mayor medida la reacción del mineralizador con los restantes componentes para formar fases líquidas, que la formación del compuesto gaseoso $\mathrm{SiF}_{4}$. Para tratar de dilucidar el comportamiento del mineralizador, se decidió realizar un experimento utilizando un ciclo térmico con unas etapas diferentes, tal como se detalla en el siguiente apartado.

\subsubsection{Modificación del tratamiento térmico}

La verificación de la importancia de la transferencia de materia en fase gas para la correcta síntesis del circón se realizó modificando el tratamiento térmico. Según las hipótesis planteadas, el calentamiento lento del Ciclo STD favorecería la aparición de una fase vítrea de alta viscosidad, cuando el mineralizador y el cuarzo se hallan próximos (caso de la mezcla preparada en el molino planetario vía húmeda), fenómeno que no ocurriría si estuvieran relativamente alejados (caso de las mezclas preparadas vía seca). Sin embargo, una velocidad de calentamiento elevada puede favorecer que una fracción importante del mineralizador pueda actuar como generador de fase gas, a pesar de la proximidad con el cuarzo, ya que, en principio, el tiempo durante el cual se mantendrían las condiciones favorables al mecanismo a través de fases vítreas sería mucho más reducido, con lo cual una mayor fracción de mineralizador podría contribuir al transporte en fase gas.

Para llevar a cabo el experimento, se diseñó un nuevo ciclo térmico. Dicho tratamiento mantuvo las seis horas de permanencia a $1000^{\circ} \mathrm{C}$ del Ciclo STD, pero se caracterizaba por una velocidad de calentamiento constante de $25^{\circ} \mathrm{C} / \mathrm{min}$ entre la temperatura ambiente y la temperatura máxima del ciclo (este tratamiento recibió la denominación de Ciclo Rápido). 


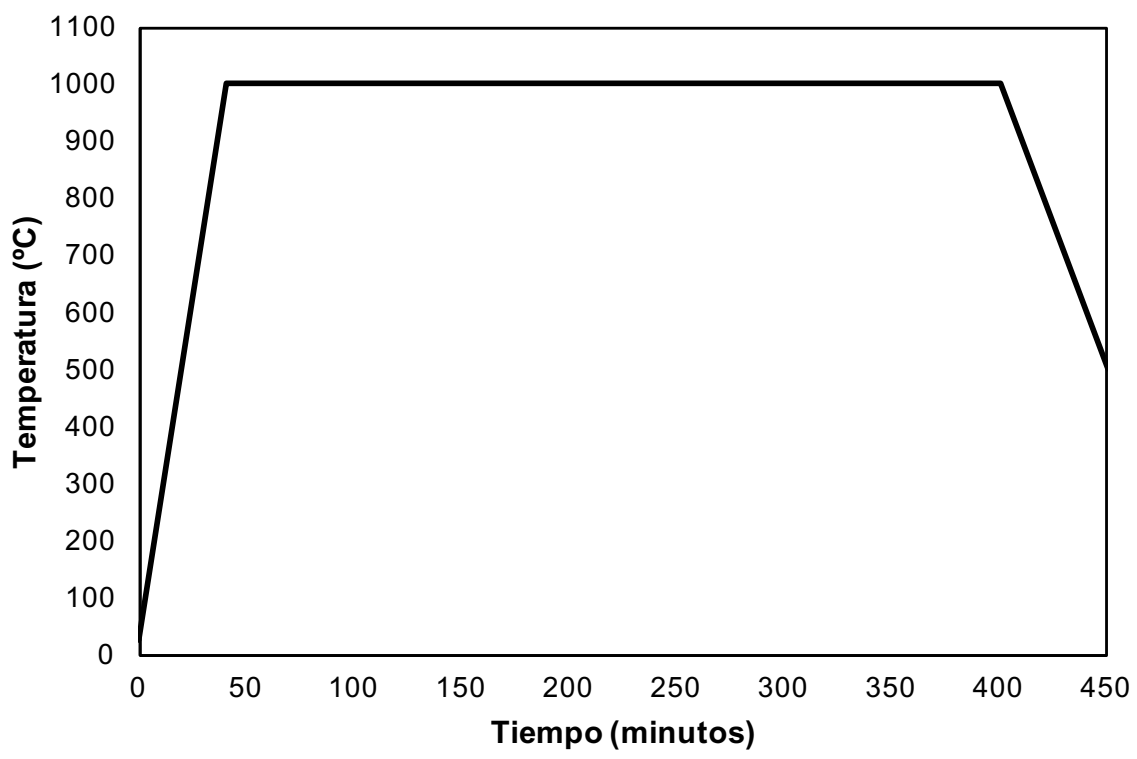

Figura 4.49 Ciclo Rápido utilizado para la síntesis de pigmentos

Para disponer de una muestra representativa de diferentes microestructuras de la mezcla de materias primas, con el Ciclo Rápido se sintetizaron pigmentos a partir de la fórmula N04 obtenida con tres métodos de preparación diferentes, la mezcla preparada industrialmente vía seca (referencia D01), la mezcla preparada vía húmeda en el molino planetario (referencia D02), y la mezcla preparada en el molino de cuchillas (referencia D03).

Tras el tratamiento térmico los tres pigmentos sintetizados se analizaron mediante difracción de rayos $\mathrm{X}$ obteniendo los porcentajes de fases cristalinas detallados en la Tabla 4.13.

Del mismo modo que en los apartados anteriores de estimaron los parámetros $\varsigma_{1}$ y $\varsigma_{2}$ que muestran el grado de avance de la reacción en función de la fracción de cuarzo que interviene en la formación del circón $\left(\varsigma_{1}\right)$ y la que pasa a formar parte de la fase vítrea (\$2). 
Tabla 4.13 Porcentaje de las fases cristalinas identificadas y composición de la fase amorfa (\% peso)

\begin{tabular}{|c|c|c|c|c|}
\hline & & D01 & D02 & D03 \\
\hline \multirow{4}{*}{ 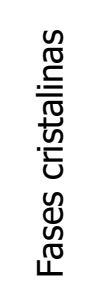 } & Cuarzo & $<1$ & 1 & 1 \\
\hline & Baddeleyita & 10 & 13 & 13 \\
\hline & Hematites & 21 & 24 & 21 \\
\hline & Circón & 49 & 62 & 49 \\
\hline & Fase amorfa total & 20 & 1 & 16 \\
\hline \multirow{3}{*}{ 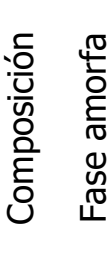 } & $\% \mathrm{Fe}_{2} \mathrm{O}_{3}$ & 3 & $<1$ & 2 \\
\hline & $\% \mathrm{SiO}_{2}$ & 5 & $<1$ & 5 \\
\hline & $\% \mathrm{ZrO}_{2}$ & 8 & $<1$ & 4 \\
\hline
\end{tabular}

Comparando los datos con los correspondientes a los pigmentos sintetizados a partir de las mismas mezclas, pero con el Ciclo STD (Figura 4.50) se apreciaron las siguientes tendencias:

- La mezcla preparada en el molino planetario vía húmeda es la que posee una mayor reactividad. Los pigmentos D01 y D03 son muy similares en cuanto a la formación de circón.

- El cambio del Ciclo STD al Ciclo Rápido muestra el notable efecto que una elevada velocidad de calentamiento provoca en la fracción de circón sintetizada, independientemente del método de preparación de la mezcla. Para todos los métodos de preparación se produce un aumento del porcentaje de circón formado, llegando a un $62 \%$ en el caso del pigmento D02, así como una disminución de baddeleyita y cuarzo.

- El incremento en el avance de la reacción de síntesis es mucho mayor en el caso de la mezcla preparada con el mezclado vía húmeda, seguida por la sintetizada en el molino de cuchillas. La mezcla preparada vía seca es la que presenta un menor aumento en la proporción de circón sintetizado ya que con el Ciclo STD se generaba una elevada cantidad de circón (45\%).

- En el caso de la baddeleyita las tendencias provocadas por los cambios en la velocidad de calentamiento poseen el sentido opuesto al circón, ya que disminuye al aumentar la velocidad de calentamiento, independientemente de 
la preparación de la mezcla. Sin embargo, las diferencias por efecto en la preparación sólo son notables con el calentamiento lento, y se amortiguan notablemente en el caso del calentamiento rápido.

- El porcentaje de cuarzo se reduce notablemente al pasar del Ciclo STD al Ciclo Rápido para cada uno de los métodos de mezclado ensayados, llegando casi a su total reacción.

- Comparando los resultados correspondientes al cuarzo y a la baddeleyita, es probable que con el Ciclo Rápido se consiga la reacción casi total del cuarzo y, por tanto, la señal de la baddeleyita corresponda al exceso presente en la composición de materias primas.

- Por otra parte, los resultados obtenidos en la determinación de la fase amorfa en estos tres experimentos son cruciales, observándose diferencias muy significativas. Las composiciones D01 y D03 presentan un porcentaje en fase amorfa importante (15-20\%) mientras que la composición D02 apenas presenta fase amorfa, en torno a $1 \%$.

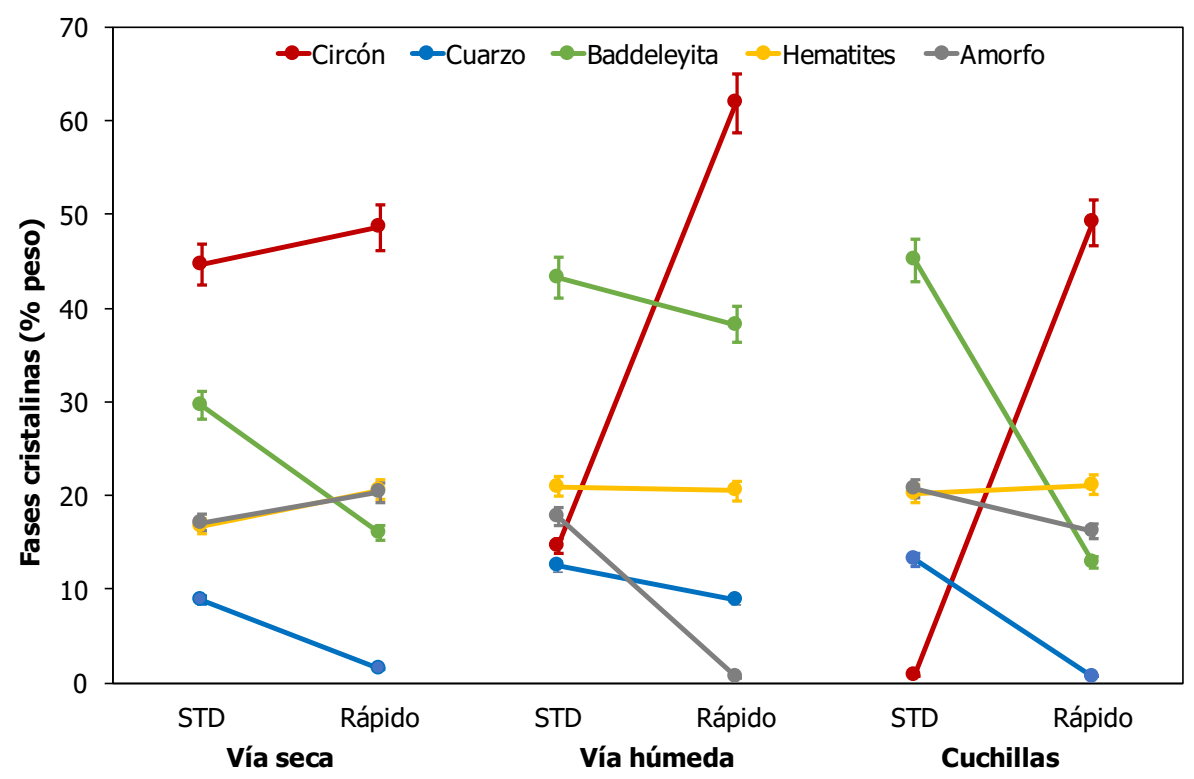

Figura 4.50 Evolución de las fases cristalinas presentes en los pigmentos, frente a la velocidad de calentamiento y el método de mezclado

En relación a los parámetros $\varsigma_{1}$ y $\varsigma_{2}$ que muestran la evolución del grado de avance en función de la fracción de sílice que reaccionará para formar circón ( $\left.\varsigma_{1}\right)$ o se incorporará a la fase vítrea o amorfa (\$2), se observan diferencias muy importantes (Figura 4.51). 
- El parámetro $\varsigma_{1}$ aumenta de forma muy importante cuando se utiliza el ciclo rápido en el tratamiento térmico, siendo este incremento mucho mayor en las composiciones mezcladas vía húmeda y mezclado vía seca con cuchillas, ya que, en estos casos, el porcentaje de circón formado ha aumentado mucho al modificar el ciclo térmico. En el caso del mezclado vía húmeda $\varsigma_{1}$ alcanza valores de 0,95 lo que confirma que la reacción se ha llevado a cabo casi completamente.

- $\quad$ El aumento de $\varsigma_{1}$ es moderado en la composición industrial mezclada mediante vía seca lo que coincidiría con el ligero aumento de formación de circón.

- Por otro lado, el parámetro §2 se modifica en sentido inverso. Al utilizar el ciclo rápido §2 disminuye de forma muy importante en las composiciones mezcladas vía húmeda y vía seca con cuchillas debido a la disminución en la formación de la fase vítrea. En la composición industrial mezclada vía seca el parámetro §2 apenas se modifica.

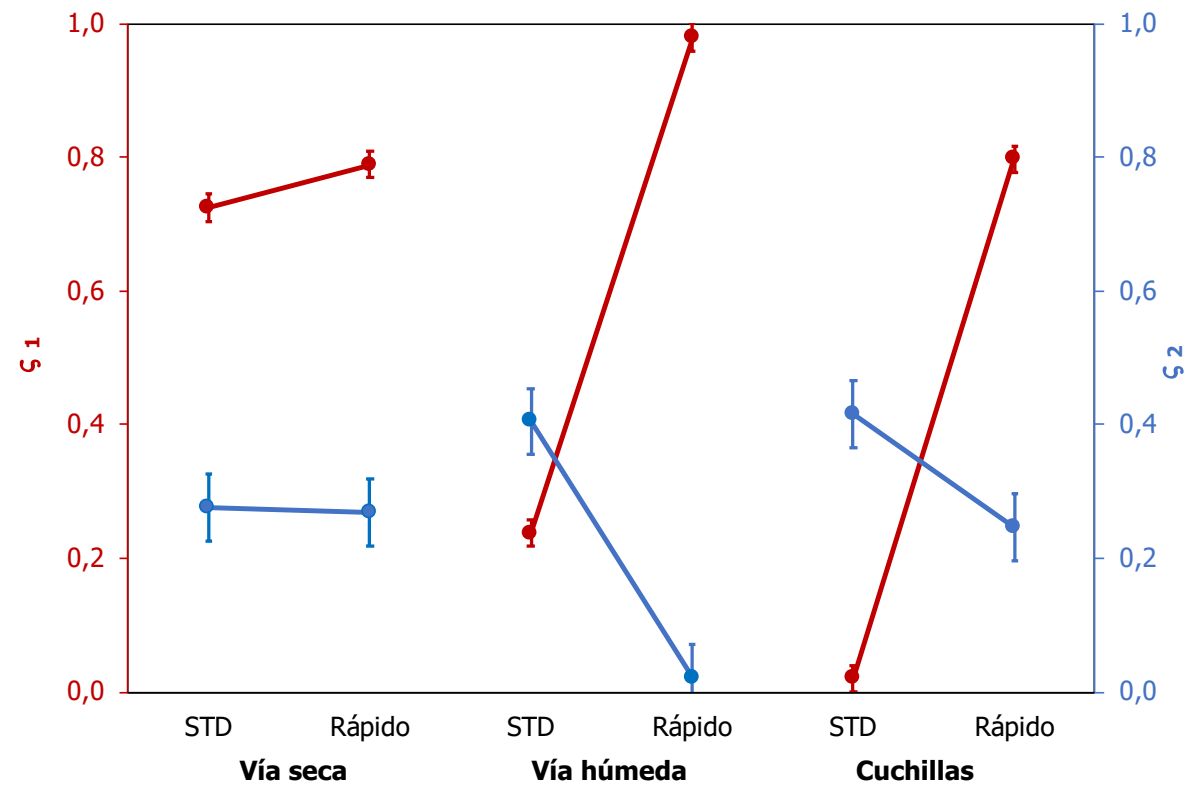

Figura 4.51 Evolución de parámetros $\varsigma 1$ y $\varsigma 2$, frente a la velocidad de calentamiento y el método de mezclado

Estos experimentos parecían confirmar que, independientemente del proceso de mezclado de materias primas, la génesis del circón aumentaba si la reacción se llevaba a cabo preferentemente mediante el transporte de la sílice a través de la fase gas, lo cual se conseguía fácilmente empleando un ciclo con calentamiento rápido, que favorecía la acción del mineralizador vía intermedios 
gaseosos. Sin embargo, un calentamiento lento como corresponde al Ciclo STD, parecía beneficiar la acción del mineralizador a través de una fase líquida silícea de alta viscosidad ralentizando notablemente la reacción. Esta reacción podría atenuarse si el mineralizador y el cuarzo se hallaran espacialmente separados, de modo que la fracción de líquido que se pudiera formar antes de alcanzar la temperatura máxima del tratamiento térmico fuera muy pequeña, y por tanto el mineralizador actuara preferentemente vía intermedios gaseosos.

\section{4 .3 Desarrollo de collor}

Los tres pigmentos sintetizados con el Ciclo Rápido se incorporaron a los vidriados para evaluar si el circón generado había rodeado a las partículas de hematites, o, por el contrario, los cristales de dicha fase habían crecido sin crear la cápsula protectora que caracteriza el pigmento.

Las piezas esmaltadas obtenidas incorporando los pigmentos D01, D02 y D03 a los dos vidriados presentaron tonalidades rojizas de diversa intensidad en el caso del vidriado transparente (Figura 4.52), que fueron rosadas en el vidriado opaco (Figura 4.53). Dado el notable color generado, se midieron las coordenadas cromáticas de todas las piezas, las cuales se detallan en la Tabla 4.14 y Tabla 4.15 .
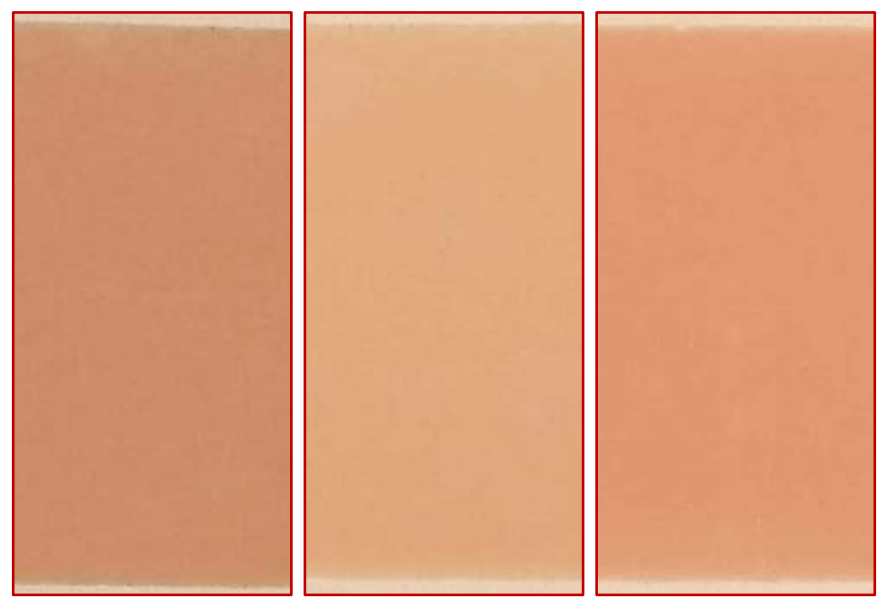

Figura 4.52 Probetas esmaltadas de las piezas D01, D02 y D03 con el vidriado transparente 
Tabla 4.14 Coordenadas cromáticas desarrolladas por los pigmentos en el vidriado transparente $\left(1120^{\circ} \mathrm{C}\right)$

\begin{tabular}{|ccccccc|}
\hline Referencia & \multicolumn{3}{c}{ L* $^{*}$} & \multicolumn{3}{c|}{$\mathrm{a}^{*}$} \\
& $\mathrm{X}$ & $\sigma$ & $\mathrm{X}$ & $\sigma$ & $\mathrm{X}$ & $\sigma$ \\
D01 & 65,50 & 0,14 & 17,56 & 0,42 & 21,23 & 0,16 \\
D02 & 73,59 & 0,14 & 13,30 & 0,22 & 22,86 & 0,10 \\
D03 & 69,05 & 0,19 & 18,74 & 0,12 & 22,49 & 0,07 \\
\hline
\end{tabular}
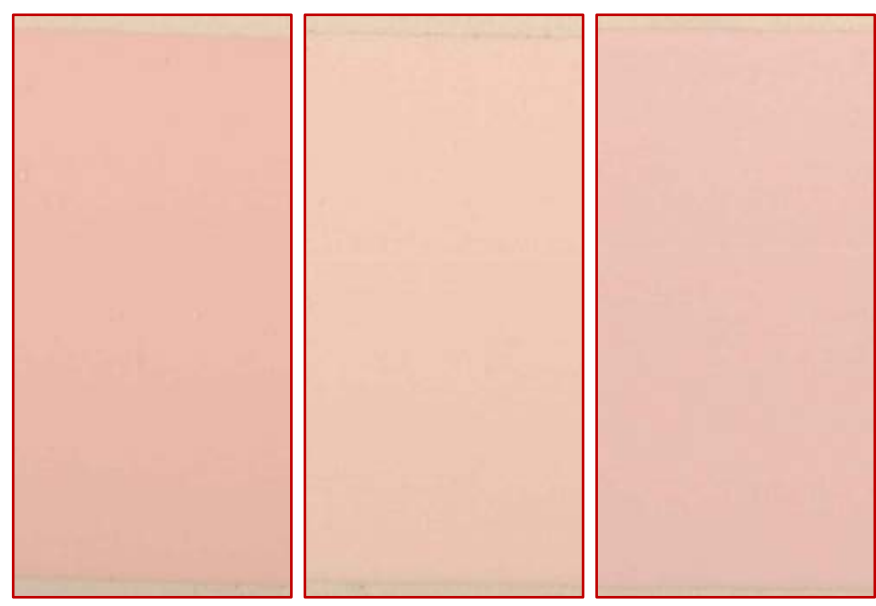

Figura 4.53 Probetas esmaltadas de las piezas D01, D02 y D03 con el vidriado opaco

Tabla 4.15 Coordenadas cromáticas desarrolladas por los pigmentos en el vidriado opaco $\left(1040^{\circ} \mathrm{C}\right)$

\begin{tabular}{|ccccccc|}
\hline Referencia & \multicolumn{3}{c}{ L* $^{*}$} & \multicolumn{3}{c}{$\mathrm{a}^{*}$} \\
& $\mathrm{X}$ & $\sigma$ & $\mathrm{X}$ & $\sigma$ & $\mathrm{X}$ & $\sigma$ \\
D01 & 79,35 & 0,06 & 12,03 & 0,02 & 10,21 & 0,02 \\
D02 & 82,36 & 0,04 & 9,25 & 0,06 & 10,44 & 0,11 \\
D03 & 80,63 & 0,10 & 10,09 & 0,07 & 8,16 & 0,03 \\
\hline
\end{tabular}


La representación de los datos colorimétricos de estos tres pigmentos, junto con los datos correspondientes a la pieza preparada con el pigmento A04 (mezclada vía seca industrialmente y calcinada con el Ciclo STD), permiten extraer las relaciones que se detallan a continuación (Figura 4.54, Figura 4.55, Figura 4.56).

- Los cuatro pigmentos abarcan un intervalo de luminosidad bastante amplio, sobre todo en el vidriado transparente (unas nueve unidades frente a tres en el vidriado opaco). Los dos pigmentos sintetizados a partir de la mezcla preparada vía seca (D01, D03) son los que conducen a los valores más reducidos de $L^{*}$ en el vidriado transparente, aunque algo más en el caso del sintetizado con el Ciclo Rápido. En este vidriado la mayor luminosidad se obtiene con el pigmento sintetizado a partir de la mezcla preparada en el molino planetario vía húmeda, mientras que la elaborada en el molino de cuchillas ocupa una posición intermedia. Sin embargo, en el vidriado opaco las diferencias son mucho más reducidas y, además, el orden de los pigmentos se altera notablemente, obteniéndose los valores más reducidos de $L^{*}$ con los productos obtenidos a partir de las mezclas vía seca y con el molino de cuchillas cuando son calcinadas con el Ciclo Rápido. Por otra parte, los otros dos pigmentos generan valores de luminosidad más elevados y similares entre sí.

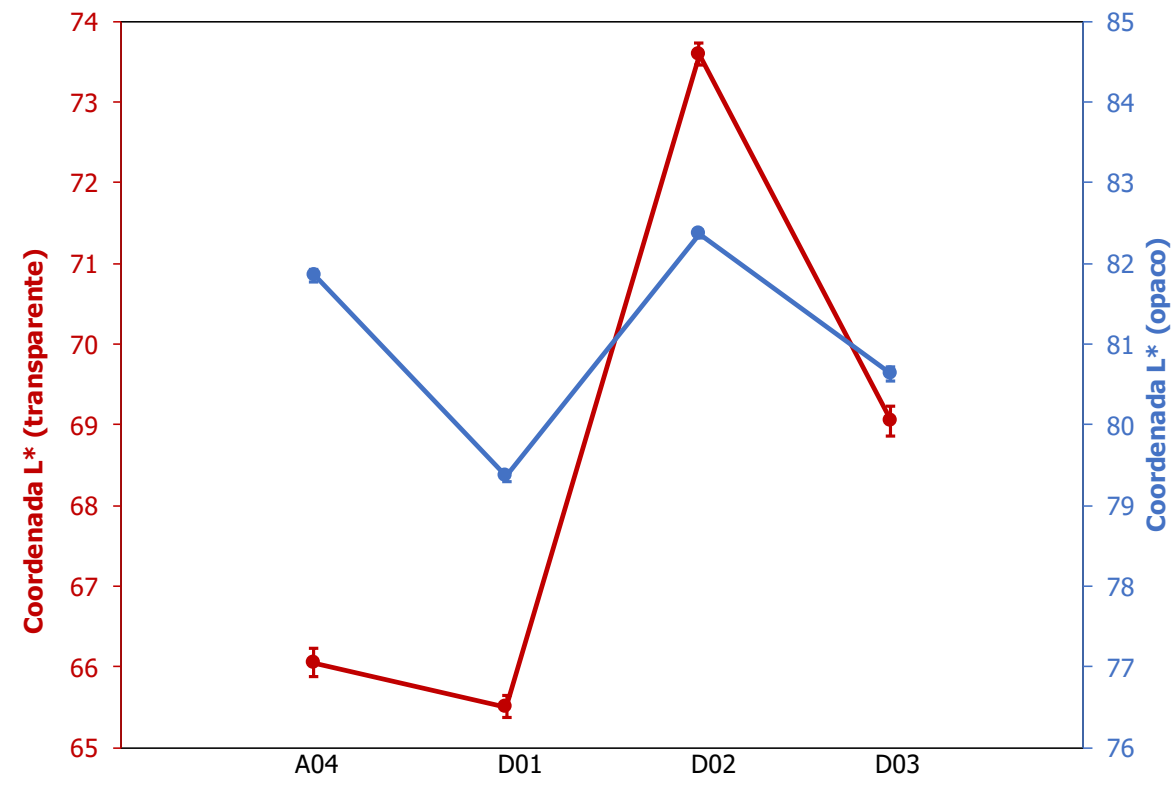

Figura 4.54 Evolución de la coordenada L* generada en los dos vidriados ensayados

- La componente roja presenta un intervalo de variación no tan amplio como la luminosidad (seis unidades en el vidriado transparente y tres en el opaco), pero algunos resultados son bastante inesperados. El valor de a* más elevado en el vidriado transparente se obtiene a partir del pigmento cuya 
mezcla se había preparado en el molino de cuchillas, si bien dicho pigmento genera uno de los valores más reducidos en el vidriado opaco. Salvo dicho comportamiento anómalo, los otros tres pigmentos muestran un comportamiento bastante paralelo en los dos vidriados. Los valores de a* más elevados se obtienen con los pigmentos sintetizados a partir de la mezcla preparada vía seca y calcinada con el Ciclo Rápido, mientras que la misma mezcla calcinada con el Ciclo STD conduce a un pigmento que genera valores de a* inferiores y relativamente próximos a los generados por la mezcla preparada en el molino planetario vía húmeda y calcinada con el Ciclo Rápido.

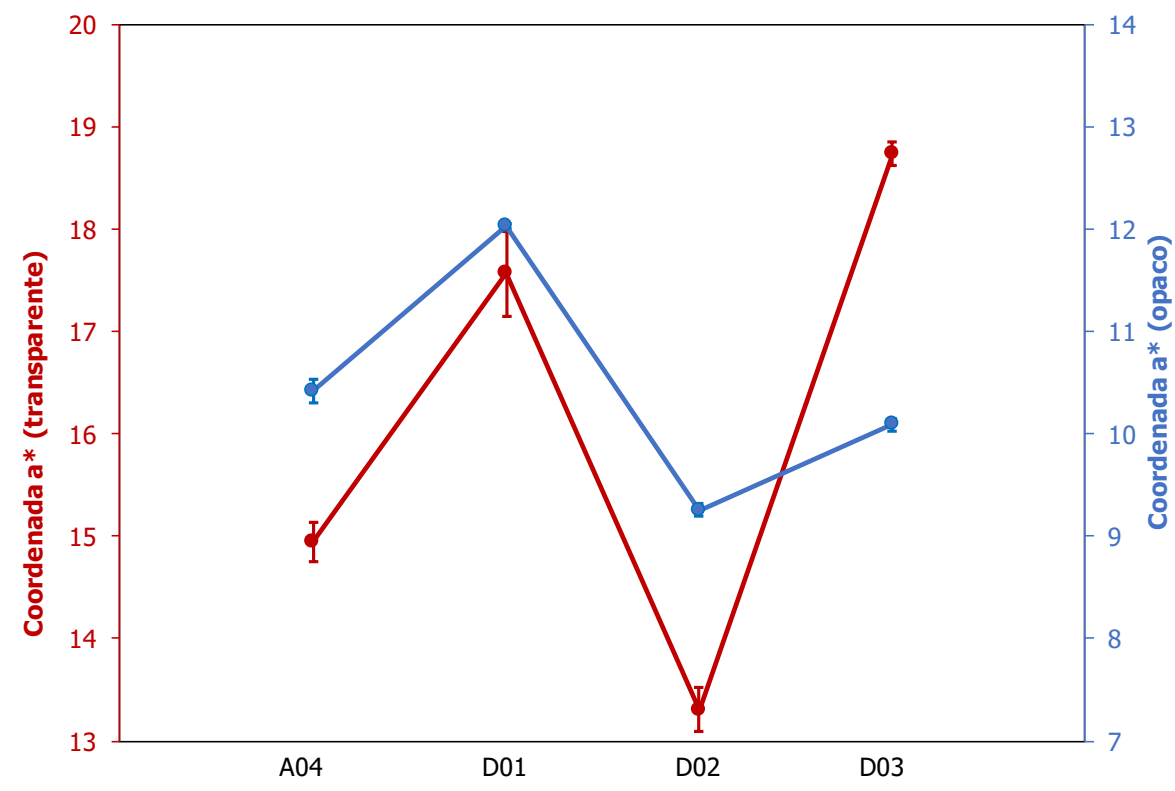

Figura 4.55 Evolución de la coordenada a* generada en los dos vidriados ensayados

- La componente amarilla es la que presenta el menor intervalo de variación (unas cuatro unidades en los dos vidriados), si bien se aprecia que la ordenación de los pigmentos con respecto al parámetro b* cambia según el vidriado considerado. Los más estables son los pigmentos obtenidos a partir de la mezcla preparada vía seca y calcinada con el Ciclo STD (b* más reducida en los dos vidriados), y a partir de la mezcla preparada en el molino planetario vía húmeda sometida al Ciclo Rápido (b* más elevada en los dos vidriados). Por el contrario, las otras dos mezclas conducen a pigmentos que generan valores de b* muy variables según el vidriado al que se incorporan. 


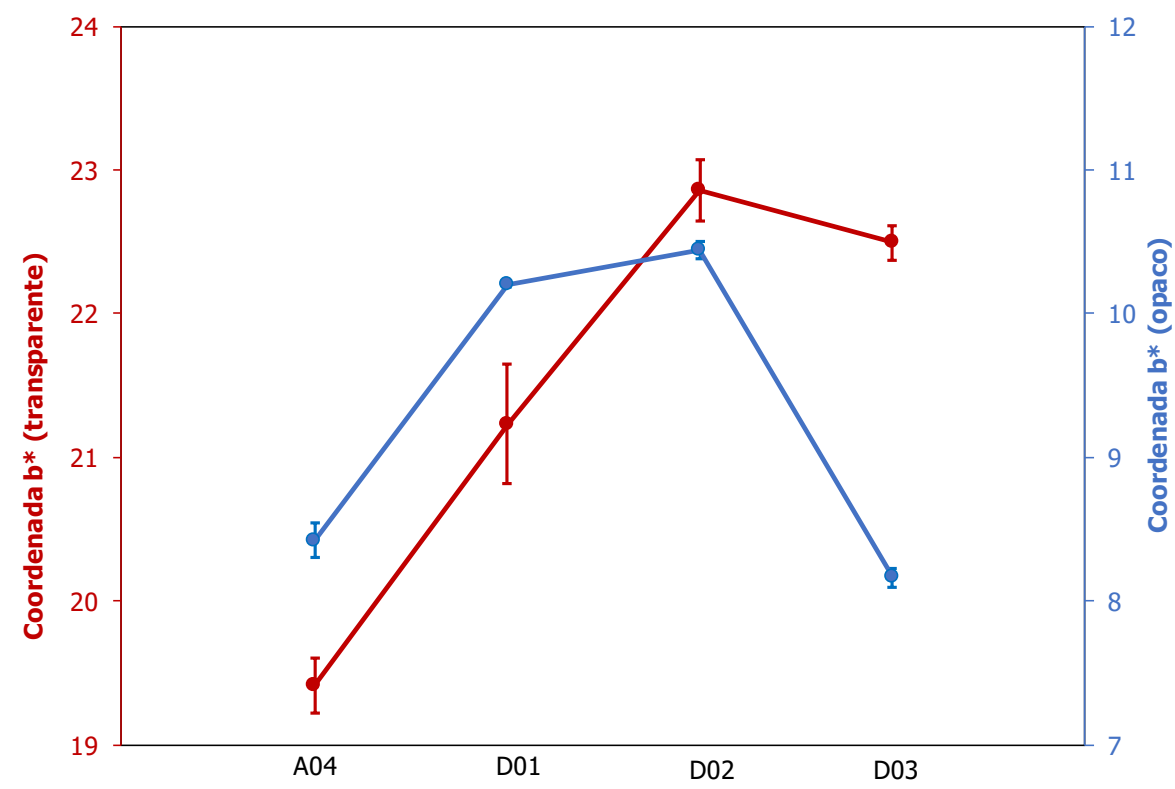

Figura 4.56 Evolución de la coordenada b* generada en los dos vidriados ensayados

Los resultados confirman que no existe una relación directa entre la cantidad de circón generado y el poder colorante del pigmento (que está relacionado con la proporción de hematites encapsulado por el circón), si bien con los cuatro pigmentos ensayados se obtiene una coloración no despreciable en los vidriados. El pigmento con un mayor porcentaje de circón era el que se había mezclado vía húmeda con el molino Pulverisette (D02), sin embargo, este pigmento presentaba un valor de a* más bajo y L* más alto.

Desde el punto de vista de la componente roja, el pigmento con mayor poder colorante es el obtenido a partir de la mezcla preparada en el molino de cuchillas (D03), pero si se tiene en cuenta que también es conveniente una luminosidad reducida, el más adecuado sería el sintetizado a partir del mezclado vía seca con el Ciclo Rápido (D01). La mezcla preparada en el molino planetario vía húmeda genera el pigmento con menor poder colorante desde todos los puntos de vista.

Los datos colorimétricos confirman que el Ciclo Rápido resulta mucho más favorable para sintetizar los pigmentos que el Ciclo STD, ya que no sólo mejora los resultados para la mezcla preparada vía seca, sino que consigue obtener pigmentos con notable poder colorante a partir de mezclas que apenas reaccionaban con el Ciclo STD. 
Los resultados obtenidos con la técnica de difracción de rayos X y colorimetría confirman que al incrementar la velocidad de calentamiento se mejoran notablemente los resultados, con un mayor porcentaje de circón formado, y ello se puede correlacionar con una mayor influencia del mecanismo vía fase gas. A través de la fase gas el transporte de reactantes es más rápido y por tanto se puede compensar en parte una microestructura menos favorable de la mezcla de materias primas, por lo menos desde el punto de vista de la síntesis del circón. Sin embargo, resulta complejo evitar el efecto de una distribución inadecuada de la hematites, que impide su encapsulado por parte del circón sintetizado.

\subsubsection{Caracterización microestructural}

Dadas las enormes diferencias halladas en el porcentaje de circón formado para la misma mezcla calcinada con los dos tratamientos térmicos ensayados (ciclos STD y Rápido), y el notable poder colorante obtenido con los pigmentos generados con el Ciclo Rápido, se consideró conveniente comparar la microestructura de los pigmentos sintetizados utilizando los dos ciclos ensayados. El objetivo era determinar si las diferencias en la cantidad de circón generado y el poder colorante se podían correlacionar con cambios en la microestructura.

El análisis se realizó sobre los dos pigmentos sintetizados a partir de la mezcla preparada en el molino de cuchillas, pero sometidos a los Ciclos STD y Rápido (pigmentos C04 y D03 respectivamente), que presentaban un cambio sustancial tanto en la proporción de circón generado, como en el poder colorante. Los resultados obtenidos de la caracterización microestructural de los pigmentos utilizando el microscopio electrónico de barrido se detallan a continuación.

- $\quad$ El análisis en el MEB del pigmento C04 (Ciclo STD) indicó que estaba formado en parte por aglomerados de partículas de forma y tamaño irregulares, lo cual indicaba una baja tasa de formación de cristales de circón (ver Figura 4.57 y Figura 4.58). Como puede apreciarse en las micrografías, dichas partículas se hallaban cementadas por una matriz de aspecto vítreo, que en principio podrían ser tanto partículas de cuarzo a medio reaccionar, como el vidrio de sílice que permite la transferencia de materia durante la reacción. Sin embargo la imagen de la misma partícula de la Figura 4.58 tomada a mayor voltaje, de forma que la señal recogida por el detector es de más profundidad (mayor volumen de interacción haz de electrones-muestra) (Figura 4.59), mostró que en el interior de la matriz de aspecto vítreo se hallan zonas ricas en elementos pesados (presumiblemente el circonio), por lo que se puede suponer que inicialmente se ha formado un vidrio que las ha englobado. Esta suposición se ve reforzada por el microanálisis EDX realizado en la zona de aspecto vítreo de la partícula de la Figura 4.58 (ver Figura 4.60), donde además de silicio, hierro y circonio, también se detecta sodio, que procedería del mineralizador y que sería un componente imprescindible para formar un vidrio de bajo punto de fusión a las condiciones de reacción. 


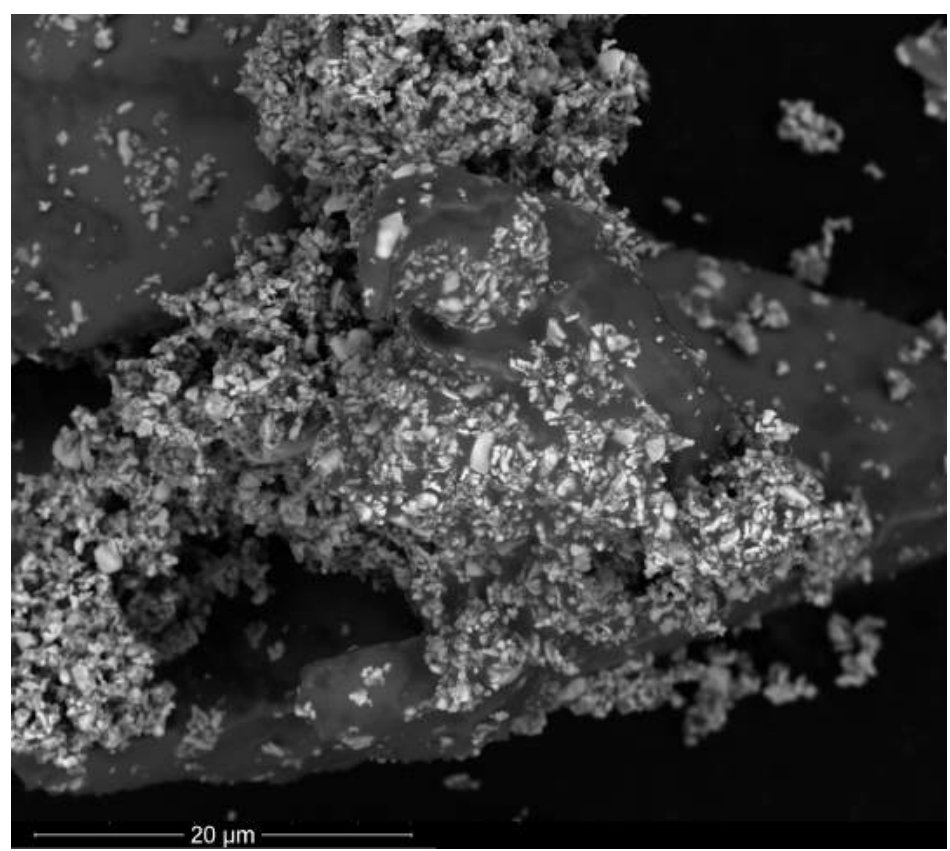

Figura 4.57 Micrografía de una partícula del pigmento C04 obtenida con la señal de electrones retrodispersados del MEB (x6000)

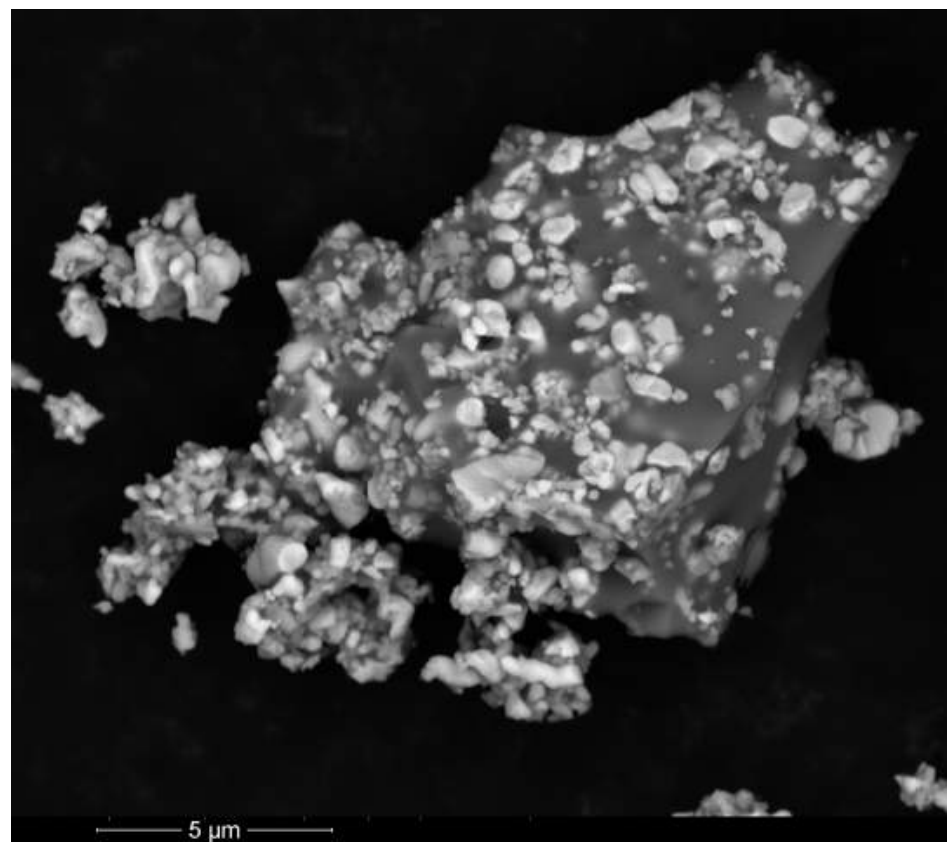

Figura 4.58 Micrografía de una partícula del pigmento C04 obtenida con la señal de electrones retrodispersados del MEB (x15000) 


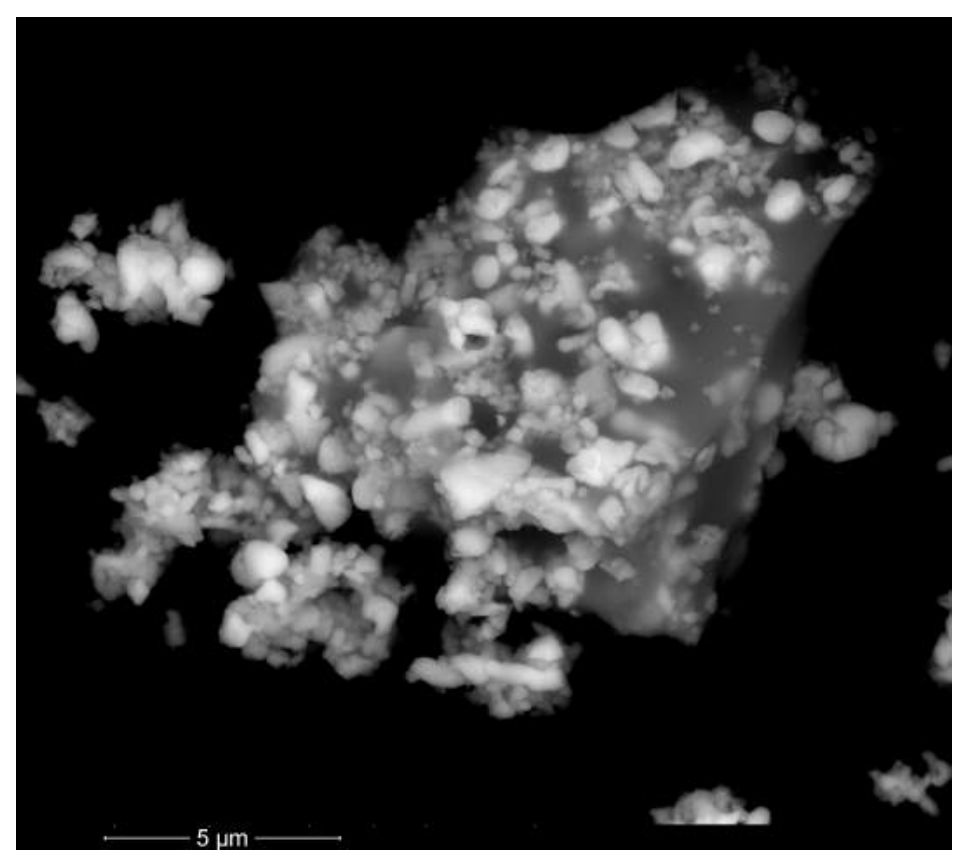

Figura 4.59 Micrografía de una partícula del pigmento C04 obtenida con la señal de electrones retrodispersados del MEB (x15000)

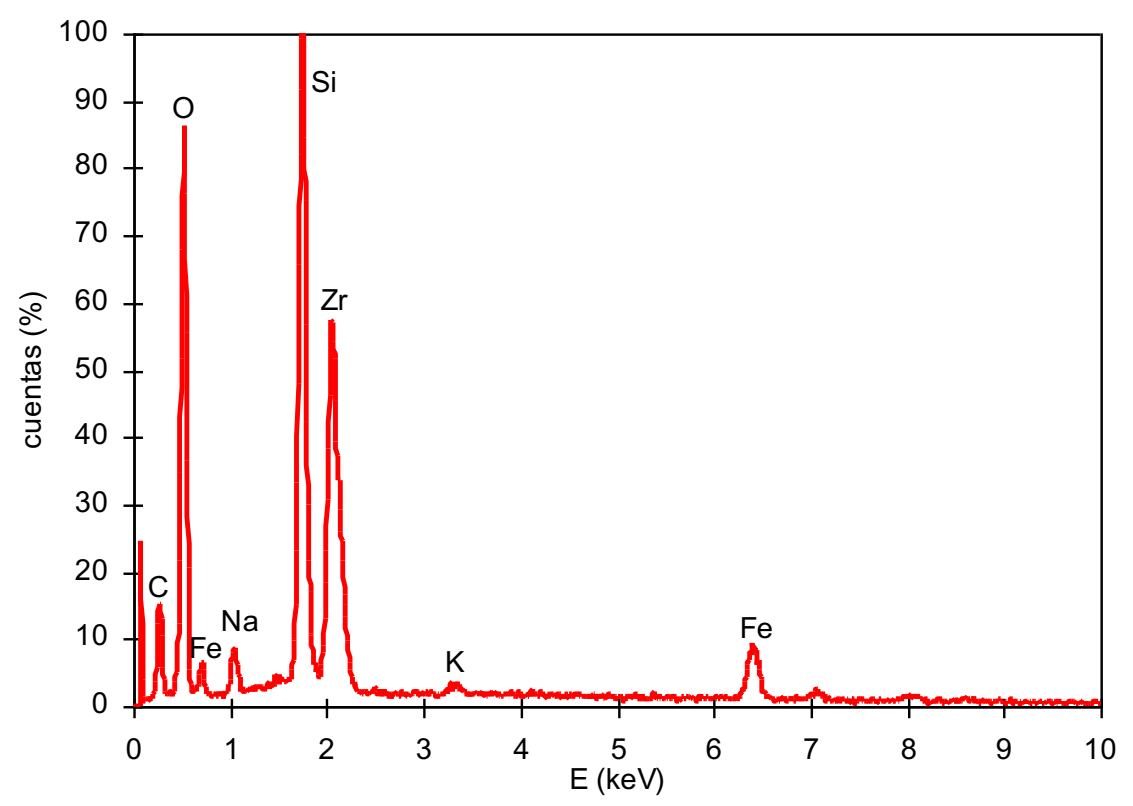

Figura 4.60 Análisis EDX global de la zona de aspecto vítreo en el pigmento $\mathrm{CO} 4$ 
- El pigmento D03 (Ciclo Rápido) presentó una microestructura muy diferente, ya que una parte importante de las partículas eran cristales bipiramidales de circón, con un tamaño en torno a las 5 micras, entre los que se distinguían partículas redondeadas más pequeñas, las cuales podrían contener el hierro y el circonio que quedaba por reaccionar (Figura 4.61). Utilizando más aumentos en el microscopio, se puede apreciar en algunos casos como los cristales de circón engloban durante su crecimiento partículas más pequeñas, ya sea de circona o de hematites (Figura 4.62). En este pigmento no se hallaron partículas o zonas con aspecto vítreo, lo cual indicaba que había actuado un mecanismo diferente al que había operado con el Ciclo STD, muy probablemente un transporte en fase gas que había permitido la génesis de cristales bien formados.

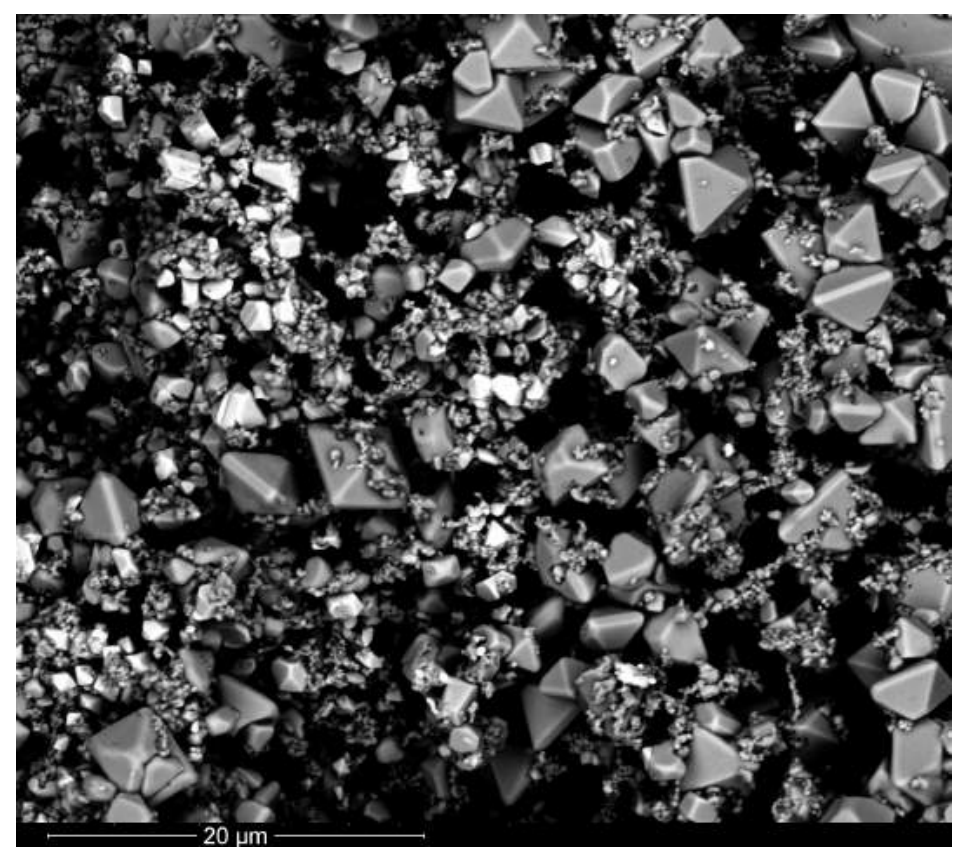

Figura 4.61 Micrografía de una partícula del pigmento D03 obtenida con la señal de electrones retrodispersados del MEB (x6000) 


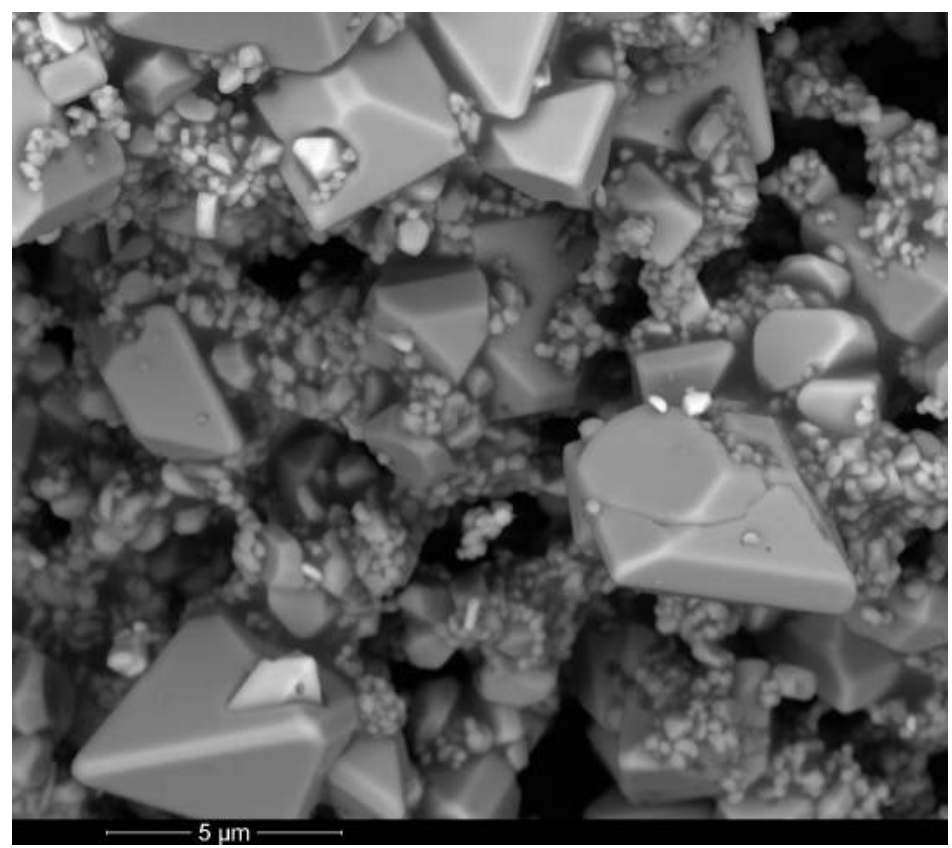

Figura 4.62 Micrografía de una partícula del pigmento C04 obtenida con la señal de electrones retrodispersados del MEB (x15000)

Los resultados de la caracterización indicaron que los pigmentos C04 y D03 se parecían en su microestructura a los pigmentos A06 y A02 respectivamente (caracterizados en el apartado 4.1.3), por lo que se podría suponer que los mecanismos que habían actuado durante la síntesis eran similares. Así en los pigmentos A06 y C04, sintetizados con el Ciclo STD y una velocidad de calentamiento lenta, la reacción habría transcurrido mediante la generación de una fase líquida viscosa, a través de la cual el transporte de materia es lento, y por tanto la proporción de circón obtenida era de moderada a prácticamente nula. Por el contrario, en los pigmentos A02 y D03 (éste último sintetizado con el Ciclo Rápido y velocidad de calentamiento más rápida), habría actuado un mecanismo de transporte en fase gas, que habría permitido generar una elevada cantidad de circón, y que además los cristales hubiesen crecido lo suficiente para encapsular otras partículas, especialmente de hematites, obteniendo un material con elevado poder colorante.

Los análisis de microestructura confirman la importancia que tiene favorecer el mecanismo de reacción a través de la fase gas para sintetizar correctamente el pigmento. En el caso del pigmento A02 o A04 ello se consigue con una microestructura adecuada de la mezcla de partida, que aparentemente evita que se forme la fase vítrea a baja temperatura, aun cuando se calcine con el Ciclo STD. Por el contrario, la mezcla de partida para obtener el D03 no es favorable a dicho mecanismo, pero este problema puede soslayarse, al menos 
parcialmente, utilizando el Ciclo Rápido, que favorece el mecanismo de reacción vía intermedios gaseosos.

Se puede concluir que los experimentos realizados confirman la importancia que posee la microestructura de la mezcla de materias primas o cómo están distribuidas espacialmente las materias primas sobre el mecanismo de la reacción, sobre todo cuando se opera con el Ciclo STD. Por el contrario, el Ciclo Rápido parece amortiguar en buena medida los efectos de la microestructura de la mezcla de materias primas, favoreciendo que la reacción transcurra vía intermedios gaseosos, pero sin llegar a eliminar del todo la influencia de dicha variable. 


\subsection{Métodos de mezclado vía seca}

Los resultados descritos previamente apuntaban a una variabilidad muy importante en la reactividad de la mezcla de materias primas en función del método de preparación utilizado. El proceso industrial utilizado para preparar las muestras tras el mezclado vía seca conducía a porcentajes de circón más elevados que las mezclas preparadas en el molino planetario vía húmeda o en el molino de cuchillas en el laboratorio, sobre todo cuando la calcinación se realizaba con el Ciclo STD.

En consecuencia, se decidió ampliar los ensayos, analizando otros métodos de mezclado vía seca, para determinar si se podían obtener pigmentos con un mayor poder colorante que los obtenidos hasta el momento. En primer lugar se trató de mejorar el proceso en el molino de cuchillas, introduciendo las materias primas en diferentes etapas [56]. En segundo lugar, se utilizó el molino planetario Pulverisette operando vía seca, incluyendo del mismo modo la variable de la introducción de las materias primas por etapas. Finalmente se ensayó el mezclado en un molino de bastidores y en un molino de mortero. Los experimentos se llevaron a cabo utilizando la Fórmula № 4.

\subsubsection{Mezclado por etapas en el molino de cuchillas}

Dado que el molino de cuchillas generaba una mezcla poco reactiva cuando se introducían simultáneamente todas las materias primas del pigmento, se realizó una variante del método para tratar de separar espacialmente el cuarzo del resto de reactantes.

Para realizar el experimento se preparó primero la mezcla de circona, mineralizador y hematites, a la que se añadió una pequeña proporción de humedad para favorecer una granulación incipiente, y luego se agregó el cuarzo y el fluidificante. La idea era tratar de separar espacialmente el cuarzo del resto de materias primas, mediante la formación de gránulos de éstas últimas, alrededor de los cuales se dispondrían las partículas de $\mathrm{SiO}_{2}$.

El pigmento se sintetizó con el Ciclo STD, obteniéndose un material de color rojizo, cuya cuantificación de fases cristalinas mediante difracción de rayos $\mathrm{X}$ condujo a los resultados recogidos en la Tabla 4.16. 
Tabla 4.16 Porcentaje de las fases cristalinas identificadas y composición de la fase amorfa (\% peso)

\begin{tabular}{|c|c|c|}
\hline & & E01 \\
\hline \multirow{4}{*}{ 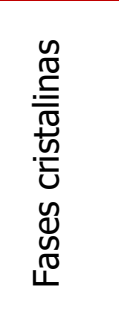 } & Cuarzo & 14 \\
\hline & Baddeleyita & 49 \\
\hline & Hematites & 22 \\
\hline & Circón & $<1$ \\
\hline & Fase amorfa total & 15 \\
\hline \multirow{3}{*}{ 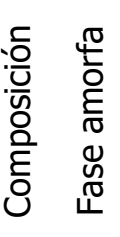 } & $\% \mathrm{Fe}_{2} \mathrm{O}_{3}$ & 2 \\
\hline & $\% \mathrm{SiO}_{2}$ & 8 \\
\hline & $\% \mathrm{ZrO}_{2}$ & 1 \\
\hline
\end{tabular}

Los datos indican que la formación de circón había sido prácticamente nula, lo cual es un resultado similar al pigmento obtenido mezclando en el molino de cuchillas todos los componentes desde el inicio (pigmento C04, con un $1 \%$ de circón).

Los resultados apuntaban que la pretendida granulación incipiente de la circona, el cromóforo y el mineralizador, o bien no se había conseguido con el método utilizado, o si se había conseguido no permitió mejorar la distribución espacial de las materias primas en la mezcla sometida a tratamiento térmico, y por tanto su reactividad seguía siendo muy baja.

En consecuencia, debido a la escasa presencia de circón obtenida utilizando este método de mezclado, se decidió ensayar otras vías alternativas. 


\subsubsection{Mezclado en el molino planetario vía seca}

Este grupo de experimentos se realizaron en el mismo molino planetario Pulverisette utilizado para los experimentos vía húmeda, pero operando vía seca.

Siguiendo el esquema expuesto en el apartado anterior, se decidió separar la incorporación de las materias primas, para tratar de favorecer la proximidad espacial de la circona, la hematites y el mineralizador. Por ello el mezclado se realizó en dos etapas, pero en ambas se mantuvo la velocidad del molino en $230 \mathrm{rpm}$ :

- Una primera etapa de 15 minutos donde se mezclaron todas las materias primas excepto el cuarzo.

- Una segunda etapa de 5 minutos donde se incorporó el cuarzo.

Para llevar a cabo este experimento, se dosificaron las materias primas según la fórmula $\mathrm{N}^{04}$, y se mezclaron según el procedimiento expuesto anteriormente, obteniéndose una mezcla de aspecto homogéneo (pigmento E02). La calcinación de esta con el Ciclo STD generó un material de color rojizo homogéneo, cuya caracterización mediante difracción de rayos $X$ condujo a los datos reflejados en la Tabla 4.17.

Tabla 4.17 Porcentaje de las fases cristalinas identificadas y composición de la fase amorfa (\% peso)

\begin{tabular}{|c|c|c|c|}
\hline & & & E02 \\
\hline \multirow{4}{*}{\multicolumn{2}{|c|}{ 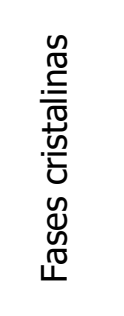 }} & Cuarzo & 14 \\
\hline & & Baddeleyita & 45 \\
\hline & & Hematites & 20 \\
\hline & & Circón & 1 \\
\hline & & Fase amorfa total & 19 \\
\hline \multirow{3}{*}{\multicolumn{2}{|c|}{ 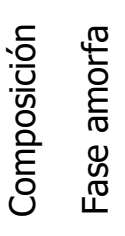 }} & $\% \mathrm{Fe}_{2} \mathrm{O}_{3}$ & 3 \\
\hline & & $\% \mathrm{SiO}_{2}$ & 7 \\
\hline & & $\% \mathrm{ZrO}_{2}$ & 4 \\
\hline
\end{tabular}


El resultado indicaba claramente que la mezcla preparada vía seca con el método descrito poseía una reactividad tan baja que no permitía la síntesis del circón con el ciclo térmico empleado. En este sentido el resultado apenas difería de los experimentos realizados con el molino de cuchillas, a pesar de que el método era claramente diferente.

Aparentemente el mezclado vía seca ya sea en el molino de bolas o en el molino de cuchillas, no generaba una mezcla con las características necesarias para sintetizar el circón utilizando el Ciclo STD.

\subsubsection{Mezclado en molino de bastidor}

Los experimentos realizados en este apartado estaban basados en un método de mezclado bastante suave, como es el mezclado vía seca en un molino de bastidores para jarras cilíndricas, con una velocidad de rotación baja. Siguiendo con la metodología expuesta en este apartado para favorecer la proximidad espacial de la circona y de la hematites, la incorporación de las materias primas se realizó en dos etapas.

Las mezclas se prepararon en un recipiente de $200 \mathrm{~cm}^{3}$ aproximadamente, con una carga de $142 \mathrm{~g}$ de bolas de alúmina de $1 \mathrm{~cm}$ de diámetro. En el recipiente se introdujeron las materias primas correspondientes a $50 \mathrm{~g}$ de la fórmula $\mathrm{N}^{04}$, utilizando tres metodologías diferentes.

- $\quad$ Pigmento E03: En primer lugar, se introdujo la circona, la hematites y el mineralizador, y se mezcló durante dos horas. En segundo lugar, se introdujo el cuarzo y el fluidificante, y se mezcló durante otra hora.

- Pigmento E04: En primer lugar, se introdujo la circona, la hematites, el mineralizador y el fluidificante, y se mezcló durante dos horas. En segundo lugar, se introdujo el cuarzo y se mezcló durante otra hora.

- $\quad$ Pigmento E05: Las condiciones fueron idénticas a las descritas para el pigmento E04, pero con la diferencia de que el mineralizador $\left(\mathrm{Na}_{2} \mathrm{SiF}_{6}\right)$ se había molturado previamente en mortero de ágata hasta atravesar una malla de 40 $\mu \mathrm{m}$. Puesto que dicho componente se suministró en forma de cristales de tamaño elevado, se dedujo que este factor podría afectar a su reactividad dado que el método de mezclado utilizado no favorecía la reducción en su tamaño de partícula. 
El material generado mediante los tres procedimientos descritos presentó un aspecto diferente al generado vía húmeda en el molino planetario, menos suelto y con un color distinto, como si las partículas de hematites se hubiesen dispuesto de un modo diferente.

Los tres materiales se calcinaron con el Ciclo STD, obteniéndose un producto de color rojizo granate, que había sinterizado ligeramente. Las masas eran relativamente blandas, pero la principal diferencia que se apreció fue la mayor dureza de los gránulos que las constituían en el caso del E03. Aparentemente la incorporación inicial del fluidificante conduce a gránulos más blandos (pigmentos E04 y E05).

La caracterización de los tres pigmentos mediante difracción de rayos $X$ condujo a los resultados que se detallan en la Tabla 4.18.

Tabla 4.18 Porcentaje de las fases cristalinas identificadas y composición de la fase amorfa (\% peso)

\begin{tabular}{|c|c|c|c|c|c|}
\hline & & & E03 & E04 & E05 \\
\hline \multirow{4}{*}{\multicolumn{2}{|c|}{ 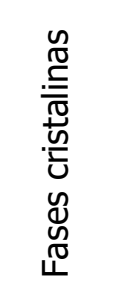 }} & Cuarzo & 12 & 12 & 13 \\
\hline & & Baddeleyita & 42 & 40 & 45 \\
\hline & & Hematites & 19 & 19 & 18 \\
\hline & & Circón & 1 & 3 & 2 \\
\hline & & Fase amorfa total & 25 & 25 & 23 \\
\hline \multirow{2}{*}{\multicolumn{2}{|c|}{ 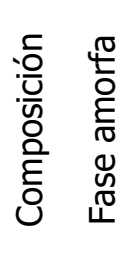 }} & $\% \mathrm{Fe}_{2} \mathrm{O}_{3}$ & 5 & 5 & 6 \\
\hline & & $\% \mathrm{ZrO}_{2}$ & 7 & 7 & 4 \\
\hline
\end{tabular}

El análisis de los datos obtenidos en la cuantificación de fases cristalinas conduce a las siguientes conclusiones:

- $\quad$ En los tres experimentos la síntesis del circón había progresado en muy baja medida, de lo que se dedujo que el sistema de mezclado utilizado no mejoraba la reactividad de la mezcla con el ciclo térmico ensayado. 
- De las tres variantes, la que facilitaba en alguna medida la reacción fue el mezclado en una segunda etapa del cuarzo, pero utilizando la granulometría original del mineralizador. Por otra parte, la incorporación del fluidificante en la primera fase del mezclado también parece mejorar los resultados.

- La reducción en el tamaño de partícula del mineralizador $\mathrm{Na}_{2} \mathrm{SiF}_{6}$ no provoca una mejoría en la reactividad de la mezcla. Es posible que dicha reducción facilite su reacción con la sílice para formar un vidrio viscoso, y por tanto dificulte la génesis del circón.

En la Figura 4.63 se representan los resultados de la caracterización por difracción de rayos $\mathrm{X}$ de todos los pigmentos de la serie $\mathrm{E}$ sintetizados, comparados con los correspondientes al sintetizado con la mezcla preparada vía seca industrialmente (A04) y el obtenido en el molino planetario vía húmeda (A08) para la fórmula No 4.

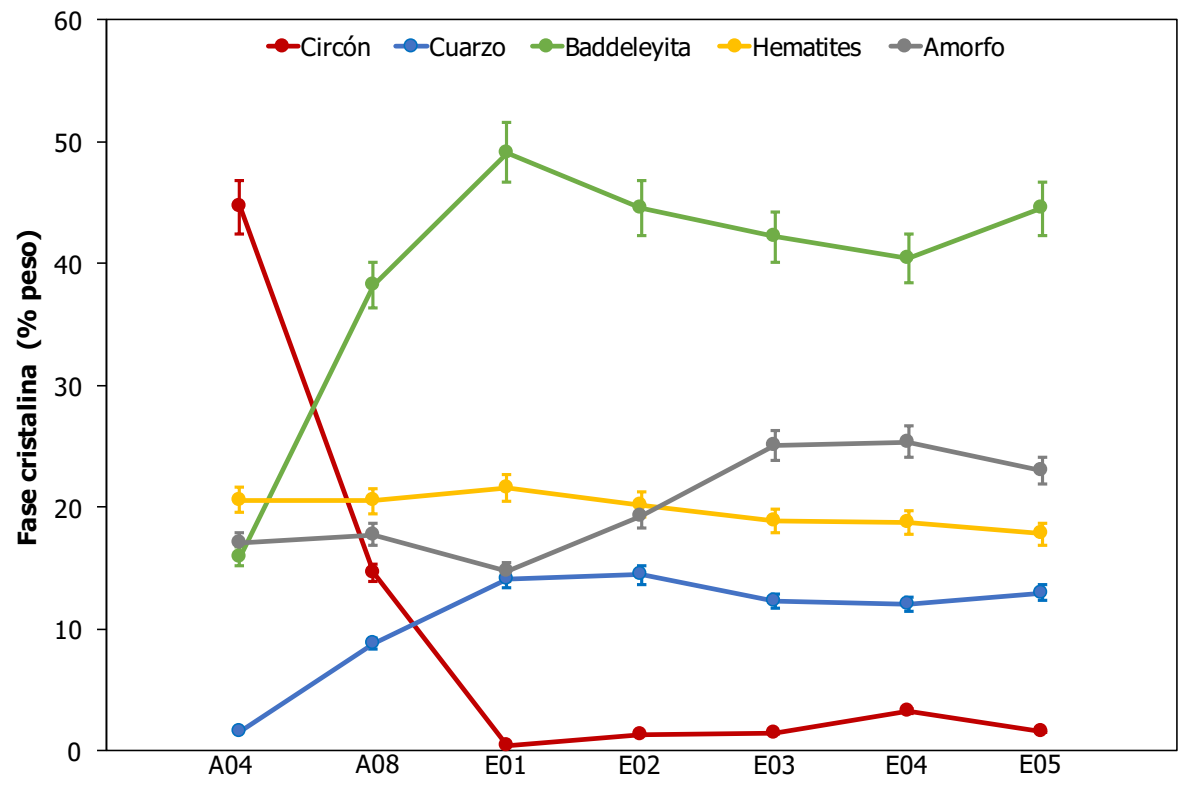

Figura 4.63 Evolución de las fases cristalinas presentes en los pigmentos

En cuanto a los parámetros $\varsigma_{1}$ y $\varsigma_{2}$ que definen el grado de avance de la reacción, en la Figura 4.64 se muestra como la fracción de sílice que pasa a formar circón es casi nula mientras que la sílice que interviene en la formación de la fase vítrea es elevada y permanece casi invariable en las diferentes condiciones de síntesis estudiadas utilizando el molino de bastidor. 


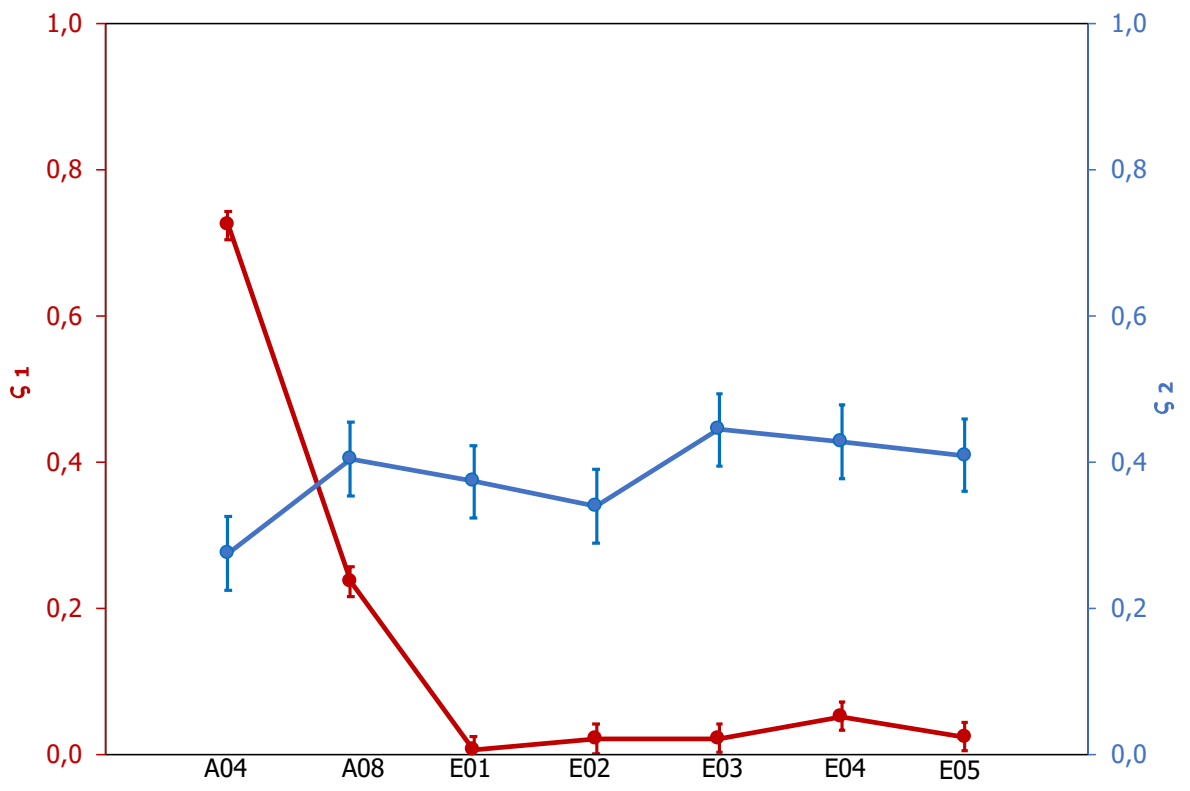

Figura 4.64 Evolución de parámetros $\varsigma_{1}$ y $\varsigma_{2}$, frente a la velocidad de calentamiento y el método de mezclado

Los resultados indican claramente que los métodos vía seca ensayados conducen a resultados muy inferiores, no sólo a los correspondientes a la mezcla preparada inicialmente vía seca, sino también a la mezcla preparada en el molino planetario vía húmeda.

Los valores de conversión del cuarzo a circón con los procedimientos de mezclado ensayados son muy bajos en todos los casos, confirmando que la reacción de interés apenas tiene lugar, independientemente de los parámetros concretos del proceso de mezcla. Sin embargo, la conversión a fase vítrea sí que muestra ciertas diferencias, ya que es más intensa en las composiciones preparadas en el molino de bastidor, y sensiblemente más baja cuando se prepara en el molino de cuchillas. Es decir, el procesado con el molino de cuchillas genera una mezcla poco reactiva para las dos reacciones, pero en el molino de bastidor está favorecida la formación de fase vítrea, ocupando una posición intermedia el mezclado vía seca en molino de bolas. 


\subsubsection{Efecto del tiempo de mezclado y del orden de adición de las materias primas}

Los experimentos que se detallan a continuación se diseñaron para evaluar el efecto del tiempo de mezclado y de la conveniencia de incorporar el cuarzo una vez ya estuviesen homogeneizadas las restantes materias primas. Como paso inicial se diseñaron cuatro experimentos, utilizando dos tiempos de mezclado y la variable de incorporar el cuarzo desde el principio, o tras el tiempo de mezclado. Las referencias asignadas y las condiciones de operación utilizadas en la preparación de cada mezcla se detallan en la Tabla 4.19.

En los experimentos en los que se adicionó posteriormente el cuarzo, la mezcla preparada se extrajo de la jarra y se tamizó antes de devolverla a la jarra y añadir el cuarzo.

Tabla 4.19 Condiciones de preparación de las mezclas

\begin{tabular}{|ccc|}
\hline Referencia & $\begin{array}{c}\text { Tiempo de mezclado } \\
\text { (minutos) }\end{array}$ & Adición del cuarzo \\
\hline E06 & 30 & Inicial \\
E07 & 60 & Inicial \\
E08 & 30 & Posterior \\
E09 & 60 & Posterior \\
\hline
\end{tabular}

Los pigmentos se sintetizaron utilizando como tratamiento térmico el Ciclo STD. En todos los casos se obtuvieron materiales relativamente blandos, de color rojizo oscuro homogéneo, cuya caracterización mediante difracción de rayos $X$ condujo a los resultados mostrados en la Tabla 4.20.

Comparando estos datos con los obtenidos en los primeros experimentos vía seca, resulta evidente que el mezclado en el molino de bastidores no consigue generar una mezcla con una estructura similar a la obtenida inicialmente, ya que con el mismo tratamiento térmico se obtiene una proporción de circón más reducida, para todas las condiciones de trabajo ensayadas. 
Tabla 4.20 Porcentaje de las fases cristalinas identificadas y composición de la fase amorfa (\% peso)

\begin{tabular}{|c|c|c|c|c|c|c|}
\hline & & & E06 & E07 & E08 & E09 \\
\hline \multirow{4}{*}{\multicolumn{2}{|c|}{ 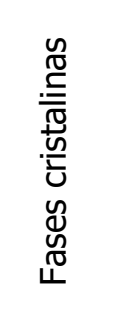 }} & Cuarzo & 8 & 6 & 7 & 6 \\
\hline & & Baddeleyita & 31 & 28 & 24 & 22 \\
\hline & & Hematites & 20 & 30 & 20 & 19 \\
\hline & & Circón & 22 & 18 & 28 & 27 \\
\hline & & Fase amorfa total & 19 & 28 & 21 & 27 \\
\hline \multirow{3}{*}{\multicolumn{2}{|c|}{ 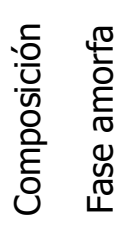 }} & $\% \mathrm{Fe}_{2} \mathrm{O}_{3}$ & 3 & 4 & 4 & 5 \\
\hline & & $\% \mathrm{SiO}_{2}$ & 6 & 10 & 5 & 7 \\
\hline & & $\% \mathrm{ZrO}_{2}$ & 5 & 10 & 7 & 10 \\
\hline
\end{tabular}

La representación gráfica de los datos (Figura 4.65), indica con claridad que resulta recomendable incorporar el cuarzo cuando las restantes materias primas ya se han mezclado, independientemente del tiempo de permanencia en el molino. Sin embargo, el tiempo de permanencia no parece ejercer un efecto tan definido ya que las diferencias apreciadas son pequeñas.

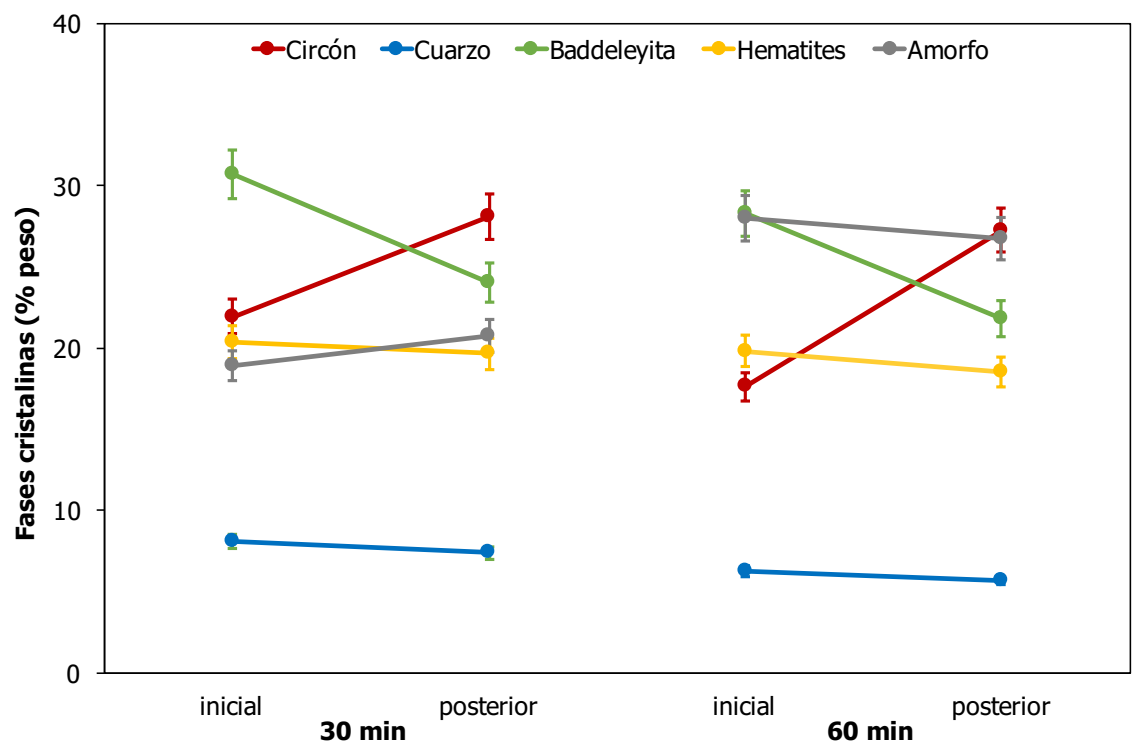

Figura 4.65 Evolución de las fases cristalinas presentes en los pigmentos, con el tiempo de mezcla y la incorporación del cuarzo a la mezcla de materias primas 
Al estudiar la evolución de los parámetros $\varsigma_{1}$ y $\varsigma_{2}$ (Figura 4.66), se observa:

- Existe un ligero aumento de $\varsigma_{1}$ cuando el cuarzo es incorporado en una etapa posterior al resto de materias primas, lo que concordaría con el aumento de circón formado observado en la figura anterior.

- El parámetro §2 disminuye al introducir el cuarzo en una segunda etapa de mezclado, lo que indicaría una menor fracción de sílice que va a formar parte de la fase vítrea y por tanto un menor porcentaje de ésta.

- $\quad$ En cuanto al tiempo de mezcla, los parámetros $\varsigma_{1}$ y $\varsigma_{2}$ no muestran diferencias muy importantes entre un tiempo de mezclado de 30 minutos o 60 minutos.

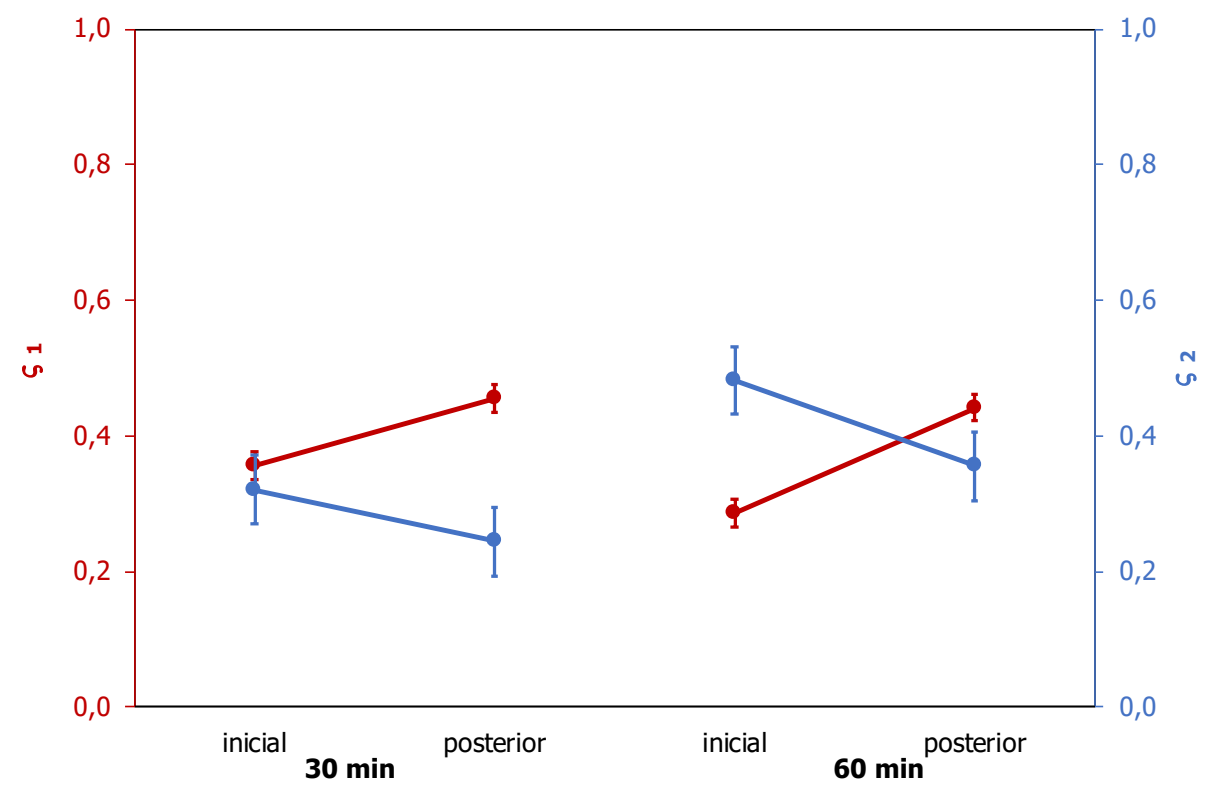

Figura 4.66 Evolución de los parámetros $\varsigma 1$ y $\varsigma 2$, con el tiempo de mezcla y la incorporación del cuarzo a la mezcla de materias primas

Una posible interpretación para las observaciones realizadas se relacionaría con el hecho de que tras el tiempo de mezclado la mayoría de la materia prima se ha depositado en el fondo de la jarra, quedando el remanente adherido a las paredes y a la carga de bolas (esto ocurre tanto con los tiempos de mezclado de 30 como de 60 minutos). Por tanto, es muy probable que a partir de cierto instante el prolongar el tiempo de mezclado no altere el grado de homogeneidad de la mezcla, ya que es poco probable que en una capa compacta se produzcan alteraciones en las posiciones relativas de las partículas que la constituyen. 
Cuando todas las materias primas se introducen desde el principio, el aumento en el tiempo de mezclado sólo se traduce en una mayor compactación de este material, que aparentemente resulta desfavorable para la síntesis del circón. Por el contrario, cuando el cuarzo se introduce después, como la mezcla de las restantes materias primas se extrae de la jarra y se tamiza previamente, se reduciría su compactación y se mejoraría la distribución del cuarzo (considerando que debería rodear aglomerados de hematites alrededor de un núcleo central de circona). Además, como el tratamiento final para mezclar el cuarzo es de tan sólo 10 minutos, no se podría alcanzar una compactación excesiva de la capa depositada en el fondo del molino, en comparación con los 30 o 60 minutos de mezclado del resto de materias primas.

\subsubsection{Efecto del tiempo de mezclado $y$ del modo de procesar las materias primas}

Para definir en mayor medida los efectos del tiempo de mezclado y del procedimiento seguido para incorporar todos los componentes de la mezcla, se diseñaron dos nuevos experimentos. Las condiciones de operación fueron las siguientes:

- $\quad$ E10: Se mantuvo la adición de cuarzo tras el mezclado de las restantes materias primas y su tamizado, pero el tiempo de mezclado se redujo a 15 minutos, en lugar de 30 o 60 minutos.

- E11: Se mantuvo la adición de cuarzo tras 30 minutos de mezclado de las restantes materias primas, pero la mezcla no se extrajo de la jarra para tamizarla, sino que se introdujo directamente el cuarzo en la jarra.

La síntesis se realizó con el Ciclo STD, y se obtuvieron materiales de coloración rojiza. El análisis cuantitativo de fases cristalinas mediante Rietveld condujo a los datos recogidos en la Tabla 4.21.

La representación gráfica del porcentaje de cada fase frente al tiempo de mezclado antes del tamizado y la incorporación del cuarzo (Figura 4.67) indica que los tiempos cortos de mezclado conducen a una mezcla poco reactiva, que genera escasa cantidad de circón ( $y$ por lo tanto el pigmento contiene elevados porcentajes de baddeleyita y cuarzo). Por el contrario, tiempos de mezclado de 30 minutos ya generan una mezcla más reactiva, pero que no cambia apenas sus características con posteriores incrementos en el tiempo de mezclado. Este hecho indicaría que, en las condiciones de trabajo utilizadas, la capa de materias primas comprimida y prácticamente estacionaria se formaría en algún tiempo intermedio entre los 15 y 30 minutos de mezclado con el método ensayado. 
Tabla 4.21 Porcentaje de las fases cristalinas identificadas y composición de la fase amorfa (\% peso)

\begin{tabular}{|c|c|c|c|c|}
\hline & & & E10 & E11 \\
\hline \multirow{4}{*}{\multicolumn{2}{|c|}{ 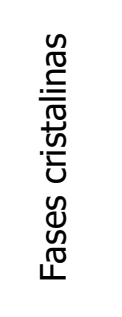 }} & Cuarzo & 11 & 7 \\
\hline & & Baddeleyita & 35 & 27 \\
\hline & & Hematites & 19 & 20 \\
\hline & & Circón & 11 & 25 \\
\hline & & Fase amorfa total & 24 & 21 \\
\hline \multirow{3}{*}{\multicolumn{2}{|c|}{ 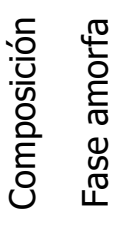 }} & $\% \mathrm{Fe}_{2} \mathrm{O}_{3}$ & 5 & 4 \\
\hline & & $\% \mathrm{SiO}_{2}$ & 7 & 7 \\
\hline & & $\% \mathrm{ZrO}_{2}$ & 7 & 6 \\
\hline
\end{tabular}

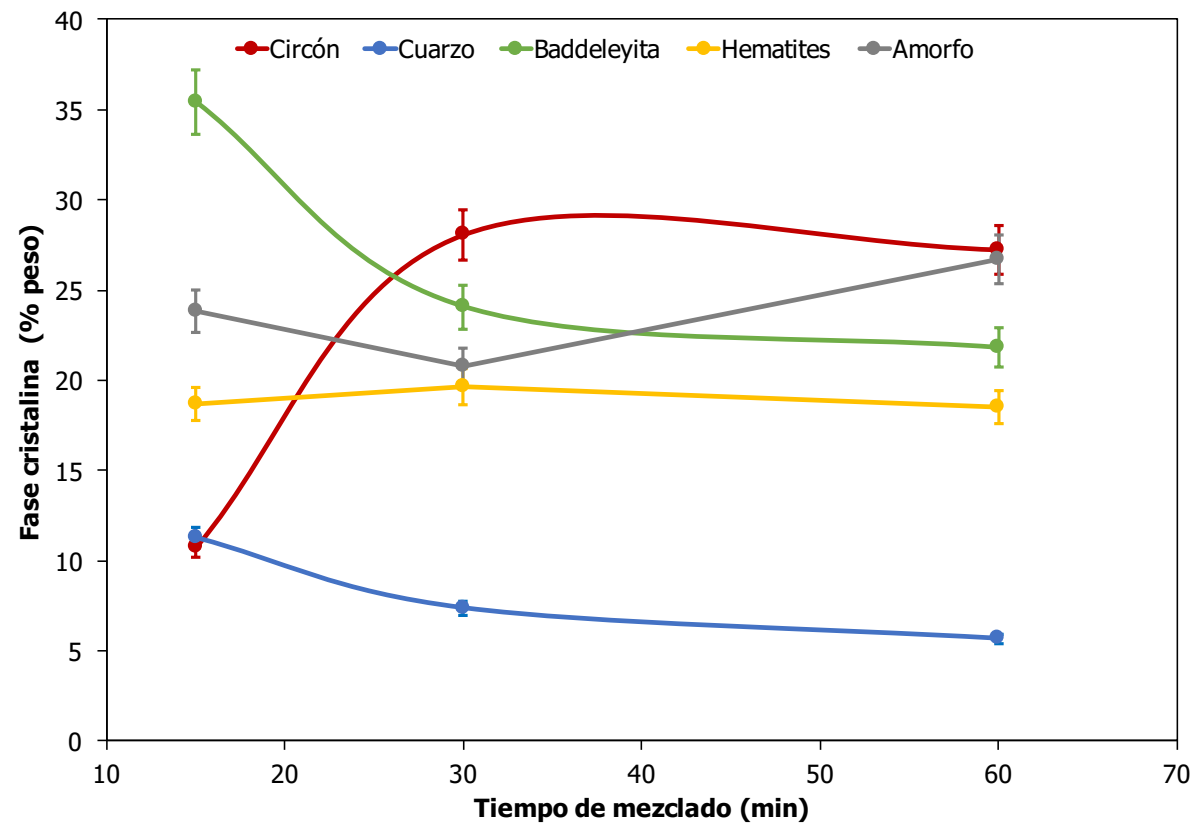

Figura 4.67 Evolución de las fases cristalinas presentes en los pigmentos, con el tiempo de mezclado de las materias primas 
La comparación de la composición mineralógica de los pigmentos obtenidos en las mismas condiciones, con la única variante de tamizar o no la mezcla de materias primas antes de incorporar el cuarzo, demuestra que las diferencias no son demasiado importantes. El tamizado intermedio permite incrementar ligeramente la reactividad de la mezcla, y su efecto más notable es un aumento del circón y la disminución de la baddeleyita.

Los experimentos han demostrado que el efecto del tiempo de mezclado es notable cuando se utilizan intervalos cortos, pero a partir de cierto punto, ya ejerce una influencia muy escasa. Por otra parte, el tamizado intermedio de la mezcla de hematites, circona, mineralizador y fluidificante permite mejorar ligeramente la reactividad, aunque dicho incremento no es lo bastante elevado como para plantear su implementación en un escalado del proceso de síntesis.

En cuanto a los parámetros $\varsigma_{1}$ y $\varsigma_{2}$ que nos muestran el grado de avance de la reacción, se observa que un aumento en el tiempo de mezclado se refleja en un aumento del parámetro $\varsigma_{1}$ (Figura 4.68). Esto demostraría un aumento en el porcentaje de cuarzo que interviene en la formación del circón, más importante cuando se pasa de un tiempo de mezclado de 15 minutos a 30 minutos. Sin embargo, el parámetro $\varsigma_{2}$ apenas se modifica con el tiempo de mezclado.

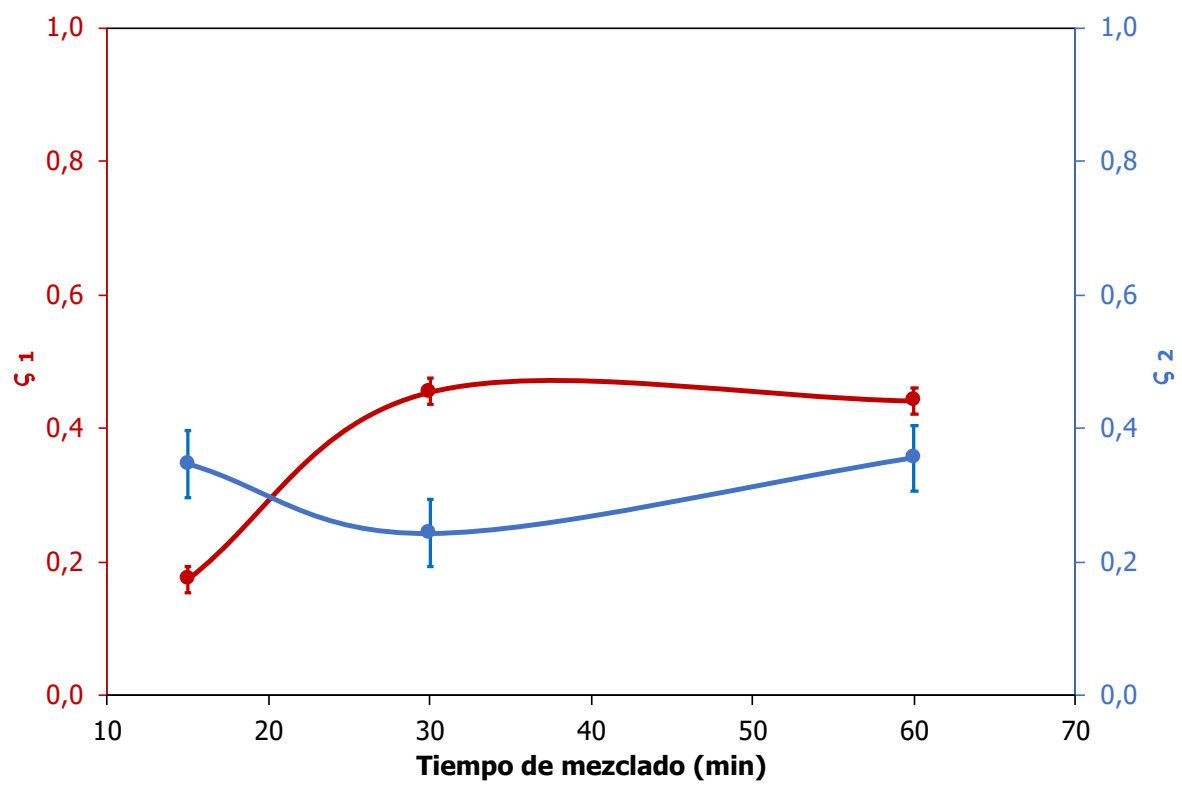

Figura 4.68 Evolución de los parámetros $\varsigma_{1}$ y $\varsigma_{2}$, con el tiempo de mezclado de las materias primas 
Con respecto a las hipótesis planteadas, los resultados apuntan a que durante los primeros 30 minutos del proceso de homogeneización se forman los aglomerados responsables de la reactividad de la mezcla. La prolongación del proceso no se traduce en una mayor reactividad de los mismos, ya que las materias primas forman una capa prácticamente fija dentro de la jarra.

Al mismo tiempo, la distribución de cuarzo en teoría algo más homogénea que se consigue tamizando la mezcla antes de la incorporación de dicha materia prima, posee un efecto muy reducido, lo cual apunta a que se consigue una distribución relativamente aceptable introduciendo directamente la sílice en la jarra del molino, aunque el resto de las materias primas estén compactadas en el fondo y las paredes de la jarra. Este resultado podría estar relacionado con el mecanismo de transporte de la sílice en forma de compuestos gaseosos $\left(\mathrm{SiF}_{4}\right)$, ya descrito anteriormente. Según dicho mecanismo no sería necesaria una gran proximidad entre las partículas de cuarzo y los aglomerados del resto de materias primas, ya que el transporte en fase gas sería lo suficientemente rápido para permitir que la reacción de síntesis del circón avanzase en grado elevado durante el tratamiento térmico utilizado. Por el contrario, una mezcla muy homogénea de todas las materias primas favorecería el mecanismo vía fase líquida, que no permite sintetizar correctamente el pigmento.

\subsubsection{Efecto del tratamiento térmico}

En apartados anteriores se indicó que el Ciclo STD utilizado inicialmente como tratamiento térmico para la síntesis del pigmento no favorecía la formación del circón, y que un ciclo con mayor velocidad de calentamiento (el Ciclo Rápido), permitía obtener mayores grados de avance en la síntesis del silicato de circonio, incluso con mezclas que presentaban una reactividad baja con el Ciclo STD. Para confirmar este hecho se consideró conveniente verificar si el cambio de ciclo resultaba igual de beneficioso cuando se utilizaba un mezclado vía seca con molino de bastidor.

El experimento se realizó con la mezcla E08, con un tiempo de mezclado de 30 minutos, tamizado antes de devolverla a la jarra y posterior adición del cuarzo. El pigmento sintetizado con el Ciclo Rápido recibió la referencia E12.

Tras la síntesis se obtuvo un material de color rojizo, cuya caracterización mineralógica por difracción de rayos $X$ y cuantificación mediante Rietveld indicó que se había formado una proporción elevada de circón (Tabla 4.22), que superaba a la obtenida con la mezcla inicial N04 vía seca y tratada con el ciclo STD (A04 con un 45\% de circón), e incluso superaba al resultado obtenido cuando se trató con el Ciclo Rápido (composición D01 con un 49\% de circón formado). 
Comparando los resultados del pigmento E12 con el E08, en el que se formó un $28 \%$ de circón, se aprecia que el cambio de ciclo térmico conduce a un pigmento con una proporción mucho más elevada de circón, y en el que prácticamente se ha agotado el cuarzo. Por otra parte, el porcentaje de fase amorfa se ha reducido considerablemente en relación al pigmento E08 que presentaba un $21 \%$. Con ello se confirma que el Ciclo Rápido resulta mucho más conveniente para conseguir un elevado grado de avance en la reacción de síntesis del circón.

Tabla 4.22 Porcentaje de las fases cristalinas identificadas y composición de la fase amorfa (\% peso)

\begin{tabular}{|c|c|c|c|}
\hline & & & E12 \\
\hline \multirow{4}{*}{\multicolumn{2}{|c|}{ 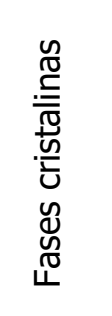 }} & Cuarzo & $<1$ \\
\hline & & Baddeleyita & 7 \\
\hline & & Hematites & 22 \\
\hline & & Circón & 57 \\
\hline & & Fase amorfa total & 14 \\
\hline \multirow{3}{*}{\multicolumn{2}{|c|}{ 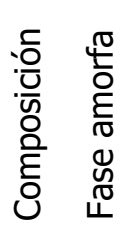 }} & $\% \mathrm{Fe}_{2} \mathrm{O}_{3}$ & 2 \\
\hline & & $\% \mathrm{SiO}_{2}$ & 3 \\
\hline & & $\% \mathrm{ZrO}_{2}$ & 5 \\
\hline
\end{tabular}

Como comprobación final, el pigmento E12 se incorporó a los dos vidriados para evaluar su poder colorante y así determinar si los cristales de circón generados habían crecido del modo adecuado para encapsular las partículas de hematites, obteniendo probetas con una coloración apreciable. Las coordenadas cromáticas se detallan en la Tabla 4.23 y Tabla 4.24. 
Tabla 4.23 Coordenadas cromáticas desarrolladas por los pigmentos en el vidriado transparente $\left(1120^{\circ} \mathrm{C}\right)$

\begin{tabular}{|ccccccc|}
\hline Referencia & \multicolumn{3}{c}{ L* $^{*}$} & \multicolumn{3}{c}{$\mathrm{a}^{*}$} \\
$\mathrm{X}$ & $\sigma$ & $\mathrm{X}$ & $\sigma$ & $\mathrm{X}$ & $\sigma$ \\
\hline E12 & 66,79 & 0,10 & 13,92 & 0,18 & 20,52 & 0,07 \\
\hline
\end{tabular}

Tabla 4.24 Coordenadas cromáticas desarrolladas por los pigmentos en el vidriado opaco $\left(1040^{\circ} \mathrm{C}\right)$

\begin{tabular}{|ccccccc|}
\hline Referencia & \multicolumn{3}{c}{ L* $^{*}$} & \multicolumn{3}{c|}{$\mathrm{a}^{*}$} \\
$\mathrm{X}$ & $\sigma$ & $\mathrm{X}$ & $\sigma$ & $\mathrm{X}$ & $\sigma$ \\
\hline E12 & 79,17 & 0,27 & 12,33 & 0,19 & 9,49 & 0,10 \\
\hline
\end{tabular}

Las probetas esmaltadas de las piezas con el pigmento E12, tanto con el vidriado transparente como con el vidriado opaco se muestran en la Figura 4.69.

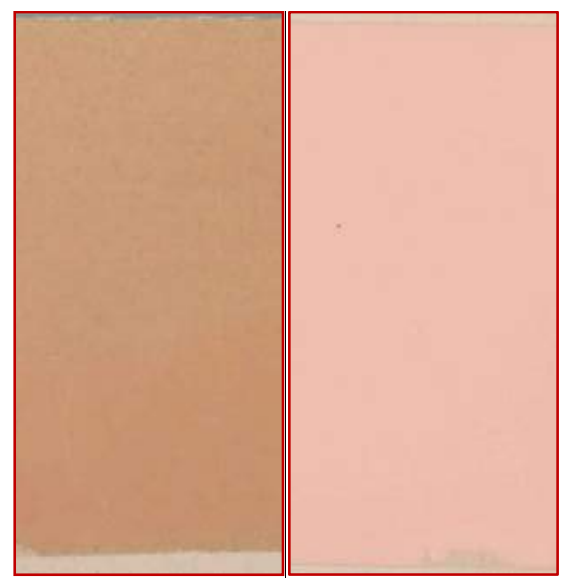

Figura 4.69 Probetas esmaltadas de las piezas E12 con el vidriado transparente y opaco

La comparación de las coordenadas cromáticas generadas por el pigmento E12 con los dos pigmentos de referencia sintetizados con el Ciclo STD y Ciclo Rápido (A04 y D01) y su representación gráfica (Figura 4.70, Figura 4.71, Figura 4.72), permite obtener las siguientes deducciones:

- La luminosidad no sigue una tendencia homogénea ya que, en el vidriado transparente, el valor más elevado se consigue con el pigmento E12, mientras que en el vidriado opaco dicho pigmento genera el valor más reducido. 


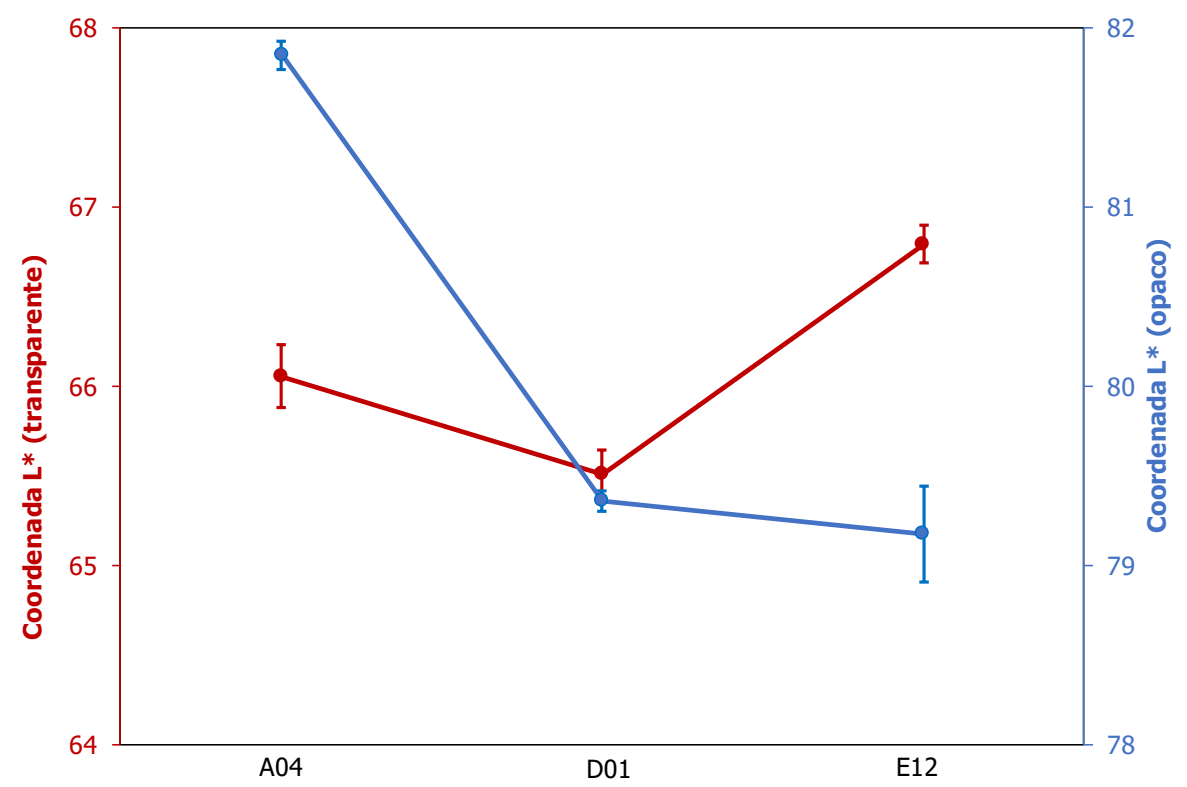

Figura 4.70 Evolución de la coordenada L* generada en los dos vidriados ensayados

- La componente roja presenta un comportamiento opuesto al de la luminosidad. El pigmento E12 genera el valor más reducido en el vidriado transparente, mientras que en el opaco conduce al mejor resultado.

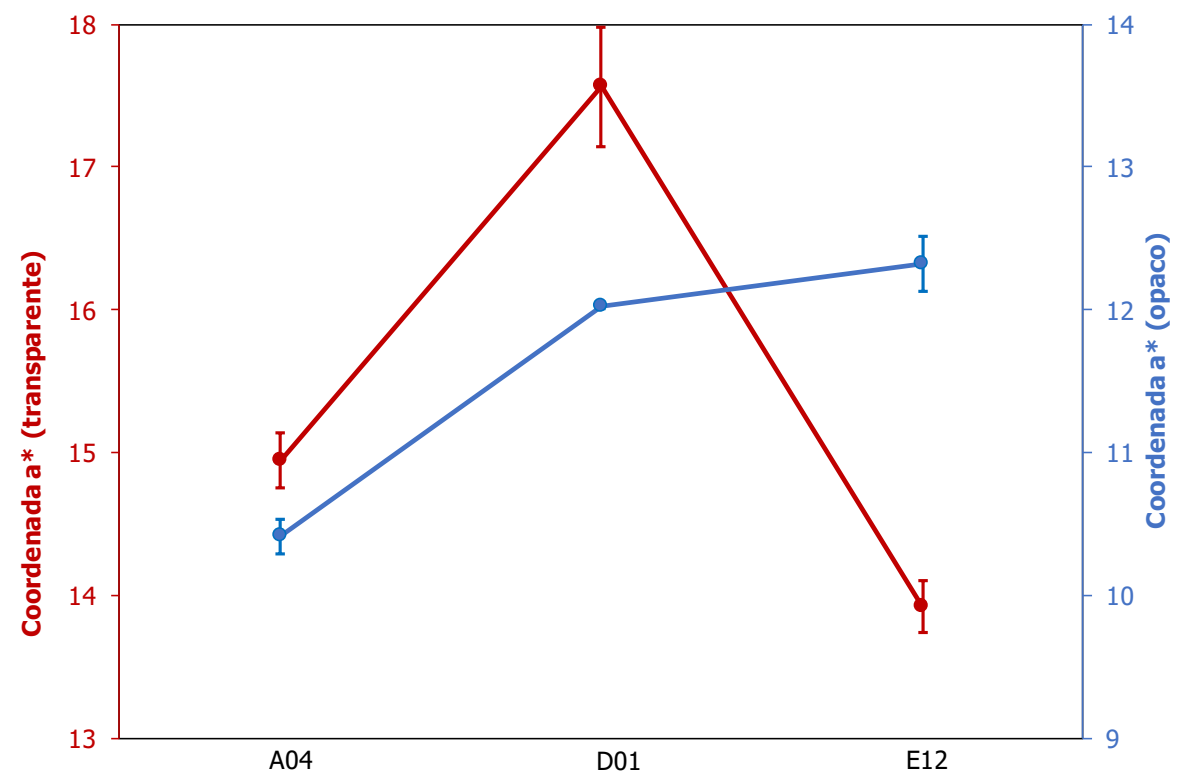

Figura 4.71 Evolución de la coordenada a* generada en los dos vidriados ensayados 
- La componente amarilla es la única que se comporta de modo similar en los dos vidriados, ya que el pigmento E12 genera un valor intermedio entre las dos referencias.

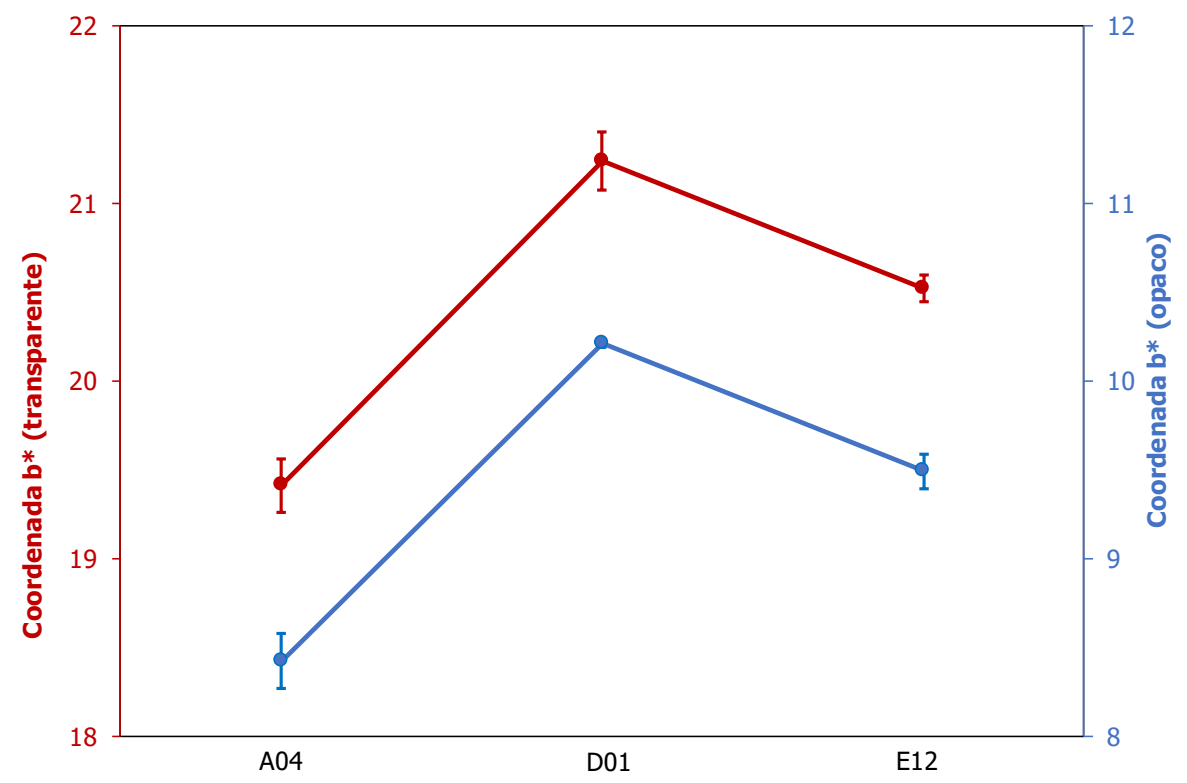

Figura 4.72 Evolución de la coordenada b* generada en los dos vidriados ensayados

Los datos colorimétricos indican que el pigmento E12 posee un poder colorante en el vidriado opaco algo más elevado que las dos referencias escogidas pero, en cambio, en el vidriado transparente presenta un rendimiento inferior, que se aproxima al conseguido con el pigmento A04. Este hecho apunta a que la capacidad colorante de los pigmentos depende notablemente de su interacción con el vidriado al que se incorpora.

\subsubsection{Efecto de la carga de bolas en la jarra}

Otro de los factores que podrían modificar la microestructura de la mezcla y por tanto influir en la reactividad de la mezcla es la carga de bolas de la jarra, por lo que se consideró conveniente verificar dicha hipótesis.

Como se ha indicado en el apartado de preparación de las mezclas mediante molino horizontal de bastidores, la carga de bolas utilizada de modo habitual en los experimentos estaba constituida por $244 \mathrm{~g}$ de bolas grandes y $163 \mathrm{~g}$ de bolas pequeñas. Para analizar el efecto de la carga y la distribución de tamaño de bola se diseñaron cuatro experimentos, con las cargas que se detallan en la Tabla 4.25. En dos de los experimentos se redujo la masa de bolas utilizando exclusivamente la fracción correspondiente a uno de los diámetros, mientras 
que en los otros dos se mantuvo la masa total, pero únicamente utilizando bolas de uno de los dos diámetros disponibles.

Tabla 4.25 Condiciones de preparación de las mezclas

\begin{tabular}{|ccc|}
\hline Referencia & Bolas grandes $(\mathrm{g})$ & Bolas pequeñas $(\mathrm{g})$ \\
\hline E13 & 244 & - \\
E14 & - & 163 \\
E15 & 407 & - \\
E16 & - & 407 \\
\hline
\end{tabular}

Los experimentos se realizaron con un tiempo de homogeneización de 30 minutos, y el cuarzo se añadió tras tamizar la mezcla de materias primas, seguido de otros 10 minutos de homogeneización final.

Las mezclas se calcinaron con el Ciclo STD y el análisis mineralógico por difracción de rayos $X$ condujo a los resultados detallados en la Tabla 4.26.

Tabla 4.26 Porcentaje de las fases cristalinas identificadas y composición de la fase amorfa (\% peso)

\begin{tabular}{|c|c|c|c|c|c|c|}
\hline & & & E13 & E14 & E15 & E16 \\
\hline \multirow{4}{*}{\multicolumn{2}{|c|}{ 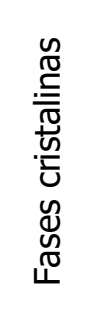 }} & Cuarzo & 10 & 10 & 7 & 7 \\
\hline & & Baddeleyita & 32 & 34 & 25 & 26 \\
\hline & & Hematites & 19 & 19 & 19 & 21 \\
\hline & & Circón & 16 & 12 & 26 & 30 \\
\hline & & Fase amorfa total & 22 & 25 & 24 & 17 \\
\hline \multirow{3}{*}{\multicolumn{2}{|c|}{ 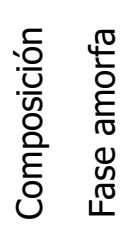 }} & $\% \mathrm{Fe}_{2} \mathrm{O}_{3}$ & 5 & 5 & 5 & 3 \\
\hline & & $\% \mathrm{SiO}_{2}$ & 6 & 8 & 6 & 5 \\
\hline & & $\% \mathrm{ZrO}_{2}$ & 7 & 8 & 8 & 4 \\
\hline
\end{tabular}


La evolución de las fases cristalinas presentes en los pigmentos frente al porcentaje en peso de la masa total de bolas presente en la jarra en cada experimento (Figura 4.73), indica que, a mayor carga de bolas, la reactividad de la mezcla aumenta, tal como demuestra el crecimiento en la proporción de circón y la reducción en la baddeleyita y el cuarzo. Por lo tanto, el aumento de la presión ejercida sobre la mezcla de materias primas conducirá a una mayor compactación de los aglomerados de hematites, circona y mineralizador, lo cual aparentemente mejora su reactividad. Este hecho también se refleja en los parámetros $\varsigma_{1}$ y $\varsigma_{2}$ que muestran el grado de avance de la reacción (Figura 4.74).

El efecto del tipo de bolas utilizadas en la carga, manteniendo constante la masa total de bolas no parece ser importante, apreciándose como los pigmentos obtenidos con la misma masa de bolas, pero con diferente diámetro de éstas, poseen una composición mineralógica muy similar.

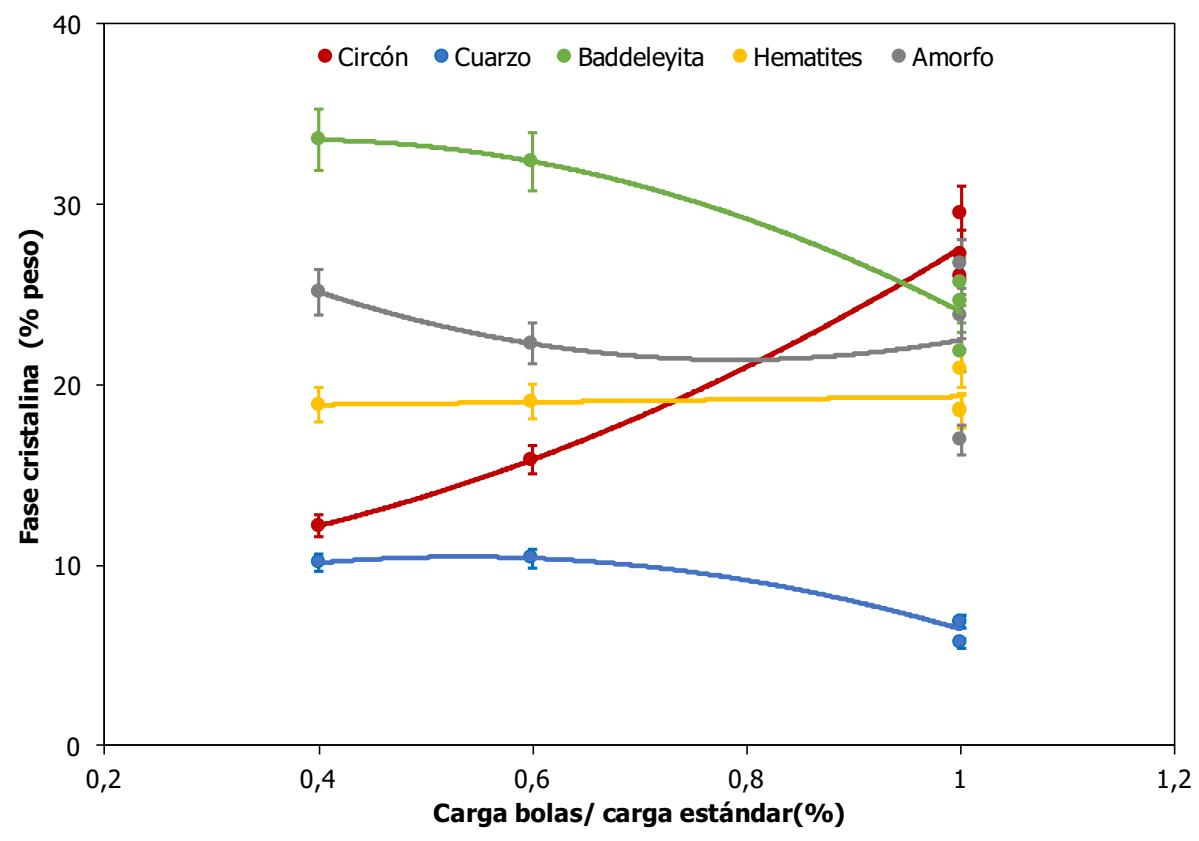

Figura 4.73 Evolución de las fases cristalinas presentes en los pigmentos frente a la masa de bolas utilizada en el molino durante el mezclado de materias primas, expresada como porcentaje en peso de la masa estándar 


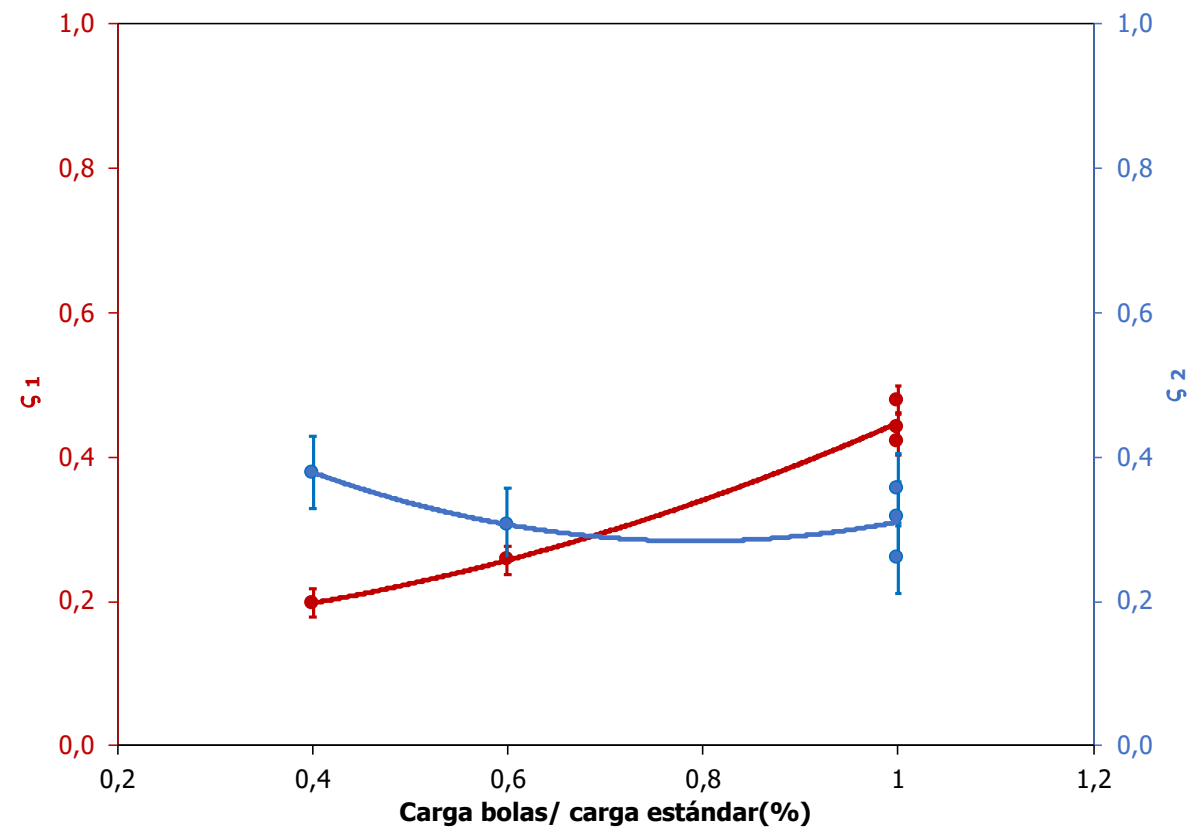

Figura 4.74 Evolución de los parámetros $\$ 1$ y $\varsigma 2$, frente a la masa de bolas utilizada en el molino durante el mezclado de materias primas, expresada como porcentaje en peso de la masa estándar

Los resultados indican que la carga de bolas en la jarra, y en consecuencia, la presión ejercida para formar los aglomerados de materias primas, ejerce una notable influencia sobre la reactividad de la mezcla, y que por lo tanto éste podría ser el factor determinante en la diferencia entre el comportamiento de las mezclas preparadas mediante las diferentes metodologías, ya que diferentes molinos, ejercerán presiones distintas sobre la mezcla de materias primas. El tipo de bolas utilizado no parece ejercer un efecto apreciable, si bien cabe considerar que en los experimentos no se han utilizado bolas de tamaños exageradamente diferentes. 


\subsubsection{Mezclado en el molino de mortero}

Dado que se había apreciado cierta correlación entre la reactividad de la mezcla de materias primas, y la masa de bolas presente en el molino durante el proceso de homogeneización, la consecuencia lógica hubiese sido aumentar dicha masa, para verificar que dicha relación se mantenía. Sin embargo, los experimentos que cabía plantear no se pudieron realizar, debido a que el volumen disponible en la jarra para incorporar nuevas bolas no era suficientemente elevado para introducir una masa de bolas significativamente diferente. Además, estos cambios serían difíciles de transferir a escala industrial donde se respetan las relaciones carga-volumen especificados por el suministrador de equipos de molienda.

En consecuencia, se realizaron experimentos con otro método de mezclado para aumentar la presión ejercida sobre la mezcla de materias primas, ya que en el caso del molino de bastidores estaba limitada por el volumen de la jarra y la velocidad de giro del molino (que era fija). Se decidió preparar la mezcla en un molino de mortero, ya que permitía mezclar las capas de sólido y, además, se podía regular la presión ejercida por la mano del mortero.

El primer experimento se realizó utilizando dos tiempos de homogeneización (15 y 30 minutos), y las dos presiones extremas que permitía el equipo (contrapeso de la mano en la posición inicial y final de su recorrido, que corresponden a la presión mínima y máxima respectivamente). Inicialmente se introdujo en la jarra la circona, la hematites, el fluidificante y el mineralizador, y tras el tiempo de homogeneización establecido, se añadió el cuarzo y se homogeneizó la mezcla otros cinco minutos. Las condiciones de trabajo utilizadas en la preparación de cada mezcla se detallan en la Tabla 4.27.

Tabla 4.27 Condiciones de preparación en las mezclas en el molino de mortero

\begin{tabular}{|ccc|}
\hline Referencia & Tiempo de mezcla $($ min) & Presión \\
\hline E17 & 15 & Mínima \\
E18 & 30 & Mínima \\
E19 & 15 & Máxima \\
E20 & 30 & Máxima \\
\hline
\end{tabular}

Visualmente se apreció que con las cuatro condiciones ensayadas se obtenían mezclas de color homogéneo. Los pigmentos se sintetizaron con el Ciclo STD, obteniéndose materiales de color rojizo. 
Los análisis mineralógicos por difracción de rayos $\mathrm{X}$ de los pigmentos sintetizados se muestran en la Tabla 4.28.

Tabla 4.28 Porcentaje de las fases cristalinas identificadas y composición de la fase amorfa (\% peso)

\begin{tabular}{|c|c|c|c|c|c|c|}
\hline & & & E17 & E18 & E19 & E20 \\
\hline \multirow{4}{*}{\multicolumn{2}{|c|}{ 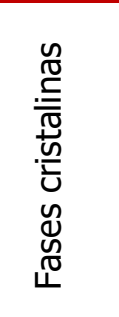 }} & Cuarzo & 5 & 3 & 2 & 3 \\
\hline & & Baddeleyita & 20 & 17 & 16 & 16 \\
\hline & & Hematites & 21 & 18 & 21 & 21 \\
\hline & & Circón & 42 & 33 & 48 & 44 \\
\hline & & Fase amorfa total & 13 & 29 & 13 & 18 \\
\hline \multirow{3}{*}{\multicolumn{2}{|c|}{ 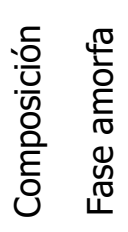 }} & $\% \mathrm{Fe}_{2} \mathrm{O}_{3}$ & 3 & 6 & 2 & 3 \\
\hline & & $\% \mathrm{SiO}_{2}$ & 3 & 8 & 4 & 5 \\
\hline & & $\% \mathrm{ZrO}_{2}$ & 2 & 11 & 2 & 5 \\
\hline
\end{tabular}

Representando el contenido en fases cristalinas de forma comparativa (Figura 4.75) se observa que la preparación en el molino de mortero conduce a mezclas mucho más reactivas. De hecho, en las peores condiciones (pigmento E18) se consigue un porcentaje de circón que es un 60\% aproximadamente de la referencia E12 (que se había sintetizado con el Ciclo Rápido). Además, en los pigmentos E17 y E19 se observa una disminución clara del contenido en fase amorfa. En consecuencia, al cambiar el método de mezclado se ha producido una mejora notable en la reactividad de las mezclas.

En cuanto a los parámetros $\varsigma_{1}$ (fracción de sílice que reacciona para formar circón) y $\varsigma_{2}$ (fracción de sílice que formará parte de la fase vítrea) se obtienen las mismas conclusiones (Figura 4.76). Al aumentar la presión de la mano del mortero hacia la mezcla de materias primas aumenta el parámetro $\varsigma_{1}$ lo que indica que una mayor parte del cuarzo introducido inicialmente interviene en la formación del circón. El parámetro §2 no sigue una tendencia tan pronunciada, aunque sí que se observa una disminución de este parámetro al aumentar la presión y con un mayor tiempo de mezclado, que indica una menor fracción de cuarzo que pasa a formar parte de la fase vítrea. 


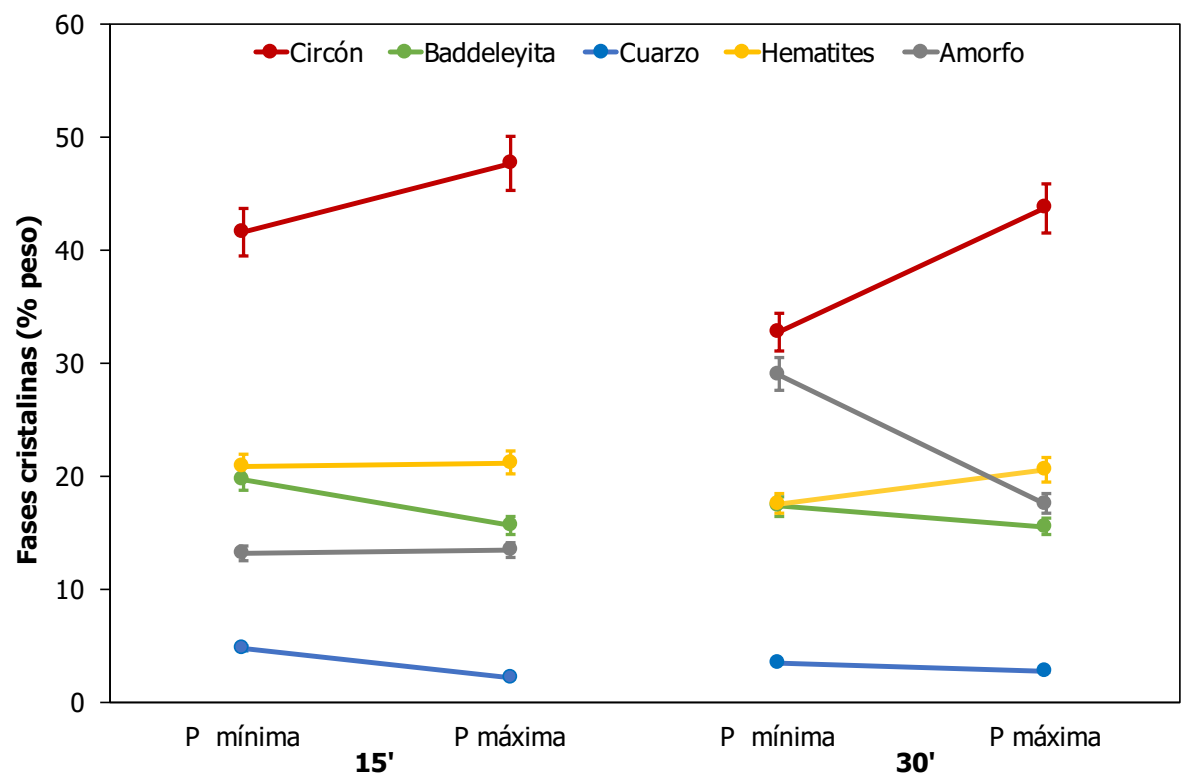

Figura 4.75 Evolución de las fases cristalinas presentes en los pigmentos frente al tiempo de mezclado y presión ejercida por la mano del mortero

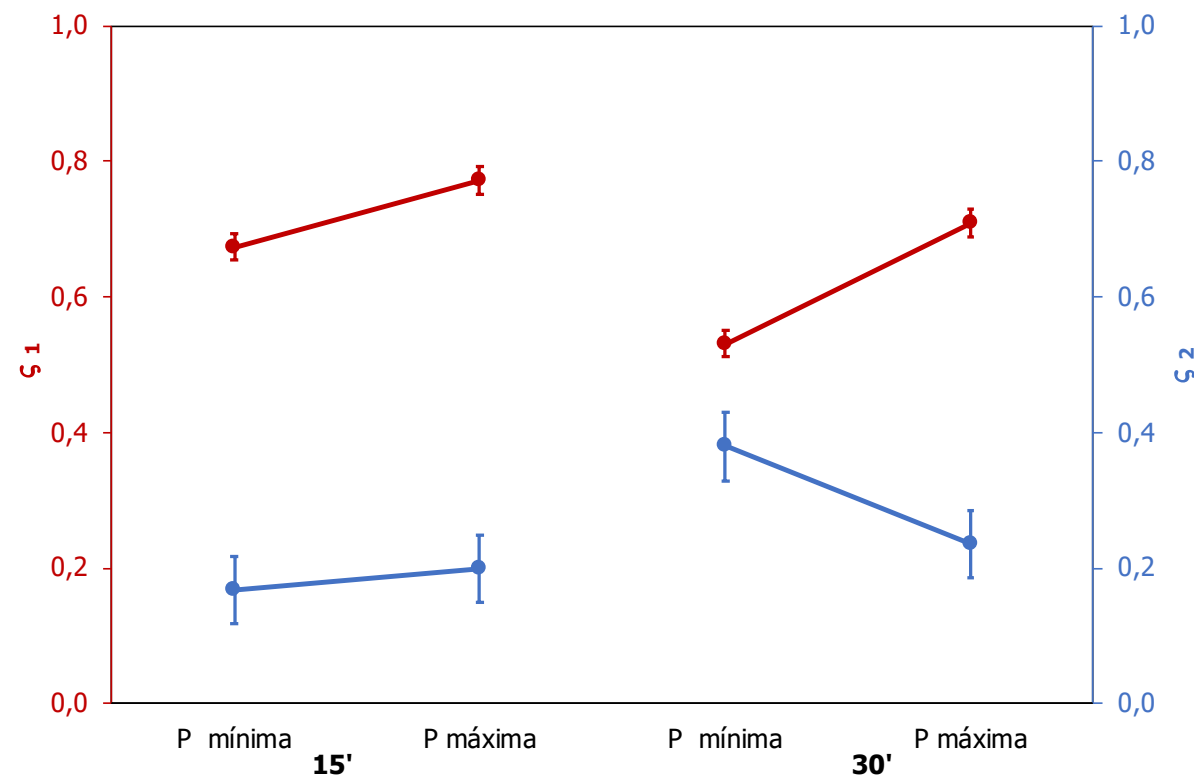

Figura 4.76 Evolución de los parámetros $\varsigma_{1}$ y $\varsigma_{2}$ frente al tiempo de mezclado y presión ejercida por la mano del mortero 
En cuanto al efecto de las variables estudiadas, de su representación gráfica se puede inferir que el aumento en la presión durante el mezclado ejerce un efecto ligeramente favorable sobre la reactividad de la muestra, ya que se consigue una mayor proporción de circón en los pigmentos, así como una reducción en la proporción de cuarzo y circona. Por el contrario, un aumento en el tiempo de mezclado, manteniendo constante la presión, parece ejercer un efecto ligeramente desfavorable, aunque no demasiado acusado.

Los cuatro pigmentos sintetizados con los últimos experimentos realizados (E17 a E20) se incorporaron a los dos vidriados, para determinar si la formación del circón se había realizado en paralelo con el encapsulado de la hematites y estudiar el color desarrollado. Como resultado se obtuvieron probetas de tonalidad entre rojiza y rosada dependiendo del vidriado al que fueron incorporados.
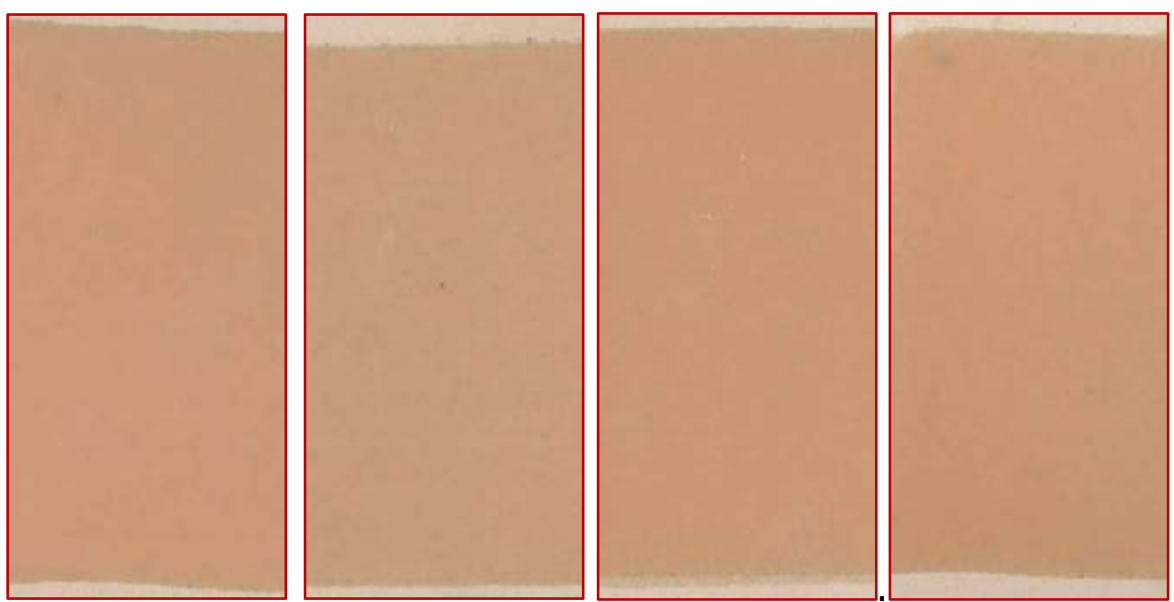

Figura 4.77 Probetas esmaltadas de las piezas E17, E18, E19 y E20 con el vidriado transparente
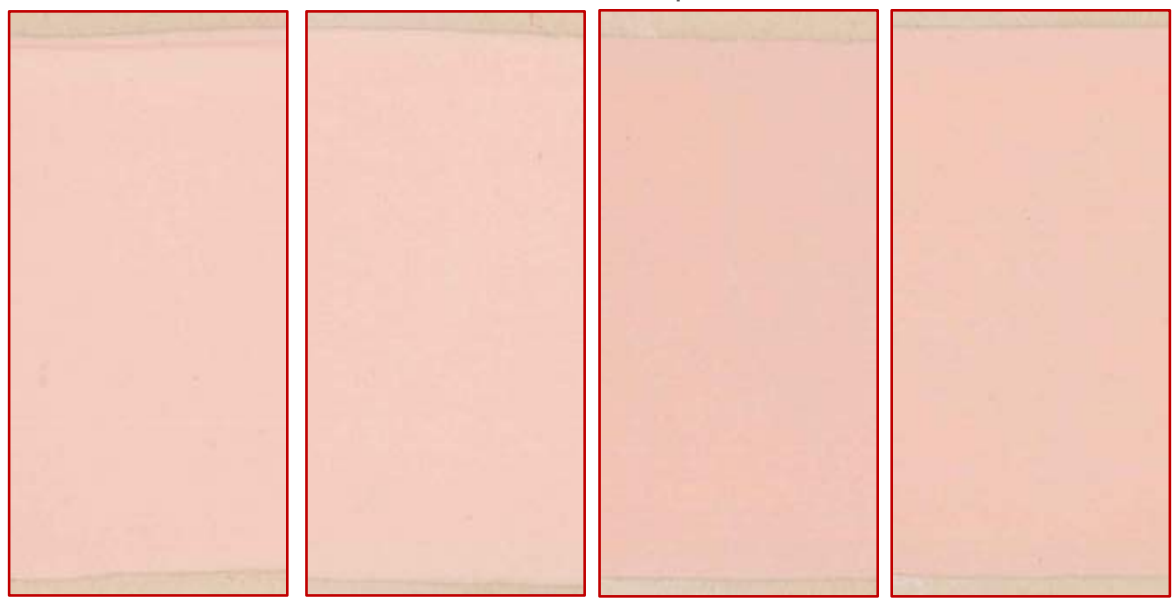

Figura 4.78 Probetas esmaltadas de las piezas E17, E18, E19 y E20 con el vidriado opaco 
Se determinaron las coordenadas cromáticas tal y como se indica en el apartado 3.5 .4 y los valores obtenidos se detallan en la Tabla 4.29 y Tabla 4.30.

Tabla 4.29 Coordenadas cromáticas desarrolladas por los pigmentos en el vidriado transparente $\left(1120^{\circ} \mathrm{C}\right)$

\begin{tabular}{|ccccccc|}
\hline Referencia & \multicolumn{3}{c}{ L* $^{*}$} & \multicolumn{3}{c}{$\mathrm{a}^{*}$} \\
$\mathrm{X}$ & $\sigma$ & $\mathrm{X}$ & $\sigma$ & $\mathrm{X}$ & $\sigma$ \\
E17 & 68,36 & 0,09 & 12,54 & 0,18 & 18,91 & 0,07 \\
E18 & 69,09 & 0,04 & 11,59 & 0,20 & 18,79 & 0,06 \\
E19 & 67,73 & 0,05 & 13,54 & 0,13 & 19,20 & 0,05 \\
E20 & 67,74 & 0,13 & 13,24 & 0,18 & 19,40 & 0,11 \\
\hline
\end{tabular}

Tabla 4.30 Coordenadas cromáticas desarrolladas por los pigmentos en el vidriado opaco $\left(1040^{\circ} \mathrm{C}\right)$

\begin{tabular}{|ccccccc|}
\hline Referencia & \multicolumn{2}{c}{ L* $^{*}$} & \multicolumn{3}{c}{$\mathrm{a}^{*}$} & \multicolumn{2}{c|}{$\mathrm{b}^{*}$} \\
\hline & $\mathrm{X}$ & $\sigma$ & $\mathrm{X}$ & $\sigma$ & $\mathrm{X}$ & $\sigma$ \\
E17 & 83,59 & 0,12 & 9,21 & 0,09 & 7,74 & 0,12 \\
E18 & 83,98 & 0,04 & 8,86 & 0,06 & 7,84 & 0,03 \\
E19 & 82,27 & 0,07 & 10,24 & 0,04 & 8,40 & 0,02 \\
E20 & 82,42 & 0,04 & 10,09 & 0,02 & 8,27 & 0,02 \\
\hline
\end{tabular}

Al comparar los datos colorimétricos de los pigmentos de esta serie con los correspondientes al pigmento A04, que se sintetizó con el mismo tratamiento térmico (Figura 4.79, Figura 4.80, Figura 4.81), se deducen las siguientes tendencias:

- La luminosidad de los colores generados por los pigmentos en los dos vidriados siempre es superior a la obtenida con el pigmento A04, oscilando la variación media de $L^{*}$ entre las dos unidades del vidriado transparente y la unidad en el opaco. Dentro de la serie de pigmentos, se aprecia que los preparados con una presión superior en el mortero, conducen a colores algo más oscuros y menos sensibles a los cambios en el tiempo de mezclado (de hecho, en el vidriado opaco casi se igualan los valores con el pigmento A04). Por el contrario, los pigmentos generados con la presión mínima generan colores más luminosos, y que tienden a clarear para tiempos de mezclado más prolongados. 


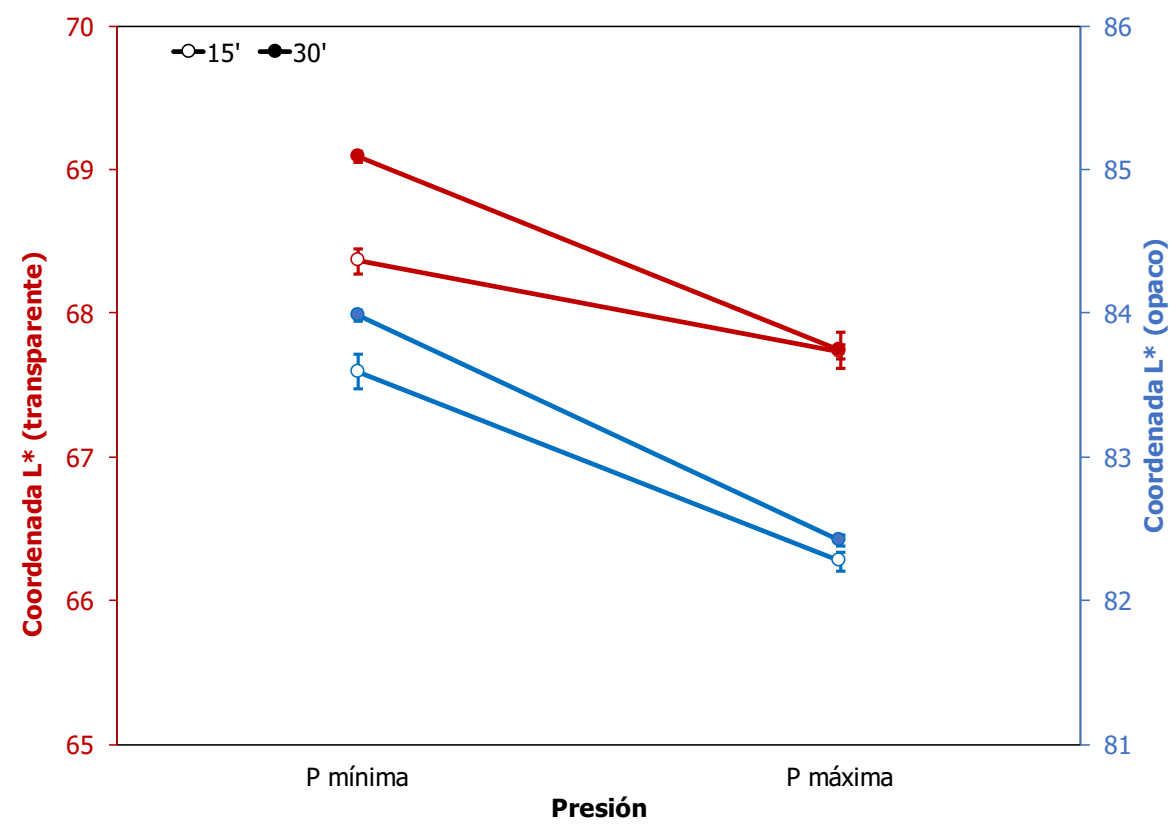

Figura 4.79 Evolución de la coordenada L* generada en los dos vidriados ensayados

- La componente roja presenta un comportamiento en cierto modo inverso al de la luminosidad. Los pigmentos sintetizados en esta última serie (A17 a A20) generan colores con una coordenada a* inferior a la referencia, que en promedio varía desde dos unidades en el vidriado transparente a una unidad en el opaco. Para esta coordenada también se aprecia que los pigmentos sintetizados con una mayor presión en el mortero generan valores más elevados de $a^{*}$, junto con un efecto desfavorable de la prolongación del tiempo de mezclado, si bien es más notable para la presión de trabajo inferior.

- La componente amarilla es la que muestra menos variaciones, ya que en promedio las diferencias con respecto al pigmento de referencia A04 son inferiores a 0,5 unidades tanto en el vidriado transparente como en el opaco. Para esta coordenada se mantiene que los pigmentos obtenidos a partir de mezclas tratadas con la presión mínima generan valores más reducidos de $b^{*}$, si bien en este caso no se aprecia una tendencia definida con el tiempo de mezclado. 


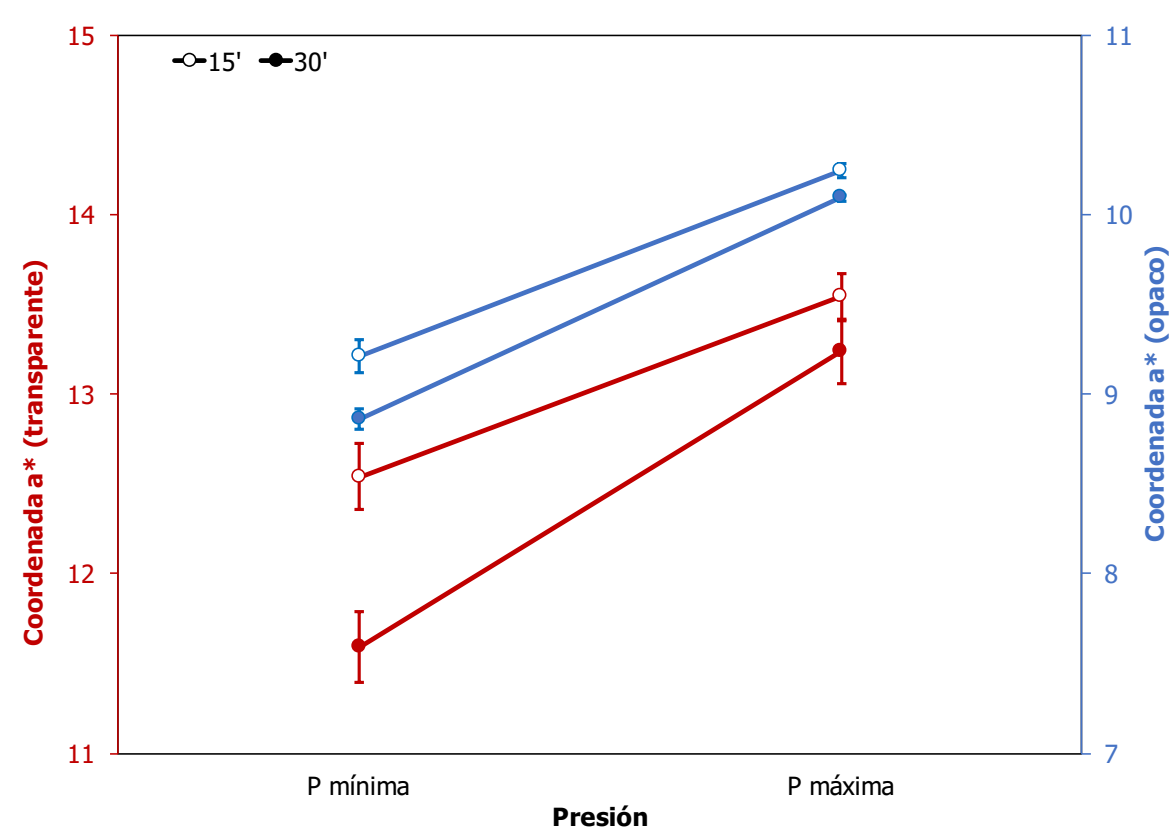

Figura 4.80 Evolución de la coordenada a* generada en los dos vidriados ensayados

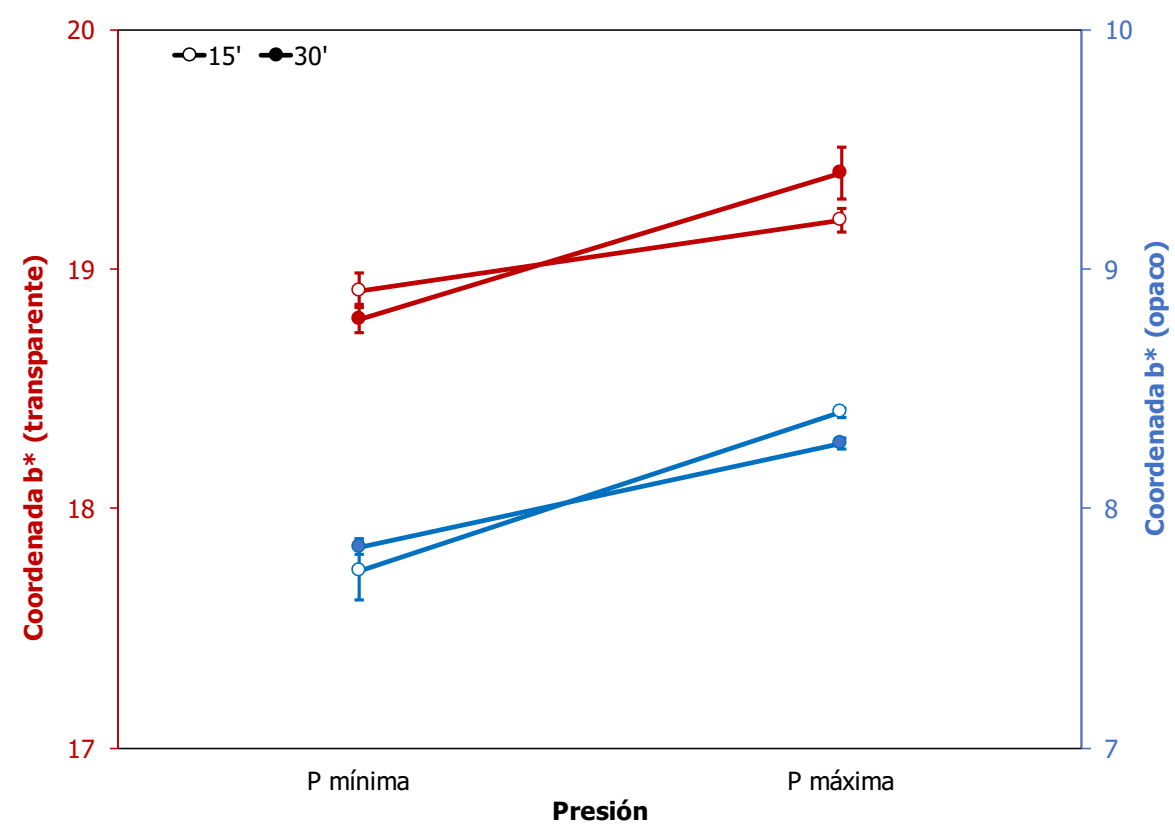

Figura 4.81 Evolución de la coordenada b* generada en los dos vidriados ensayados 
El análisis colorimétrico indica que el poder colorante de los pigmentos obtenidos con un tiempo de mezclado de 15 minutos y utilizando la presión máxima (pigmento E19 con un 48\% de circón), se aproxima bastante al del pigmento A04. Al modificar el tiempo de mezclado o la presión en el mortero, se obtienen pigmentos con menor poder colorante.

\subsubsection{Efecto del tiempo de mezclado tras la adición del cuarzo}

Los experimentos detallados en el apartado anterior se realizaron manteniendo constante el tiempo de mezclado tras la incorporación del cuarzo, y según los datos recogidos previamente, existía la posibilidad de que un mezclado demasiado enérgico del cuarzo produjese la ruptura de los aglomerados circona-hematites-mineralizador, mermando la reactividad de la mezcla, al conseguir una mayor homogeneización del conjunto de materias primas y, por tanto, disminuyendo la formación de circón y reduciendo la eficacia del encapsulamiento de las partículas de hematites en el interior de los cristales de circón.

Por ello se decidió diseñar una nueva serie de experimentos, tomando las condiciones más favorables obtenidas en la primera serie realizada con el molino de mortero (pigmento E19 con 15 minutos de mezclado utilizando la presión máxima), y variando el tiempo de mezclado tras la adición del cuarzo. En el pigmento E19 el tiempo de mezclado de las materias primas con el cuarzo fue de 5 minutos, por lo que en estos experimentos se ensayó un tiempo más corto (2 minutos) y otro más largo (10 minutos). A las mezclas obtenidas se les asignaron las referencias E21 y E22 respectivamente.

La síntesis de los pigmentos se realizó con el Ciclo STD, de forma que se obtuvieron materiales de color rojizo. La caracterización mineralógica consistente en cuantificación de fases cristalinas y fase amorfa por difracción de rayos $X$ utilizando el método Rietveld, condujo a los resultados que se presentan en la Tabla 4.31. En ella se muestran los porcentajes de las fases cristalinas identificadas, el porcentaje de fase amorfa, así como la estimación de la composición en forma de óxidos de la fase amorfa de cada uno de los pigmentos sintetizados. 
Tabla 4.31 Porcentaje de las fases cristalinas identificadas y composición de la fase amorfa (\% peso)

\begin{tabular}{|c|c|c|c|}
\hline & & E21 & E22 \\
\hline \multirow{4}{*}{ 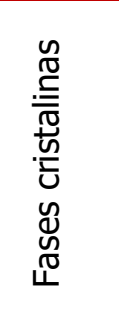 } & Cuarzo & 5 & 5 \\
\hline & Baddeleyita & 23 & 25 \\
\hline & Hematites & 19 & 20 \\
\hline & Circón & 29 & 30 \\
\hline & Fase amorfa total & 23 & 20 \\
\hline \multirow{3}{*}{ 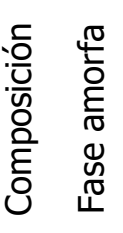 } & $\% \mathrm{Fe}_{2} \mathrm{O}_{3}$ & 4 & 3 \\
\hline & $\% \mathrm{SiO}_{2}$ & 7 & 7 \\
\hline & $\% \mathrm{ZrO}_{2}$ & 7 & 5 \\
\hline
\end{tabular}

La comparación de los datos con los correspondientes al pigmento E19 (Figura 4.82 y Figura 4.83 ) permite deducir las siguientes tendencias:

- El máximo porcentaje de circón formado se obtiene cuando el tiempo de mezclado del cuarzo se fija en cinco minutos (48\% de circón), y que un alargamiento o un acortamiento de dicha etapa se traduce en una reducción notable de la proporción de esta fase cristalina y un aumento de la fase amorfa o vítrea.

- El cuarzo y la baddeleyita siguen una tendencia inversa al circón, pero con unas variaciones más suaves. La menor proporción de ambas fases se consigue coincidiendo con el máximo del circón, pero el efecto de modificar el tiempo de mezclado del cuarzo es muy similar en ambos sentidos.

- Los parámetros $\varsigma_{1}$ (fracción de sílice que reacciona para formar circón) y $\varsigma_{2}$ (fracción de sílice que formará parte de la fase vítrea) muestran la misma tendencia que la observada para los porcentajes de fases cristalinas. El parámetro $\varsigma_{1}$ presenta un máximo para un tiempo de mezclado de 5 minutos, mientras que, para ese mismo tiempo de mezclado, el parámetro $\varsigma_{2}$ presenta un valor mínimo. 


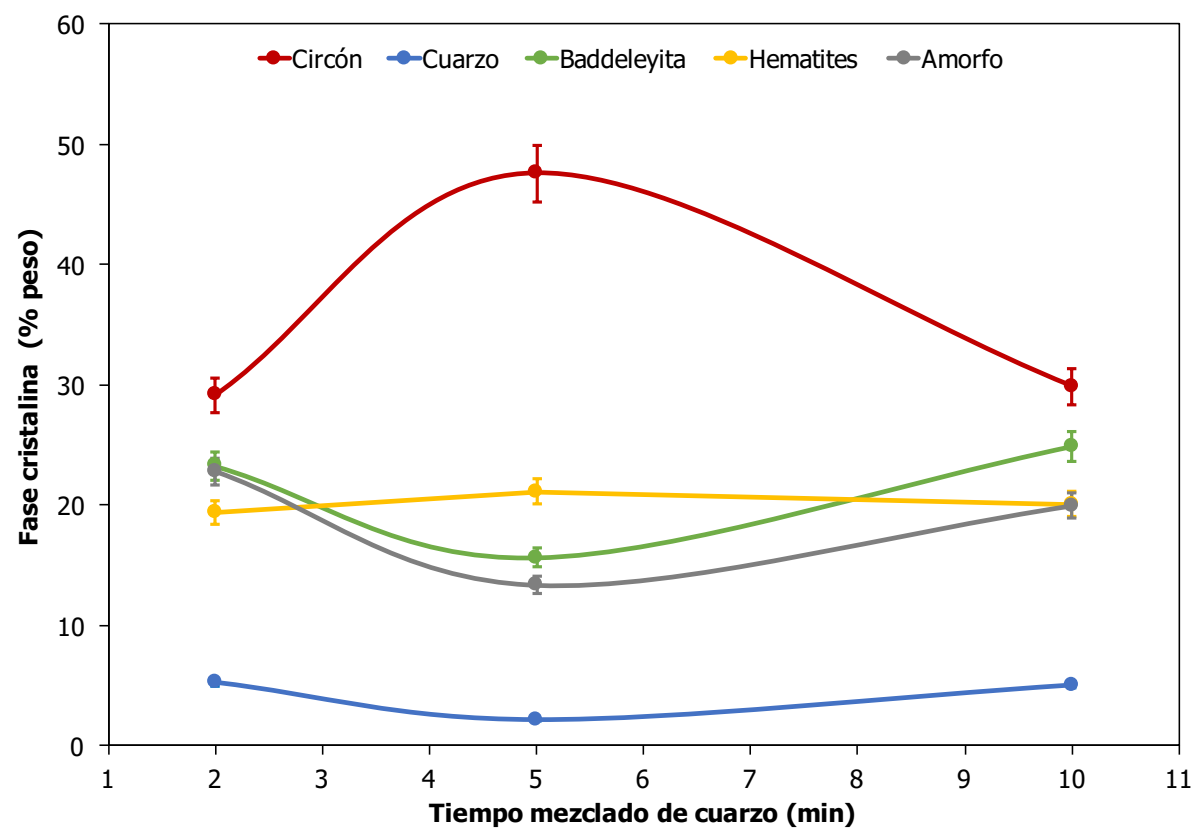

Figura 4.82 Evolución de las fases cristalinas presentes en los pigmentos frente al tiempo de mezclado del cuarzo, tras su incorporación a la mezcla de materias primas

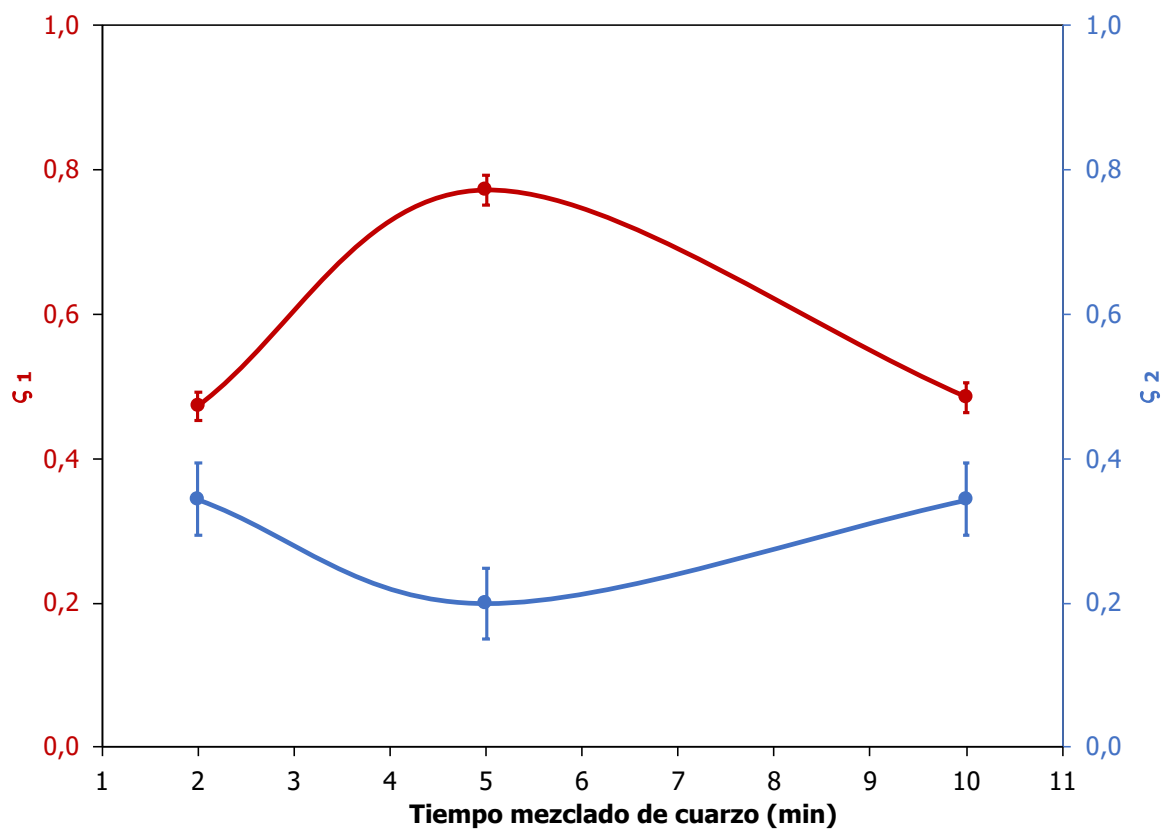

Figura 4.83 Evolución de los parámetros $\$ 1$ y $\$ 2$ frente al tiempo de mezclado del cuarzo, tras su incorporación a la mezcla de materias primas 
Los resultados confirman que existe un tiempo de mezclado óptimo para el cuarzo, que, si no se alcanza, o se supera, produce una merma importante en la reactividad de la mezcla. Este resultado no es inesperado, ya que se habían detectado tendencias similares en experimentos previos, y por tanto se confirma que existe una condición óptima en el mezclado del cuarzo con los aglomerados circona-hematites-mineralizador. Una permanencia en el molino demasiado corta no permitirá situar suficiente cuarzo en el entorno de los aglomerados, mientras que, si se prolonga en exceso, existe el riesgo de que dichos aglomerados se rompan, alcanzando un grado de homogeneidad de las materias primas inadecuado para la correcta síntesis del pigmento, tal como ya se verificó con los resultados descritos los apartados anteriores.

\subsubsection{Efecto de la posición de la cuchilla}

Durante la realización de los experimentos en el molino de mortero y tratando de reproducir los resultados, se detectó una variabilidad importante, a pesar de que la presión que ejercía la mano del mortero se podía controlar con cierta precisión. Este hecho hizo pensar en otra variable implicada en el funcionamiento del molino de mortero, máxime si se considera que las variaciones en la reactividad de la mezcla para el intervalo más amplio de presiones que se podía utilizar (experimentos E17 a E20) eran moderadas, pues el porcentaje de circón determinado mediante difracción de rayos X se movía dentro de un intervalo reducido.

Realizando un análisis del procedimiento de operación del molino de mortero se observó que la posición de la cuchilla que separa la mezcla en proceso de las paredes del molino, y la sitúa en posición adecuada para que la mano ejerza su presión, era una variable que no se había tenido en cuenta.
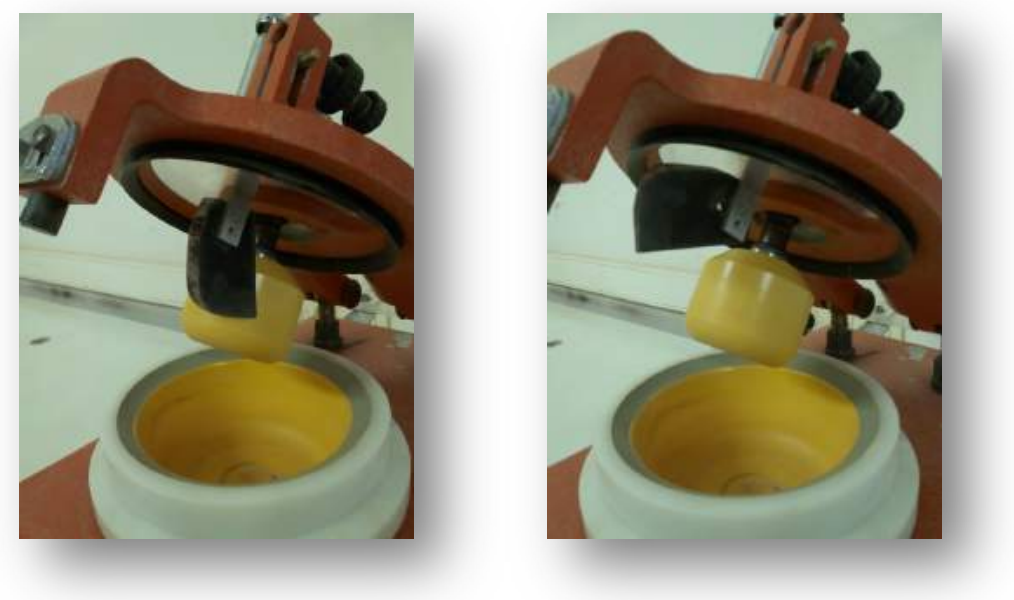

Figura 4.84 Posición de la cuchilla o espátula en el molino de mortero 
Para verificar dicha hipótesis se realizaron dos experimentos posicionando la cuchilla de dos modos diferentes:

- E23: Cuchilla lo más paralela posible a la pared de la jarra y dejando poco espacio con respecto al fondo de la jarra.

- E24: Cuchilla oblicua con respecto a las paredes, y dejando cierto espacio con respecto al fondo de la jarra.

Los experimentos se realizaron utilizando un tiempo de mezclado de la circona, la hematites, el fluidificante y el mineralizador de 15 minutos. Tras la adición del cuarzo, la mezcla se homogeneizó otros 5 minutos. Durante todo el proceso se mantuvo la presión mínima que podía ejercer la mano del mortero, con el objetivo de amplificar las posibles diferencias en reactividad como consecuencia del procesado.

Las diferencias entre las mezclas obtenidas se apreciaban a simple vista. La composición E24 presentaba un aspecto heterogéneo, mientras que la mezcla E23 mostró un color uniforme, indicio de una mayor homogeneidad. Ambas muestras se calcinaron con el Ciclo STD, obteniéndose materiales de color rojizo, cuyo análisis mineralógico generó los datos detallados en la Tabla 4.32.

Tabla 4.32 Porcentaje de las fases cristalinas identificadas y composición de la fase amorfa (\% peso)

\begin{tabular}{|c|c|c|c|c|}
\hline & & & E23 & E24 \\
\hline \multirow{4}{*}{\multicolumn{2}{|c|}{ 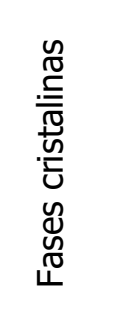 }} & Cuarzo & 9 & 12 \\
\hline & & Baddeleyita & 35 & 40 \\
\hline & & Hematites & 20 & 26 \\
\hline & & Circón & 12 & 4 \\
\hline & & Fase amorfa total & 23 & 28 \\
\hline \multirow{3}{*}{\multicolumn{2}{|c|}{ 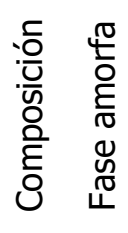 }} & $\% \mathrm{Fe}_{2} \mathrm{O}_{3}$ & 4 & 7 \\
\hline & & $\% \mathrm{SiO}_{2}$ & 9 & 8 \\
\hline & & $\% \mathrm{ZrO}_{2}$ & 7 & 7 \\
\hline
\end{tabular}


La representación gráfica de los datos, junto con los correspondientes al pigmento E17 sintetizado en las mismas condiciones, pero con una posición de la cuchilla no definida (Figura 4.85), indica que las posiciones extremas no son convenientes, y que la posición no identificada utilizada en la preparación de las mezclas de la serie anterior era más adecuada. También se aprecia que con la posición oblicua se obtiene una mezcla bastante heterogénea, que prácticamente no genera circón, mientas que la posición paralela mejora algo los resultados, pero no se puede considerar favorable, ya que únicamente genera un $12 \%$ de circón.

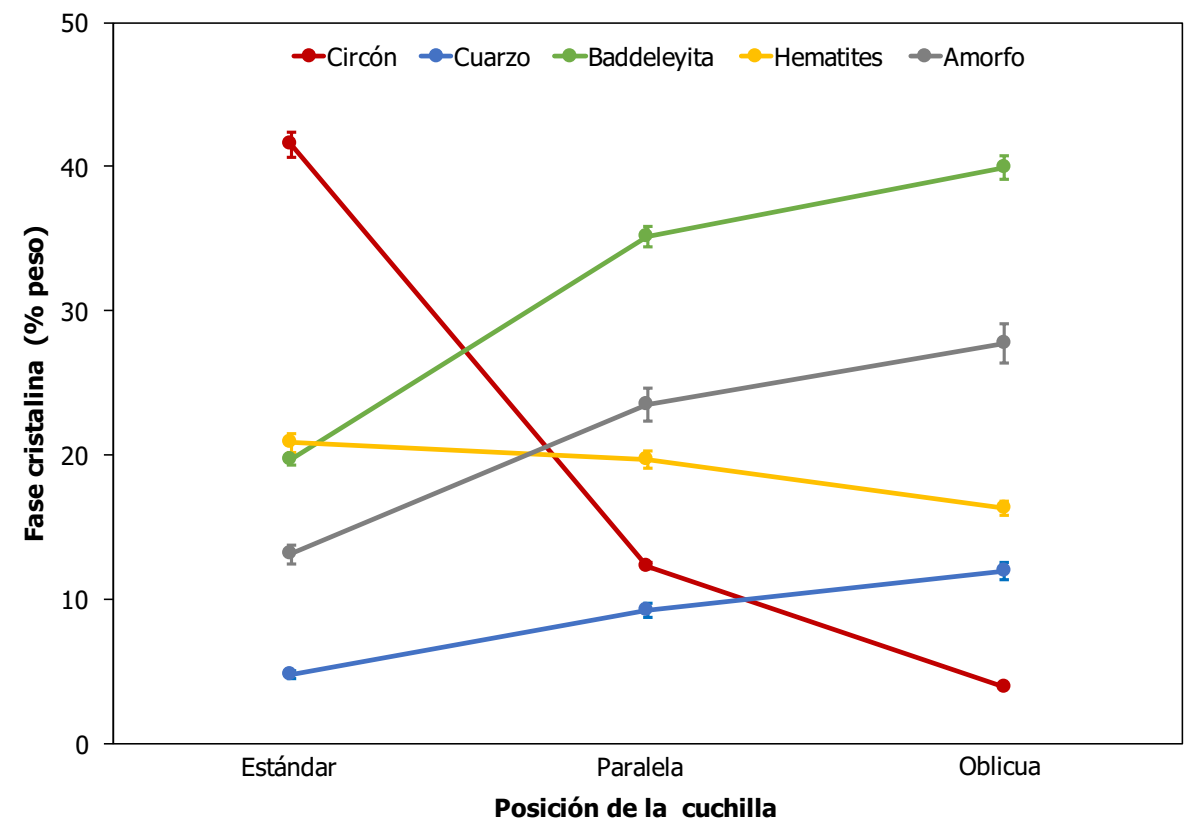

Figura 4.85 Influencia sobre las fases cristalinas presentes en los pigmentos de la posición de la cuchilla durante el mezclado de las materias primas en el molino de mortero

Los parámetros $\varsigma_{1}$ y $\varsigma_{2}$ que indican el grado de avance de la reacción muestran una tendencia similar que la observada en la figura anterior. De este modo, la posición estándar de la cuchilla es la que muestra un valor más elevado de $\varsigma_{1}$, lo que indicaría que un mayor porcentaje de cuarzo interviene en la reacción de formación del circón. No obstante, en esa posición el parámetro $\varsigma_{2}$ muestra un mínimo que confirmaría un menor porcentaje de sílice en la fase amorfa. 


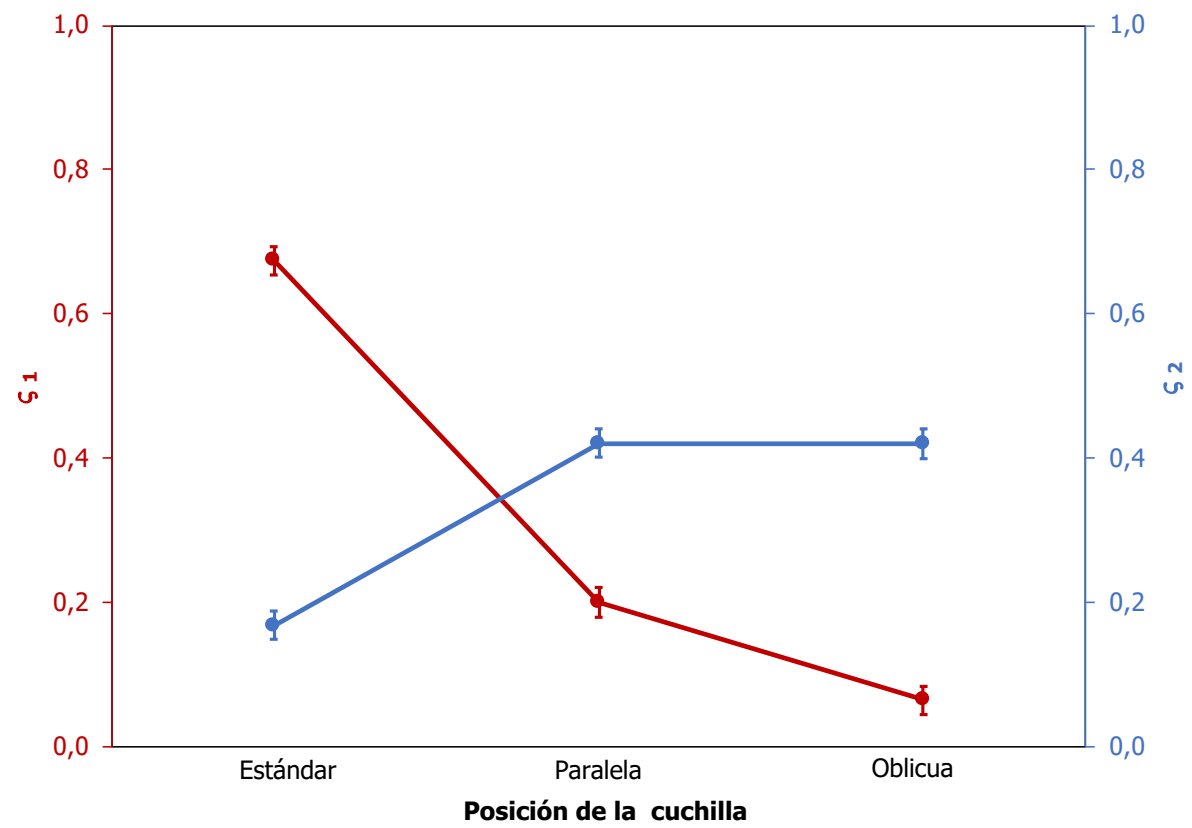

Figura 4.86 Evolución de los parámetros $\varsigma 1$ y $\$ 2$ con la posición de la cuchilla durante el mezclado de las materias primas en el molino de mortero

Obviamente, la reactividad de las mezclas depende del grado de mezcla, que está relacionado con la posición de la cuchilla, y de la compactación de los aglomerados que consigue la mano del mortero. De estos experimentos se desprende que la obtención de una mezcla con elevada reactividad depende tanto del modo en que las materias primas se distribuyen espacialmente para formar los aglomerados (consecuencia de la posición de la cuchilla), como de la compactación de los mismos (consecuencia de la presión). El problema es que la posición de la cuchilla es muy difícil de fijar en una posición exacta, ya que el equipo no fue diseñado con dicha capacidad. Por tanto, es una variable difícil de reproducir.

De los resultados obtenidos de la optimización del método de mezclado vía seca se concluye que la reactividad de la mezcla está correlacionada con la formación de aglomerados de circona, hematites, mineralizador y fluidificante, rodeados éstos a su vez de partículas de cuarzo. Asimismo, un mezclado muy enérgico capaz de destruir estos aglomerados conduce a pigmentos con un menor poder colorante. 


\subsection{Optimización del mezclado vía húmeda}

Dado que los experimentos iniciales llevados a cabo preparando la mezcla de materias primas vía húmeda no eran muy favorables en cuanto a reactividad, al menos en comparación con los experimentos vía seca, se decidió tratar de optimizar las condiciones de operación del mezclado en el molino planetario vía húmeda. El objetivo era determinar si con dicho método era posible obtener una mezcla con una reactividad similar a la que presentaba la mezcla preparada mediante vía seca, escogiendo adecuadamente las condiciones de operación.

Para llevar a cabo la optimización de condiciones de mezclado, se realizó un diseño de experimentos para acotar las condiciones de operación más favorables. En primer lugar, se modificaron únicamente los parámetros de funcionamiento del molino planetario, la velocidad y el tiempo de mezclado. Seguidamente se investigaron otros parámetros como el fluido utilizado, la adición de cuarzo tras el mezclado inicial de las materias primas, y el tamaño de partícula del mineralizador utilizado.

\subsubsection{Estudio de las variables de operación en el molino planetario}

Una de las posibles hipótesis que se podían plantear para explicar las notables diferencias halladas entre los pigmentos sintetizados industrialmente vía seca (A01 a A04), y los sintetizados a partir de las composiciones preparadas en el molino planetario vía húmeda en el laboratorio (A05 a A08), era que las condiciones de trabajo utilizadas en el molino planetario vía húmeda fueran demasiado enérgicas (15 minutos, 230 rpm). Por ello se consideró conveniente ensayar unas condiciones de trabajo más suaves, para tratar de equiparar los resultados de ambos métodos. Sin embargo, también se incluyó un experimento para evaluar el efecto de condiciones más enérgicas.

Dado que el molino planetario permitía variar independientemente el tiempo de mezclado y la velocidad de rotación, se decidió investigar el efecto de estas dos variables. Para lo cual se definieron cuatro nuevos experimentos utilizando la fórmula N04, que junto con el pigmento A08, constituyó una exploración del efecto de las dos variables. Concretamente se exploraron tres tiempos de mezclado (5, 15 y 60 minutos), y dos velocidades (100 y $230 \mathrm{rpm})$. Las nuevas referencias para los pigmentos sintetizados fueron F01, F02, F03, F04, F05 y F06. Las condiciones de operación para cada ensayo se detallan en la Tabla 4.33 . 
Tabla 4.33 Condiciones de preparación de las mezclas

\begin{tabular}{|ccc|}
\hline Referencia & $\begin{array}{c}\text { Tiempo de mezclado } \\
\text { (minutos) }\end{array}$ & $\begin{array}{c}\text { Velocidad molino } \\
(\mathrm{rpm})\end{array}$ \\
\hline F01 & 5 & 100 \\
F02 & 5 & 230 \\
F03 & 15 & 100 \\
F04 & 15 & 230 \\
F05 & 60 & 100 \\
F06 & 60 & 230 \\
\hline
\end{tabular}

Los pigmentos se sintetizaron con el Ciclo STD y se caracterización mediante difracción de rayos $X$ obteniendo los resultados mostrados en la Tabla 4.34.

Tabla 4.34 Porcentaje de las fases cristalinas identificadas y composición de la fase amorfa (\% peso)

\begin{tabular}{|c|c|c|c|c|c|c|c|c|}
\hline & & & F01 & F02 & F03 & F04 & F05 & F06 \\
\hline & & Cuarzo & 14 & 12 & 13 & 8 & 11 & 6 \\
\hline t & & Baddeleyita & 46 & 45 & 48 & 40 & 45 & 38 \\
\hline 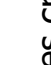 & & Hematites & 20 & 20 & 21 & 21 & 22 & 19 \\
\hline ப & & Circón & 1 & 1 & 1 & 13 & 1 & 15 \\
\hline & & Fase amorfa total & 20 & 21 & 17 & 18 & 21 & 22 \\
\hline & $\mathscr{t}$ & $\% \mathrm{Fe}_{2} \mathrm{O}_{3}$ & 4 & 3 & 3 & 3 & 2 & 5 \\
\hline 을 & है & $\% \mathrm{SiO}_{2}$ & 7 & 9 & 8 & 9 & 10 & 11 \\
\hline 8 & ए & $\% \mathrm{ZrO}_{2}$ & 4 & 4 & 1 & 1 & 4 & 2 \\
\hline
\end{tabular}


La representación gráfica de los datos de difracción (Figura 4.87), permitió detectar los siguientes hechos:

- Con respecto al pigmento A08 (15\% de circón), la reducción en el tiempo de molienda a 5 minutos o en la velocidad del molino a $100 \mathrm{rpm}$ resulta perjudicial de cara a la reactividad de la mezcla de materias primas, ya que en ambos casos prácticamente se anula la reacción de síntesis del circón (1\% de circón formado). Por otra parte, prolongar la homogeneización más allá de 15 minutos (a la velocidad de $230 \mathrm{rpm}$ ), tampoco resulta beneficioso, ya que el porcentaje de circón formado es muy similar al pigmento original A08.

- El porcentaje de baddeleyita apenas varía en las mezclas tratadas a $100 \mathrm{rpm}$, pero muestra una tendencia decreciente a $230 \mathrm{rpm}$, al menos para tiempos cortos, ya que luego se estabiliza.

- El porcentaje de baddeleyita es similar en los seis pigmentos sintetizados, lo que da a entender que el cuarzo es la fase cristalina limitante de la reacción y parte del cuarzo se está incorporando en la fase amorfa.

- Por otra parte, la fase amorfa no varía sustancialmente cuando se varían las condiciones de mezclado.

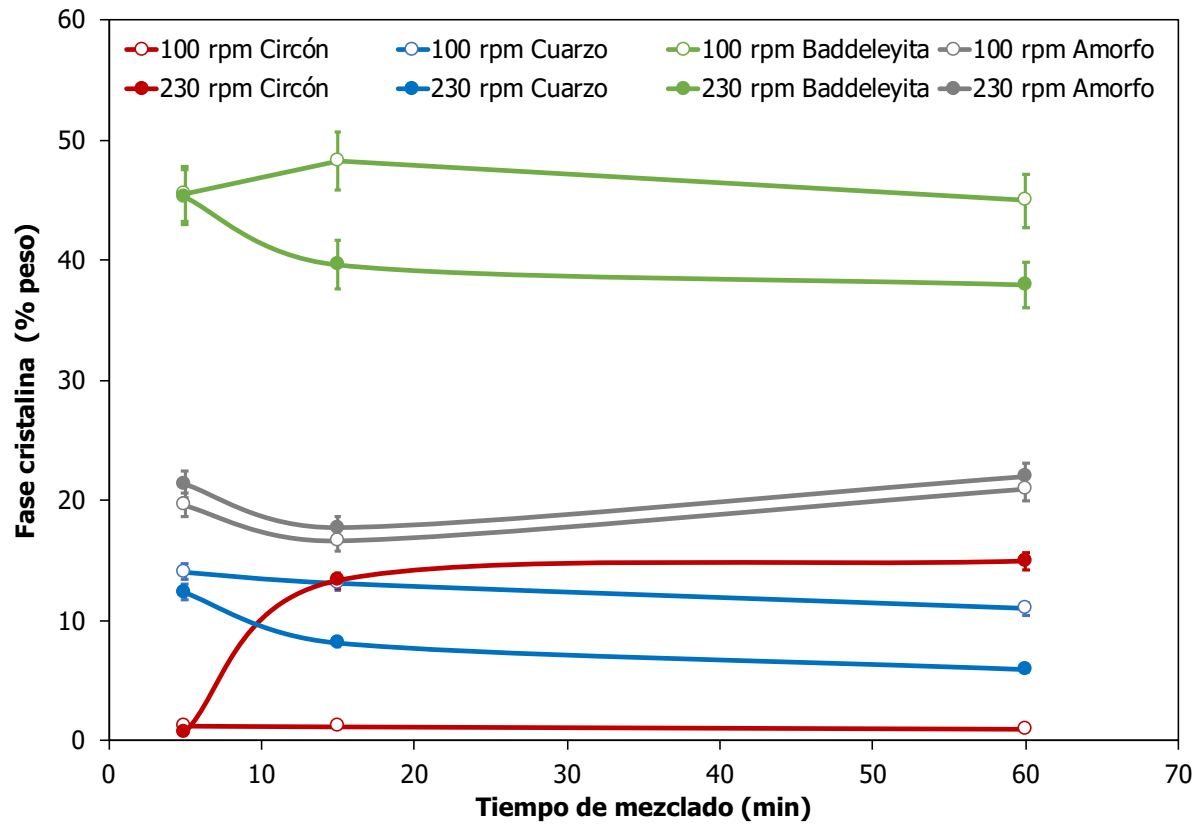

Figura 4.87 Evolución de las fases cristalinas presentes en los pigmentos, frente al tiempo de mezclado y la velocidad de rotación del molino planetario 
Al representar gráficamente los parámetros $\varsigma_{1}$ y $\varsigma_{2}$ (Figura 4.88), se observa que el grado de avance de la reacción no es muy elevado y se varían de forma sustancial al modificar el tiempo de mezclado y la velocidad de rotación del molino planetario.

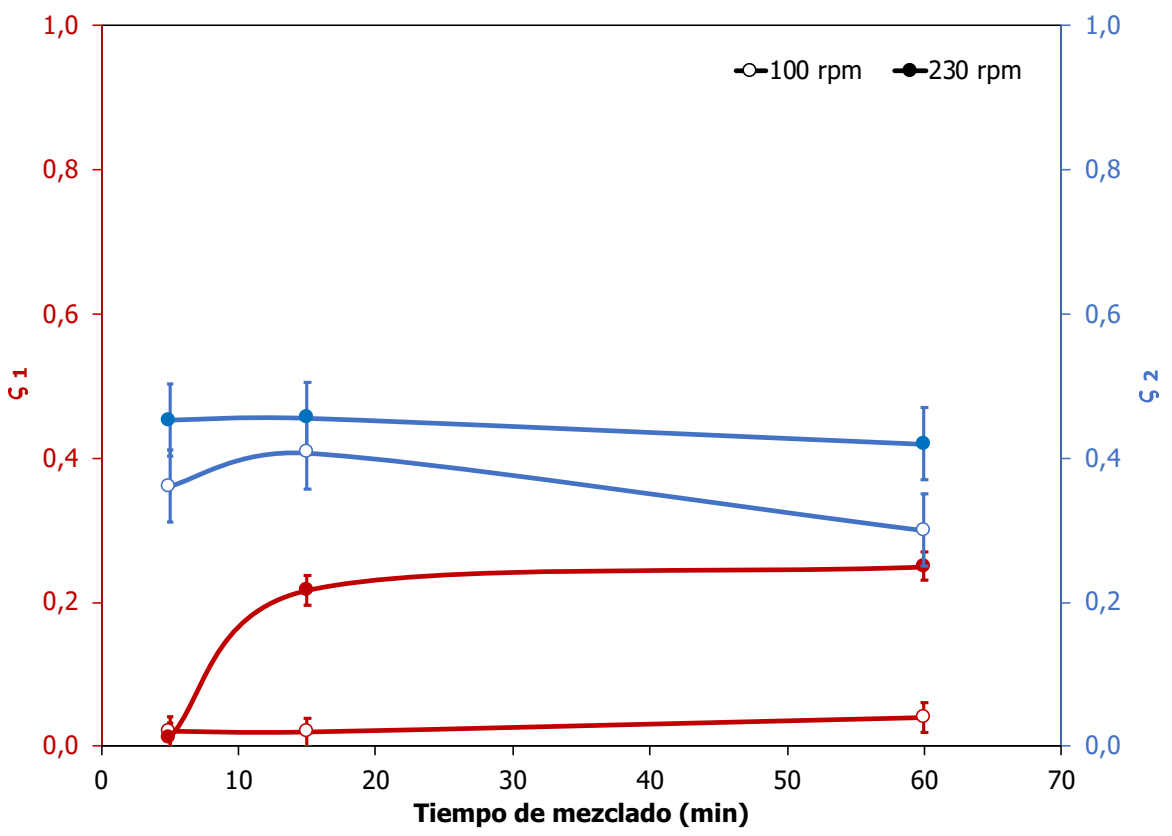

Figura 4.88 Evolución de los parámetros $\varsigma 1$ y $\varsigma 2$, frente al tiempo de mezclado y la velocidad de rotación del molino planetario

Los resultados muestran que la cantidad de circón generada con las nuevas condiciones era aún más reducida que en el pigmento A08, que de por sí ya era muy inferior a su homólogo sintetizado con el mezclado vía seca, posiblemente porque la preparación de la mezcla en el molino planetario vía húmeda conduce a una microestructura muy diferente a la que resulta del mezclado vía seca.

Por otro lado, el uso de condiciones enérgicas en el molino parece favorecer la reacción, siempre que no se prolongue demasiado tiempo.

La interpretación de los datos recogidos permite confirmar que un mezclado muy íntimo de las cuatro materias primas no favorece la síntesis del circón. Es probable que la reacción entre la sílice y el mineralizador provoque la aparición de una fase vítrea de alta viscosidad (responsable de la mayor contracción durante la síntesis). En dichas condiciones la transferencia de materia se produciría mayoritariamente por difusión a través de la fase vítrea, lo cual impediría la formación de grandes cristales de circón, que son necesarios para encapsular la hematites. 


\subsubsection{Adición del cuarzo a la mezcla en una etapa posterior}

Algunas investigaciones relacionadas con la síntesis del pigmento coral de hierro-circón apuntan a que la adición del cuarzo en etapas diferenciadas del resto de materias primas, permitiría aumentar la formación de circón durante la síntesis del pigmento [56]. Este efecto fue observado en los experimentos realizados mediante mezclado vía seca del apartado 4.5.3.

Para intentar corroborar si este efecto también se producía en el mezclado vía húmeda, se diseñaron experimentos para verificar si una adición tardía del cuarzo mejoraba las características de la mezcla de cara a su reactividad, ya que de este modo se esperaba que se formasen agrupaciones relativamente estables de circona y hematites, alrededor de las cuales se dispondría el cuarzo introducido en una segunda etapa de mezclado, de modo que las condiciones fuesen favorables para evitar una reacción previa del mineralizador y el cuarzo.

El experimento se realizó con la composición correspondiente a la fórmula N04. Para su realización se ensayaron diferentes tiempos de homogeneización en el molino planetario tal como se refleja en la Tabla 4.35, utilizando la velocidad de 230 rpm, que aparentemente era la más conveniente según los experimentos realizados previamente. Una vez finalizada la homogeneización de la circona, la hematites, el mineralizador y el fluidificante, se incorporó a la jarra de mezclado el cuarzo, y se volvió a homogeneizar la mezcla durante 5 minutos, para disminuir en lo posible la ruptura de los aglomerados que se hubiesen podido formar durante la primera etapa.

Tabla 4.35 Condiciones de preparación de las mezclas

\begin{tabular}{|cc|}
\hline Referencia & Tiempo de la primera etapa de mezclado \\
(minutos)
\end{tabular}

Tras el tratamiento térmico de las mezclas con el Ciclo STD se obtuvieron materiales de color rojizo, cuya caracterización mediante difracción de rayos $\mathrm{X}$ generó los resultados que se detallan en la Tabla 4.36. 
Tabla 4.36 Porcentaje de las fases cristalinas identificadas y composición de la fase amorfa (\% peso)

\begin{tabular}{|c|c|c|c|c|}
\hline & & G01 & G02 & G03 \\
\hline \multirow{4}{*}{ 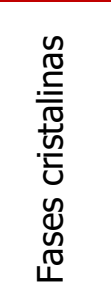 } & Cuarzo & 10 & 5 & 12 \\
\hline & Baddeleyita & 36 & 27 & 40 \\
\hline & Hematites & 20 & 20 & 20 \\
\hline & Circón & 12 & 26 & 6 \\
\hline & Fase amorfa total & 22 & 22 & 23 \\
\hline \multirow{3}{*}{ 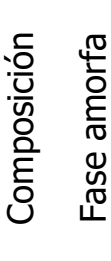 } & $\% \mathrm{Fe}_{2} \mathrm{O}_{3}$ & 4 & 4 & 4 \\
\hline & $\% \mathrm{SiO}_{2}$ & 8 & 8 & 8 \\
\hline & $\% \mathrm{ZrO}_{2}$ & 6 & 6 & 6 \\
\hline
\end{tabular}

Los resultados indican que las tres muestras contienen proporciones muy similares de fase amorfa, con una composición prácticamente idéntica, pero las proporciones de fases cristalinas son claramente diferentes. Ello indica que los mecanismos de formación de fase amorfa y de circón son distintos, y además las condiciones de síntesis les afectan de diferente modo.

La representación gráfica de los resultados obtenidos de la cuantificación de fases cristalinas y composición de fase amorfa junto a la estimación de los parámetros $\varsigma_{1}$ y $\varsigma_{2}$ (Figura 4.89 y Figura 4.90) y su comparación con los correspondientes a las mismas condiciones de operación del molino, pero incorporando el cuarzo desde el inicio permiten extraer las siguientes relaciones:

- El efecto de la duración de la primera etapa de homogeneización (circona, hematites, mineralizador y fluidificante), influye de manera notable en la reactividad de la mezcla. Tiempos demasiado largos o demasiado cortos reducen la reactividad, hallándose el óptimo para un tiempo de mezclado de 60 minutos, ya que conduce al pigmento que genera mayor proporción de circón (26\%).

- Como era de esperar, la evolución de la baddeleyita y el cuarzo es inversa a la que presenta el circón. Sin embargo, cabe resaltar que las variaciones en el porcentaje de cuarzo son mucho menos acusadas. Este hecho 
podría correlacionarse con la presencia de una fase vítrea silícea que incorporase una fracción apreciable del cuarzo inicial.

- Se aprecia que la incorporación posterior del cuarzo a la mezcla de materias primas genera un aumento apreciable de la fracción de circón en el pigmento final, cuando se opera en las condiciones óptimas (60 minutos de mezclado), en comparación con los resultados obtenidos a partir de mezclas preparadas incorporando todos los reactantes desde el inicio (A08 con un 15\% de circón formado). Sin embargo, para tiempos muy largos de mezclado, parece ser desfavorable.

- La adición posterior del cuarzo provoca que la fracción de circón formada en el pigmento sea más sensible a las variaciones en el tiempo de mezcla, ya que el porcentaje de circón abarca un intervalo mucho más amplio que en el caso de la incorporación inicial del cuarzo.

- Es posible que tiempos de molienda muy largos alteren la distribución de tamaño de partícula, especialmente del mineralizador, con lo cual se favorezca el mecanismo por fase líquida.

- $\quad$ El parámetro $\varsigma_{1}$ que nos da idea de la fracción de cuarzo que pasa a formar parte de la fase cristalina circón, presenta un máximo para un tiempo de mezclado de 60 minutos. Por otro lado, el parámetro $\varsigma 2$ apenas evoluciona con el tiempo de mezclado.

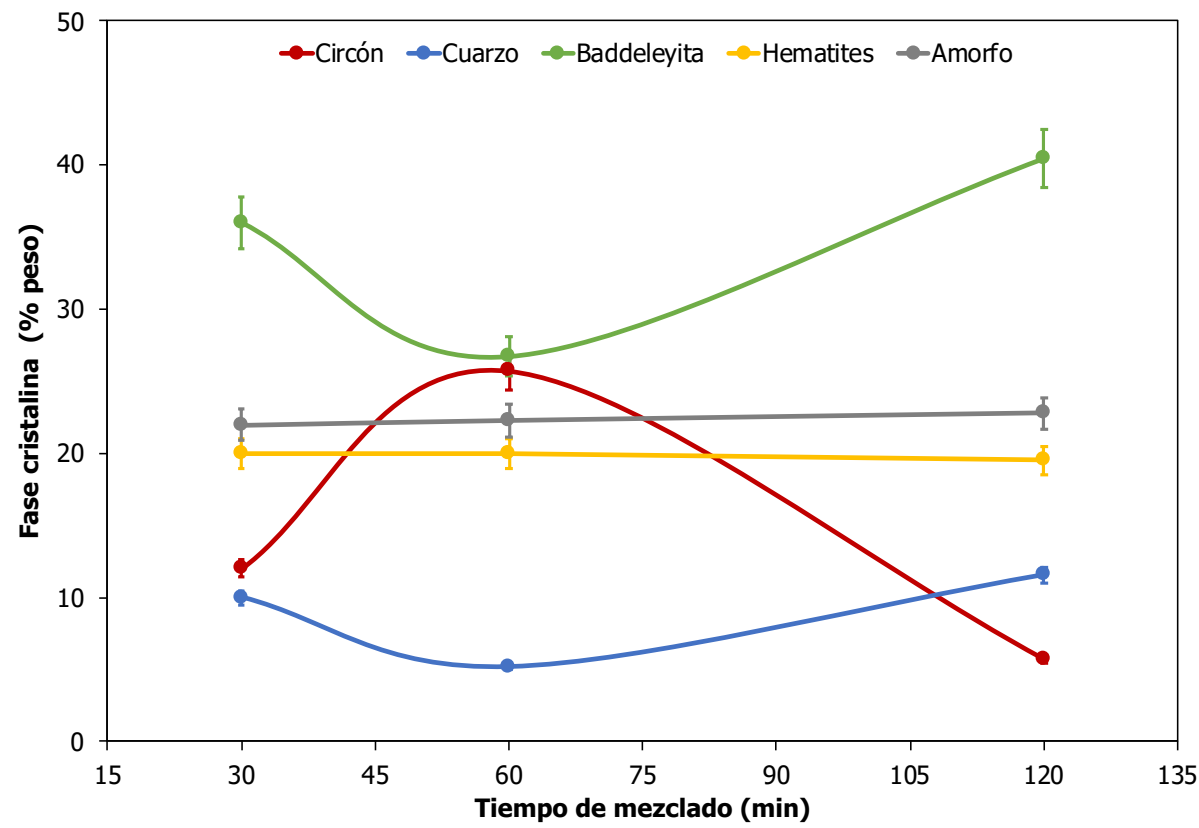

Figura 4.89 Evolución de las fases cristalinas presentes en los pigmentos en los que se incorporó el cuarzo en la etapa final de homogeneización, frente al tiempo de mezclado 


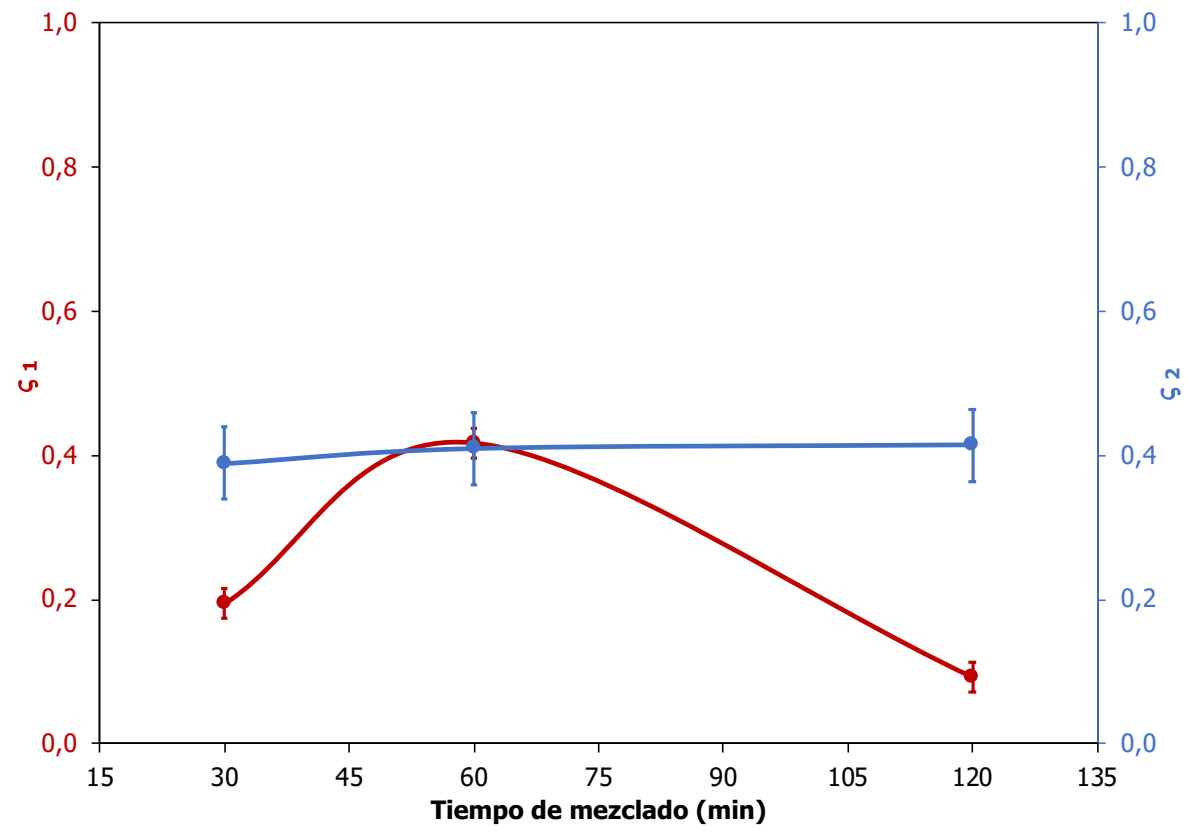

Figura 4.90 Evolución de los parámetros $\varsigma_{1}$ y $\varsigma 2$, incorporando el cuarzo en la etapa final de homogeneización, frente al tiempo de mezclado

Los resultados parecían confirmar la hipótesis planteada sobre la conveniencia de generar inicialmente aglomerados de circona y hematites, que estarían rodeados por la sílice. En dicho sentido el tiempo de mezclado de 60 minutos era el más conveniente para alcanzar el resultado óptimo, pero aun así la cantidad de circón generada (26\%) quedaba muy por debajo de la conseguida con la mezcla preparada por vía seca (45\% de circón), por lo que se decidió investigar otras variables.

\subsubsection{Utilización de agua como fluido durante el mezclado}

Es conocido que un líquido orgánico con baja tensión superficial como la acetona no facilita la aglomeración de partículas durante el secado de una suspensión. Sin embargo, los líquidos con elevada tensión superficial sí son más proclives a facilitar la formación de aglomerados de partículas durante el secado de una suspensión. Por ello se consideró conveniente ensayar un líquido con mayor tensión superficial como fluido durante el mezclado, como por ejemplo el agua, ya que podría favorecer la formación de los aglomerados circonahematites, deseables para la correcta síntesis del pigmento.

Los experimentos se realizaron a partir de la composición correspondiente a la fórmula N04, y se mantuvo la incorporación de la sílice en una etapa posterior con 5 minutos de mezclado final, dado que en principio conducía a una mayor reactividad de la mezcla obtenida. Para obtener resultados comparables, se 
utilizaron las mismas condiciones de trabajo que las descritas en el apartado anterior, tanto en la velocidad de giro del molino (230 rpm), como en los tiempos de mezclado ensayados. Las referencias de las mezclas preparadas fueron $\mathrm{H} 01, \mathrm{H} 02$ y $\mathrm{H} 03$ y las condiciones de operación utilizadas se detallan en la Tabla 4.37.

Tabla 4.37 Condiciones de preparación de las mezclas

\begin{tabular}{|cc|}
\hline Referencia & $\begin{array}{r}\text { Tiempo de la primera etapa de mezclado } \\
\text { (minutos) }\end{array}$ \\
\hline H01 & 30 \\
H02 & 60 \\
H03 & 120 \\
\hline
\end{tabular}

Tras el secado de las suspensiones en base acuosa se comprobó que el material recogido presentaba una mayor resistencia a la disgregación durante el tamizado, lo cual era coherente con la hipótesis planteada. Tras el tratamiento térmico de las mezclas con el Ciclo STD se obtuvieron materiales de color rojizo homogéneo, cuya caracterización mediante difracción de rayos $X$ generó los resultados que se detallan en la Tabla 4.38.

Tabla 4.38 Porcentaje de las fases cristalinas identificadas y composición de la fase amorfa (\% peso)

\begin{tabular}{|c|c|c|c|c|c|}
\hline & & & H01 & $\mathrm{HO2}$ & HO3 \\
\hline \multirow{4}{*}{\multicolumn{2}{|c|}{ 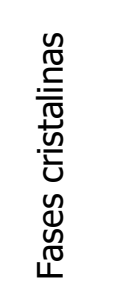 }} & Cuarzo & 8 & 6 & 7 \\
\hline & & Baddeleyita & 29 & 23 & 25 \\
\hline & & Hematites & 20 & 21 & 18 \\
\hline & & Circón & 22 & 33 & 23 \\
\hline & & Fase amorfa total & 22 & 17 & 27 \\
\hline \multirow{2}{*}{ 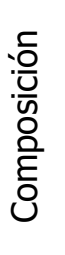 } & \multirow{2}{*}{ 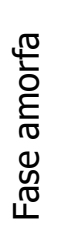 } & $\% \mathrm{Fe}_{2} \mathrm{O}_{3}$ & 4 & 3 & 5 \\
\hline & & $\% \mathrm{ZrO}_{2}$ & 6 & 5 & 10 \\
\hline
\end{tabular}


La comparación de los resultados obtenidos en esta serie de experimentos, con los correspondientes a sus homólogos variando únicamente el fluido utilizado (ver Figura 4.91), permite deducir las siguientes tendencias:

- La utilización de agua en lugar de acetona como fluido provoca un aumento en la proporción de circón generado en el pigmento para los tres tiempos de mezclado ensayados. Además, dicho efecto es más notable para tiempos largos, donde se obtenían los peores resultados utilizando acetona. Sin embargo, la mejora conseguida no genera un porcentaje de circón comparable a los mezclados vía seca, aunque se ha conseguido un porcentaje de circón para el pigmento $\mathrm{H} 02$ de un $70 \%$ del obtenido con el pigmento A04, sintetizado a partir de la misma fórmula y con el mismo tratamiento térmico).

- La baddeleyita sigue una tendencia inversa a la del circón tal y como cabría esperar.

- La evolución de los parámetros $\varsigma_{1}$ y $\varsigma_{2}$ muestra una tendencia similar. Utilizando agua como fluido se obtiene un valor mayor de $\varsigma_{1}$ lo que sugiere que una mayor fracción de cuarzo se invierte en la formación del circón.

Estos resultados indican que un mezclado en medio acuoso parece ser más favorable que en medio orgánico, debido a que el agua favorece la formación de aglomerados durante el secado, aunque no se descarta que las interacciones entre el agua y la superficie de los óxidos tuviese un papel en el comportamiento del sistema (una hidratación superficial podría favorecer la reacción, mientras que la adsorción de sustancias orgánicas podría generar localmente una atmósfera reductora, que redujese parte del $\mathrm{Fe}^{3+} \mathrm{a} \mathrm{Fe}^{2+}, 0$ interferir con la formación de especies volátiles como el $\mathrm{SiF}_{4}$ ). 


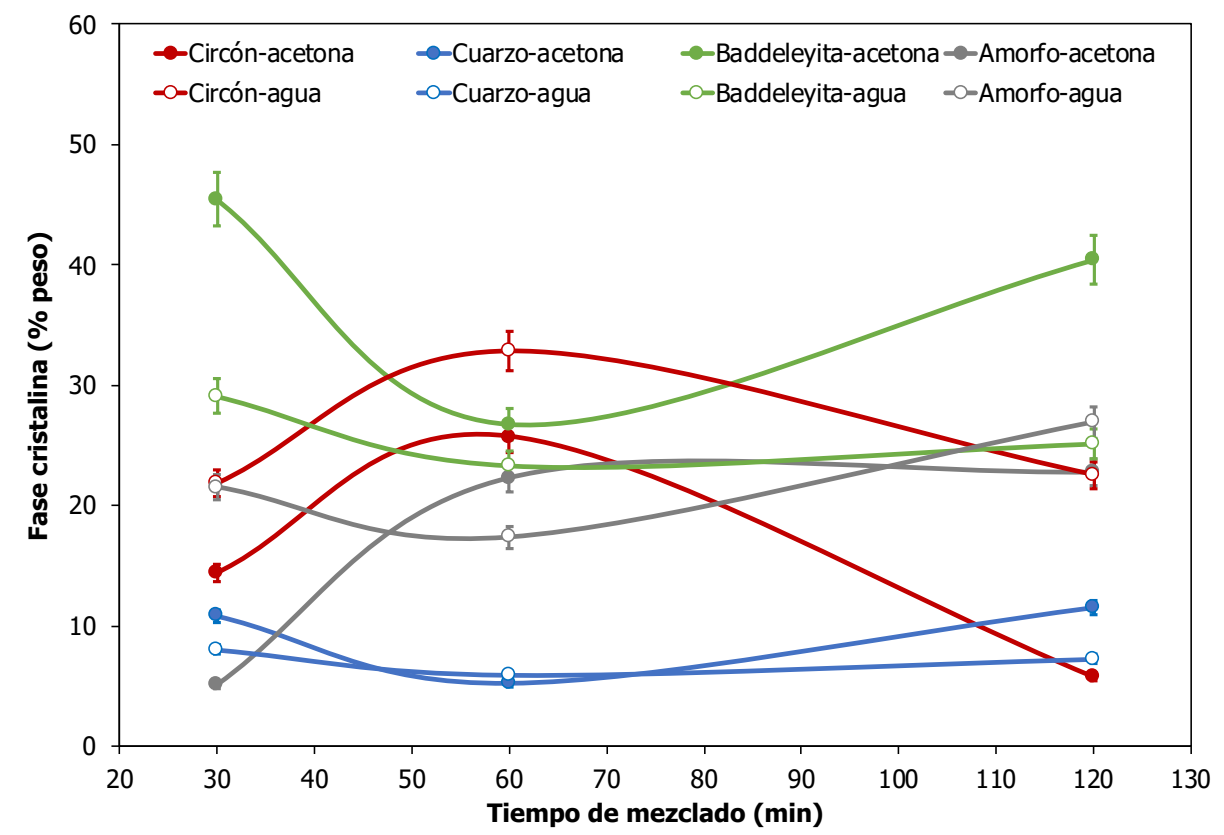

Figura 4.91 Evolución de las fases cristalinas presentes en los pigmentos en los que se incorporó el cuarzo en la etapa final de homogeneización, frente al tiempo de mezclado y fluido utilizado

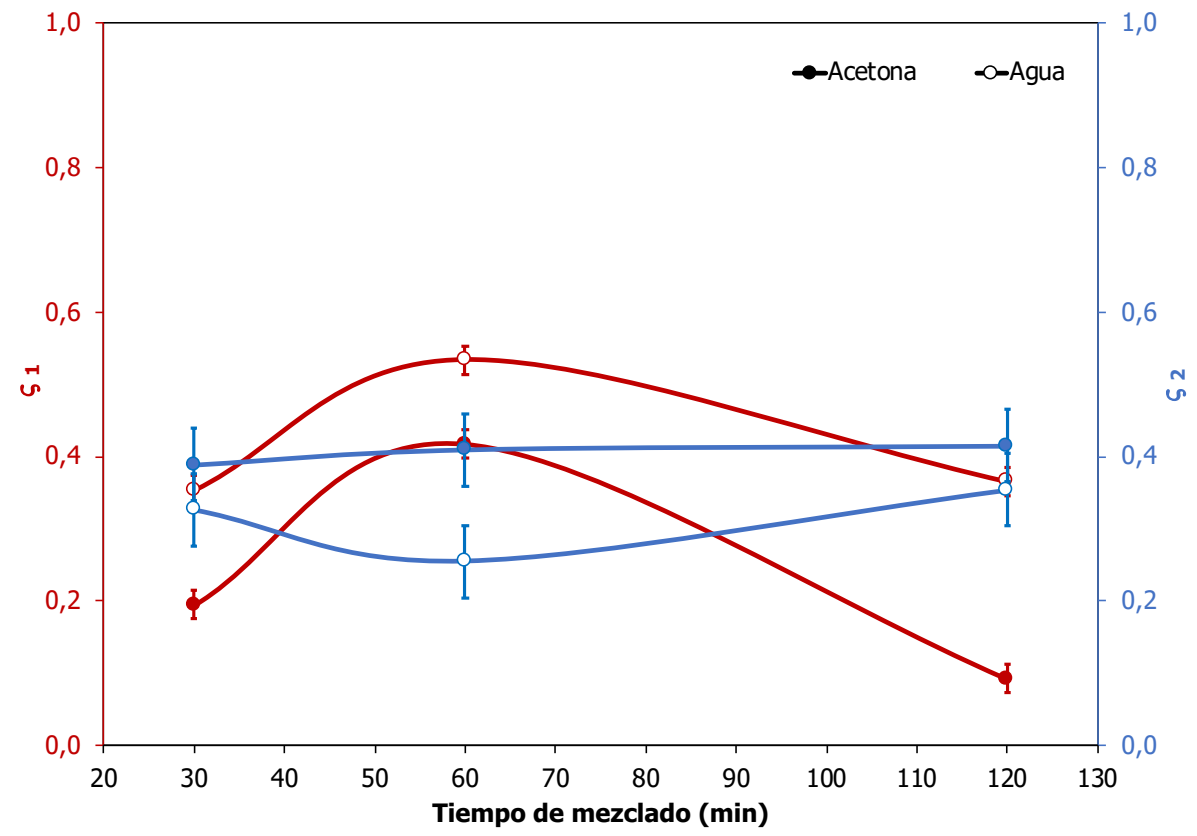

Figura 4.92 Evolución de los parámetros $\varsigma 1$ y $\varsigma 2$, en los que se incorporó el cuarzo en la etapa final de homogeneización, frente al tiempo de mezclado y fluido utilizado 


\subsubsection{Desarrollo de color}

Dado que el pigmento $\mathrm{H} 02$ poseía un porcentaje de circón relativamente elevado, se consideró conveniente ensayar su incorporación a los vidriados. En este ensayo se decidió emplear también el pigmento G02, ya que era su homólogo variando únicamente el fluido utilizado durante el mezclado (aunque la cantidad de circón formado fuera inferior).

Como resultado del ensayo se obtuvieron probetas de color anaranjado con el vidriado transparente, y rosadas con el opaco, si bien la intensidad del color fue mucho más elevada con el pigmento $\mathrm{H} 02$, como era de esperar (ver las coordenadas cromáticas en la Tabla 4.39 y Tabla 4.40).
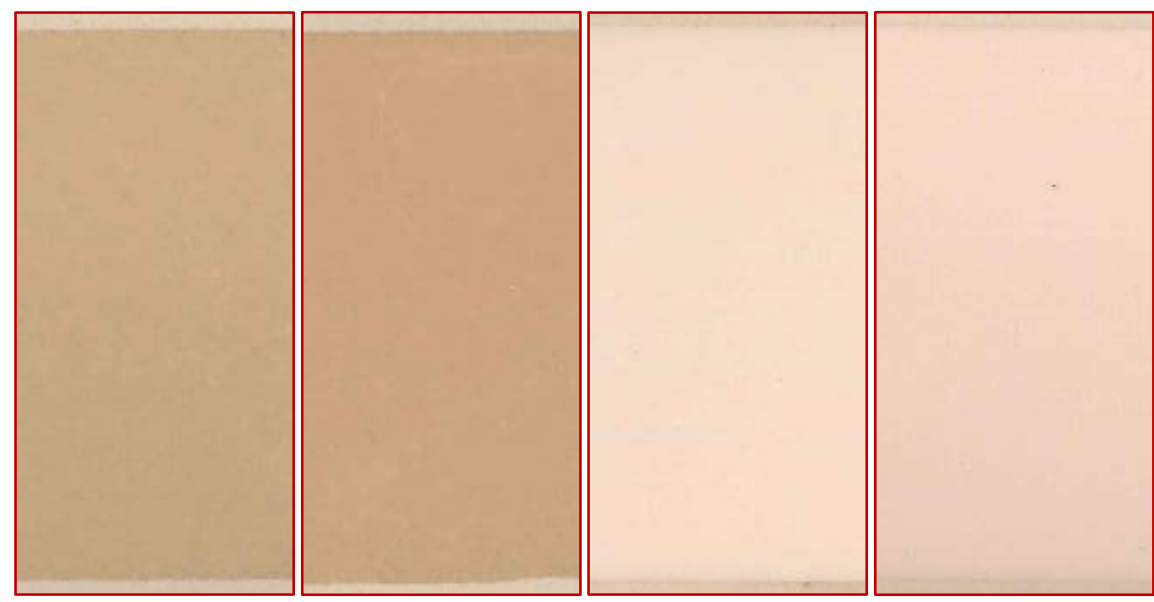

Figura 4.93 Probetas esmaltadas de las piezas G02, y H02 con el vidriado transparente y opaco respectivamente

Tabla 4.39 Coordenadas cromáticas desarrolladas por los pigmentos en el vidriado transparente $\left(1120^{\circ} \mathrm{C}\right)$

\begin{tabular}{|ccccccc|}
\hline Referencia & \multicolumn{2}{c}{ L* $^{*}$} & \multicolumn{3}{c}{$\mathrm{a}^{*}$} & \multicolumn{2}{c|}{$\mathrm{b}^{*}$} \\
\hline & $\mathrm{X}$ & $\sigma$ & $\mathrm{X}$ & $\sigma$ & $\mathrm{X}$ & $\sigma$ \\
$\mathrm{G} 02$ & 71,42 & 0,03 & 7,99 & 0,20 & 18,93 & 0,09 \\
$\mathrm{H} 02$ & 70,28 & 0,11 & 10,05 & 0,31 & 18,48 & 0,05 \\
\hline
\end{tabular}



en el vidriado opaco $\left(1040^{\circ} \mathrm{C}\right)$

\begin{tabular}{|ccccccc|}
\hline Referencia & \multicolumn{2}{c}{ L* $^{*}$} & \multicolumn{3}{c}{$\mathrm{a}^{*}$} & \multicolumn{2}{c|}{$\mathrm{b} *$} \\
\hline $\mathrm{K} 02$ & $\mathrm{X}$ & $\sigma$ & $\mathrm{X}$ & $\sigma$ & $\mathrm{X}$ & $\sigma$ \\
$\mathrm{H} 02$ & 86,43 & 0,06 & 5,75 & 0,07 & 9,62 & 0,17 \\
& 84,83 & 0,08 & 7,08 & 0,03 & 9,40 & 0,09 \\
\hline
\end{tabular}

La comparación de las coordenadas cromáticas generadas por estos pigmentos con las obtenidas para el pigmento A04 (ver Tabla 4.3 y Tabla 4.4) permiten deducir las siguientes conclusiones (Figura 4.94, Figura 4.95, Figura 4.96):

- Los pigmentos sintetizados generan colores notablemente más luminosos en los dos vidriados, con respecto al A04 (sintetizado a partir de un mezclado vía seca). Sin embargo, se aprecia que el pigmento cuya mezcla inicial se había preparado en medio acuoso ( $\mathrm{H02}$ ), conduce a valores de L* ligeramente inferiores (entre una y dos unidades), con respecto a la preparada en acetona (G02).

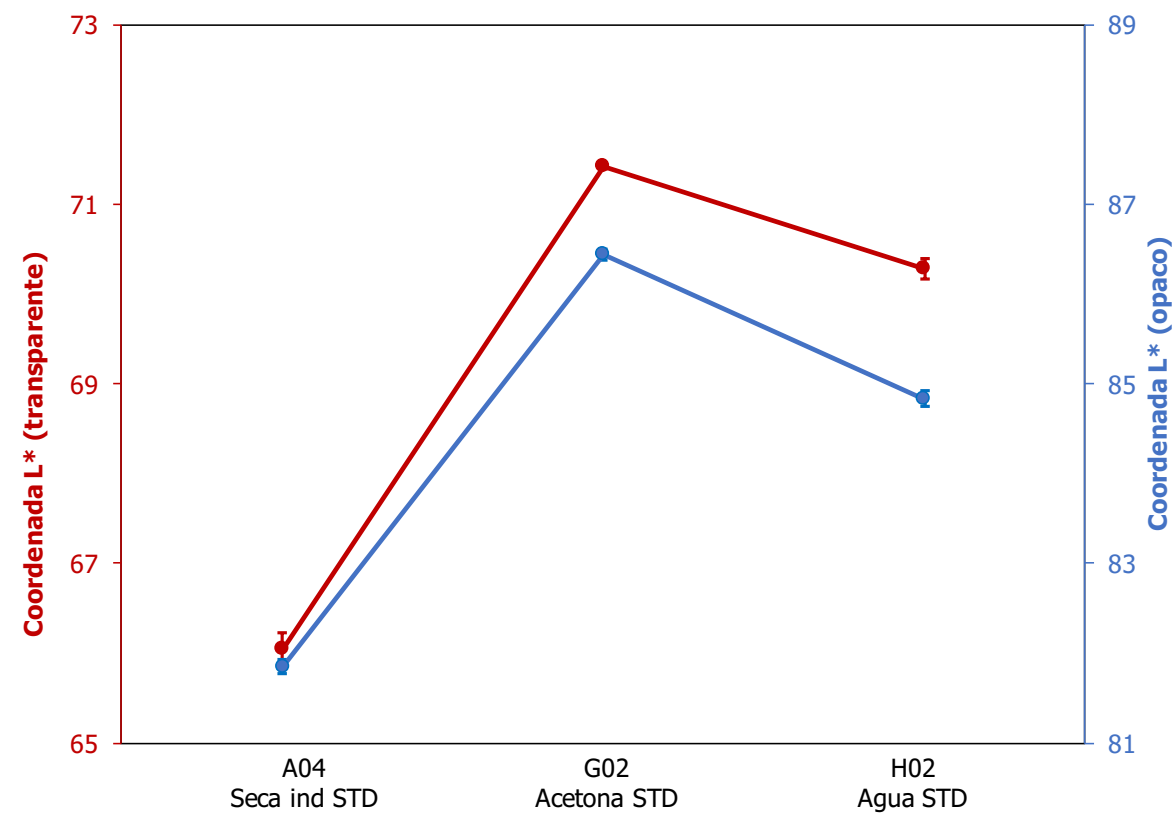

Figura 4.94 Evolución de la coordenada L* generada en los dos vidriados ensayados 
- La componente roja se comporta de modo inverso a la luminosidad, ya que los pigmentos $\mathrm{G02}$ y $\mathrm{H} 02$ generan colores con a* notablemente inferior al A04. También se aprecia que el pigmento $\mathrm{H} 02$ conduce a valores de la componente roja ligeramente superiores al G02 en los dos vidriados.

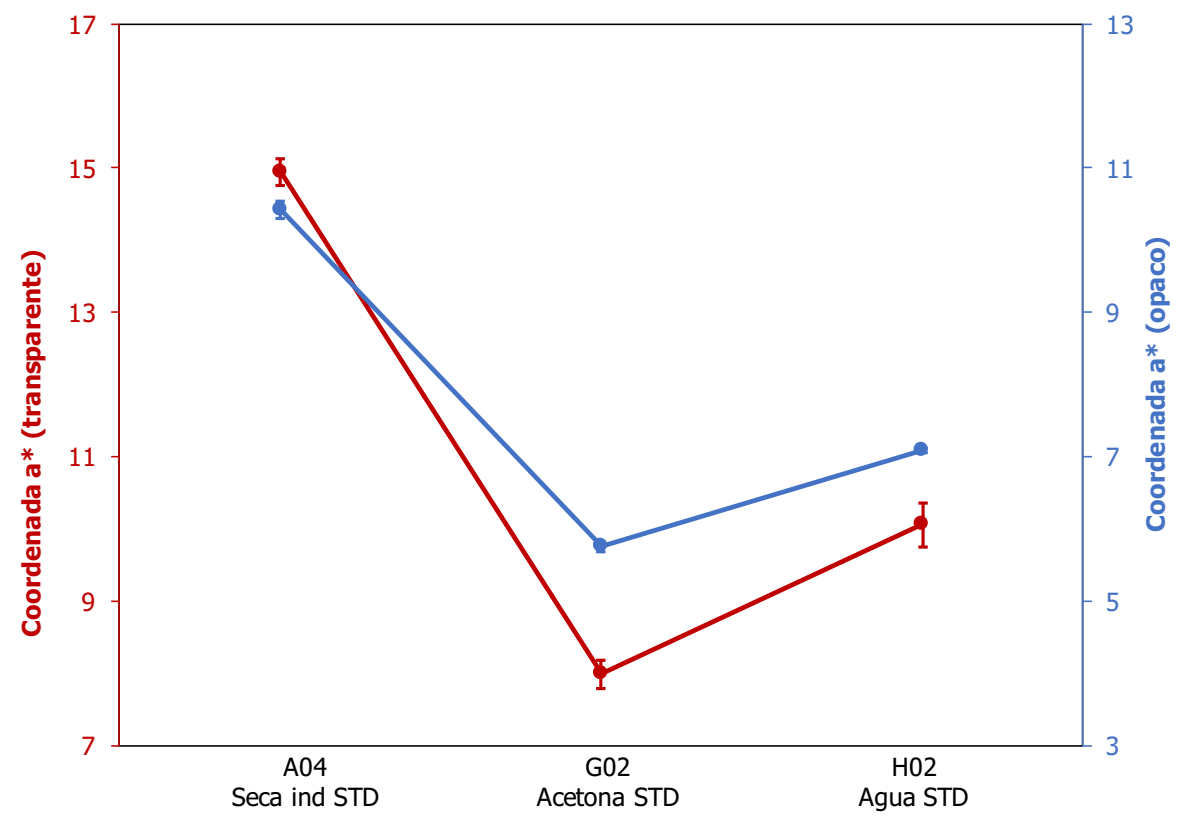

Figura 4.95 Evolución de la coordenada a* generada en los dos vidriados ensayados

- La componente amarilla es la que muestra un menor intervalo de variación de las tres coordenadas y, además, es la única en la que los valores de la coordenada no siguen tendencias similares en los dos vidriados. En el vidriado transparente, los pigmentos sintetizados vía húmeda generan valores más elevados de b* que el A04, si bien dicha variación es más acusada en el caso del pigmento sintetizado utilizando acetona como fluido. En cambio, en el vidriado opaco, b* disminuye cuando se pasa del pigmento sintetizado vía seca a los pigmentos sintetizados vía húmeda, siendo la disminución más acusada en el caso del pigmento cuya mezcla inicial se preparó en medio acuoso. 


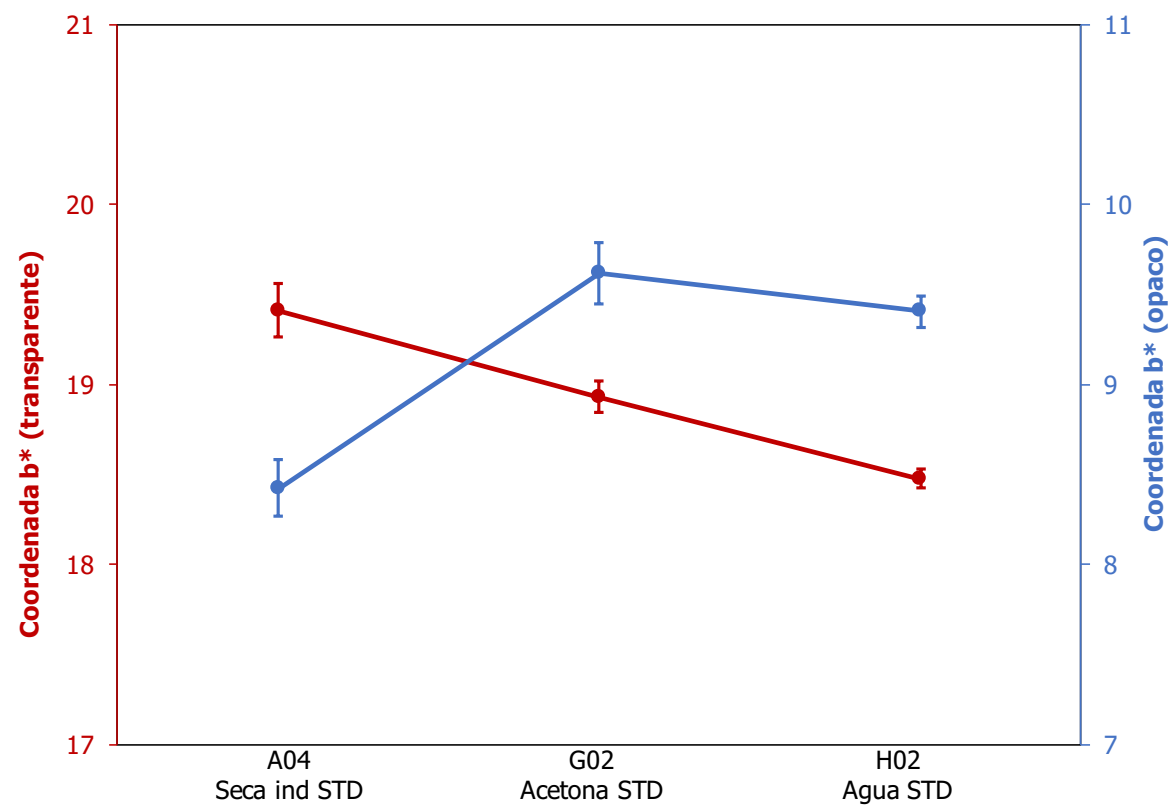

Figura 4.96 Evolución de la coordenada b* generada en los dos vidriados ensayados

Los resultados indicaban claramente que el porcentaje de circón generado en el pigmento $\mathrm{H} 02$, aunque notable, todavía no era suficiente para conseguir un encapsulado aceptable de la hematites. En consecuencia, resultaba imprescindible proseguir la investigación para tratar de mejorar la microestructura de la mezcla inicial e incrementar el grado de avance de la reacción de síntesis del circón.

\subsubsection{Efecto de la distribución granulométrica del mineralizador}

Los apartados precedentes han demostrado que separando la incorporación del cuarzo del mezclado del resto de precursores se incrementa la reactividad de la mezcla de materias primas. Por otro lado, al trabajar en medio acuoso en lugar de medio orgánico también se mejoran los resultados, pero en ningún caso se ha logrado igualar la reactividad de la mezcla preparada inicialmente mediante mezclado vía seca. Modificando ambas variables se ha observado que se alcanza un máximo en la reactividad para el tiempo de mezclado de 60 minutos, de modo que al acortar o prolongar dicho tiempo se obtienen menores porcentajes de circón. 
En principio hay dos variables a tener en cuenta al modificar el tiempo de homogeneización en el molino planetario, por un lado, el grado de mezclado del $\mathrm{ZrO}_{2}$ con el $\mathrm{Fe}_{2} \mathrm{O}_{3}$, y por otro la distribución granulométrica del mineralizador, ya que éste se introduce con un tamaño de partícula apreciablemente mayor que las otras dos materias primas y, por tanto, sería el más sensible a las variaciones en el tiempo de mezclado, ya que dicha variable alteraría notablemente su distribución granulométrica.

La evaluación del efecto de la distribución granulométrica del mineralizador se realizó partiendo de dos fracciones extremas, una por debajo de $40 \mu \mathrm{m}$, y otra por encima de $200 \mu \mathrm{m}$, que se utilizaron para sintetizar varias muestras de pigmento. La preparación de la mezcla se realizó en medio acuoso, utilizando una velocidad de molino de 230 rpm y tres tiempos de mezclado (30,60 y 120 minutos). Inicialmente en la jarra se introdujo la circona, la hematites y el fluidificante, y tras el tiempo de mezcla prefijado se incorporó el cuarzo y el mineralizador, finalizando la preparación con cinco minutos de tratamiento en el molino. Esta estrategia se adoptó para modificar en la menor medida posible la distribución granulométrica del mineralizador, si bien se era consciente de que alteraría el grado de mezcla del $\mathrm{Na}_{2} \mathrm{SiF}_{6}$ con la circona y la hematites. Las referencias de las muestras y las condiciones de operación durante el proceso de mezclado se detallan en la Tabla 4.41.

Tabla 4.41 Condiciones de preparación de las mezclas

\begin{tabular}{|ccc|}
\hline Referencia & $\begin{array}{c}\text { Tiempo de mezclado } \\
(\text { min) }\end{array}$ & $\begin{array}{c}\text { Granulometría } \\
(\mu \mathrm{m})\end{array}$ \\
\hline I01 & 30 & $\mathrm{X}<40$ \\
I02 & 30 & $\mathrm{X}>200$ \\
I03 & 60 & $\mathrm{X}<40$ \\
I04 & 60 & $\mathrm{X}>200$ \\
I05 & 120 & $\mathrm{X}<40$ \\
I06 & 120 & $\mathrm{X}>200$ \\
\hline
\end{tabular}

Tras la síntesis con el Ciclo STD se obtuvieron materiales de color rojizo, cuya caracterización mineralógica por difracción de rayos $\mathrm{X}$ condujo a los resultados que se detallan en la Tabla 4.42 . 
Tabla 4.42 Porcentaje de las fases cristalinas identificadas y composición de la fase amorfa (\% peso)

\begin{tabular}{|c|c|c|c|c|c|c|c|}
\hline & & I01 & 102 & I03 & I04 & I05 & I06 \\
\hline \multirow{4}{*}{ 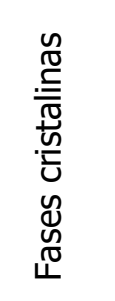 } & Cuarzo & 9 & 12 & 8 & 11 & 9 & 12 \\
\hline & Baddeleyita & 28 & 36 & 30 & 34 & 33 & 37 \\
\hline & Hematites & 19 & 19 & 19 & 19 & 20 & 19 \\
\hline & Circón & 23 & 11 & 19 & 11 & 20 & 8 \\
\hline & Fase amorfa total & 21 & 22 & 25 & 25 & 18 & 23 \\
\hline \multirow{3}{*}{ 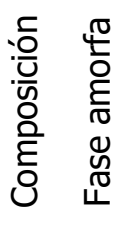 } & $\% \mathrm{Fe}_{2} \mathrm{O}_{3}$ & 4 & 4 & 5 & 5 & 3 & 4 \\
\hline & $\% \mathrm{SiO}_{2}$ & 6 & 6 & 7 & 7 & 7 & 7 \\
\hline & $\% \mathrm{ZrO}_{2}$ & 7 & 7 & 8 & 8 & 4 & 7 \\
\hline
\end{tabular}

Los resultados obtenidos en la cuantificación de fases cristalinas por Rietveld, estimación de la composición de la fase amorfa y los parámetros de los parámetros $\varsigma_{1}$ y $\varsigma_{2}$ relacionados con el grado de avance de la reacción, permiten extraer las siguientes tendencias (Figura 4.97 y Figura 4.98):

- Los pigmentos sintetizados con el mineralizador cuya fracción es inferior a $40 \mu \mathrm{m}$ contienen una mayor proporción de circón, a igualdad en el tiempo de mezclado, que los elaborados con la fracción superior a $200 \mu \mathrm{m}$.

- A igualdad en el tamaño de partícula del mineralizador, el aumento en el tiempo de mezclado ejerce un efecto desfavorable, si bien es algo más acusado en el caso de los pigmentos sintetizados con el mineralizador cuyo tamaño de partícula es menor a $40 \mu \mathrm{m}$.

- A grandes rasgos el porcentaje de baddeleyita se comporta de modo acorde a la evolución del circón. Sin embargo, la serie de pigmentos sintetizados con la fracción del mineralizador superior a $200 \mu \mathrm{m}$ posee un mínimo para un tiempo de mezclado de 60 minutos que, en principio, no es coherente con la evolución casi lineal de la proporción de circón para esta serie. Esta aparente anomalía se puede interpretar considerando que la estimación de la composición de la fase vítrea apunta a que es algo más rica en circona para estas condiciones. 
- La fase cristalina cuarzo muestra un comportamiento acorde con la evolución del circón, si bien las diferencias entre las dos series de experimentos son muy reducidas, considerando la notable diferencia en la señal de circón. Ello podría explicarse considerando que el mineralizador con mayor tamaño de partícula favorece la formación de fase vítrea silícea que permanece como tal una vez finalizada la reacción y que consume una parte no despreciable del cuarzo inicialmente presente, aunque no haya reaccionado para generar el circón.

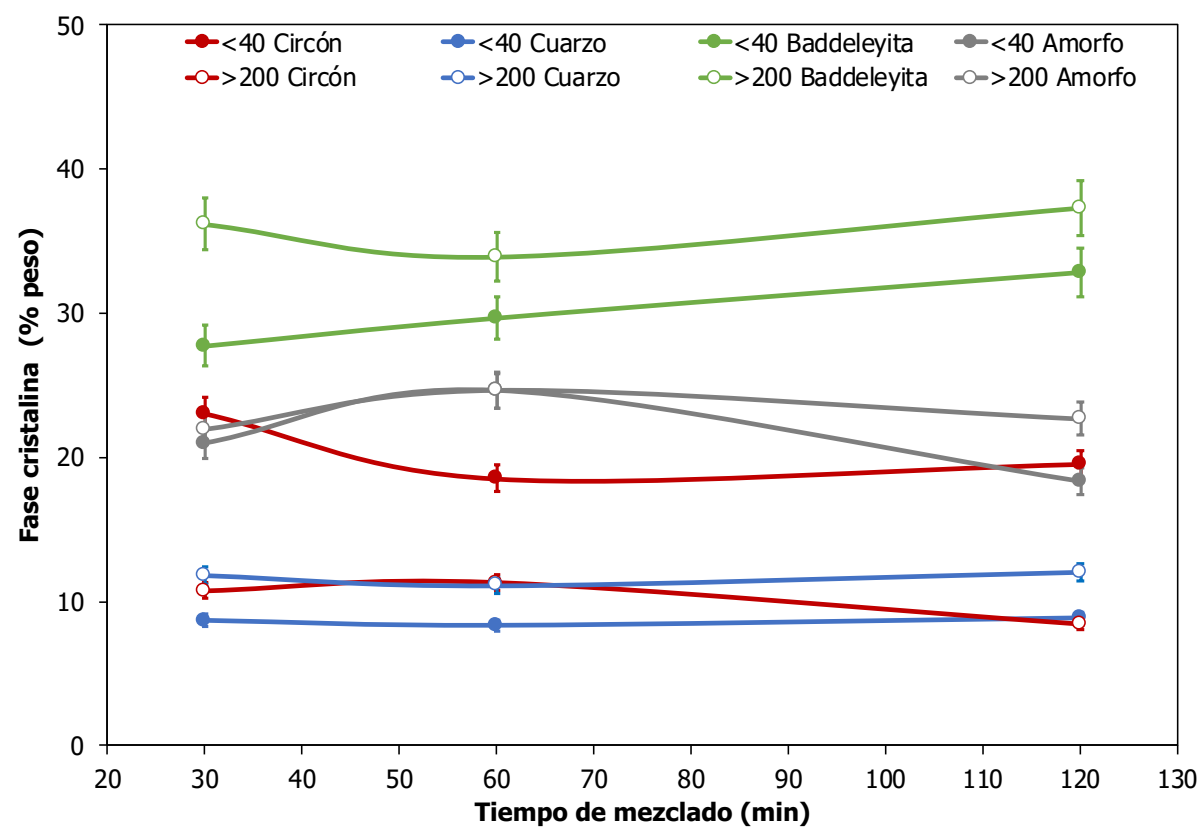

Figura 4.97 Evolución de las fases presentes en los pigmentos, frente al tiempo de mezclado y la granulometría del mineralizador utilizados en la síntesis 


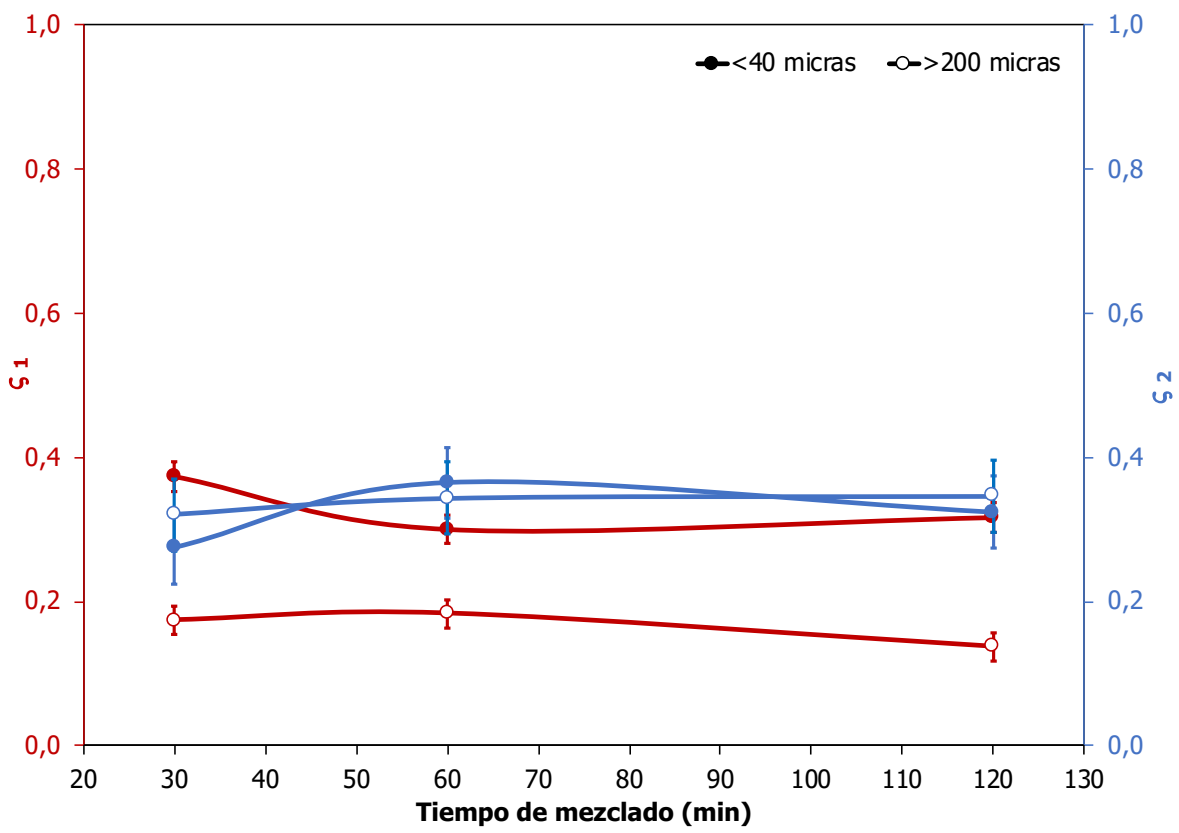

Figura 4.98 Evolución de los parámetros $\varsigma 1$ y $\varsigma 2$, frente al tiempo de mezclado y la granulometría del mineralizador utilizados en la síntesis

La comparación de los resultados obtenidos en estas dos series de experimentos con la serie $\mathrm{H}$, en la cual el mineralizador se introdujo en la carga inicial del molino (Figura 4.99), permite extraer las siguientes deducciones:

- Salvo para el tiempo más reducido, la incorporación del mineralizador al inicio del proceso de mezclado conduce a los pigmentos con mayor proporción de circón, aunque una vez pasado el óptimo para un tiempo de 60 minutos, la diferencia se atenúa notablemente.

- Siguiendo la secuencia de las series de tamaño $>200 \mu \mathrm{m}$ y $<40 \mu \mathrm{m}$, se puede plantear que una reducción en el tamaño de partícula del mineralizador, en principio, resulta beneficiosa.

- La incorporación del mineralizador desde el principio del proceso de mezclado implicaría que sufre una reducción en su tamaño de partícula variable en función del tiempo de permanencia en el molino. Para el tiempo más corto, no llegaría a reducirse por debajo de las $40 \mu \mathrm{m}$. Para 60 minutos de permanencia se alcanzaría la distribución granulométrica óptima y al prolongar el tiempo de mezclado la granulometría sería demasiado fina, con lo cual la reacción de síntesis del circón avanzaría más lentamente, por la mayor facilidad para la reacción entre el mineralizador y la sílice para formar fase vítrea durante el calentamiento. 


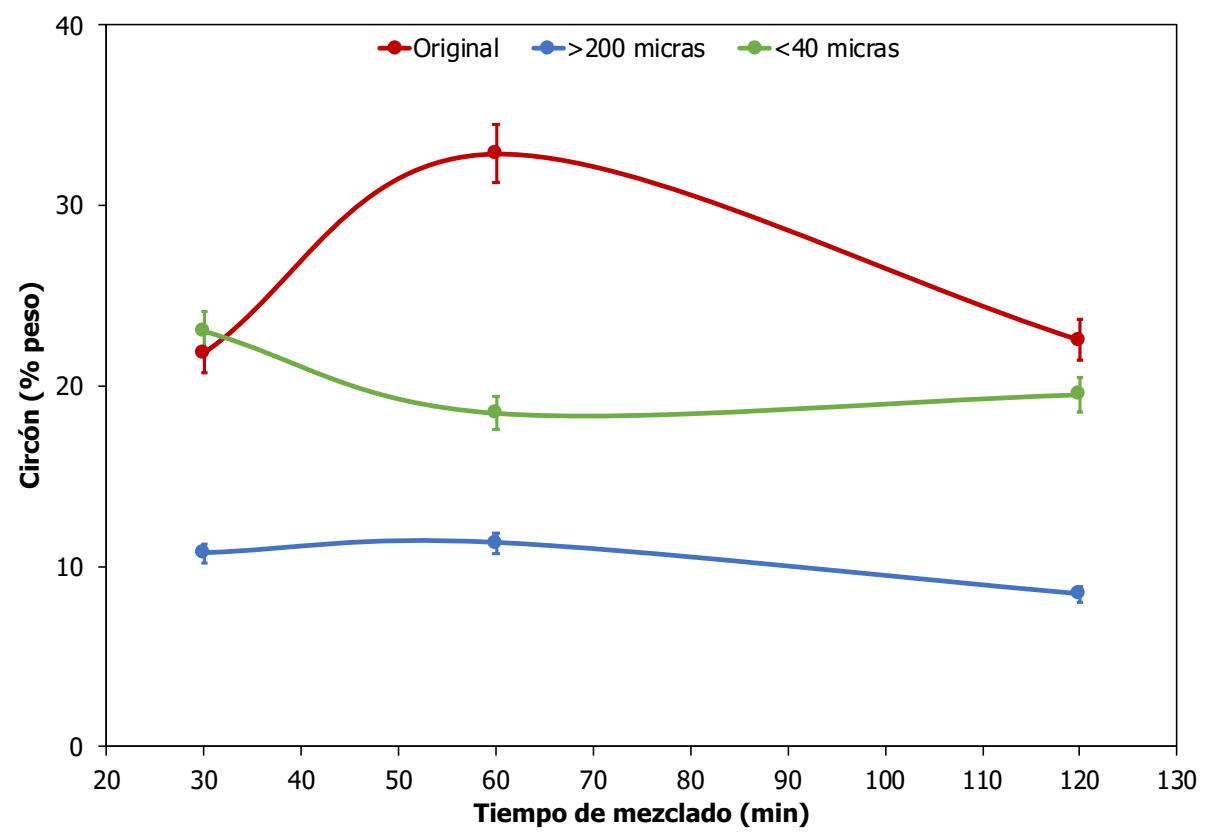

Figura 4.99 Evolución del circón formado en los pigmentos, frente al tiempo de mezclado y la granulometría del mineralizador utilizados en la síntesis

Los resultados obtenidos en esta serie de experimentos apuntan a que existe una distribución granulométrica óptima para el mineralizador. Un tamaño demasiado grueso o demasiado fino impediría que participase adecuadamente en la síntesis del circón, ya sea porque no interviniese en el momento adecuado o bien que se modificase el mecanismo por el cual interviene (formación de una fase líquida o intermedios gaseosos).

Una posible variable que no ha podido evaluarse con estos experimentos es la distribución espacial del mineralizador al cambiar el instante de su incorporación. Si se incorpora al inicio de la preparación de la mezcla de materias primas, además de la reducción en su tamaño correspondiente al tiempo de mezclado, también tenderá a estar más próximo a las partículas de hematites y circona. Por el contrario, si se incorpora al final, tenderá a estar más próximo a las partículas de cuarzo, suponiendo que durante el tiempo de mezclado final no se pueda conseguir una homogeneización completa de la mezcla. En el primer caso, se podría plantear la hipótesis que la reacción vía intermedios gaseosos estuviese favorecida, mientras que en el segundo caso el sistema sería más proclive a formar una fase líquida silícea, debido a un contacto más probable entre las partículas de cuarzo y $\mathrm{Na}_{2} \mathrm{SiF} 6$. 


\subsubsection{Modificación de la velocidad del molino}

Los experimentos descritos en el apartado anterior indicaban el notable efecto que la granulometría del mineralizador ejercía sobre el desarrollo de la reacción, granulometría que, en parte, estaba condicionada por la velocidad del molino cuando se incorporaba a la carga inicial de la jarra. Por ello se planteó si un mezclado más enérgico favorecería la síntesis del pigmento (reducción del tamaño de partícula del mineralizador con tiempos de mezclado más cortos), aunque se corriese el riesgo de conseguir una mezcla más homogénea.

En las primeras etapas de la investigación se realizaron algunas pruebas con mezclados menos enérgicos reduciendo la velocidad del molino o el tiempo de molienda (ver apartado 4.6.1), con resultados claramente desfavorables. Sin embargo, en dichos experimentos se había trabajado introduciendo todas las materias primas en la carga inicial de la jarra, en lugar de separar el cuarzo. Por ello también se consideró de interés evaluar si dicha tendencia se mantenía cuando se introducía el cuarzo al final del proceso.

Se diseñaron cuatro experimentos utilizando la composición correspondiente a la fórmula N04, tomando como base los tiempos de mezclado utilizados para sintetizar los pigmentos de la serie $\mathrm{H}$ y agua como fluido. En primer lugar, se modificó la velocidad del molino a 150 rpm y 300 rpm, para determinar cuál era el cambio más favorable, y posteriormente se ampliaron los experimentos ensayando otros dos tiempos para la velocidad más elevada. Las condiciones de preparación de las mezclas y las referencias asignadas a las muestras se detallan en la Tabla 4.43.

Tabla 4.43 Condiciones de preparación de las mezclas

\begin{tabular}{|ccc|}
\hline Referencia & $\begin{array}{c}\text { Tiempo de mezclado } \\
\text { (minutos) }\end{array}$ & $\begin{array}{c}\text { Velocidad molino } \\
\text { (rpm) }\end{array}$ \\
\hline J01 & 60 & 150 \\
J02 & 60 & 300 \\
J03 & 30 & 300 \\
J04 & 120 & 300 \\
\hline
\end{tabular}

Como resultado de los experimentos se obtuvieron materiales de color rojizo, cuyo análisis mineralógico condujo a los resultados que se detallan en la Tabla 4.44 . 
Tabla 4.44 Porcentaje de las fases cristalinas identificadas y composición de la fase amorfa (\% peso)

\begin{tabular}{|c|c|c|c|c|c|}
\hline & & J01 & 302 & $\mathrm{~J} 03$ & J04 \\
\hline \multirow{4}{*}{ 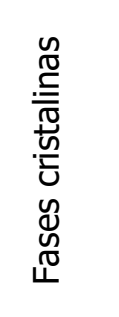 } & Cuarzo & 11 & 7 & 9 & 10 \\
\hline & Baddeleyita & 34 & 27 & 32 & 36 \\
\hline & Hematites & 20 & 18 & 20 & 19 \\
\hline & Circón & 9 & 18 & 16 & 11 \\
\hline & Fase amorfa total & 26 & 30 & 23 & 24 \\
\hline \multirow{3}{*}{ 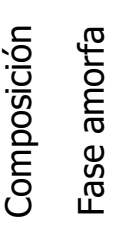 } & $\% \mathrm{Fe}_{2} \mathrm{O}_{3}$ & 4 & 6 & 4 & 4 \\
\hline & $\% \mathrm{SiO}_{2}$ & 8 & 9 & 8 & 8 \\
\hline & $\% \mathrm{ZrO}_{2}$ & 10 & 11 & 7 & 7 \\
\hline
\end{tabular}

El análisis de la representación gráfica de las fases presentes en los pigmentos frente a la velocidad del molino en la preparación de las mezclas (Figura 4.100), permitió extraer las siguientes inferencias:

- El efecto de la velocidad del molino sobre la cantidad final de circón formada es muy notable, ya que se alcanza un máximo en el porcentaje de circón para un tiempo de 60 minutos y una velocidad de $230 \mathrm{rpm}$ (el pigmento H02 presenta un 33\% de circón). Una velocidad de rotación superior o inferior resulta perjudicial, si bien la segunda alternativa lo es en mayor medida ( $18 \%$ y $9 \%$ de circón respectivamente).

- En rasgos generales, la evolución de la baddeleyita y del cuarzo es inversa a la del circón. Sin embargo, se aprecia que las variaciones en la baddeleyita están más correlacionadas con las del circón que las del cuarzo, fenómeno que ya se había apreciado en experimentos anteriores, y que se puede relacionar con la incorporación del cuarzo a una fase vítrea silícea. 


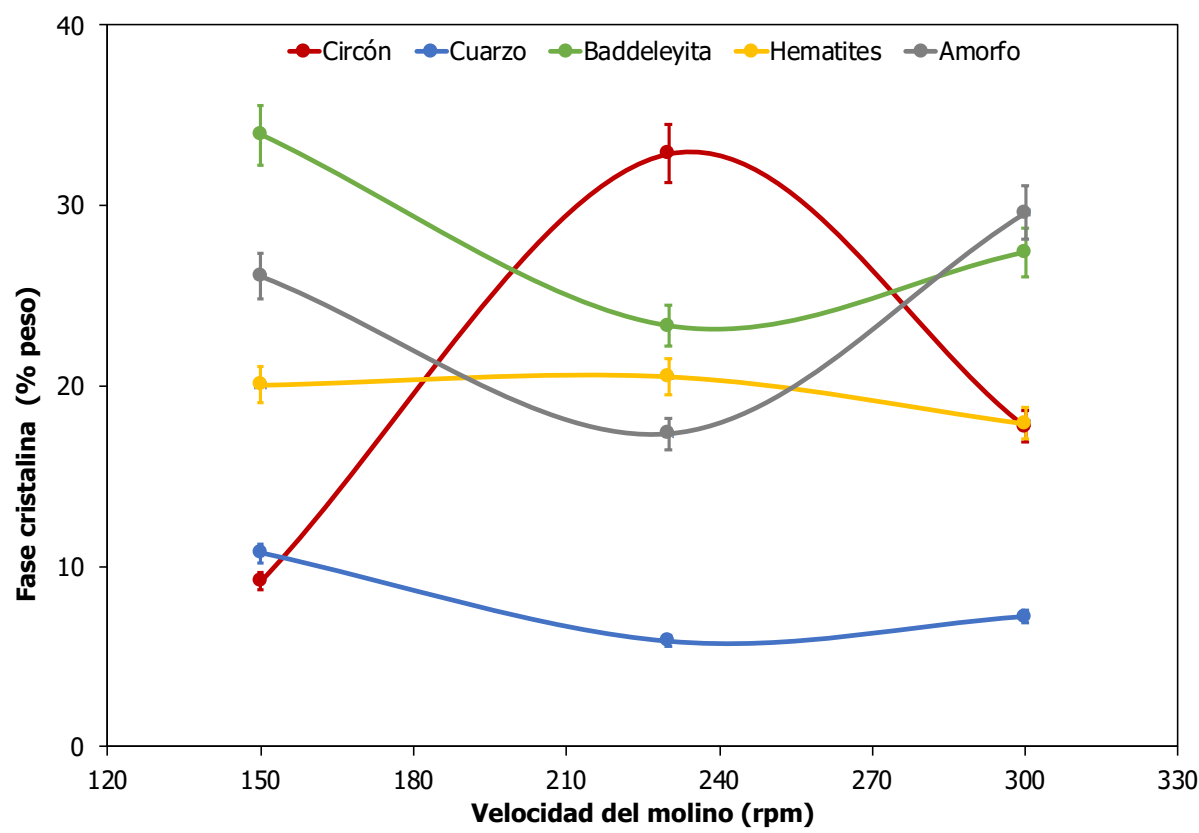

Figura 4.100 Evolución de las fases presentes en los pigmentos, frente a la velocidad del molino planetario (tiempo de mezclado 60 minutos)

Los valores obtenidos en la estimación de los parámetros $\varsigma_{1}$ y $\varsigma_{2}$ (Figura 4.101) que representan la sílice que reacciona para formar circón y la sílice que forma parte de la fase vítrea indican que, para una velocidad del molino de 230 rpm, el valor de $\varsigma_{1}$ se hace máximo, y por tanto una mayor fracción de cuarzo estaría contribuyendo a la formación del circón.

Por otro lado, el parámetro §2 respaldaría la idea según la cual, para 230 rpm de velocidad de giro del molino, la fracción de sílice que pasa a formar parte de la fase vítrea es mucho menor. 


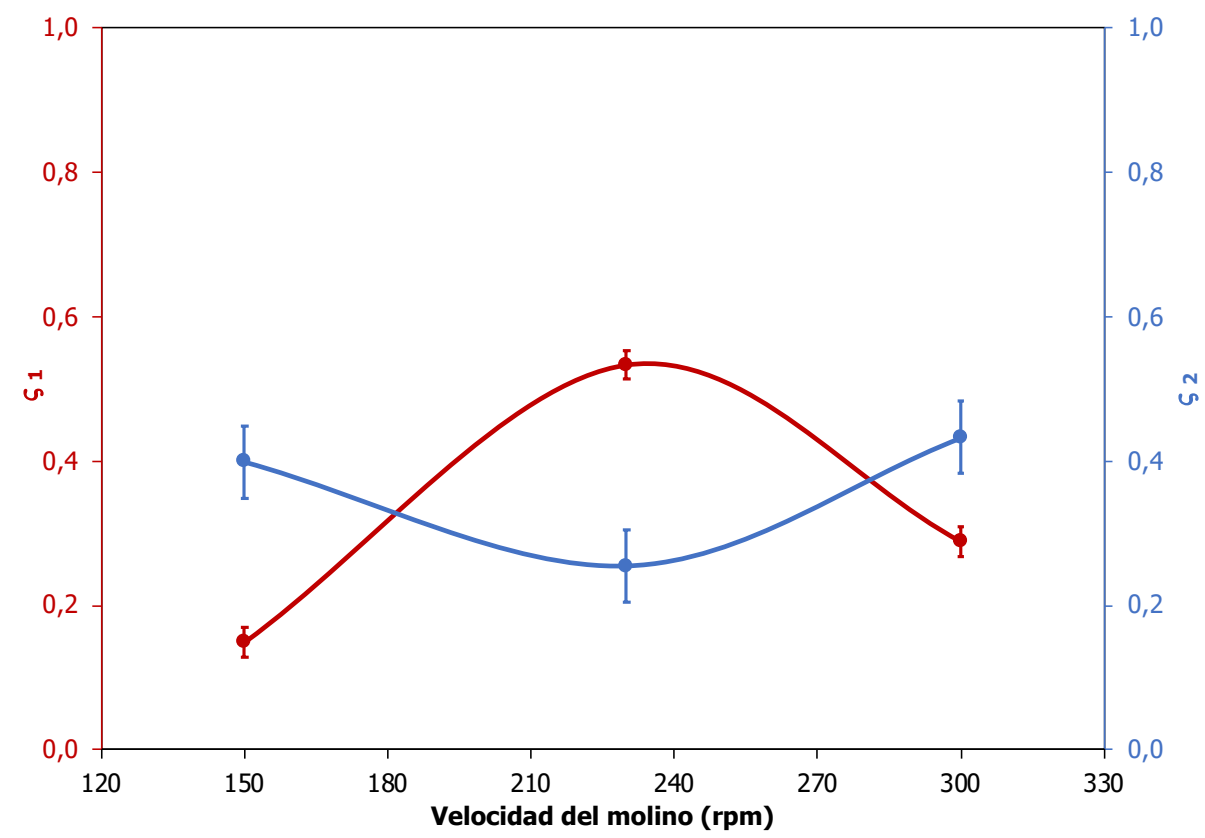

Figura 4.101 Evolución de los parámetros $\$ 1$ y $\varsigma 2$, frente a la velocidad del molino planetario (tiempo de mezclado 60 minutos)

La comparación de los datos obtenidos con diferentes tiempos de mezclado y velocidades de giro (Figura 4.102 y Figura 4.103), condujo a los siguientes resultados:

- El efecto de la velocidad del molino es más notable que el tiempo de molienda sobre la aptitud de una mezcla para generar circón. Las mezclas preparadas a $230 \mathrm{rpm}$ generan mayor cantidad de circón que las preparadas a 300 rpm, independientemente del tiempo de mezclado.

- Para las dos velocidades de molino ensayadas, se obtiene un máximo en la proporción de circón para un tiempo de mezcla dado, que se estima en torno a 60 minutos, pero que está desplazado hacia valores inferiores en el caso de la velocidad de molino más elevada. En ambos casos resulta más perjudicial alargar el tiempo de mezclado que disminuirlo.

- $\quad$ La evolución del porcentaje de baddeleyita de los diferentes pigmentos es coherente en líneas generales con la correspondiente al circón, alcanzando un mínimo para el tiempo de mezclado intermedio.

- El porcentaje de la fase cristalina cuarzo no presenta diferencias significativas entre las dos velocidades de molino ensayadas, comparándolas con las diferencias apreciadas en el circón y la baddeleyita, sobre todo para los tiempos más extremos dentro del intervalo estudiado. 


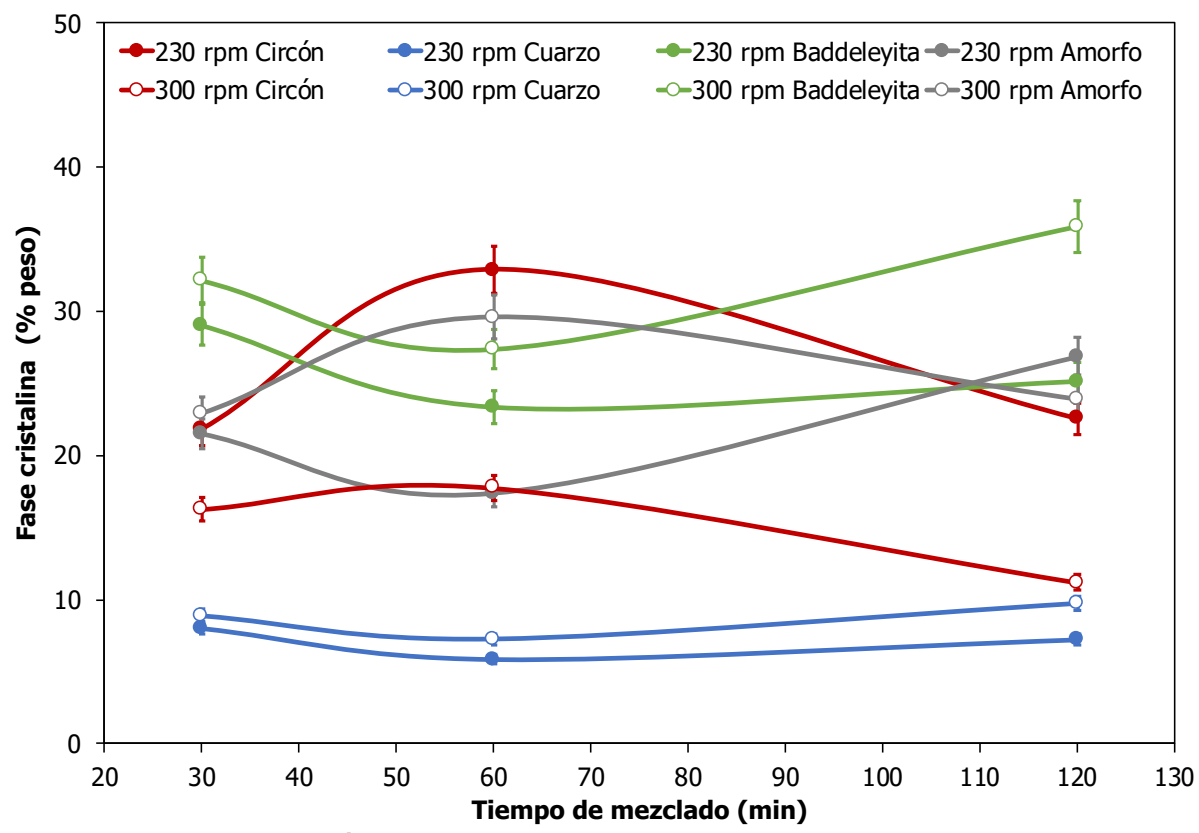

Figura 4.102 Evolución de las fases presentes en los pigmentos, frente al tiempo de mezclado y la velocidad de giro del molino planetario

En relación con los parámetros $\varsigma_{1}$ y $\varsigma_{2}$, los valores obtenidos muestran un mayor grado de avance de la reacción cuando se utiliza una velocidad de giro del molino de $230 \mathrm{rpm}$ y un tiempo de mezclado de 60 minutos.

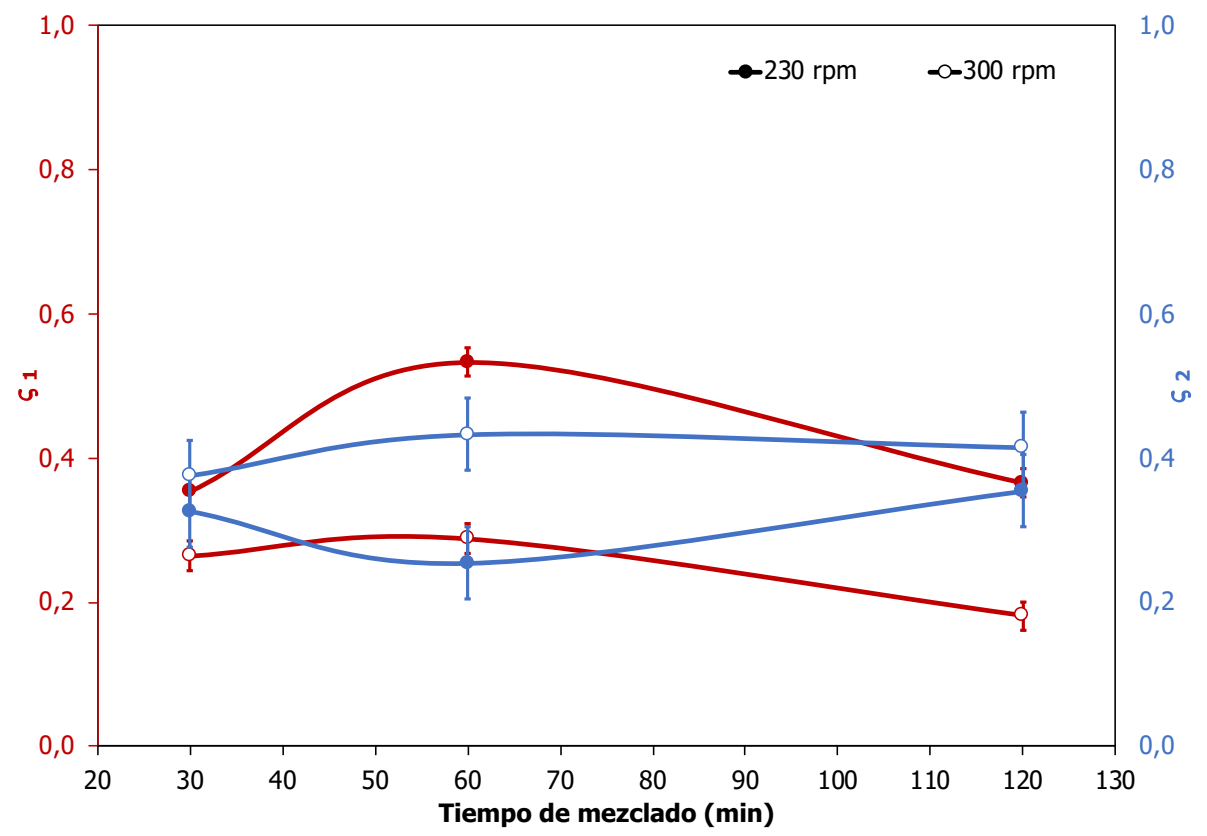

Figura 4.103 Evolución de los parámetros $\$ 1$ y \$2, frente al tiempo de mezclado y la velocidad de giro del molino planetario 
El efecto de la velocidad del molino y del tiempo de mezclado sobre la reactividad de la mezcla queda claramente evidenciado en estos experimentos, de los que se infiere que existen unos valores óptimos para ambas variables. Estos resultados son coherentes con el efecto de la granulometría del mineralizador deducido de los experimentos descritos en el apartado anterior. A mayor velocidad del molino cabe esperar que las partículas de mineralizador disminuyan de tamaño en mayor medida, mientras que a velocidades más lentas la distribución granulométrica en la mezcla sería más próxima a la original.

\subsubsection{Modificación del ciclo de cocción}

En esta etapa de la investigación se decidió realizar un ensayo para confirmar que el cambio del Ciclo STD por el Ciclo Rápido, podía mejorar en gran medida la reactividad de la mezcla, y así generar una elevada cantidad de circón, en mezclas que con el Ciclo STD apenas generaban circón.

Se preparó una composición siguiendo el mismo procesado que el pigmento J02 (mezclado a $300 \mathrm{rpm}$ durante 60 minutos en medio acuoso), pero se sometió al Ciclo Rápido, asignándose al pigmento generado la referencia 05. Dicho material presentó un color rojizo, y los resultados de su caracterización mediante difracción de rayos $X$ se detallan en la Tabla 4.45 .

Tabla 4.45 Porcentaje de las fases cristalinas identificadas y composición de la fase amorfa (\% peso)

\begin{tabular}{|c|c|c|}
\hline & & $J 05$ \\
\hline \multirow{4}{*}{ 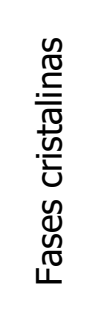 } & Cuarzo & $<1$ \\
\hline & Baddeleyita & 8 \\
\hline & Hematites & 22 \\
\hline & Circón & 60 \\
\hline & Fase amorfa total & 10 \\
\hline \multirow{3}{*}{ 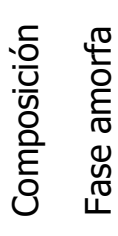 } & $\% \mathrm{Fe}_{2} \mathrm{O}_{3}$ & 1 \\
\hline & $\% \mathrm{SiO}_{2}$ & 2 \\
\hline & $\% \mathrm{ZrO}_{2}$ & 2 \\
\hline
\end{tabular}


Los resultados confirman que el Ciclo Rápido permite obtener una elevada proporción de circón, en mezclas que con el Ciclo STD no muestran una reactividad suficientemente elevada y mejorando los resultados conseguidos inicialmente con la mezcla vía seca calcinada con el ciclo STD (A04). La composición mineralógica de este pigmento resultaba comparable a los pigmentos sintetizados a partir de mezclas preparadas en el laboratorio vía húmeda y vía seca que habían sido sometidos al Ciclo Rápido (D01, D02 y D03 con $49 \%, 62 \%$ y $49 \%$ de circón respectivamente).

\subsubsection{Desarrollo de color}

Como comprobación final se incorporó el pigmento 05 a los dos vidriados para evaluar si la elevada proporción de circón se correspondía con un poder colorante elevado. En ambos vidriados se obtuvieron superficies con una coloración intensa, cuyas coordenadas cromáticas se detallan en la Tabla 4.46 y Tabla 4.47.

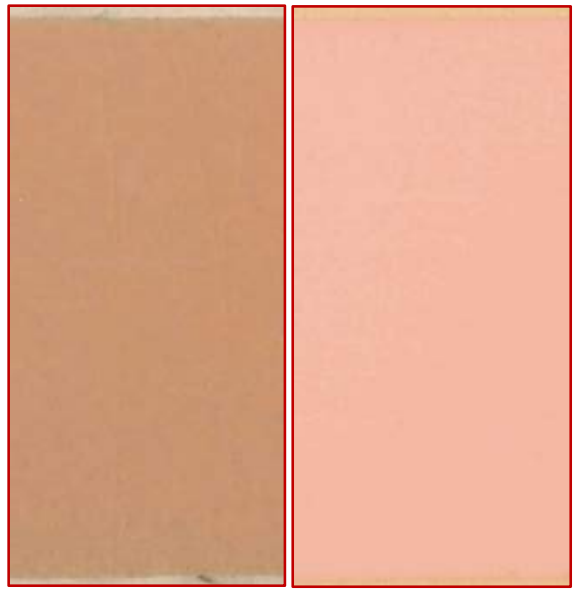

Figura 4.104 Probetas esmaltadas de la pieza J05 con el vidriado transparente y opaco

Tabla 4.46 Coordenadas cromáticas desarrolladas por los pigmentos en el vidriado transparente $\left(1120^{\circ} \mathrm{C}\right)$

\begin{tabular}{|c|c|c|c|c|c|c|}
\hline Referencia & \multicolumn{2}{|c|}{ L* } & \multicolumn{2}{|c|}{ a* } & \multicolumn{2}{|c|}{ b* } \\
\hline & $X$ & $\sigma$ & $X$ & $\sigma$ & $X$ & $\sigma$ \\
\hline$J 05$ & 66,68 & 0,06 & 14,22 & 0,23 & 20,27 & 0,08 \\
\hline
\end{tabular}


Tabla 4.47 Coordenadas cromáticas desarrolladas por los pigmentos en el vidriado opaco $\left(1040^{\circ} \mathrm{C}\right)$

\begin{tabular}{|ccccccc|}
\hline Referencia & \multicolumn{3}{c}{ L* $^{*}$} & \multicolumn{3}{c|}{$\mathrm{a}^{*}$} \\
$\mathrm{X}$ & $\sigma$ & $\mathrm{X}$ & $\sigma$ & $\mathrm{X}$ & $\sigma$ \\
\hline $\mathrm{J} 05$ & 79,93 & 0,11 & 11,27 & 0,04 & 10,13 & 0,09 \\
\hline
\end{tabular}

Para evaluar con mayor criterio las coordenadas cromáticas obtenidas en el desarrollo del pigmento J05, se han comparado con las correspondientes al pigmento A04 (mezcla preparada vía seca industrialmente y calcinada con el Ciclo STD), y al pigmento D02 (mezcla preparada en molino planetario vía húmeda con acetona a $230 \mathrm{rpm}$, introduciendo todas las materias primas desde el inicio, y calcinada con el Ciclo Rápido). El análisis de las gráficas (Figura 4.105, Figura 4.106 y Figura 4.107), permite deducir las siguientes inferencias:

- La luminosidad de los colores generados en los dos vidriados posee la característica común de presentar un máximo para el pigmento D02. Sin embargo, el orden de los otros dos pigmentos depende del vidriado al que se incorporan, obteniendo diferencias más acusadas en el vidriado transparente. En el vidriado transparente la menor $L^{*}$ se obtiene con el A04, si bien el valor correspondiente al $\mathrm{J05}$ se halla a menos de una unidad. Por el contrario, en el vidriado opaco la menor luminosidad se obtiene con el J05, y el valor para el A04 es superior en cuatro unidades.

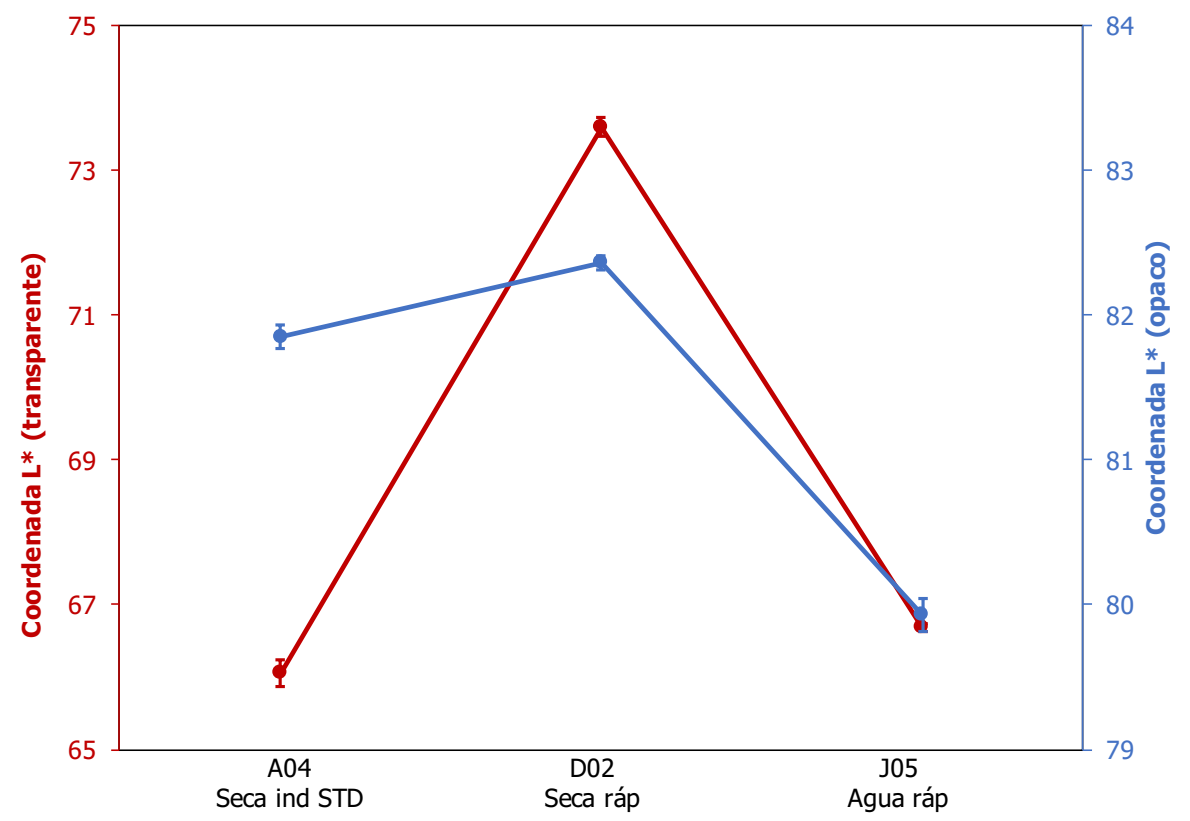

Figura 4.105 Evolución de la coordenada L* generada en los dos vidriados ensayados 
- La coordenada roja posee un intervalo de variación relativamente parecido en los dos vidriados, siendo el peor resultado el del pigmento D02. Sin embargo, el orden de los otros dos pigmentos varía con el vidriado, generando el pigmento A04 un valor más elevado de a* en el vidriado transparente, mientras que, en el opaco, el mejor valor se obtiene con el J05.

- La componente amarilla presenta el menor intervalo de variación de las tres coordenadas (unas dos unidades). Tanto en el vidriado transparente como en el opaco, se obtiene el b* mínimo para el pigmento A04 y el máximo para el pigmento D02.

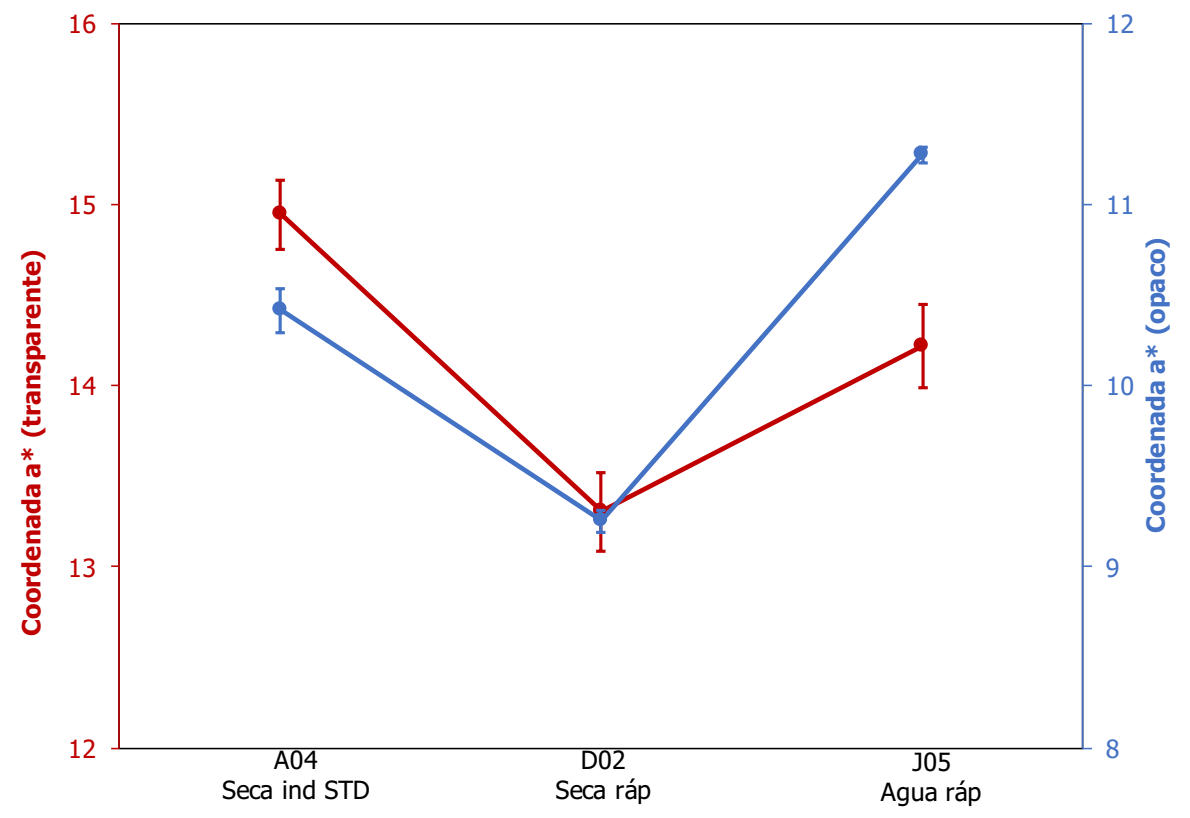

Figura 4.106 Evolución de la coordenada a* generada en los dos vidriados ensayados 


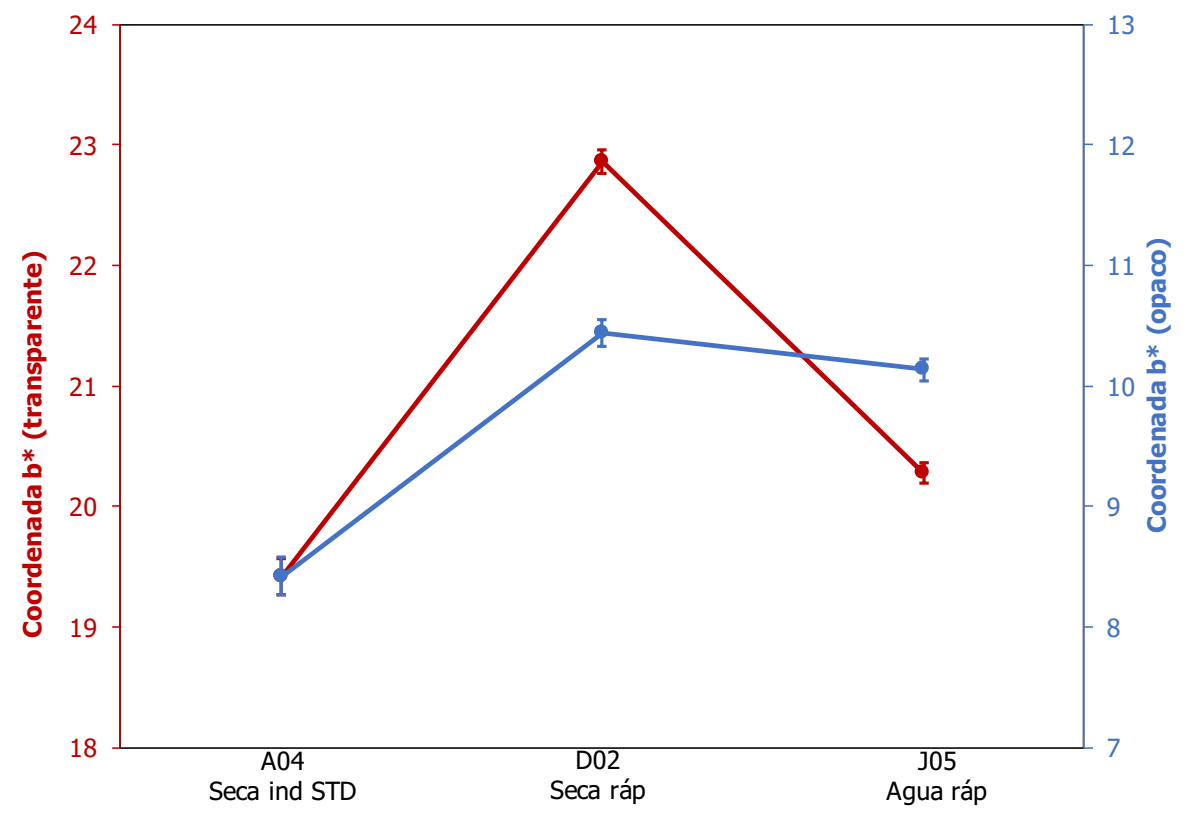

Figura 4.107 Evolución de la coordenada b* generada en los dos vidriados ensayados

Los datos colorimétricos confirman que el Ciclo Rápido permite generar pigmentos con un poder colorante apreciable, partiendo de mezclas preparadas en condiciones de operación muy diferentes. Este hecho haría posible que, acelerando convenientemente la etapa de calentamiento del ciclo térmico, algunas mezclas que no presentan circón de forma significativa con el Ciclo STD, sean capaces de formar un mayor porcentaje de circón con el Ciclo Rápido y, por tanto, desarrollen un mayor poder colorante.

\subsubsection{Adición del cuarzo por etapas}

Con los ensayos descritos en los apartados anteriores, se había comprobado que la reactividad de la mezcla precursora del pigmento varía enormemente entre la incorporación del cuarzo al inicio del proceso de mezclado, o su introducción al final, cuando el mineralizador, la hematites y la circona ya han sufrido la mayor parte del proceso de homogeneización. Aparentemente, la presencia de cuarzo desde el inicio del mezclado resultaba perjudicial, pero se decidió comprobar si dicho efecto se debía a la gran proporción de cuarzo presente, o bien con que hubiese una pequeña cantidad de esta materia prima ya era suficiente para afectar a la reactividad de la mezcla. 
Se diseñó un experimento en el cual se prepararon dos mezclas con la composición correspondiente a la fórmula N04, pero con las siguientes condiciones experimentales:

- K01: Se introdujo un $10 \%$ del cuarzo junto con las demás materias primas, y el $90 \%$ restante tras el proceso de homogeneización, y con 5 minutos de mezclado final.

- K02: Se introdujo un 25\% del cuarzo junto con las demás materias primas, y el $75 \%$ restante tras el proceso de homogeneización, y con 5 minutos de mezclado final.

La homogeneización se realizó en medio acuoso, con un tiempo de molienda de 60 minutos y una velocidad del molino fijada en $230 \mathrm{rpm}$.

Tras la síntesis de los pigmentos con el Ciclo STD se obtuvieron pigmentos cuya caracterización mediante difracción de rayos $\mathrm{X}$ generó los datos recogidos en la Tabla 4.48.

Tabla 4.48 Porcentaje de las fases cristalinas identificadas y composición de la fase amorfa (\% peso)

\begin{tabular}{|c|c|c|c|}
\hline & & K01 & KO2 \\
\hline \multirow{4}{*}{ 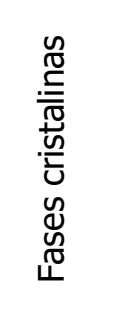 } & Cuarzo & 6 & 10 \\
\hline & Baddeleyita & 31 & 29 \\
\hline & Hematites & 22 & 23 \\
\hline & Circón & 19 & 21 \\
\hline & Fase amorfa total & 22 & 17 \\
\hline \multirow{3}{*}{ 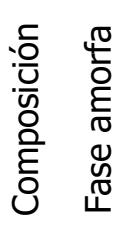 } & $\% \mathrm{Fe}_{2} \mathrm{O}_{3}$ & 3 & 1 \\
\hline & $\% \mathrm{SiO}_{2}$ & 11 & 5 \\
\hline & $\% \mathrm{ZrO}_{2}$ & 5 & 7 \\
\hline
\end{tabular}

Los datos obtenidos se representaron junto con los correspondientes a los pigmentos G02 y F04, que serían los extremos con el cuarzo introducido en una segunda etapa tras el mezclado de las restantes materias primas, y con el $100 \%$ presente desde el inicio (G02 con 26\% de circón formado y F04 con 13\% de circón respectivamente, ver Figura 4.108). 


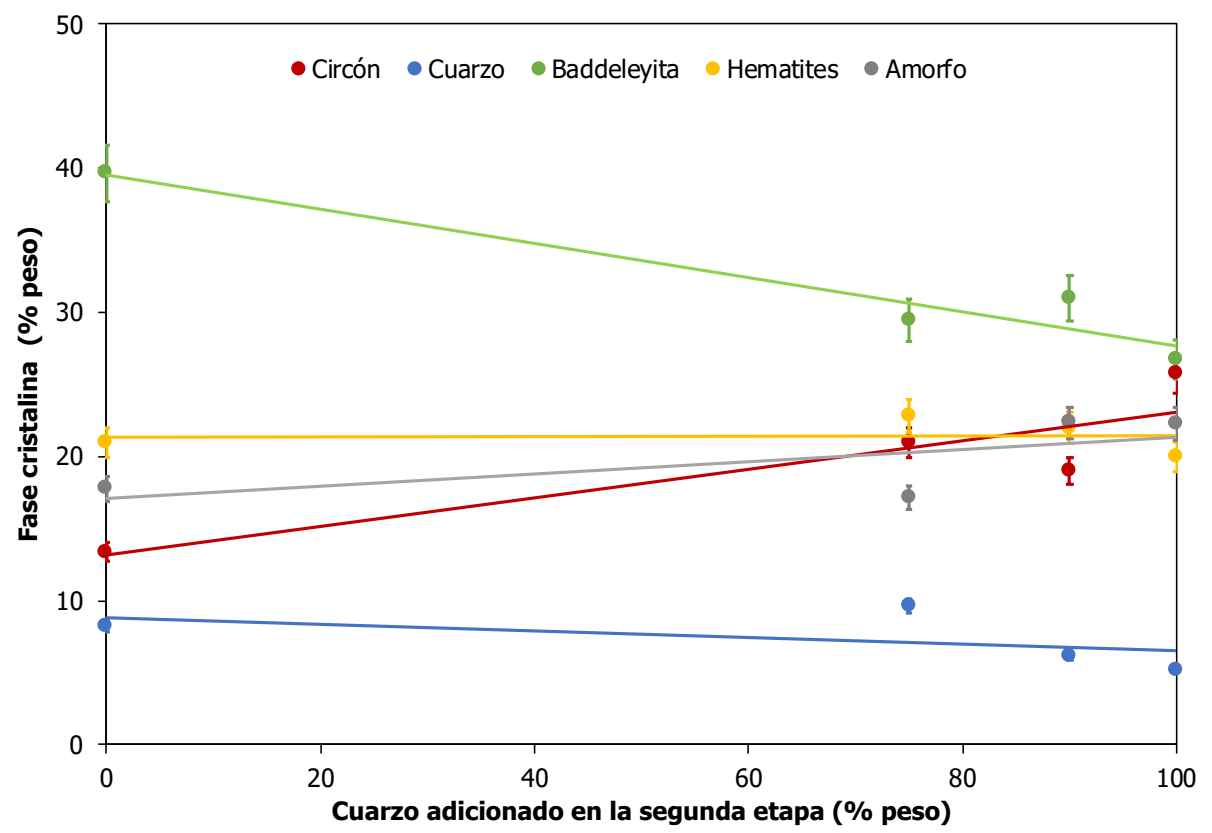

Figura 4.108 Evolución de las fases presentes en los pigmentos, frente a la proporción de cuarzo incorporado en la etapa final de mezclado de las materias primas

Por otra parte, se representaron los valores estimados para los parámetros $\varsigma 1$ y $\varsigma 2$, definidos anteriormente como la fracción de cuarzo que reacciona para formar circón y como la fracción de cuarzo que pasa a formar parte de la fase vítrea respectivamente.

En primer lugar se observó un aumento del parámetro $\varsigma_{1}$ conforme se introducía más cantidad de cuarzo en la segunda etapa de mezclado lo que indicaría que añadir el cuarzo en esta segunda etapa de mezclado favorece la formación de circón. Por otro lado, tal y como era de esperar, se observó una ligera disminución en el parámetro $\varsigma_{2}$ al ir introduciendo cuarzo en la segunda etapa de mezclado.

A pesar de que la tendencia a evolucionar de los parámetros $\varsigma_{1}$ y $\varsigma 2$ estarían de acuerdo con las hipótesis planteadas hasta el momento, se ha observado alguna desviación puntual en la estimación de estos parámetros que podría deberse a pequeños cambios en la preparación de las mezclas. 


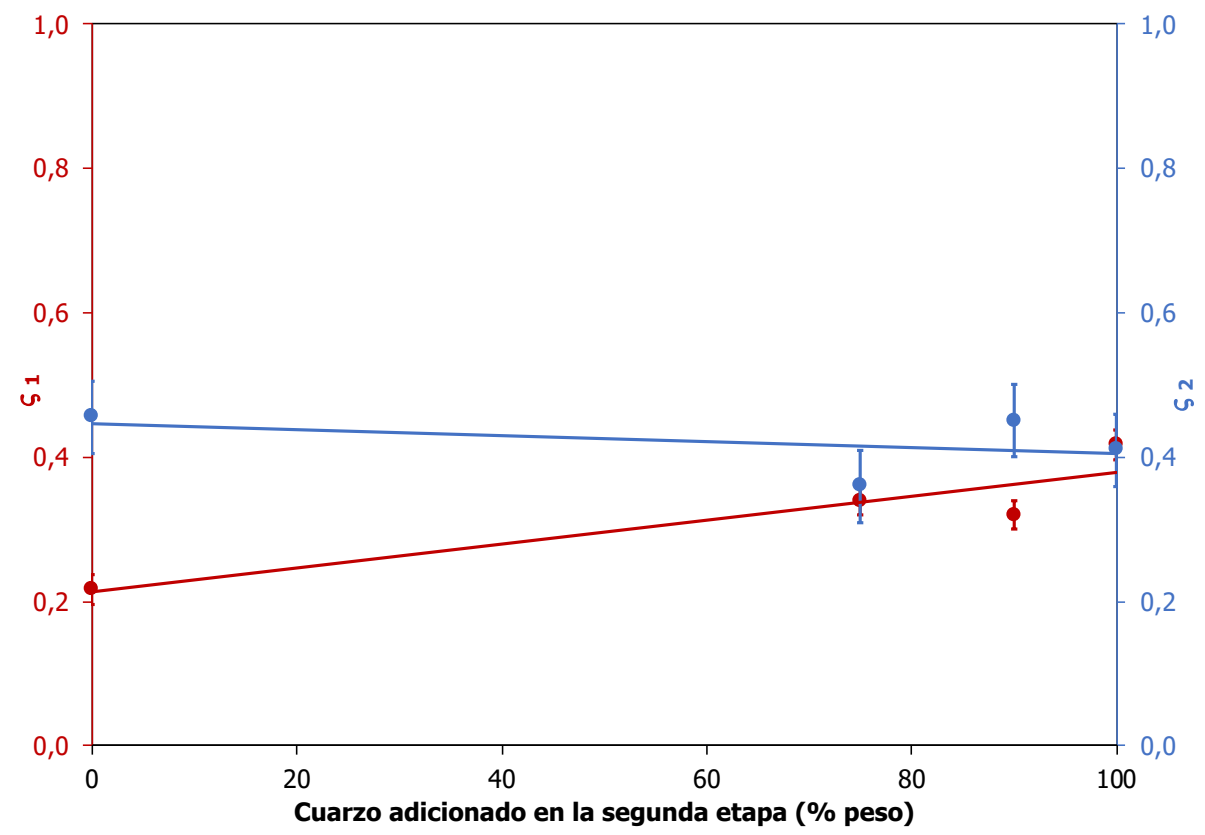

Figura 4.109 Evolución de los parámetros $\varsigma 1$ y $\varsigma 2$, frente a la proporción de cuarzo incorporado en la etapa final de mezclado de las materias primas

Evaluando los resultados obtenidos, se extrajeron las conclusiones que se detallan a continuación.

- Ya se había deducido que la incorporación de cuarzo durante el mezclado junto al resto de materias primas era perjudicial para obtener una fracción elevada de circón en el pigmento final. Sin embargo, en este experimento se comprueba que incorporando proporciones reducidas de cuarzo en dicha etapa (del orden del $10 \%$ del total de la composición), la génesis del circón ya se ve notablemente perjudicada, puesto que se produce una reducción en torno al $50 \%$ en el porcentaje de circón.

- El porcentaje de baddeleyita sigue una evolución mucho más suave que la del circón, aunque en líneas generales disminuye a medida que se incorpora menos cuarzo en la etapa inicial de mezclado, como era de esperar debido a la mayor generación de circón.

- El cuarzo evoluciona dentro de un intervalo de variación mucho más estrecho que las otras dos fases y, además, la evolución es más suave, acelerándose su desaparición cuando se incorpora mayoritariamente en la última etapa del mezclado. 
Los resultados obtenidos en este experimento son coherentes con el modelo planteado para explicar la reacción de síntesis del pigmento y siguen la tendencia esperada. Sin embargo, se ha observado alguna desviación en los porcentajes de fases cristalinas y fase amorfa en alguna composición debida probablemente a pequeños cambios en la preparación de las mezclas.

Por tanto, cuando se incorpora una fracción de cuarzo en la mezcla inicial, se forma un vidrio silíceo al combinarse el $\mathrm{SiO}_{2}$ con el mineralizador a temperaturas relativamente bajas, lo cual obliga a que la reacción prosiga por transporte en fase líquida de las partículas de sílice hasta las de circona, para poder formar el circón. Por el contrario, si el cuarzo se halla ausente en las primeras etapas, la falta de proximidad entre el cuarzo y el mineralizador evitaría la formación de la fase líquida, y el $\mathrm{Na}_{2} \mathrm{SiF}_{6}$ podría alcanzar la temperatura a la que puede facilitar el transporte de la sílice como $\mathrm{SiF}_{4}$, acelerando de este modo la reacción. Teniendo en cuenta que la relación molar cuarzo/mineralizador en las fórmulas utilizadas es 14 aproximadamente, aun reduciendo su proporción en la composición sometida al mezclado al $10 \%$ como en el pigmento $\mathrm{K} 01$, todavía quedaría un exceso de cuarzo con respecto al mineralizador (sin contar con el fluidificante de naturaleza silícea), para formar una fase vítrea que lo retuviese en gran medida.

A modo de conclusión, se confirma que la metodología de mezclado vía húmeda confiere a las mezclas una menor reactividad que aquellas mezclas preparadas vía seca. Sin embargo, este hecho puede mejorarse modificando el orden de adición de los reactantes, introduciendo el cuarzo cuando el resto de las materias primas ya han sido homogeneizadas, evitando condiciones de mezclado muy enérgicas o aumentando la velocidad de calentamiento durante la síntesis del pigmento. De esta forma se favorece el transporte en fase gas de la sílice hacia la circona, obteniendo pigmentos con elevado poder colorante debido a un eficiente encapsulamiento de la hematites en los cristales de circón. 


\subsection{Confirmación del mecanismo de formación del pigmento coral hierro-circón}

A la vista de los resultados obtenidos en los experimentos realizados en la síntesis del pigmento coral hierro-circón y la relación que tiene la forma en la que se mezclan las materias primas y el mecanismo de formación del pigmento, se decidió realizar un estudio para comprobar que el mecanismo que favorecía el encapsulamiento de las partículas de hematites en la matriz de circón era el de transporte en fase gaseosa.

Para ello se prepararon probetas mezclando el óxido de hierro y la circona utilizados en la fórmula 4 (Tabla 3.5), utilizando una carga de 0,5 gramos en un molde de $8 \mathrm{~mm}$ de diámetro utilizando una prensa manual Expert-System, con la que se ejerció una fuerza de $20 \mathrm{~N}$. La probeta se depositó sobre un tubo de alúmina en cuyo interior se había introducido una mezcla de cuarzo, mineralizador y fluidificante de forma que la probeta no estaba en contacto con las materias primas de sílice. Todo el dispositivo se introdujo en un crisol de porcelana tapado con fibra de vidrio para evitar la evacuación de los gases formados durante la reacción (Figura 4.110). El conjunto se introdujo en un horno y se trató térmicamente con el ciclo STD (Figura 3.16) y el ciclo Rápido (Figura 4.49), hasta temperatura máxima de $1000^{\circ} \mathrm{C}$ durante 6 horas y posterior enfriamiento. De la misma forma, se realizaron experimentos sin mineralizador y variando el porcentaje de mineralizador en $5 \%$ y $10 \%$ cuyas referencias se muestran en la Tabla 4.49.

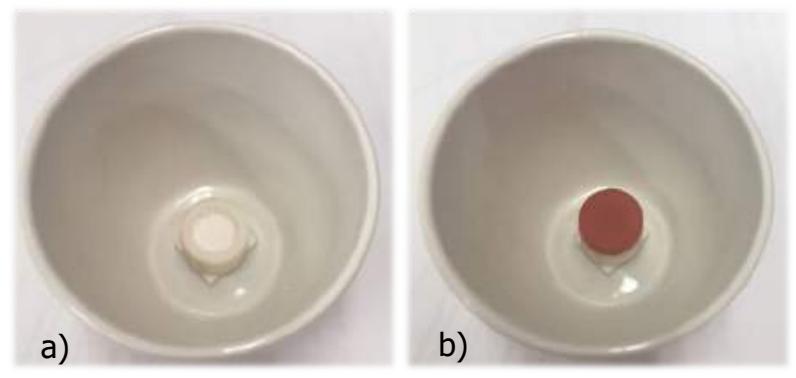

Figura 4.110 Montaje utilizado para confirmar el mecanismo de reacción a) Mezcla de $\mathrm{SiO}_{2}$, fluidificante y mineralizador; b) Mezcla de $\mathrm{Fe}_{2} \mathrm{O}_{3}$ y $\mathrm{ZrO}_{2}$

Además, se prepararon dos probetas con un $10 \%$ de mineralizador cuya particularidad consistía en que todas las materias primas (sílice, circona, óxido de hierro, mineralizador y fluidificante) se mezclaron conjuntamente utilizando un molino de ágata mediante vía seca. Las probetas fueron referenciadas como $\mathrm{G}$ para la probeta tratada con el ciclo Rápido y $\mathrm{H}$ para la probeta tratada con el ciclo STD. 
Tabla 4.49 Referencias de los experimentos de difusión

\begin{tabular}{|ccc|}
\hline Mineralizador & $\begin{array}{c}\text { Ciclo Rápido } \\
\mathrm{V}=25^{\circ} \mathrm{C} / \mathrm{min}\end{array}$ & $\begin{array}{c}\text { Ciclo STD } \\
\mathrm{V}=5^{\circ} \mathrm{C} / \mathrm{min}\end{array}$ \\
\hline $0 \%$ & $\mathrm{~A}$ & $\mathrm{D}$ \\
$5 \%$ & $\mathrm{~B}$ & $\mathrm{E}$ \\
$10 \%$ & $\mathrm{C}$ & $\mathrm{F}$ \\
$10 \%$ & $\mathrm{G}^{*}$ & $\mathrm{H}^{*}$ \\
\hline
\end{tabular}

(*) Mezcla de materias primas

Las probetas obtenidas fueron observadas con el microscopio electrónico de barrido realizando micrografías y microanálisis por dispersión de energías de rayos X (EDX) en la superficie más cercana a la mezcla de sílice, observándose diferencias importantes.

Para determinar la composición superficial de las probetas, se efectuaron cinco análisis en áreas seleccionadas al azar, utilizando unos aumentos que permitieran considerar la zona de análisis como una zona homogénea y representativa. La composición química de cada muestra se determinó promediando los resultados de los análisis y el error se estableció como la desviación estándar de las medidas.

Conviene señalar que la penetración del haz de electrones, aunque reducido (del orden de 2-3 um), es apreciable por lo que, el análisis que se obtiene no corresponde exactamente a la superficie irradiada sino a una capa de muy pequeño espesor. A pesar de ello, por simplicidad, denominaremos análisis superficial a lo que corresponde estrictamente al análisis de una capa delgada superficial.

\subsubsection{Tratamiento térmico en Ciclo Rápido}

En primer lugar, se estudiaron las condiciones que en anteriores experimentos favorecían el mecanismo en fase gaseosa, es decir velocidades de calentamiento rápido.

La probeta tratada con el ciclo Rápido y con presencia de mineralizador mostraba un aspecto más sinterizado y oscuro que el experimento sin mineralizador (Figura 4.111), lo que podría confirmar la reacción mediante mecanismo gaseoso, ya que la circona y el óxido de hierro no habían estado en contacto con la sílice. 
a)

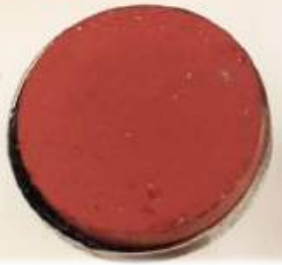

b)

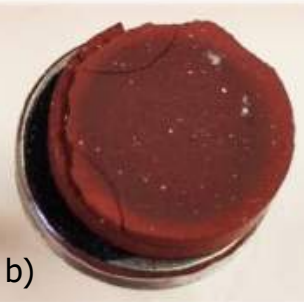

Figura 4.111 a) Probeta $A\left(0 \%\right.$ mineralizador, $\left.v=25^{\circ} \mathrm{C} / \mathrm{min}\right)$ b) Probeta $B\left(5 \%\right.$ mineralizador, $\left.v=25^{\circ} \mathrm{C} / \mathrm{min}\right)$

En la Figura 4.112 se muestra la micrografía y microanálisis EDX global de la superficie de la probeta que no ha sido sometida a tratamiento térmico, para poder comparar con las probetas calcinadas. En la superficie de la probeta se observaron partículas con diferente morfología, tamaño y composición. El análisis EDX mostró que las partículas grandes de color blanquecino correspondían a la circona y aquellas partículas más pequeñas y de color oscuro, correspondían al óxido de hierro.
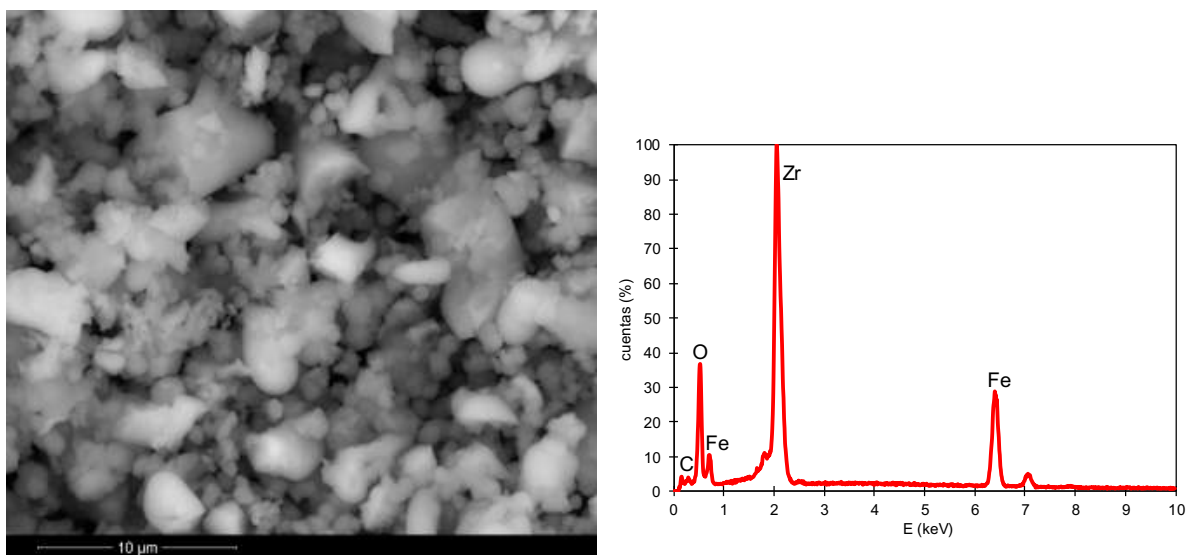

Figura 4.112 Micrografía y análisis EDX global de la probeta sin cocer con la señal de electrones retrodispersados del MEB (x50000)

A continuación, se realizó el estudio sobre la probeta tratada térmicamente a la que no se le había añadido mineralizador. En la Figura 4.113 se presentan la micrografía y análisis EDX de la probeta $A$, que fue analizada del mismo modo que la probeta sin calcinar. Los análisis mostraban que la superficie de la probeta A no presentaba sílice en su composición, aunque las partículas si que presentaban un aspecto más sinterizado que las que fueron observadas en la probeta que no había experimentado tratamiento térmico. 

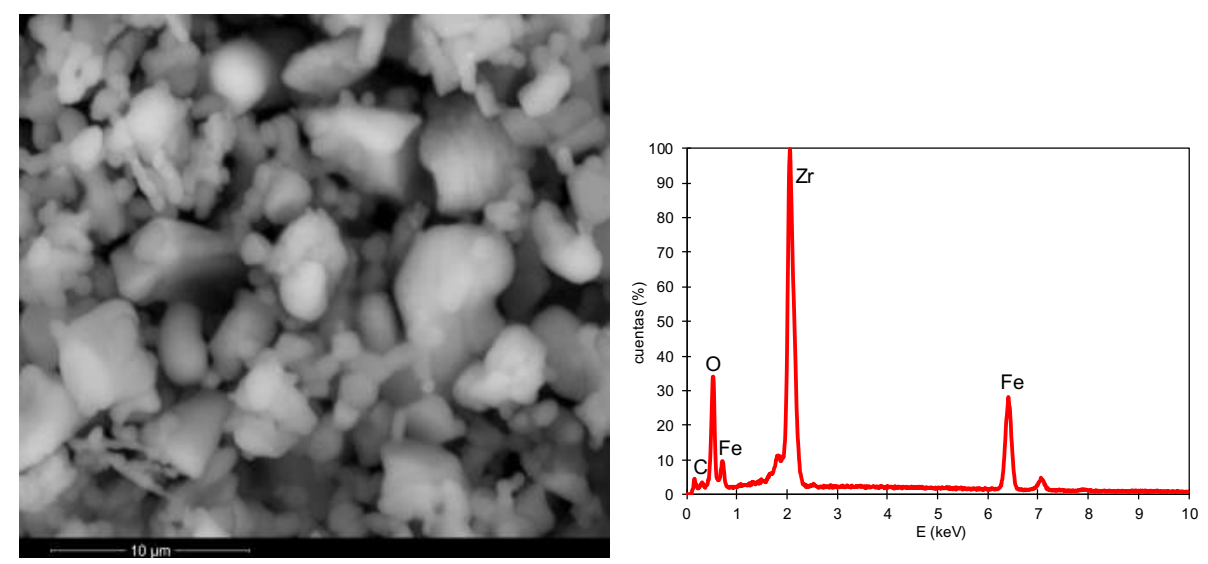

Figura 4.113 Micrografía y análisis EDX global de la probeta A ( $0 \%$ mineralizador, $v=25^{\circ} \mathrm{C} / \mathrm{min}$ ) con la señal de electrones retrodispersados del MEB (x50000)

Una vez estudiada la probeta procedente de los experimentos en los que no se había añadido mineralizador, se procedió a estudiar el efecto del mineralizador en la reacción de formación del circón.

En la Figura 4.114 se detalla la micrografía y análisis EDX global de la superficie de la probeta $\mathrm{B}$ tratada térmicamente con el ciclo Rápido en cuyo experimento se había añadido un $5 \%$ de mineralizador. El análisis EDX reveló la presencia de sílice y un pequeño porcentaje de sodio que podría proceder de compuestos volátiles formados a partir del mineralizador. Por otra parte, las partículas tenían un aspecto más redondeado debido a la sinterización que habían sufrido durante el tratamiento térmico.

Realizando un análisis EDX sobre los diferentes tipos de partículas se comprobó que las partículas pequeñas y oscuras se enriquecían en oxígeno y hierro y podrían asociarse a partículas de hematites, las partículas blancas más grandes corresponderían a circona y las partículas blancas más pequeñas corresponderían a circón, ya que la intensidad del pico de sílice aumentaba con respecto al resto de análisis. 

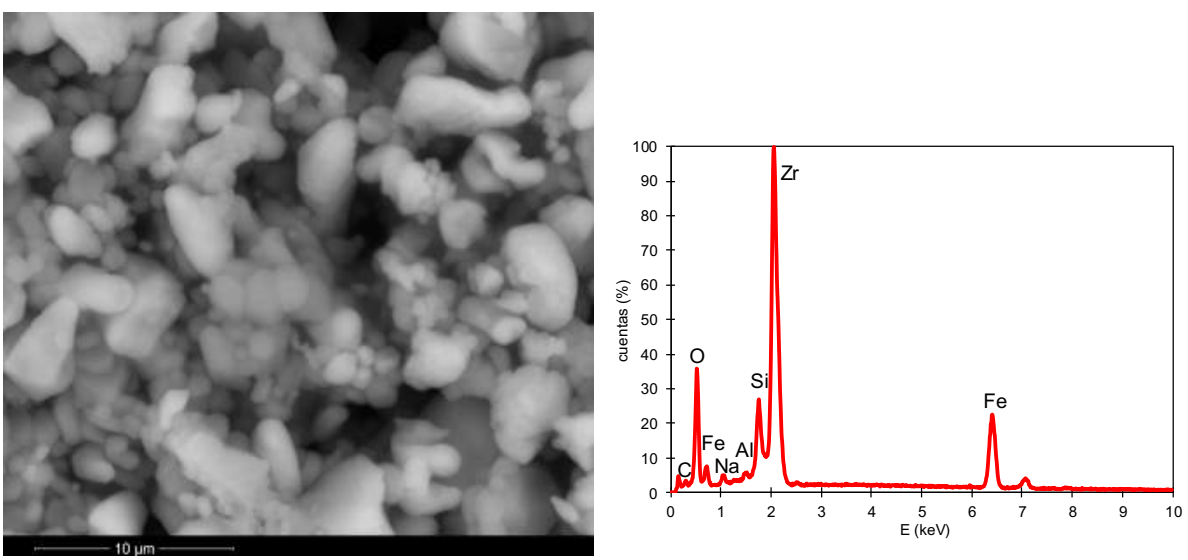

Figura 4.114 Micrografía y análisis EDX global de la probeta B ( $5 \%$ mineralizador, $v=25^{\circ} \mathrm{C} / \mathrm{min}$ ) con la señal de electrones retrodispersados del MEB (x50000)

Otro hecho que se observó durante el estudio fue la presencia de agregados de partículas de óxido de hierro que tras el tratamiento térmico se enriquecían en oxígeno y aumentaban su tamaño.
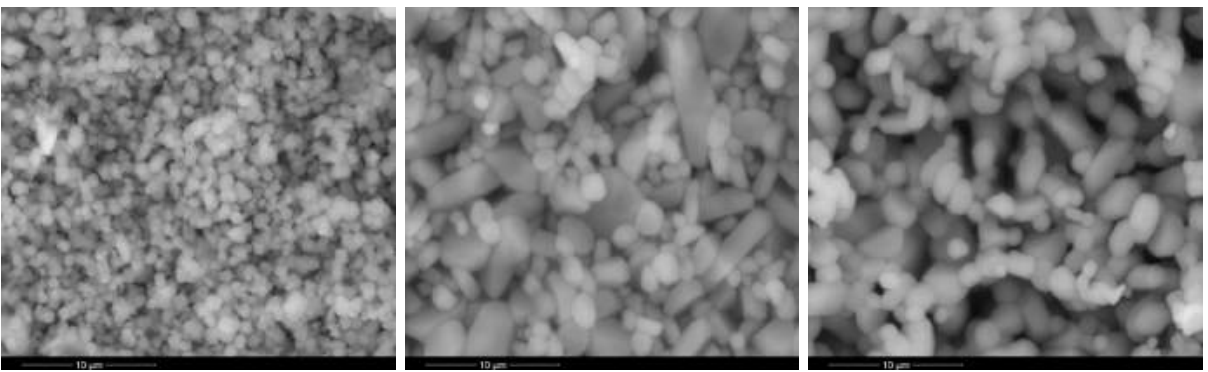

Figura 4.115 Micrografía de los agregados de óxido de hierro en las probetas cruda, A y B con la señal de electrones retrodispersados del MEB ( $x 50000)$

Del mismo modo, se realizó el estudio morfológico y químico de la probeta $\mathrm{C}$, que había sido sometida al ciclo Rápido y en cuyo experimento se había añadido un $10 \%$ de mineralizador junto con la sílice y el fluidificante. El análisis EDX mostró también la presencia de sílice en la superficie de la probeta, así como un pequeño porcentaje de sodio ( $1,8 \%$ aproximadamente). En este experimento también se observó que la mezcla de sílice, mineralizador y fluidificante, tras la cocción poseía un aspecto más sinterizado debido a la fase vítrea formada tras la reacción entre la sílice y el mineralizador. 


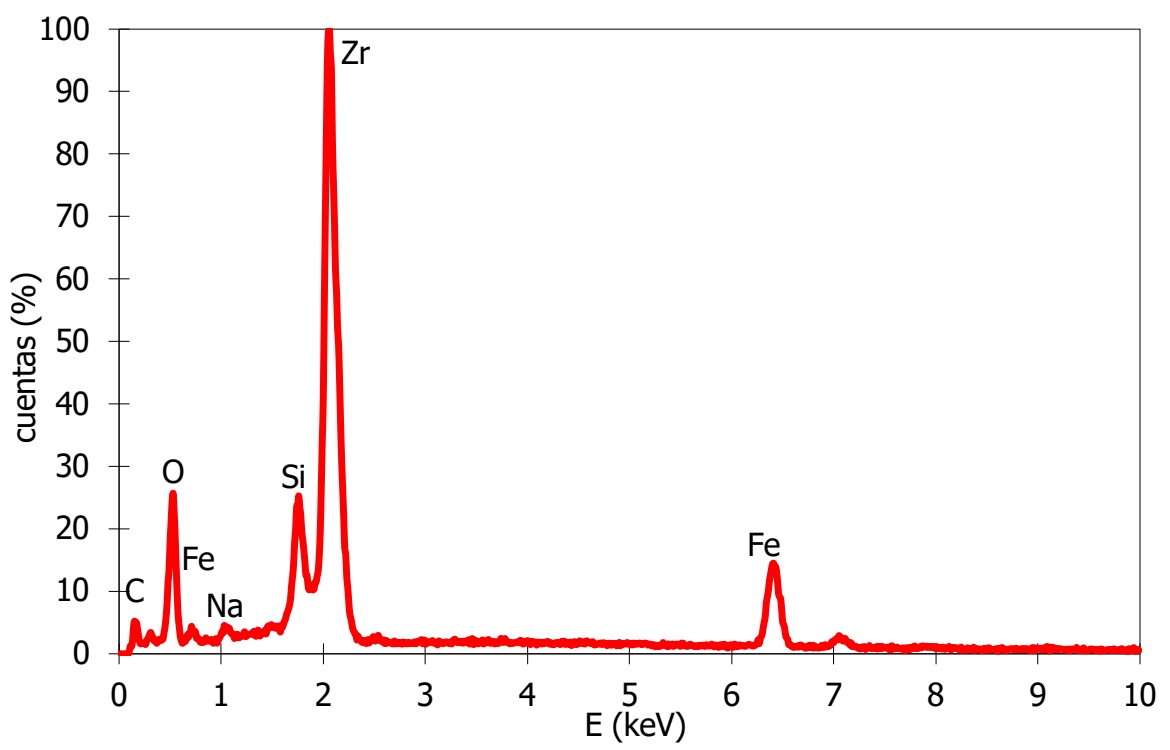

Figura 4.116 Análisis EDX global de la probeta $C$

$\left(10 \%\right.$ mineralizador, $v=25^{\circ} \mathrm{C} / \mathrm{min}$ ) con la señal de electrones retrodispersados del MEB (x10000)

En la Tabla 4.50 se muestran las composiciones en óxidos de la superficie de las probetas, determinadas por EDX y expresadas en porcentaje atómico. Los valores mostrados son el promedio de los análisis realizados en distintas zonas de cada muestra.

Tabla 4.50 Análisis EDX en forma de porcentaje atómico de la superficie de las probetas

\begin{tabular}{|ccccccc|}
\hline \multirow{2}{*}{\begin{tabular}{c} 
Mineralizador \\
\cline { 2 - 4 }
\end{tabular}} & 0 & $\mathrm{~F}$ & $\mathrm{Na}$ & $\mathrm{Ni}$ & $\mathrm{Zr}$ & $\mathrm{Fe}$ \\
\hline $0 \%$ & $62,0 \pm 0,3$ & - & - & - & $21,6 \pm 0,2$ & $22,4 \pm 0,3$ \\
$5 \%$ & $50,2 \pm 0,2$ & - & $1,8 \pm 0,1$ & $5,5 \pm 0,2$ & $20,6 \pm 0,3$ & $12,3 \pm 0,2$ \\
$10 \%$ & $56,1 \pm 0,3$ & - & $1,8 \pm 0,2$ & $6,3 \pm 0,1$ & $25,6 \pm 0,3$ & $10,0 \pm 0,3$ \\
\hline
\end{tabular}

Por tanto, el microanálisis por EDX, confirmaba la presencia de sílice en el experimento con un $5 \%$ y $10 \%$ de mineralizador, indicando que había tenido lugar un transporte en fase gaseosa de la sílice hacia la probeta. En la probeta sin cocer y la que no poseía mineralizador en su composición, no se observó la presencia de sílice. 
Tras comprobar la presencia de sílice en la superficie de las probetas en las que se había utilizado mineralizador, todo parecía indicar que o bien había un transporte de silicio hacia la probeta que podía realizarse en fase gaseosa, o bien, cabía la posibilidad de que fuese debido únicamente a un fenómeno de difusión superficial. Para aclarar estas cuestiones, se decidió realizar un perfil de concentraciones hacia el interior de la probeta.

Para ello se realizaron análisis EDX en áreas de $70 \mu \mathrm{m}$ por $12 \mu \mathrm{m}$, a diferentes profundidades en las probetas A, B y C, para poder comparar los experimentos llevado a cabo con diferente porcentaje de mineralizador $(0 \%, 5 \%$, y $10 \%)$ y utilizando como tratamiento térmico, el ciclo rápido.

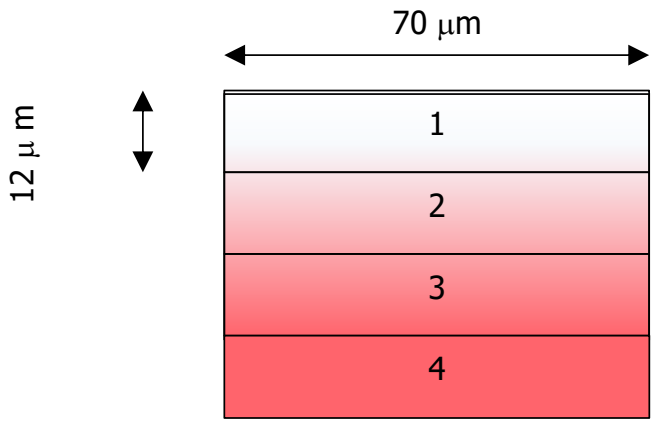

Figura 4.117 Esquema del análisis EDX en profundidad con la señal de electrones retrodispersados del MEB

Representando los valores obtenidos tras el análisis EDX (Figura 4.119, Figura 4.118 y Figura 4.120), no se observan diferencias significativas en el análisis elemental de las diferentes áreas analizadas en profundidad. Estos ensayos indican pues que la sílice se difunde a través de la probeta porosa en forma de gas para reaccionar con las partículas de óxido de hierro y la circona para formar circón.

Por otra parte, no se ha detectado la presencia de átomos de silicio en el experimento en el que no se había introducido como materia prima el mineralizador. Esto se explicaría debido a que no se podía formar el compuesto tetrafluoruro de silicio $\left(\mathrm{SiF}_{4}\right)$ formado por reacción entre la sílice y el mineralizador $\left(\mathrm{Na}_{2} \mathrm{SiF}_{6}\right)$, y por tanto la sílice no sería capaz de llegar a la superficie de la probeta. 


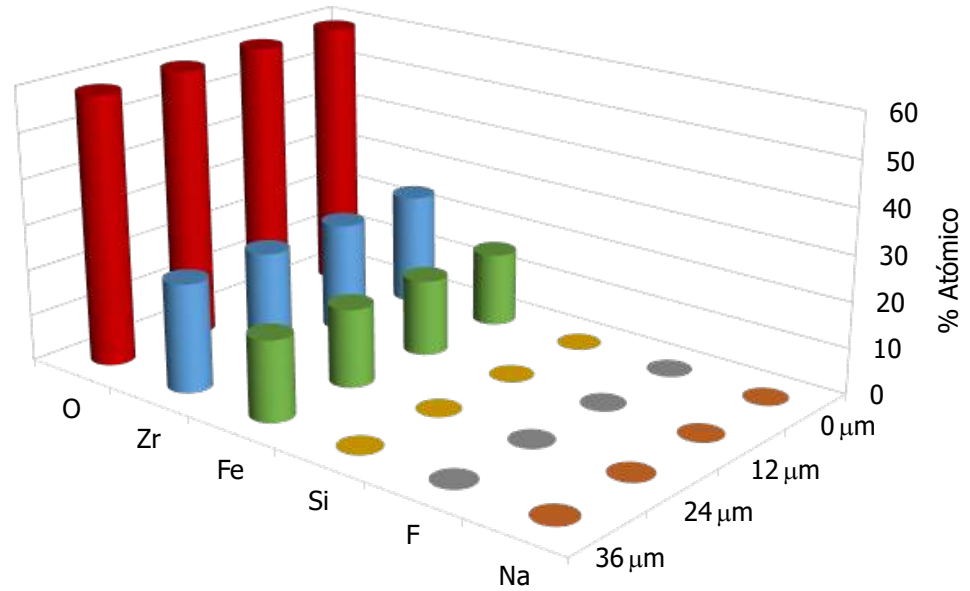

Figura 4.118 Evolución del análisis EDX en profundidad con la señal de electrones retrodispersados del MEB, experimento con $0 \%$ de mineralizador y ciclo Rápido

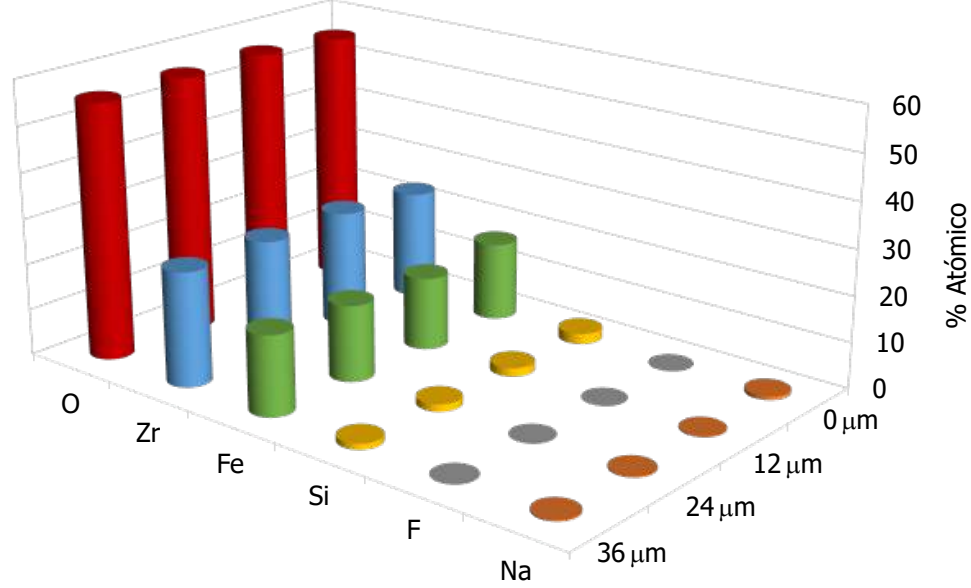

Figura 4.119 Evolución del análisis EDX en profundidad con la señal de electrones retrodispersados del MEB, experimento con $5 \%$ de mineralizador y ciclo Rápido 


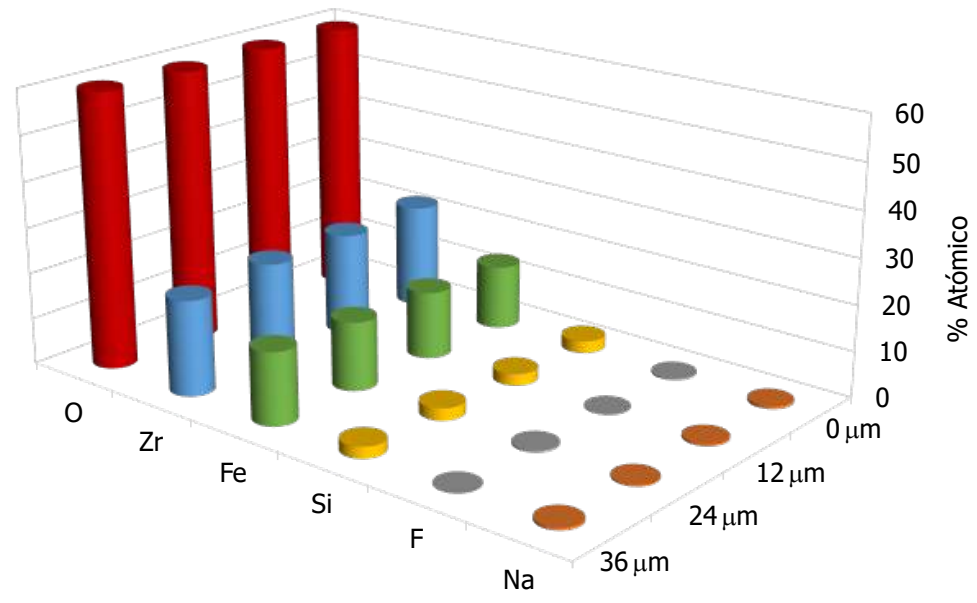

Figura 4.120 Evolución del análisis EDX en profundidad con la señal de electrones retrodispersados del MEB, experimento con $10 \%$ de mineralizador y ciclo Rápido

\subsubsection{Tratamiento térmico en Ciclo STD}

En el siguiente diseño de experimentos se repitieron los ensayos realizados en el apartado anterior, pero en aquellas condiciones que parecían favorecer un mecanismo de transporte en fase líquida, es decir, utilizando velocidades de calentamiento lentas con el ciclo STD $\left(5^{\circ} \mathrm{C} / \mathrm{min}\right)$.

Las micrografías y microanálisis realizados en la superficie de las probetas mostraban resultados muy similares a los obtenidos cuando estas probetas eran sometidas a tratamiento térmicos con el ciclo Rápido. Sin embargo, los experimentos con $5 \%$ y $10 \%$ de mineralizador mostraban un menor porcentaje de sílice, lo que podría confirmar una menor formación de circón que en las mismas probetas tratadas con el ciclo Rápido. Por otra parte, el experimento con una mayor cantidad de mineralizador presentaba un pequeño porcentaje de sodio en su composición, debido probablemente a la formación de algún compuesto volátil formado a partir del mineralizador.

Los microanálisis EDX globales de la superficie de las probetas analizadas se muestran en las siguientes figuras (Figura 4.121, Figura 4.122 y Figura 4.123). 


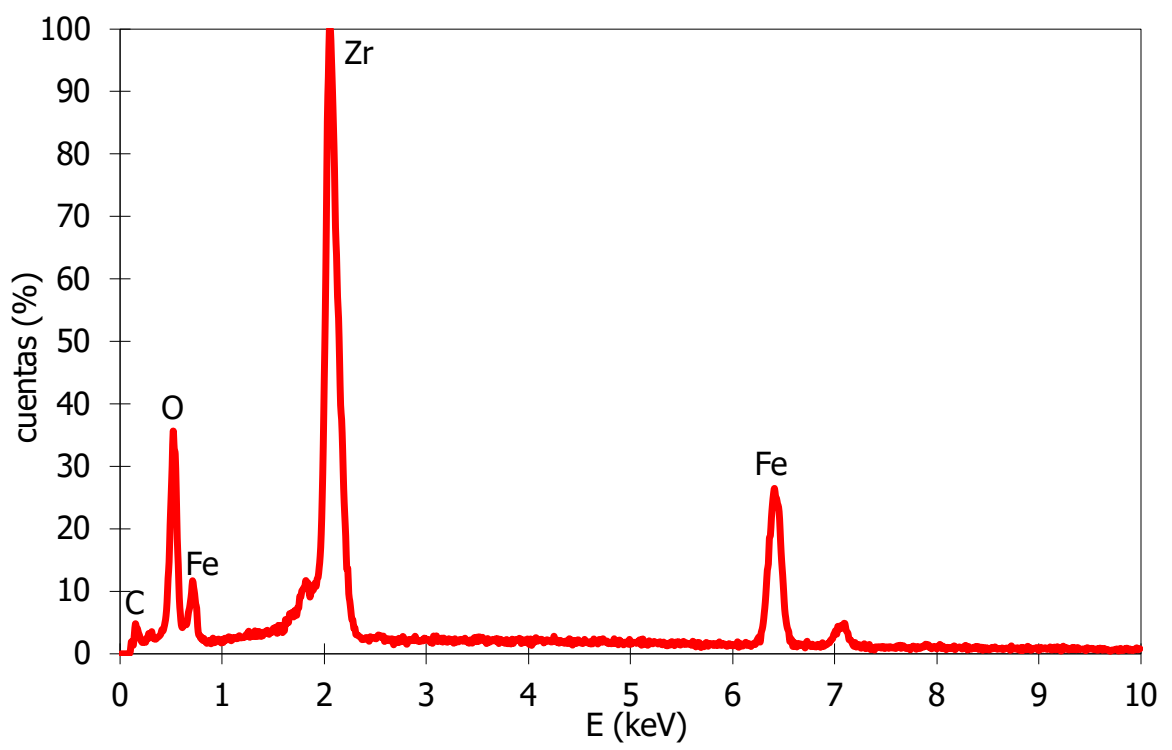

Figura 4.121 Análisis EDX global de la probeta D

$\left(0 \%\right.$ mineralizador, $v=5^{\circ} \mathrm{C} / \mathrm{min}$ ) con la señal de electrones retrodispersados del MEB (x10000)

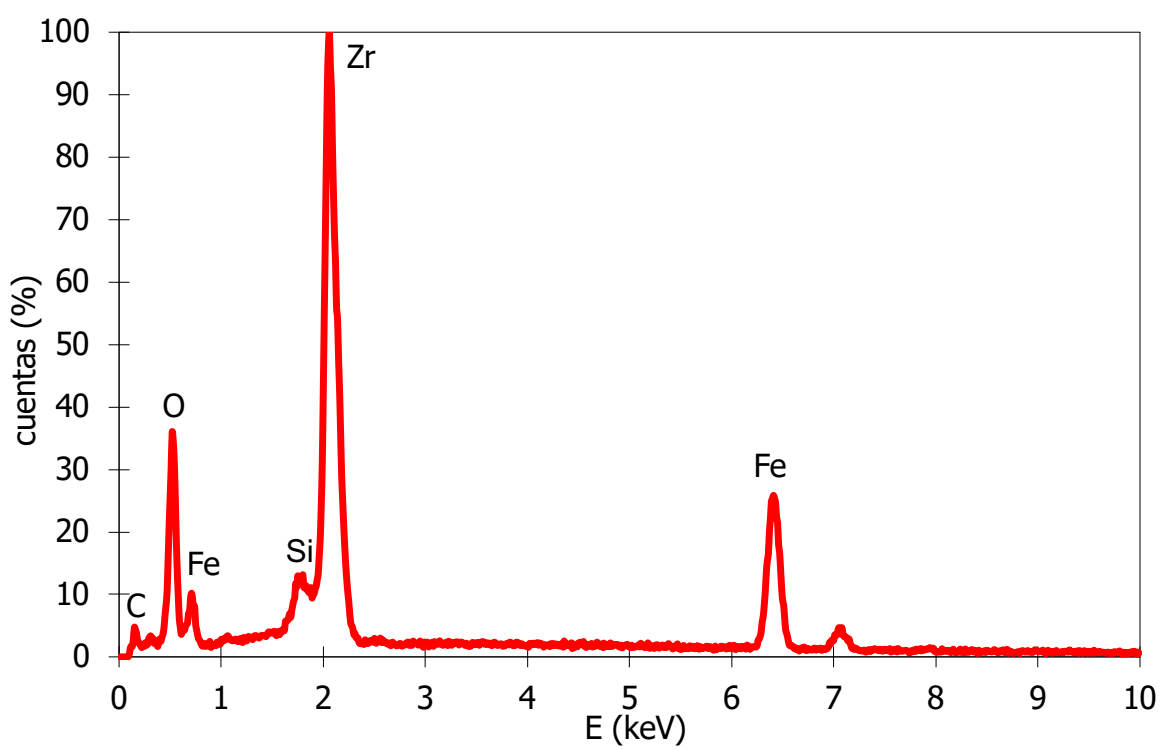

Figura 4.122 Análisis EDX global de la probeta E ( $5 \%$ mineralizador, $v=5^{\circ} \mathrm{C} / \mathrm{min}$ ) con la señal de electrones retrodispersados del MEB (x10000) 


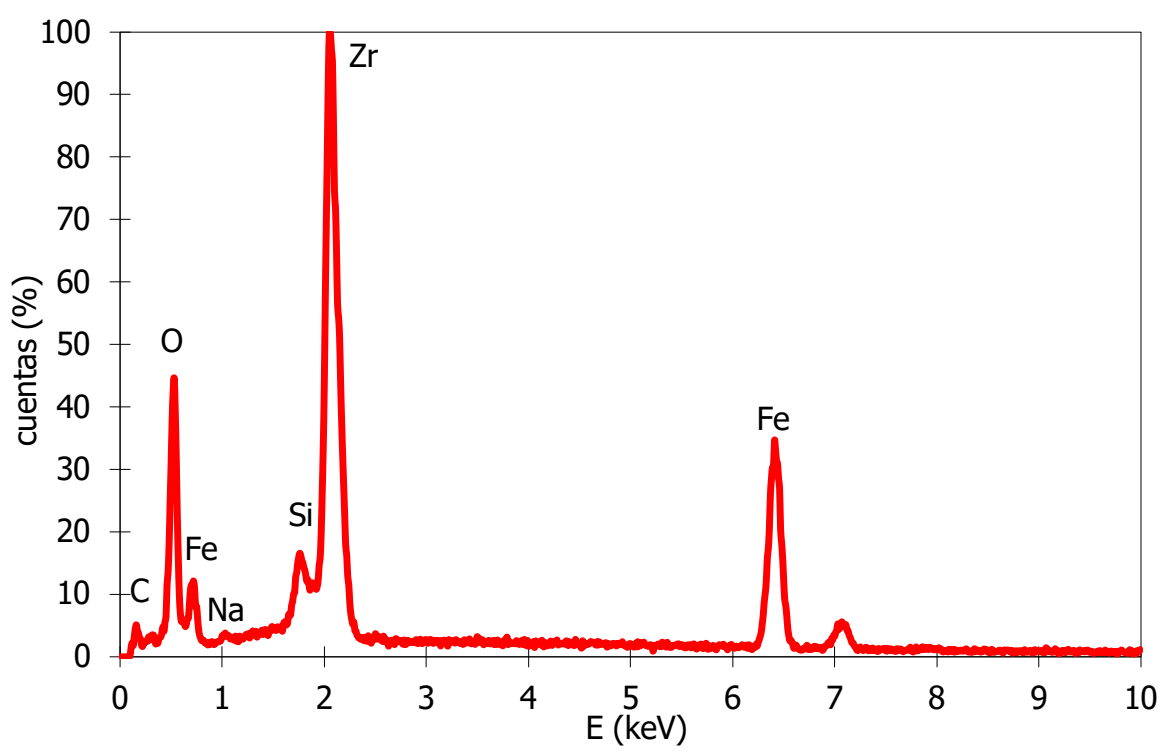

Figura 4.123 Análisis EDX global de la probeta $\mathrm{F}$ ( $10 \%$ mineralizador, $v=5^{\circ} \mathrm{C} / \mathrm{min}$ ) con la señal de electrones retrodispersados del MEB (x10000)

En la Tabla 4.51 se muestran las composiciones en óxidos de la superficie de las probetas, determinadas por EDX y expresadas en porcentaje atómico. Los valores mostrados son el promedio de los análisis realizados en distintas zonas de cada muestra.

Tabla 4.51 Análisis EDX expresado en porcentaje atómico de la superficie de las probetas

\begin{tabular}{|ccccccc|}
\hline \multirow{2}{*}{\begin{tabular}{c} 
Mineralizador \\
\cline { 2 - 4 }
\end{tabular}} & $\mathrm{O}$ & $\mathrm{F}$ & $\mathrm{Na}$ & $\mathrm{Si}$ & $\mathrm{Zr}$ & $\mathrm{Fe}$ \\
\hline $0 \%$ & $62,1 \pm 0,3$ & - & - & $0,4 \pm 0,1$ & $21,7 \pm 0,3$ & $15,8 \pm 0,2$ \\
$5 \%$ & $61,0 \pm 0,2$ & - & $0,6 \pm 0,1$ & $2,0 \pm 0,2$ & $21,0 \pm 0,3$ & $15,2 \pm 0,1$ \\
$10 \%$ & $61,4 \pm 0,1$ & - & $0,7 \pm 0,1$ & $2,4 \pm 0,2$ & $18,6 \pm 0,2$ & $16,8 \pm 0,2$ \\
\hline
\end{tabular}

Los experimentos realizados parecen confirmar que el mecanismo de formación del pigmento coral de hierro-circón, transcurre mediante transporte en fase gas favoreciendo la formación de especies gaseosas como el $\mathrm{SiF}_{4}$ que reaccionan con la circona formando cristales de circón que encapsulan las pequeñas partículas de óxido de hierro. Este fenómeno es más acusado con tratamientos 
térmicos que implican velocidades de calentamiento altas, ya que dificulta la formación de la fase vítrea silícea.

Por otra parte, los experimentos ponen de manifiesto la necesidad de la adición de mineralizador para la formación del pigmento, ya que aquellos ensayos en los que no está presente el mineralizador, no se ha formado circón en la superficie de la probeta.

Al igual que en el apartado anterior, se decidió realizar un perfil de concentraciones hacia el interior de la probeta. Para ello se realizaron análisis EDX a diferentes profundidades en las probetas $D, E$ y $F$ con diferente porcentaje de mineralizador $(0 \%, 5 \%$, y $10 \%)$ y utilizando como tratamiento térmico, un ciclo a $5^{\circ} \mathrm{C} / \mathrm{min}$ (Ciclo STD).

Los valores obtenidos en porcentajes atómicos se muestran en la Figura 4.124, Figura 4.125 y Figura 4.126.

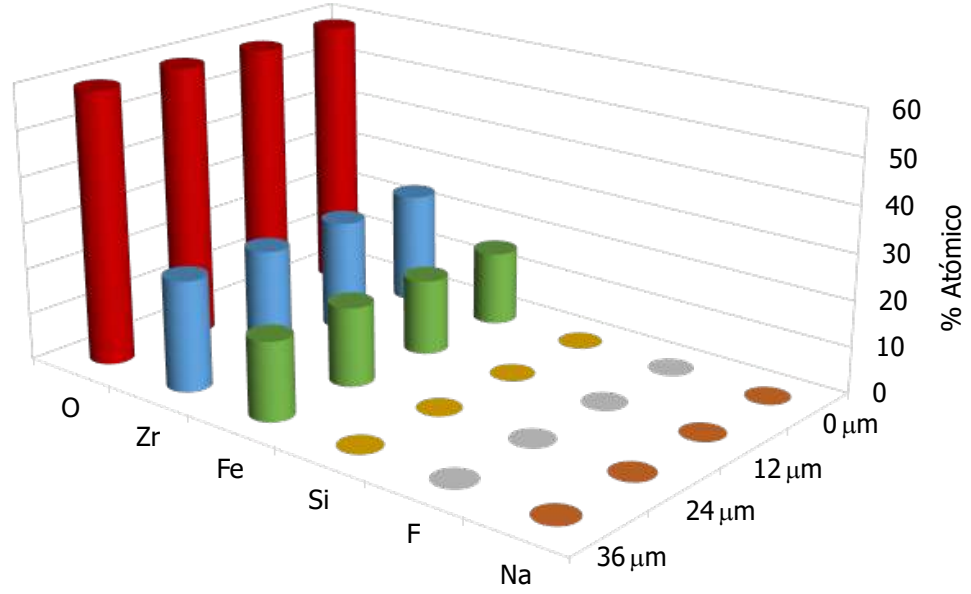

Figura 4.124 Evolución del análisis EDX en profundidad con la señal de electrones retrodispersados del MEB, experimento con $0 \%$ de mineralizador y ciclo STD 


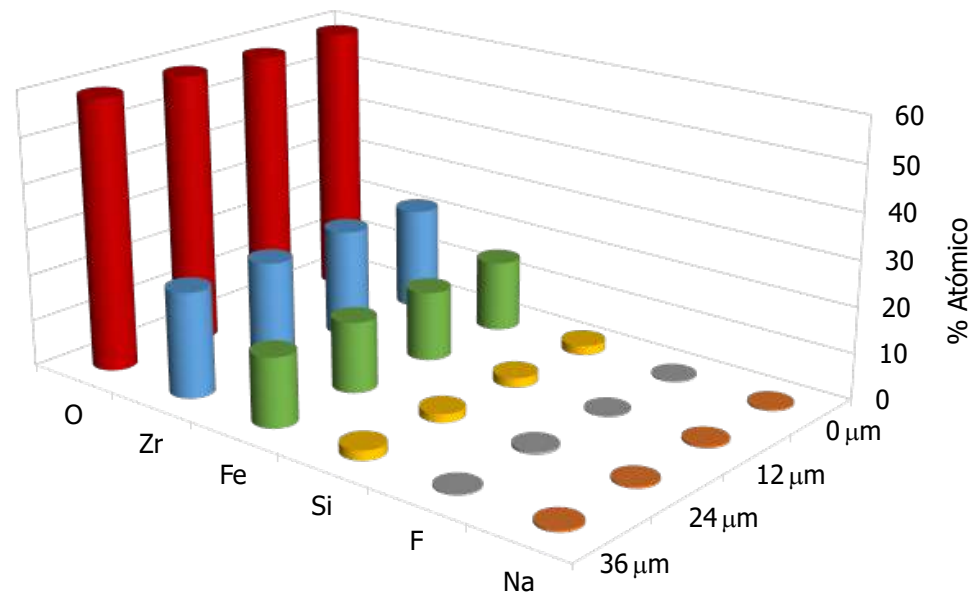

Figura 4.125 Evolución del análisis EDX en profundidad con la señal de electrones retrodispersados del MEB, experimento con $5 \%$ de mineralizador y ciclo STD

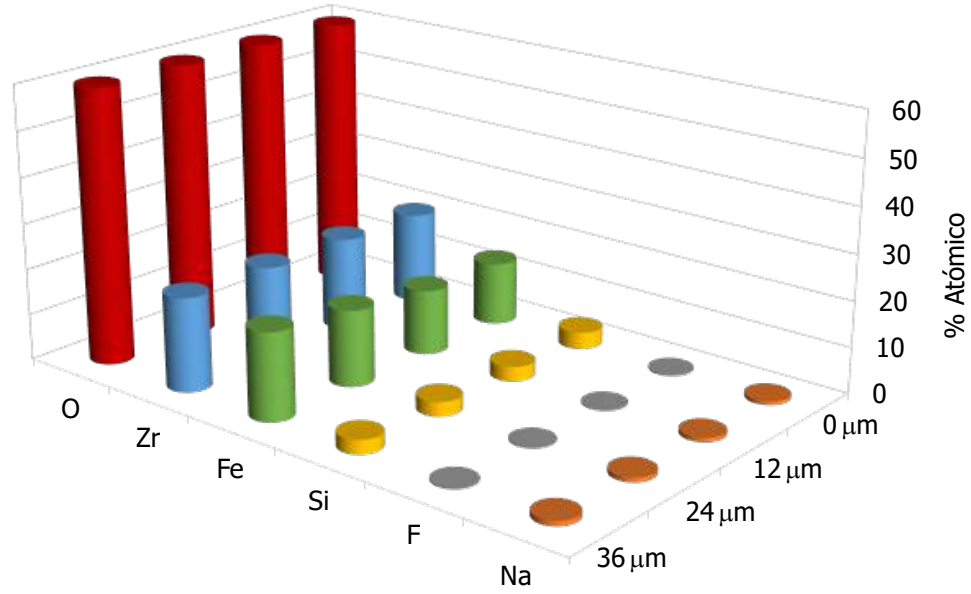

Figura 4.126 Evolución del análisis EDX en profundidad con la señal de electrones retrodispersados del MEB, experimento con $10 \%$ de mineralizador y ciclo STD 


\subsubsection{Mezcla de materias primas}

Tal y como se comentó al inicio del apartado, se prepararon dos probetas utilizando un $10 \%$ de mineralizador donde todas las materias primas (sílice, circona, óxido de hierro, mineralizador y fluidificante) se habían mezclado conjuntamente en un molino de ágata mediante la vía seca. Las probetas fueron referenciadas como $\mathrm{G}$ para la probeta tratada con el ciclo Rápido y $\mathrm{H}$ para la probeta tratada con el ciclo STD con una velocidad de calentamiento de $5^{\circ} \mathrm{C} / \mathrm{min}$.

En primer lugar, se observó y fotografió la superficie de la probeta $G$ donde se detectaron bastante cantidad de cristales de circón y pequeñas partículas blancas de circona (Figura 4.127).

Al mismo tiempo, en las micrografías se observó la presencia de una elevada cantidad de grandes cristales de óxido de hierro de tipo aventurina. Los cristales de óxido de hierro con forma acicular presentaban un tamaño entre 3 y 6 micras, mientras que aquellos cristales en forma de hexágonos tenían tamaños entre 10 y 20 micras.

Este fenómeno ocurre cuando durante el tratamiento térmico, el óxido de hierro se disuelve en el vidrio formado y posteriormente, en el enfriamiento, se recristaliza en forma de cristales laminares que pueden segregarse hacia la superficie. Estas aventurinas dan lugar a cristales de hematites en forma dendrítica o de láminas hexagonales donde el ciclo térmico influye de manera muy importante en el crecimiento de los cristales. El mecanismo de formación suele constar de dos etapas: una primera de disolución del óxido metálico en el fundido, seguida por un enfriamiento lento y controlado que permita la formación de los cristales laminares o, en su defecto, un cierto tiempo de permanencia a una temperatura más baja, donde la velocidad de crecimiento cristalino sea elevada [123].
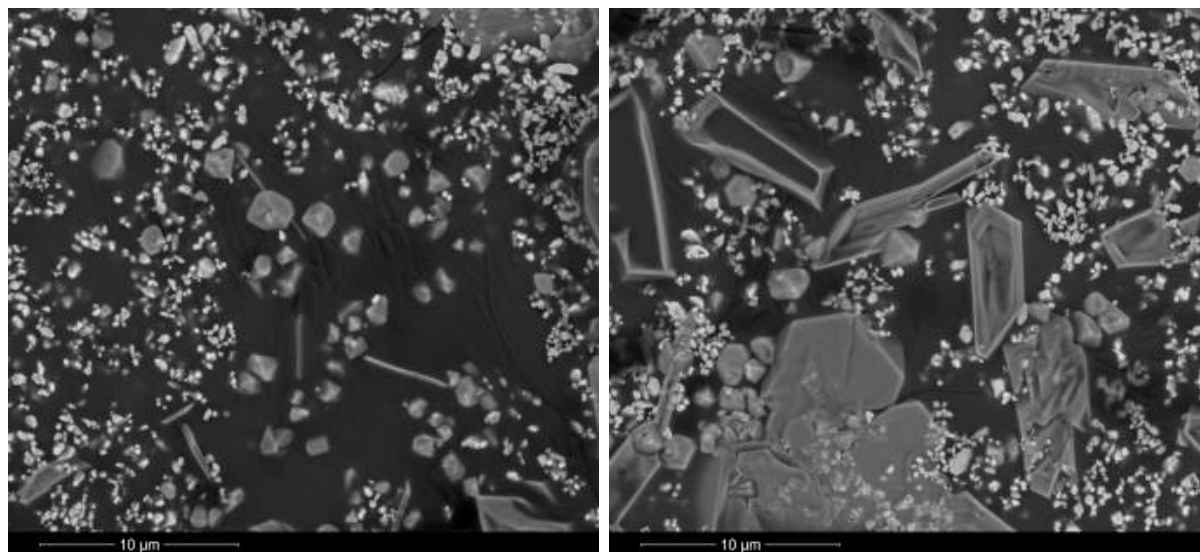

Figura 4.127 Micrografías de la probeta $\mathrm{G}$

$\left(10 \%\right.$ mineralizador, $v=25^{\circ} \mathrm{C} / \mathrm{min}$ ) con la señal de electrones retrodispersados del MEB (x5000) 
Posteriormente, la probeta $\mathrm{G}$ fue embutida y pulida para su observación en el microscopio electrónico de barrido utilizando 5000 aumentos. La muestra presentaba poca cantidad de fase vítrea debido a la elevada velocidad de calentamiento utilizada durante el tratamiento térmico. Se detectó también la presencia de cristales bipiramidales de circón y algún cristal grande de forma laminar y hexagonal que correspondería a óxido de hierro desvitrificado tipo aventurina (Figura 4.128).
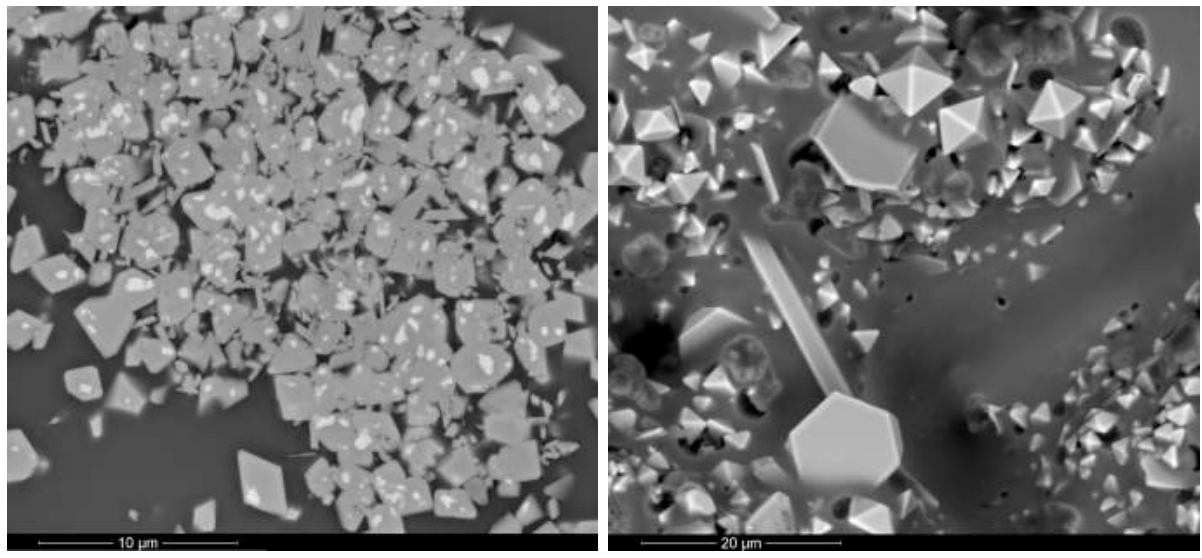

Figura 4.128 Micrografías de la superficie pulida de la probeta G $\left(10 \%\right.$ mineralizador, $\left.v=25^{\circ} \mathrm{C} / \mathrm{min}\right)$ con la señal de electrones retrodispersados del MEB (x5000).

Una vez analizada la probeta $\mathrm{G}$, se procedió al estudio de la probeta $\mathrm{H}$ que había sido tratada térmicamente utilizando el ciclo STD, es decir, 50 $\mathrm{C} / \mathrm{min}$, observando diferencias importantes respecto a la probeta tratada con el ciclo rápido .

La probeta $\mathrm{H}$ tratada térmicamente con el ciclo STD fue fotografiada en superficie con el microscopio electrónico de barrido donde se observaron diferentes tipos de cristales (Figura 4.129 y Figura 4.130). Las imágenes tomadas a 5000 y 10000 aumentos mostraban gran cantidad de cristales bipiramidales de circón, pequeñas partículas blancas de óxido de circonio y cristales aciculares e incluso laminares que corresponderían a óxido de hierro. Además, se observó mucha cantidad de fase vítrea debido al elevado porcentaje de mineralizador y al ciclo térmico utilizado. Con un $10 \%$ de mineralizador y utilizando una baja velocidad de calentamiento, favorecería la reacción entre el cuarzo y el mineralizador con posterior formación del vidrio viscoso. 

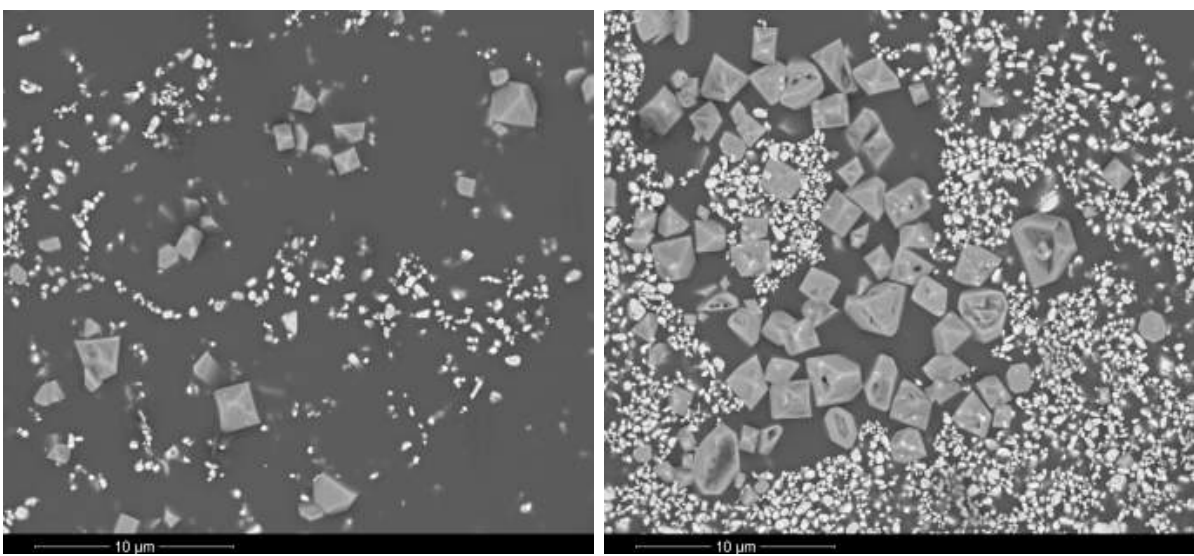

Figura 4.129 Micrografías de la probeta $\mathrm{H}$

( $10 \%$ mineralizador, $v=5^{\circ} \mathrm{C} / \mathrm{min}$ ) con la señal de electrones retrodispersados del MEB (x5000)
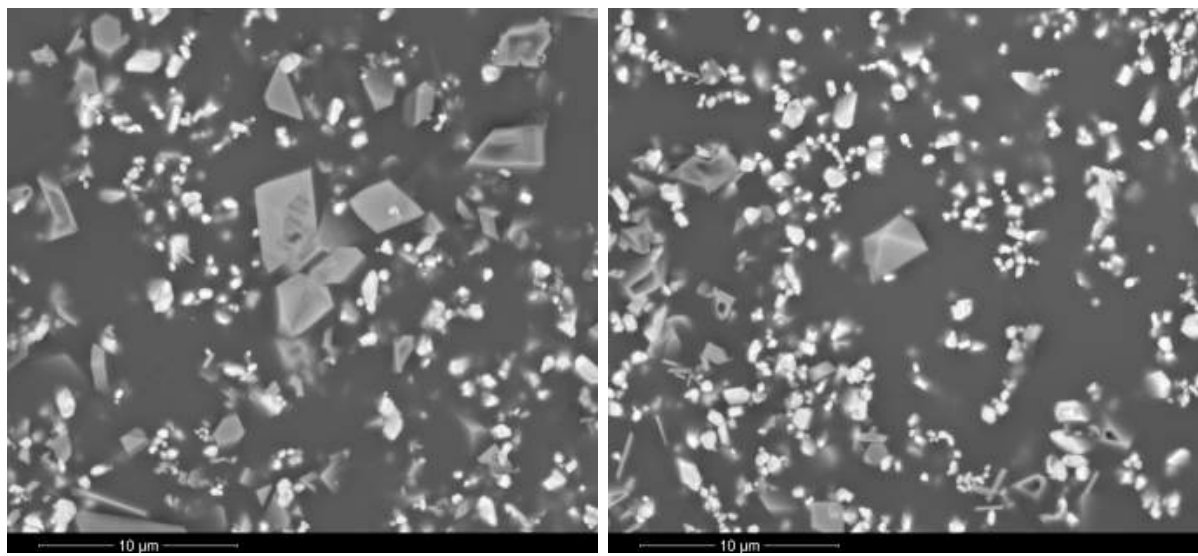

Figura 4.130 Micrografías de la probeta $\mathrm{H}$ ( $10 \%$ mineralizador, $v=5^{\circ} \mathrm{C} / \mathrm{min}$ ) con la señal de electrones retrodispersados del MEB (x10000)

Debido a que en este experimento todas las materias primas habían sido mezcladas conjuntamente, se suponía que la reacción de formación del circón ocurriría no sólo en superficie sino en todo el interior de la probeta. Por ello, se decidió pulir la superficie de la probeta y realizar micrografías del interior de ésta (Figura 4.131).

Se observó una gran cantidad de cristales de circón formado a partir de la circona y la sílice. De igual forma se fotografiaron zonas donde se observaba aglomerados de cristales de circón, en cuyo interior se localizaban pequeñas partículas blancas. Realizando un análisis EDX de estas pequeñas partículas blancas se reveló que se trataba de circona y que los cristales de circón se estaban formando alrededor de ellas. 

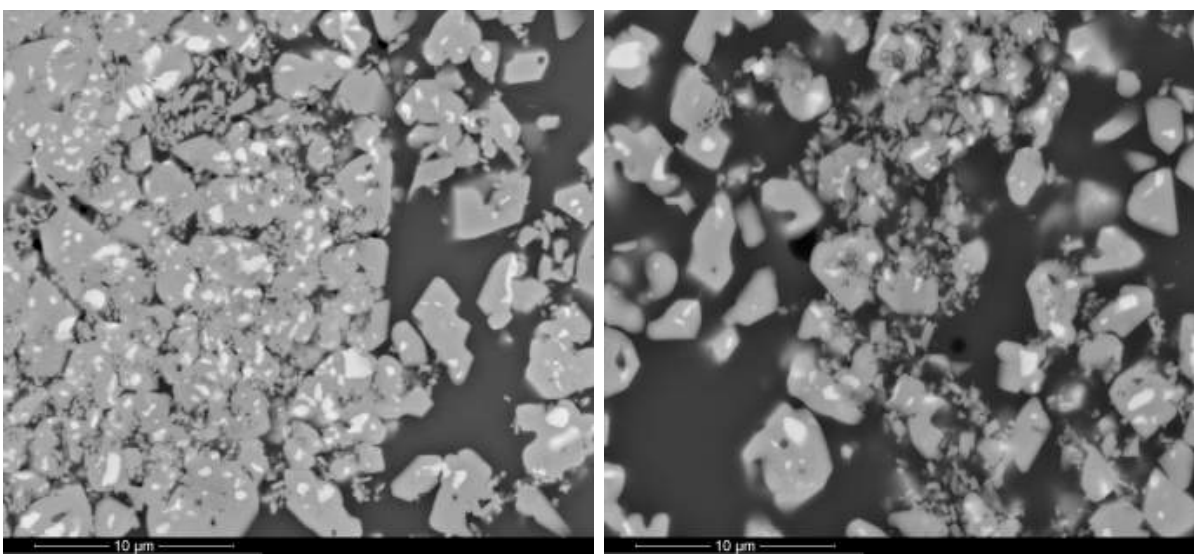

Figura 4.131 Micrografías de la superficie pulida de la probeta $\mathrm{H}$ $\left(10 \%\right.$ mineralizador, $\left.v=5^{\circ} \mathrm{C} / \mathrm{min}\right)$ con la señal de electrones retrodispersados del MEB (x10000)

Por otra parte, en las micrografías se observó como la hematites no se encontraba distribuida homogéneamente por toda la probeta, sino que se encontraba formando aglomerados de pequeñas partículas aciculares y/o hexagonales muy bien definidas. Por ello, y considerando que en la muestra G se habían detectado grandes cristales ricos en $\mathrm{Fe}$ y $\mathrm{O}$ que obviamente no estaban en la mezcla de materias primas (por su elevado tamaño), se puede concluir que la hematites participa en un proceso de disolución-recristalización en la fase vítrea formada, por tanto, son más frecuentes en las zonas más ricas en vidrio, aunque el resultado final es que la proporción de $\mathrm{Fe}_{2} \mathrm{O}_{3}$ detectada por difracción de rayos $\mathrm{X}$ es aproximadamente constante, si bien cambia su tamaño de partícula o cristal, fenómeno que no se puede detectar por DRX (Figura 4.132).
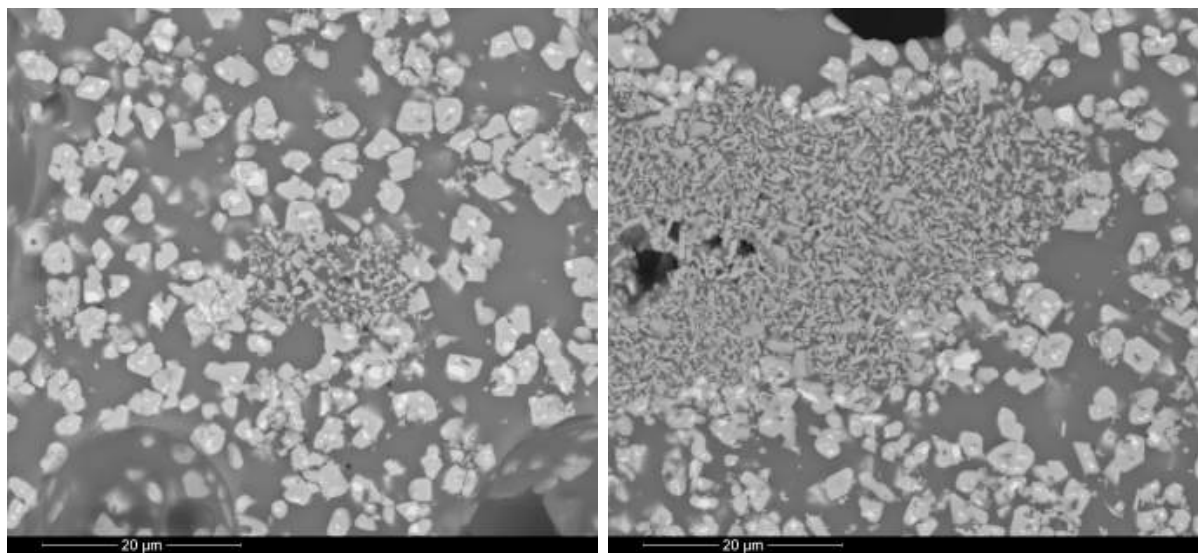

Figura 4.132 Micrografías de la superficie pulida de la probeta $\mathrm{H}$ $\left(10 \%\right.$ mineralizador, $\mathrm{v}=5^{\circ} \mathrm{C} / \mathrm{min}$ ) con la señal de electrones retrodispersados del MEB (x10000) 
Los resultados obtenidos en los experimentos descritos en el apartado 4.7 parecen confirmar el mecanismo de formación del pigmento de hierro-circón a través de un mecanismo en fase gaseosa.

En los experimentos en los que la mezcla de hierro y circona y la mezcla de sílice y fluidificante no se encontraban en contacto, se observó que:

- Cuando se incorpora mineralizador en las composiciones, se observaba en la superficie de la probeta la presencia de sílice. Este hecho indicaría que la sílice es transportada en fase gaseosa depositándose en la superficie de la probeta preparada a partir de una mezcla de circona y óxido de hierro.

- En los experimentos en los que se utilizaba mineralizador, se detectó en la superficie de las probetas la presencia de sodio y flúor, lo que confirmaría que el mineralizador interviene en la formación del circón.

- Se detectaron cristales bipiramidales de circón en aquellas probetas en las que sí se había introducido mineralizador en la mezcla de sílice y fluidificante.

- En aquellos experimentos en los que no se había introducido el mineralizador no se detectó silicio en la superficie de la probeta y no se encontraron cristales de circón.

- Los experimentos llevados a cabo con el ciclo STD, mostraban un menor porcentaje de sílice, lo que podría confirmar una menor formación de circón que en las mismas probetas tratadas con el ciclo Rápido.

En los experimentos llevados a cabo con la mezcla de todas las materias primas se concluyó que:

- En los experimentos con un $10 \%$ de mineralizador en la composición, se observó una elevada presencia de fase vítrea, lo que favorecía la desvitrificación del óxido de hierro en forma de cristales de aventurina.

- El estudio del perfil de concentraciones hacia el interior de las probetas utilizando el análisis EDX no mostró diferencias significativas en el análisis de elementos, lo que parece confirmar el mecanismo en fase gaseosa, ya que la sílice en fase gaseosa se difundiría a través de la red porosa de la probeta porosa para reaccionar con la circona para formar circón (y si la distribución espacial de los reactantes es adecuada, encapsular el $\mathrm{Fe}_{2} \mathrm{O}_{3}$ ). 
5. CONCLUSIONES 

En este trabajo se ha evaluado la influencia de las variables del proceso de síntesis del pigmento coral de hierro. Los resultados obtenidos durante la realización de este trabajo permiten definir las siguientes conclusiones:

1. El método utilizado en la preparación de la mezcla de materias primas resulta muy importante para obtener el pigmento coral, ya que puede definir el mecanismo por el cual transcurre el proceso global. Frente a este factor, las materias primas concretas escogidas poseen una menor influencia, al menos en el caso de las utilizadas en esta investigación.

2. Se ha confirmado que la reactividad de la mezcla de materias primas depende en gran medida del método de preparación de ésta. El mecanismo de operación del equipo de mezclado ejerce una influencia fundamental en la reactividad. Por tanto, el estudio de dicha etapa es crucial para la síntesis del pigmento coral de hierro-circón.

3. Se ha verificado que la reactividad de la mezcla está correlacionada con la distribución espacial de las diferentes materias primas. Los métodos de mezcla que favorezcan la formación de aglomerados de circona, hematites, mineralizador y fluidificante, y dejen el cuarzo rodeando dichos aglomerados, son los que conducen a pigmentos con un mayor poder colorante.

4. Los ensayos realizados con diferentes métodos vía seca para preparar la mezcla de materias primas utilizando un ciclo térmico estándar, no han permitido obtener las características óptimas que presentan las mezclas preparadas en la industria, a pesar de las numerosas variantes analizadas. En todos los casos la reactividad ha sido muy reducida, incluso en comparación con las mezclas preparadas vía húmeda.

5. El orden en el que se adicionan los reactantes resulta esencial, habiéndose comprobado la conveniencia de introducir el cuarzo cuando las restantes materias primas han sufrido el proceso de homogeneización, y no utilizar condiciones demasiado enérgicas con esta última materia prima, para no romper los posibles aglomerados que se hubiesen podido formar. En este sentido, proporciones relativamente reducidas de cuarzo presentes desde el inicio del proceso de preparación de la mixtura de materias primas, pueden ejercer una acción sumamente perjudicial sobre la velocidad de formación del circón.

6. En cuanto a las materias primas, una circona más fina parece favorecer la obtención de pigmentos con mayor proporción de circón, y un mayor poder colorante, si bien presentan mayor sensibilidad a las características específicas de la hematites utilizado como cromóforo.

7. La síntesis del pigmento es bastante sensible a las variaciones en las características del tratamiento térmico. En el caso de las mezclas preparadas industrialmente, su mayor reactividad las hace muy sensibles a los cambios en la temperatura máxima o la duración del tiempo de permanencia a la misma. 
Por otra parte, las mezclas preparadas en el molino planetario vía húmeda poseen una dependencia menos acusada, pero puede deberse a su menor reactividad. Estas diferencias se pueden relacionar, más que con un efecto de la temperatura sobre la velocidad de reacción, con un cambio en el mecanismo por el cual transcurre la reacción en el caso de las mezclas industriales, situación que no ocurriría en las mezclas preparadas con el molino planetario.

8. Se ha comprobado que una velocidad de calentamiento elevada en el tratamiento térmico permite amortiguar en buena medida los efectos de la microestructura de la mezcla de materias primas, aunque no eliminarla por completo. De este modo es posible generar materiales que contienen una elevada proporción de circón, y un poder colorante apreciable, a partir de mezclas que apenas reaccionan cuando se someten a un ciclo térmico caracterizado por una velocidad de calentamiento reducida. Aparentemente las velocidades de calentamiento elevadas favorecen que la reacción de síntesis del circón se realice mediante transporte en fase gas de la sílice, y no mediante la formación de una fase líquida viscosa, y difusión de los reactantes a través de la misma.

9. La microestructura de las mezclas obtenidas en un molino planetario vía húmeda es muy sensible a las condiciones de operación del equipo. Se ha detectado un efecto importante de la velocidad de giro del molino, ya que los pigmentos con mayor proporción de circón se obtienen para una velocidad de $230 \mathrm{rpm}$ en el equipo utilizado y una hora de permanencia. Velocidades o tiempos de mezclado superiores o inferiores resultan perjudiciales. También resulta importante escoger el fluido utilizado, ya que las mezclas preparadas en medio acuoso poseen una mayor reactividad que las obtenidas en las mismas condiciones, pero utilizando acetona como fluido.

10. La distribución granulométrica del mineralizador también ejerce una influencia notable sobre el progreso de la reacción, y es susceptible de variar notablemente en función del método y las condiciones en las que se lleva a cabo la homogeneización de las materias primas. Los resultados disponibles apuntan a que un tamaño por debajo de las $40 \mu \mathrm{m}$ puede resultar beneficioso (el mineralizador se ha suministrado en forma de cristales de tamaño superior a las $200 \mu \mathrm{m})$, pero un refinado excesivo también puede resultar contraproducente.

11. La microestructura de los pigmentos con elevado poder colorante se caracteriza por la presencia de cristales de circón bien formados, los cuales presentan el hábito bipiramidal típico de esta fase cristalina. Además, su tamaño es del orden de las 5 micras y, por tanto, son capaces de encerrar en su interior partículas de hematites, creando así la cápsula protectora. Por el contrario, las microestructuras de los pigmentos con escaso o nulo poder colorante, se caracteriza por la presencia de masas de partículas sin forma definida, entre las cuales se hallan grandes partículas de aspecto vítreo, en las cuales se detecta sodio además de sílice. 
12. Los resultados llevan a plantear dos posibles modelos extremos para la síntesis del pigmento, que podrán actuar en diferentes proporciones en los procesos reales.

- El primer mecanismo consistiría en la formación de una fase vítrea viscosa por reacción de la sílice con el mineralizador (y posiblemente algo de hematites e incluso circona), durante la etapa de calentamiento del tratamiento térmico. La transferencia de la sílice hasta las partículas de circona se realizaría por difusión a través de la fase vítrea, y la cristalización del circón se realizaría en la superficie de las partículas de circona en contacto con el líquido. Este mecanismo, además de ser lento, no permitiría la formación de cristales de circón de tamaño suficiente para encapsular las partículas de hematites, y por tanto conduciría a pigmentos con escaso contenido en circón y bajo poder colorante.

- El segundo mecanismo se basaría en una velocidad de calentamiento lo bastante rápida, o en una separación espacial entre la sílice y el mineralizador, que impidiese la formación de la fase vítrea silícea, y permitiese que se formasen especies gaseosas como el $\mathrm{SiF}_{4}$, que serían las responsables del transporte del silicio por difusión en fase gas desde las partículas de sílice hasta las de circona, en cuya superficie se formaría el circón. Este mecanismo sería mucho más rápido, y permitiría la formación de cristales de circón en gran cantidad y con suficiente tamaño para encapsular las partículas de hematites. En consecuencia, se obtendrían pigmentos con alto contenido en circón y elevado poder colorante.

13. Las condiciones más favorables para sintetizar el pigmento, considerando los resultados obtenidos en la investigación, serían las siguientes:

- Partir de una mezcla en la cual el mineralizador esté íntimamente mezclado con la circona y la hematites, y separado espacialmente de la sílice. Para ello es necesario disponer de un método de mezclado perfectamente ajustado para dicho objetivo. En este sentido la vía seca parece adaptarse mejor a estos requisitos que vía húmeda, pero el ajuste de las condiciones de operación no es una tarea que se pueda considerar inmediata, ya que depende del modo de operación del equipo de mezclado.

- Las condiciones que permitirían sintetizar un coral de circonio con elevado poder colorante, utilizando molinos de bolas vía seca son aquellas que permitieran formar aglomerados compactos y resistentes. Esta mezcla se extraería del molino, se tamizaría y se mezclaría con el cuarzo, pero utilizando bolas de menor diámetro, para no romper los aglomerados formados previamente. Finalmente, se utilizaría un tratamiento térmico con una velocidad de calentamiento elevada (en torno a $25^{\circ} \mathrm{C} / \mathrm{min}$ si fuese posible), para favorecer que la síntesis del circón se realice vía intermedios gaseosos, y no mediante fases líquidas, para asegurar el encapsulamiento de las partículas de hematites, y así garantizar que la mayor parte del $\mathrm{Fe}_{2} \mathrm{O}_{3}$ pudiese ejercer su función cromófora. 
En cuanto al trabajo realizado para proponer un índice de mezcla se extraen las siguientes conclusiones:

14. El problema de evaluar el grado de homogeneidad de una mezcla pulverulenta se ha estudiado bastante desde el punto de vista estadístico, pero ello no ha conducido a métodos prácticos para calcular los denominados índices de mezcla. La transformada de Fourier de la imagen de una mezcla real posee propiedades adecuadas para definir un índice de mezcla, pero no se ha hallado ninguna aplicación práctica en la revisión bibliográfica realizada. Por ello, se han definido índices a partir de características directamente obtenibles a partir de la imagen del espectro de frecuencias correspondiente a TFD de imágenes de microscopio electrónico de las muestras.

15. La utilización del nivel medio de gris del espectro de potencias como índice de mezcla no parece adecuado, ya que no permite diferenciar claramente entre micrografías de mezclas que visualmente se aprecian bastante diferentes.

16. El número de píxeles del espectro de potencias dentro del intervalo 255-200 parece comportarse relativamente bien como índice de mezcla. Aparentemente permite diferenciar entre las muestras que contienen la circona gruesa y fina, y para la misma circona diferencia las mezclas en función del óxido de hierro utilizado en la preparación. También parece diferenciar entre el mezclado realizado vía seca y el ejecutado vía húmeda, si bien este punto requeriría una mayor experimentación para verificarlo.

17. La razón $\mathrm{M}_{\mathrm{i}} / \mathrm{M}_{0}$ calculada a partir de la matriz numérica correspondiente al espectro de potencia de la TFD sí que parece poseer las características adecuadas para clasificar las mezclas, ya que permite distinguirlas en función del método de preparación y del óxido de hierro utilizado, aunque el efecto de la circona no resulta evidente.

18. Se ha comprobado que los espectros de frecuencia son sensibles a las condiciones de obtención de las imágenes de microscopía electrónica, por lo que es preciso definir con precisión las condiciones de trabajo para obtener resultados comparativos. Además, resultaría recomendable contar con uno o varios patrones para poder corregir derivas en el comportamiento del equipo.

19. Los trabajos realizados se pueden considerar una primera aproximación al problema de establecer un parámetro único para diferenciar mezclas de materias primas, que ha conducido a una alternativa con posibilidades de resultar viable. Sin embargo, sería necesario una experimentación más extensa para confirmar la validez de la razón $\mathrm{M}_{\mathrm{i}} / \mathrm{M}_{0}$ como índice de mezcla. En una segunda etapa sería necesario investigar la posibilidad de reproducir los resultados obtenidos con imágenes de microscopía electrónica, utilizando imágenes de microscopía óptica, ya que de este modo se facilitaría la transferencia del método al entorno industrial. 
6. PUBLICACIONES
Y CONGRESOS 

A continuación, se detallan las publicaciones y congresos en los que se han utilizado los resultados obtenidos durante el presente trabajo de investigación.

- Propuesta de un índice para evaluar el mezclado de materias primas: aplicación al caso del coral de hierro-circón. Trabajo final de Máster Universitario en Ciencia, Tecnología y Aplicaciones de los Materiales Cerámicos. Curso académico 2014-2015, Universitat Jaume I, 2015.

- Synthesis of Coral Iron Pigment. Effect of some process variables. E. Zumaquero, M.D. Palacios Tejero, A. Gozalbo, M.J. Orts Tarí, S. Mestre Beltrán. 14th International Conference European Ceramic Society. Toledo (España). 2015. Ed. European Ceramic Society (ECERS). ISBN 9788460692577.

- Síntesis del coral de hierro-circón: Influencia del de mezclado en el poder colorante. E. Zumaquero, M.J. Orts Tarí, M.D. Palacios Tejero, S. Mestre Beltrán. LV Congreso de la Sociedad Española de Cerámica y Vidrio y I Congreso Bienal de la SECV. Sevilla (España). 2016. Ed. Sociedad Española de Cerámica y Vidrio. ISBN 9788461752553.

- Síntesis del pigmento coral de hierro-circón: Optimización de las variables de mezclado. E. Zumaquero, S. Arrufat, M.J. Orts, S. Mestre. I Jornada Jóvenes Investigadores. Instituto de Tecnología Cerámica. Castellón de la Plana (España). 2017.

- Síntesis del pigmento de hierro-circón: Propuesta de un índice de mezclado para mezclas de materias primas. E. Zumaquero, M.J. Orts Tarí, V. Sanz Solana, S. Mestre Beltrán. Boletín de la Sociedad Española de Cerámica y Vidrio. Núm. 4. Vol. 56. pp. 177-185. 2017. 

7. BIBLIOGRAFÍA 

[1] J. Carda, M.A. Tena, G. Monros, P. Escribano, Pigments ceramics encapsulats, Butll. Sot. Cat. Cicn. XIII (1992).

[2] G. Buxbaum, G. Pfaff, Industrial inorganic pigments, 3rd ed., WileyVCH, Weinheim:, 2005. doi:10.1002/3527603735.

[3] L. Tcheichvili, W.A. Weyl, Síntesis de pigmentos cerámicos a la luz de la moderna cristalquímica de alta temperatura, Boletín La Soc. Española Cerámica y Vidr. 4 (1965) 461-494.

[4] W.D.J. Evans, Ceramic Pigments: a structural approach, Br. Ceram. Trans. J. 67 (1968) 397-419.

[5] Dry Color Manufacturers' Association. Metal Oxides and Ceramic Colors Subcommittee, DCMA Classification and Chemical Description of the Mixed Metal Oxide Inorganic Colored Pigments, 3rd ed., 1991.

[6] Color Pigments Manufacturers' Association, CPMA Classification and chemical descriptions of the complex inorganic color pigments, 4th ed, Color Pigments Manufacturers' Association Inc., Alexandria, USA, 2013.

[7] E.B. Faulkner, R.J. Schwart, High performance pigments, Wiley-VCH, Weinheim, 2009.

[8] G. Monrós, El Color de la cerámica : nuevos mecanismos en pigmentos para los nuevos procesados de la industria cerámica, Publicacions de la Universitat Jaume I. Servei de Comunicació i Publicacions, Castelló de la Plana, 2003.

[9] V.J. Esteve Cano, L.E. Ochando Gómez, Perspectivas de la cristalografía ante el nuevo milenio, Universitat Jaume I, Castellón, 2004.

[10] S. Sorlí, A. García, F.J. Paús, A. Mestre, M.A. Gómez Tena, G. Monrós, Modificación de la Banda de Transferencia de Carga de la Zircona Monoclínica por Inclusión de Pentóxido de Vanadio. . Castellón. 28-062001. Nacional. Científic. 2001., in: XII Simp. Del Grup. Espec. Cristalogr., Castellón, 2001.

[11] R.A. Eppler, Zirconia-based color for ceramic glazes, Ceram. Bull. 56 (2) (1977) 213-224.

[12] M. Llusar, J.A. Badenes, J. Calbo, M.A. Tena, G. Monrós, Estudio del efecto de la adición de distintos mineralizadores en la síntesis cerámica del pigmento rosa coral de hierro-circón, Bol. La Soc. Española Cerámica y Vidr. 38 (1999) 201-208. doi:10.3989/cyv.1999.v38.i3.959.

[13] P. Escribano López, J.B. Carda Castelló, E. Cordoncillo Cordoncillo, Esmaltes y pigmentos cerámicos, Faenza Editrice Iberica, Castellón, 2001.

[14] G. Cohn, Reactions in the Solid State, Chem. Rev. 42 (1948) 527-579. doi: $10.1021 /$ cr60133a002. 
[15] C. Kooy, Material transport in solid-state reactions, Pure Appl. Chem. 9 (1964) 441-452. doi:https://doi.org/10.1351/pac196409030441.

[16] P.P. Budnikov, A.M. Ginstling, Principles of solid state chemistry: reactions in solids, Maclaren and Sons, London, 1968.

[17] G.H. Frischat, Mass Transport in Solids, Angew. Chemie Int. Ed. English. 13 (1974) 384-398. doi:10.1002/anie.197403841.

[18] S.S. Tamhankar, L.K. Doraiswamy, Analysis of solid-solid reactions: A review, AIChE J. 25 (2004) 561-582. doi:10.1002/aic.690250402.

[19] S. Mestre, Compuestos del sistema Fe2O3-Cr2O3 : estudio cinético y colorimétrico, Universitat Jaume I, 1997.

[20] H. Schmalzried, Solid-State Reactions, in: N.B. Hannay (Ed.), Treatise Solid State Chem. Vol. 4 React. Solids, Springer US, Boston, MA, 1976: pp. 233-279. doi:10.1007/978-1-4684-8082-5_5.

[21] A.R. West, Solid state chemistry and its applications, 2nd ed., Wiley, Chichester, 2014.

[22] L. Del Olmo, Vidriados opacificados con circonio, Boletín La Soc. Española Cerámica y Vidr. 5 (1966) 661-676. doi:10.3989 / cyv.1966.v5.i5.

[23] C. Klein, J.D. Dana, C.S. Hurlbut, Manual de mineralogía : basado en la obra de J.D. Dana, 4th ed., Reverté, Barcelona, 1996.

[24] J.L. Amorós, A. Barba, V. Beltrán, Estructuras cristalinas de los silicatos y óxidos de las materias primas cerámicas, 1st ed., Asociación de Investigación de las Industria Cerámicas, Castellón, 1994.

[25] C.A. Seabright, Ceramic pigments, 1948. https://www.google.es/patents/US2441447.

[26] C.A. Seabright, Yellow ceramic pigments, 1961. https://www.google.es/patents/US2992123.

[27] C.A. Seabright, Iron-silica ceramic stain, 1961. https://www.google.es/patents/US3005724.

[28] C.A. Seabright, Iron ceramic pigment, 1965. https://www.google.es/patents/US3166430.

[29] E. Ozel, S. Turan, Production of coloured zircon pigments from zircon, J. Eur. Ceram. Soc. 27 (2007) 1751-1757. doi:10.1016/j.jeurceramsoc.2006.05.008.

[30] L. Sánchez-Muñoz, J.B. Carda Castelló, Materias primas y aditivos cerámicos, Faenza Editrice Iberica, Castellón de la Plana, 2003.

[31] J. Gascón, Preparation of coloured pigments based on synthetic zircon, 3528835, 1970. 
[32] J. Gascón, Production of zirconium based ceramic pigments containing iron, 3528834, 1970.

[33] F. Bondioli, T. Manfredini, C. Siligardi, A.M. Ferrari, A new glass-ceramic red pigment, J. Eur. Ceram. Soc. 24 (2004) 3593-3601. doi:10.1016/j.jeurceramsoc.2003.12.017.

[34] W.G. Huckle, G.F. Swigert, S.E. Wiberley, Cadmium pigments: Structure and composition, Ind. Eng. Chem. Prod. Res. Dev. 5 (1966) 362-366. doi: $10.1021 / \mathrm{i} 360020 \mathrm{a} 016$.

[35] J.B. Martinez, G.Z. Monzonis, V.L. Lavilla, Estudio de la formación del pigmento cerámico sulfo-seleniuro de cadmio a partir de CdS y Se. Estudio de la reacción en estado sólido de mezclas CdS-Se., Boletín La Soc. Española Cerámica y Vidr. 16 (1977) 291-294.

[36] J. Rincón, Pigment zircon- cadmium for ceramics, in: Conf. SECVVolume Trans. J. Br. Ceram. Soc., 1981.

[37] J. Paulus, U. Knuutinen, Cadmium colours: Composition and properties, Appl. Phys. A Mater. Sci. Process. 79 (2004) 397-400. doi:10.1007/s00339-004-2646-6.

[38] J. Wu, K. Li, X. Xu, Y. Zhang, X. Xu, X. Lao, Research and development of cadmium sulphoselenide red pigment, J. Wuhan Univ. Technol. Mater. Sci. Ed. 30 (2015) 1247-1254. doi:10.1007/s11595-015-1303-6.

[39] G.F. NORDBERG, Health hazards of environmental cadmium pollution, Ambio, J. Hum. Environ. 3 (1974) 55-66.

[40] A.D. Lemly, Aquatic selenium pollution is a global environmental safety issue, Ecotoxicol. Environ. Saf. 59 (2004) 44-56. doi:10.1016/S01476513(03)00095-2.

[41] J.M. Ray, The technology of zirconium iron pink stains, Can. Ceram. Soc. 32 (1963) 83-88.

[42] R.A. Eppler, Solid state reactions in the preparation of zircon stains, in: Marcel Dekker Inc. (Ed.), Phys. Electron. Mater. Part B, New York, 1972: pp. 1021-1045.

[43] B. Lei, W. Qin, G. Kang, C. Peng, J. Wu, Modeling and evaluation for encapsulation efficiency of zircon-based heteromorphic encapsulation pigments, Dye. Pigment. $112 \quad$ (2015) 245-254. doi:10.1016/j.dyepig.2014.07.010.

[44] E. Carreto, C. Piña, H. Arriola, A. Barahona, N. Nava, V. Castaño, Mossbauer study of the structure of Fe-zircon system, J. Radioanal. Nucl. Chem. 250 (2001) 453-458. doi:10.1023/A:1017988720055. 
[45] R.A. Eppler, Kinetics of formation of an iron-zircon pink color, J. Am. Ceram. Soc. 62 (1979) 47-49. doi:10.1111/j.11512916.1979.tb18803.x.

[46] R.A. Eppler, Mechanism of formation of zircon stains, J. Am. Ceram. Soc. 53 (1970) 457-462. doi:10.1111/j.1151-2916.1970.tb12677.x.

[47] C.A.C. Sequeira, L. Amaral, Role of Kirkendall effect in diffusion processes in solids, Trans. Nonferrous Met. Soc. China (English Ed. 24 (2014) 1-11. doi:10.1016/S1003-6326(14)63021-1.

[48] C. Kooy, Material transport in solid-state reactions, Pure Appl. Chem. 9 (1964) 441-452. doi:10.1351/pac196409030441.

[49] F.J. Berry, D. Eadon, J. Holloway, L.E. Smart, Iron-doped zircon: the mechanism of formation, J. Mater. Sci. 34 (1999) 3631-3638. doi:10.1023/A:1004691019526.

[50] F.J. Berry, D. Eadon, J. Holloway, L.E. Smart, Iron-doped zirconium silicate Part 1. The location of iron, J. Mater. Chem. 6 (1996) 221-225. doi:10.1039/jm9960600221.

[51] I. Gair, R.H. Jones, A.C. Airey, G. Sankar, D. Gleeson, R.D. Farn, The nature of the chromophore centre in an iron zircon pigment prepared by conventional and sol-gel routes, Qualicer 2000. (2000) 63-65.

[52] P. Tartaj, T. González-Carreño, C.J. Serna, M. Ocaña, Iron zircon pigments prepared by pyrolysis of aerosols, J. Solid State Chem. 128 (1997) 102-108. doi:10.1006/jssc.1996.7176.

[53] J. Lahuerta, Colorantes cerámicos rojos basados en Fe2O3, Universidad de Valencia, 1993.

[54] A.C. Airey, W. Roberts, Advances in ceramic colors, Ceram. Eng. Sci. Proc. 8 (1987). doi:10.1002/9780470310458.ch6.

[55] M. Cannio, F. Bondioli, Mechanical activation of raw materials in the synthesis of Fe2O3-ZrSiO4 inclusion pigment, J. Eur. Ceram. Soc. 32 (2012) 643-647. doi:10.1016/j.jeurceramsoc.2011.10.008.

[56] Chi-Hang Li, R.D. Eppler, R.A. Eppler, Iron zircon pigments, Ceram. Eng. Sci. Proc. 13 (1992) 109/118. doi:10.1002/9780470313916.ch11.

[57] P.R. Mort, R.E. Riman, Determination of homogeneity scale in ordered and partially ordered mixtures, Powder Technol. 82 (1995) 93-104. doi:10.1016/0032-5910(94)02899-Y.

[58] R.H. Wang, L.T. Fan, Too J.R., Multivariate statistical analysis of solids mixing, Powder Technol. 21 (1978).

[59] M. Alonso, F.J. Alguacil, Dry mixing and coation of powders, Rev. Metal. 35 (1999) 315-328. doi:10.3989/revmetalm.1999.v35.i5.640. 
[60] L.T. Fan, S.J. Chen, C.A. Watson, Solids mixing, Ind. Eng. Chem. 62 (1970) 53-69. doi:10.1021/ie50727a009.

[61] A. Clausell Sebastià, R. Galindo Renau, Apuntes de operaciones básicas: en la fabricación de pavimentos y revestimientos cerámicos, Generalitat Valenciana. Consellería de Cultura, Educació i Ciència, Valencia, 1991.

[62] W.L. McCabe, J.C. Smith, P. Harriott, Operaciones unitarias en ingeniería química, MacGraw-Hill, México, 2002.

[63] N. Harnby, A.W. Nienow, M.F. Edwards, Mixing in the process industries, 2nd ed., Butterworth Heinemann, Oxford, 1992.

[64] R.H. Fan, L.T.; Wang, On mixing indices, Powder Technol. 11 (1975) 27-32.

[65] S.R. Miles, Heterogeneity of seeds lot, Proc. Inst. Seed Test. Assoc. 27 (1962) 407-412.

[66] P.M.C. Lacey, Developments in the theory of particle mixing, J. Appl. Chem. 4 (1954) 257-268. doi:10.1002/jctb.5010040504.

[67] K.R. Poole, R.F. Taylor, G.P. Wall, Mixing powders to fine scale homogeneity: studies of batch mixing, Trans. Instn. Chem. Eng. 42 (1964) 305-315.

[68] L.T. Fan, J.L. Too, Studies on multicomponent solids mixing and mixtures. Part 1. Estimation of a mixing index from contact number for a homogeneous mixture, Powder Technol. 22 (1979). doi: 10.1016/0032-5910(79)80028-5.

[69] R.J. Too, R.M. Rubinson, L.T. Fan, F.. Lai, Studies on multicomponent solids mixing and mixtures. Part 2. Estimation of mixing index and contact number by spot of a multicomponent mixture in an Inductively mixed state, Powder Technol. 23 (1979).

[70] L.T. Fan, J.R. Too, R.M. Rubison, F.S. Lai, Studies on multicomponent solids mixing and mixtures. Part 3. Mixing indices, Powder Technol. 24 (1979) 73-89. doi:10.1016/0032-5910(79)80009-1.

[71] S.H. Shin, L.T. Fan, Characterization of solids mixtures by the Discrete Fourier Transform, Powder Technol. 19 (1978) 137-146.

[72] J. Bobadilla, La transformada de Fourier. Una visión pedagógica, Estud. Fonética Exp. 10 (1999) 41-74.

[73] E.M. Stein, R. Shakarchi, Fourier analysis: an introduction, Princeton University Press, Princeton, 2003.

[74] G. González, Series de Fourier, transformadas de Fourier y aplicaciones, Divulg. Matemáticas. 5 (1997) 43-60. 
[75] J.P. Alvarado, Procesamiento y análisis de imagen digitales, Esc. Electrónica, Inst. Tecnológico Costa Rica. (2012).

[76] P. Bourke, Fast Fourier Transform, (1993).

[77] F. Bondioli, A.M. Ferrari, C. Leonelli, T. Manfredini, Synthesis of Fe203/Silica red inorganic inclusion pigments for ceramic aplications, Mater. Res. Bull. 33 (1998) 723-729. doi:10.1016/S00255408(98)00047-6.

[78] E. Carreto, E. Cordoncillo, J.B. Carda, Solid-Solution Formation in the Synthesis of Fe-Zircon, J. Am. Ceram. Soc. 87 (2004) 612-616. doi:10.1111/j.1551-2916.2004.00612.x.

[79] I. Núñez, J. V. Poré, E. Cordoncillo, P. Escribano, V. Kozhukharov, J.B. Carda, Estudio de las condiciones de síntesis del pigmento cerámico pink coral , Fe-ZrSi04, Bol. La Soc. Española Cerámica y Vidr. 37 (1998) 299306.

[80] I. Núñez, J. V. Poré, E. Cordoncillo, V. Esteve, J.B. Carda, Study of Synthesis Methods to Obtain the Ceramic Pigment Pink Coral, FeZrSiO4, Key Eng. Mater. 132-136 (1997) 57-60. doi:10.4028/www.scientific.net/KEM.132-136.57.

[81] S. Ardizzone, L. Binaghi, G. Cappelletti, P. Fermo, S. Gilardoni, Iron doped zirconium silicate prepared by a sol-gel procedure. The effect of the reaction conditions on the structure, morphology and optical properties of the powders, Phys. Chem. Chem. Phys. 4 (2002) 56835689. doi:10.1039/b207381a.

[82] M. Hosseini-Zori, E. Taheri-Nassaj, Nano encapsulation of hematite into silica matrix as a red inclusion ceramic pigment, J. Alloys Compd. 510 (2012) 83-86. doi:10.1016/j.jallcom.2011.08.086.

[83] G. Monrós, A. Garcia, S. Sorli, M. Llusar, J. Calbo, M.A. Tena, Heteromorphic pigments synthesis mechanisms, Qualicer 2002. (2002).

[84] P.A. Webb, C. Orr, Analytical methods in fine particle technology, Micromeritics Instrument Corporation, Norcross, GA, 1997.

[85] R.W. Cahn, P. Haasen, E.J. Kramer, R.J. Brook, Materials science and technology: a comprehensive treatment.Vol. 17A, Processing of ceramics, Part 1, VCH, Weinheim, 1996.

[86] I. Malvern, Dynamic Light Scattering: An Introduction in 30 Minutes, Tech. Note MRK656-01. (2011) 1-8.

[87] R. Xu, Light scattering: A review of particle characterization applications, Particuology. 18 (2015) 11-21. doi:10.1016/j.partic.2014.05.002.

[88] Horiba, A Guidebook To Particle Size Analysis, Horiba Instruments, Inc. (2013) 31. 
[89] Malvern Instruments LTD, Zetasizer nano series user manual, 2003.

[90] Malvern Instruments LTD, Sample dispersion \& Refractive index guide, 1996.

[91] S.J. Blott, D.J. Croft, K. Pye, S.E. Saye, H.E. Wilson, Particle size analysis by laser diffraction, Geol. Soc. London, Spec. Publ. 232 (2004) 63-73. doi:10.1144/GSL.SP.2004.232.01.08.

[92] Malvern Instruments LTD, Mastersizer 2000 user manual, 1996.

[93] M.J. Rhodes, Introduction to Particle Technology, 2nd ed., Wiley Online Library, 2008.

[94] S.J. Gregg, K.S.W. Sing, Adsorption, surface area and porosity, 2nd ed., Academic Press, London, 1982.

[95] J. Bermúdez Polonio, Métodos de difracción de rayos $X$ : principios $y$ aplicaciones, Pirámide, Madrid:, 1981.

[96] H.M. Rietveld, A profile refinement method for nuclear and magnetic structures, J. Appl. Crystallogr. 2 (1969) 65-71. doi: $10.1107 /$ S0021889869006558.

[97] G.W. Stinton, J.S.O. Evans, Parametric Rietveld refinement, J. Appl. Crystallogr. 40 (2007) 87-95. doi:10.1107/S0021889806043275.

[98] L.B. McCusker, R.B. Von Dreele, D.E. Cox, D. Louër, P. Scardi, Rietveld refinement guidelines, J. Appl. Crystallogr. 32 (1999) 36-50. doi: $10.1107 /$ S0021889898009856.

[99] R. Young, The Rietveld Method, By RA Young, Oxford Univ. Press. Oxford. (1993) 312. doi:10.1017/CBO9781107415324.004.

[100] V.J. Esteve Cano, El Método de Rietveld, Universitat Jaume I, Castelló de la Plana, 2014.

[101] S.P. Casagrande, R.C. Blanco, Método de Rietveld para el estudio de estructuras cristalinas, Rietveld. 2 (2004) 1-5.

[102] D. Balzar, N.C. Popa, Analyzing microstructure by rietveld refinement, Rigaku J. 22 (2005) 16-25.

[103] B.H. Toby, R factors in Rietveld analysis: How good is good enough?, Powder Diffr. 21 (2006) 67-70. doi:10.1154/1.2179804.

[104] C.T. Kniess, J. Cardoso de Lima, P.B. Prates, The quantification of crystalline phases in materials: Applications of Rietveld method, in: V. Shatokha (Ed.), Sinter. - Methods Prod., 2005: pp. 293-316.

[105] A.G. De La Torre, S. Bruque, M.A.G. Aranda, Rietveld quantitative amorphous content analysis, J. Appl. Crystallogr. 34 (2001) 196-202. doi: $10.1107 /$ S0021889801002485. 
[106] A.G. De La Torre, S. Bruque, M.A.G. Aranda, Rietveld quantitative amorphous content analysis, J. Appl. Crystallogr. 34 (2001) 196-202. doi: $10.1107 /$ S0021889801002485.

[107] T. Westphal, T. Füllmann, H. Pöllmann, Rietveld quantification of amorphous portions with an internal standard-Mathematical consequences of the experimental approach, Powder Diffr. 24 (2009) 239-243. doi:10.1154/1.3187828.

[108] P. Zhao, L. Lu, X. Liu, A.G. De La Torre, X. Cheng, Error analysis and correction for quantitative phase analysis based on rietveld-internal standard method: Whether the minor phases can be ignored?, Crystals. 8 (2018) 1-11. doi:10.3390/cryst8030110.

[109] L. León-Reina, M. Garciá-Maté, G. Álvarez-Pinazo, I. Santacruz, O. Vallcorba, A.G. De La Torre, et al., Accuracy in Rietveld quantitative phase analysis: A comparative study of strictly monochromatic Mo and $\mathrm{Cu}$ radiations, J. Appl. Crystallogr. 49 (2016) 722-735. doi: $10.1107 /$ S1600576716003873.

[110] www.webmineral.com, (n.d.).

[111] ISO 11664-4:2008 (CIE S 014-4/E:2007). Colorimetry-Part 4: CIE 1976 L*a*b* Colour space, n.d.

[112] D.R. Eppler, R.A. Eppler, Analyzing the Color of Reddish Glazes, in: A Collect. Pap. Present. 97th Annu. Meet. 1995 Fall Meet. Mater. Equipment/Whitewares Ceram. Eng. Sci. Proc., John Wiley \& Sons, Inc., 1996: pp. 77-87. doi:10.1002/9780470314807.ch13.

[113] R.S. Berns, F.W. Billmeyer, M. Saltzman, Billmeyer and Saltzman's Principles of color technology, John Wiley, New york, 2000.

[114] R.A. Eppler, Selecting Ceramic Pigments, in: Mater. Equipment/Whitewares Ceram. Eng. Sci. Proc., John Wiley \& Sons, Inc., 1987: pp. 1139-1149. doi:10.1002/9780470310458.ch1.

[115] N. Napier, Color Matching Without Computers, in: A Collect. Pap. Present. 95th Annu. Meet. 1993 Fall Meet. Mater. Equipment/Whitewares Manuf. Ceram. Eng. Sci. Proc., John Wiley \& Sons, Inc., 1994: pp. 224-232. doi:10.1002/9780470314340.ch25.

[116] M. Llusar, Optimización medioambiental de la síntesis de pigmentos cerámicos: Aplicación de métodos sol-gel, Universitat Jaume I, 2008.

[117] J. Goldstein, Scanning electron microscopy and X-ray microanalysis, 3rd ed., Plenum Press, New York, 2003.

[118] D.A. Skoog, J.J. Leary, Análisis instrumental, McGraw-Hill, Madrid, 1994.

[119] F.H. Holler, Mathcad applications for analytical chemistry, Saunders College Pub, 1994. 
[120] H. Rodríguez Alonso, Imagen digital: conceptos básicos, Marcombo, Barcelona, 2009.

[121] O. Levenspiel, G. Tojo Barreiro, Ingeniería de las reacciones químicas, Reverté, Barcelona, 1975.

[122] M. Hosseini-Zori, E. Taheri-Nassaj, A.R. Mirhabibi, Effective factors on synthesis of the hematite-silica red inclusion pigment, Ceram. Int. 34 (2008) 491-496. doi:10.1016/j.ceramint.2006.11.012.

[123] A. Gozalbo, M.J. Orts, S. Mestre, P. Gómez, P. Agut, F. Lucas, et al., Vidriados cerámicos con efecto aventurina, in: Qualicer 2006, 2007: pp. 80-89. 